\title{
Technical Basis for Internal Dosimetry at Hanford
}

\author{
M. J. Sula \\ E H. Carbaugh \\ D. E Bihi
}

July1991

Prepared for the U.S. Department of Energy under Contract DE-AC06-76RLO 1830

Pacific Northwest Laboratory Operated for the U.S. Department of Energy by Battelle Memorial Institute 


\title{
DISCLAIMER
}

This report was prepared as an account of work sponsored by an agency of the United States Government. Neither the United States Government nor any agency thereof, nor Battelle Memorial Institute, nor any of their employees, makes any warranty, expressed or implied, or assumes any legal liability or responsibility for theaccuracy, completeness, or usefulnessof any information, apparatus, product, or process disclosed, or represents that its use would not infringe privately owned rights. Referenceherein to any specific commercial product, process, or serviceby trade name, trademark, manufacturer, or otherwisedoes not necessarily constitute or imply its endorsement, recommendation, or favoring by the United States Government or any agency thereof, or Battelle Memorial Institute. The views and opinions of authors expressed herein do not necessarily state or reflect those of the United States Government or any agency thereof.

\author{
PACIFIC NORTHWEST LABORATORY \\ operatedby \\ BATTELLEMEMORIAL INSTITUTE \\ for the \\ UNITED STATES DEPARTMENT OF ENERGY \\ under Contract DE-AC06-76RLO 1830
}

Printed in the United States of America

Available to DOE and DOE contractors from the

Office of Scientific and Technical Information, P.O. Box 62, Oak Ridge, TN 371131; prices available from (615) 576-8401. FTS 626-8401.

Available to the public from the National Technical Information Service, U.S. Department of Commerce, 5285 Port Royal Rd., Springfield, VA 22161. 
PNL-6866 Rev. 1

UC-607

TECHNICAL BASIS FOR INTERNAL DOSIMETRY AT HANFORD

M. J. Sula

E. H. Carbaugh

D. E. Bihl

July 1991

Prepared for the U.S. Department of Energy under Contract DE-AC06-76RLO 1830

Pacific Northwest Laboratory

Richland, Washington 99352 
7 


\section{$\underline{\text { ABSTRACT }}$}

The Hanford Internal Dosimetry Program, administered by Pacific Northwest Laboratory (a) for the U.S. Department of Energy, provides routine bioassay monitoring for employees who are potentially exposed to radionuclides in the workplace. This report presents the technical basis for routine bioassay monitoring and the assessment of internal dose at Hanford. The radionuclides of concern include tritium, corrosion products $\left({ }^{58} \mathrm{Co},{ }^{60} \mathrm{Co},{ }^{54} \mathrm{Mn}\right.$, and $\left.{ }^{59} \mathrm{Fe}\right)$, strontium, cesium, iodine, europium, uranium, plutonium, and americium. Sections on each of these radionuclides discuss the sources and characteristics; dosimetry; bioassay measurements and monitoring; dose measurement, assessment, and mitigation; and bioassay follow-up treatment.

(a) Pacific Northwest Laboratory is operated by Battelle Memorial Institute for the U.S. Department of Energy under Contract DE-AC06-76RLO 1830. 



\section{ACKNOWLEDGMENTS}

In the production of this report, the authors gratefully acknowledge the invaluable support of R. J. Traub as peer reviewer, S. K. Ennor as editor, and Marge Johnston, Marianna Cross, Rose Moreno, and Margot White as word processors. 



\section{CONTENTS}

ABSTRACT ........................

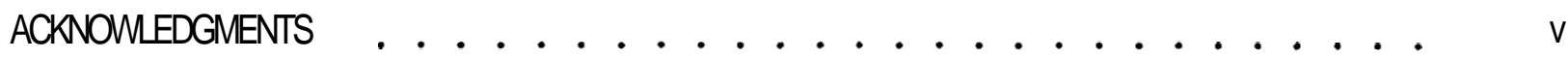

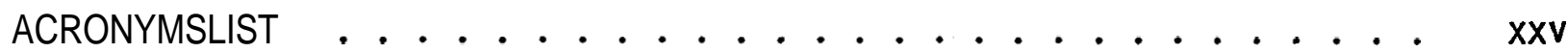
MATHEMATICAL SYMBOLOGY ................ xxvii GLOSSARY .................... . . xxix

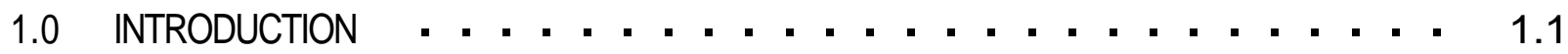

1.1 DOCLMENT DESCRIPTION . . . . . . . . . . . . . . 1.2

1.2 REVISIONS . . . . . . . . . . . . . . . . 1.2

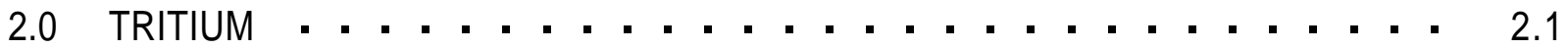

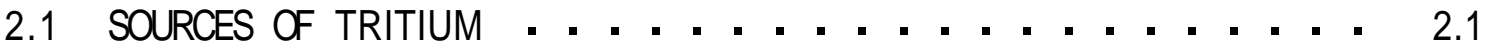

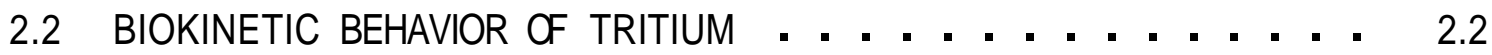

2.2.1 Chemical Form . . . . . . . . . . . . . . . . . . . 2.2

2.2.2 Transportability . . . . . . . . . . . . 2.2

2.2.3 Metabolic Model . . . . . . . . . . . . . . 2.3

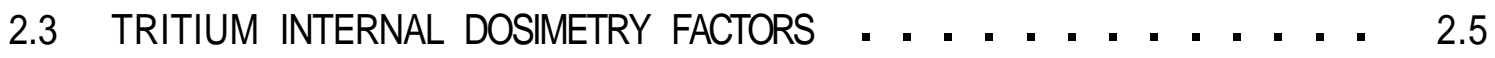

2.3.1 General Approach . . . . . . . . . . . 2.5

2.3.2 Dose Calculation for an Acute Exposure . . . . . 2.7

2.3.3 Dose Calculation for a Chronic Exposure . . . . . 2.8

2.3.4 Dosimetry Based on Multiple Sample Results . . . . 2.10

2.3.5 Dosimetry for Other Exposure Conditions . . . . . 2.10

2.4 BIOASSAYMONITORING . . . . . . . . . . . . 2.10

2.4.1 General Approach to Bioassay Monitoring ...... 2.10

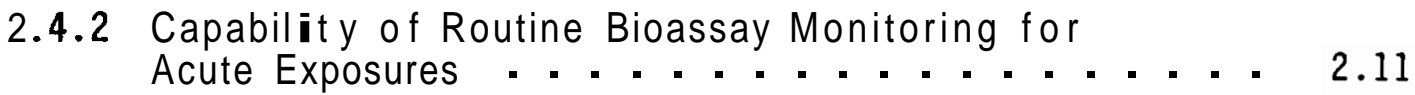


2.4.3 Capability of Routine Bioassay Monitoring for

Chronic Exposures ............ 2.13

2.4.4 Optimum Bioassay Sarnpling Intervals . . . . . 2.13

2.4.5 Special Monitoring . . . . . . . . . 2.13

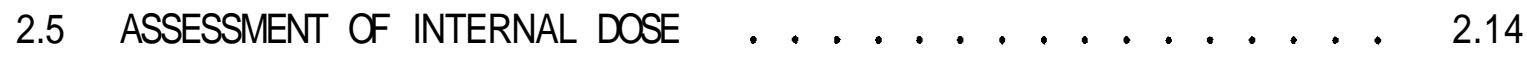

2.5.1 Simplified Dose Assessments . . . . . . . . 2.14

2.6 MITIGATION OF DOSE ROM TRITIUM $\ldots \ldots \ldots$

2.7 TRITIUM MONITORING PROGRAM FOR THE 400 AREA (FFTF) . . . . 2.16

3.0 COBALT-60 AND OTHER CORROSION PRODUCT RADIONUCLIDES . . . . . 3.1

3.1 SOURCES AND CHARACTERISTICS OF CORROSION PRODUCT

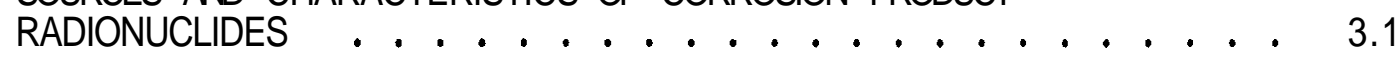

3.2 BIOKINETIC BEHAVIOR OF CORROSION PRODUCT RADIONUCLIDES . . . 3.2

3.3 INTERNAL DOSIMETRY FOR CORROSION PRODUCTS . . . . . . . . . 3.3

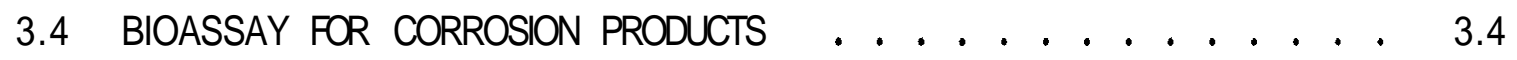

3.4.1 Bioassay Methods . . . . . . . . . . . 3.4

. 3.4 .2 Routine Bioassay Monitoring Program . . . . . . . 3.5

3.4.3 Bioassay Measurements Following an Acute Intake . . . 3.6

3.5 ASSESSMENT OF INTERNAL DOSE EQUIVALENT . . . . . . . . . . 3.7

3.6 MANAGEMENT OF INTERNAL CONTAMINATION CASES . . . . . . . 3.9

3.7 DOSIMETRY DATA FOR CORROSION PRODUCT RADIONUCLIDES . . . . 3.10

3.7.1 Cobalt-58 and Cobalt-60 ................ 3.10

3.7 .2 Manganese-54 . . . . . . . . . . . . 3.12

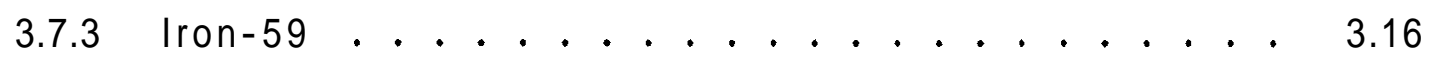

. 0 STRONTIUM . . . . . . . . . . . . . . . . . . . 4.1

4.1 SOURCES AND CHARACTERISTICS OF STRONTIUM . . . . . . . . 4.3

4.2 BIOKINETIC BEHAVIOR OF STRONTIUM . . . . . . . . . . 4.4

4.2 .1 Inhalation Class . . . . . . . . . . . 4.4 
4.2 .2 Uptake to Blood .............. 4.5

4.2.3 Internal Distribution and Retention ...... 4.5

4.2.4 Excretion of Strontium ......... 4.6

4.3 STRONTIUM INTERNAL DOSIMETRY FACTORS . . . . . . . . 4.7

4.3.1 Intake Excretion Functions . . . . . . . 4.8

4.3.2 Source-to-Target-Organ Dose Conversion Factors . . 4.9

4.3.3 Intake Dose Equivalent Factors ........ 4.11

4.3.4 Cumulative Dose Equivalents .......... 4.11

4.4 BIOASSAY TECHNIQUES FOR STRONTIUM . . . . . . . . 4.14

4.4.1 General Techniques and Applicability ...... 4.14

4.4.2 Urine and Fecal Sample Bioassay ... . . . . 4. 4.15

4.4 .3 In Vivo Measurement of ${ }^{90} \mathrm{Sr} \ldots \ldots . . . . . .4 .16$

4.4.4 Bioassay Monitoring Program Capability ..... . 4.16

4.4.5 Recommended Routine Bioassay Monitoring Program . . . 4.17

4.4.6 Special Monitoring for Suspected Exposures . . . . 4.19

4.5 INTERNAL DOSE ASSESSMENT FOR STRONTIUM INTAKES . . . . . . 4.19

4.5.1 General Approach ............. 4.19

4.5.2 Estimating Intake ........... 4.20

4.5.3 Calculating Organ and Effective Dose Equivalents . . 4.21

4.5.4 Systemic Deposition Estimate . . . . . . 4.21

4.5.5 Simplified Dose Assessments . . . . . . . . 4.22

4.6 MANAGEMENT OF POTENTIAL INTERNAL CONTAMINATION CASES . . . 4.24

4.6.1 Diagnostic Procedures ........... . 4.24

4.6.2 Therapeutic Actions ........... . 4.25

4.6.3 Long-Term Monitoring of Internal Deposition . . . 4.25 


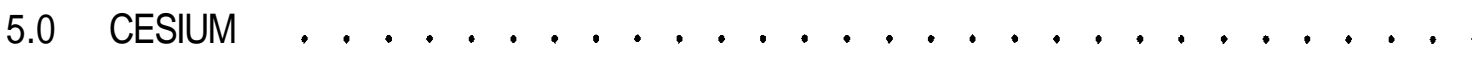

5.1 SOURCES AND CHARACTERISTICS OF RADIOCESIUM . . . . . . . 5.1

5.2 BIOKINETIC BEHAVIOR OF RADIOCESIUM . . . . . . . . 5.2

5.3 INTERNAL DOSIMETRY FOR RADIOCESIUM . . . . . . . . . 5.2

5.4 BIOASSAY FORRADIOCESIUM . . . . . . . . . . . . 5.6

5.4.1 Bioassay Methods . . . . . . . . . . 5.6

5.4.2 Routine Bioassay Monitoring Program . . . . . . . 5.7

5.4.3 Bioassay Measurements Following an Acute Intake . . . 5.8

5.5 ASSESSMENT OF INTERNAL DOSE EQUIVALENT . . . . . . . . 5.9

5.6 MANAGEMENT OF INTERNAL CONTAMINATION CASES . . . . . . 5.10

5.7 ENVIRONMENTAL LEVELS OF CESIUM . . . . . . . . . . 5.11

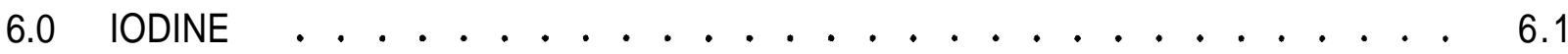

6.1 SOURCES AND CHARACTERISTICS OF RADIOIODINE . . . . . . . . 6.1

6.2 BIOKINETIC BEHAVIOR OF RADIOIODINE . . . . . . . . . 6.2

6.3 INTERNAL DOSIMETRY FOR RADIOIODINE . . . . . . . . . 6.4

6.4 BIOASSAY . . . . . . . . . . . . . . . 6.6

6.4.1 Bioassay Methods . . . . . . . . . . 6.6

6.4.2 Routine Bioassay Monitoring Program . . . . . . . 6.7

6.4.3 Bioassay Measurements Following an Acute Intake . . . 6.9

6.5 ASSESSMENT OF INTERNAL DOSE EQUIVALENT . . . . . . . . . 6.9

6.6 MANAGEMENT OF INTERNAL CONTAMINATION CASES . . . . . . 6.11

7.0 EUROPIUM $\ldots \ldots \ldots \ldots . \ldots . \ldots \ldots$

7.1 SOURCES AND CHARACTERISTICS OF EUROPIUM . . . . . . 7.1

7.2 BIOKINETIC BEHAVIOR OF EUROPIUM . . . . . . . . . 7.1

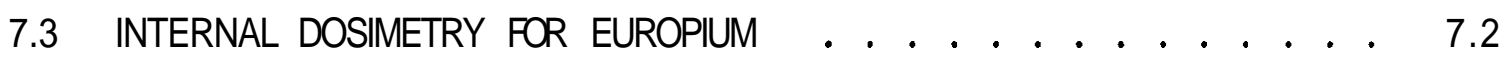

7.4 BIOASSAY . . . . . . . . . . . . . . . 7.6 
7.4.1 Bioassay Measurements . . . . . . . . . . . 7.6

7.4.2 Routine Bioassay Monitoring Program . . . . . . 7.9

7.4.3 Bioassay Measurements Following An Acute Intake . . . 7.10

7.5 ASSESSMENT OF INTERNAL DOSE . . . . . . . . . . . 7.11

7.6 MANAGEMENT OF INTERNAL CONTAMINATION CASES . . . . . 7.12

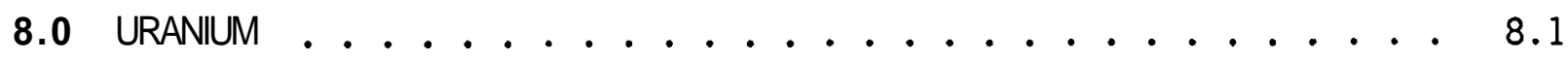

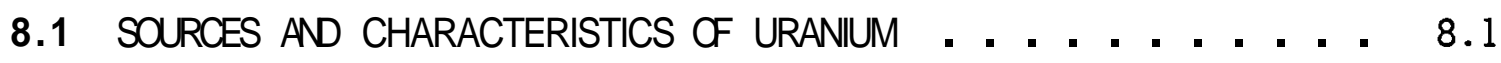

8.1 .1 Sources ...................... 8.1

8.1.2 Isotopic Composition .......... 8.2

8.1.3 Environmental Background . . . . . . . . . 8.5 8.5

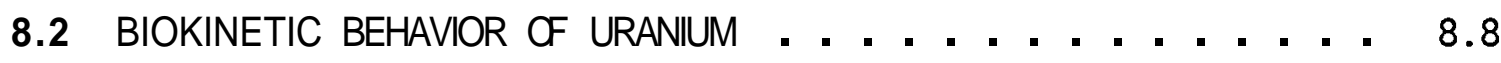

8.2.1 Inhalation Class . . . . . . . . . . 8.8

8.2.2 Particle Size . . . . . . . . . . . . . . 8.8

8.2.3 Distribution. Retention. and Excretion .... 8.8

8.2.4 Chemical Toxicity . . . . . . . . . . 8.9

8.3 INTERNAL DOSIMETRY FOR URANIUM . . . . . . . . . . . . . . . 8.14

8.4 BIOASSAY FOR URANIUM . . . . . . . . . . . . . . . . . . 8.17

8.4.1 Urine Sampling ............. 8. 8.17

8.4.2 Fecal Excretion Measurements ........ 8.23

8.4.3 In Vivo Measurements ........... 8.24

8.4.4 Routine Bioassay Monitoring Program . . . . . . 8.28

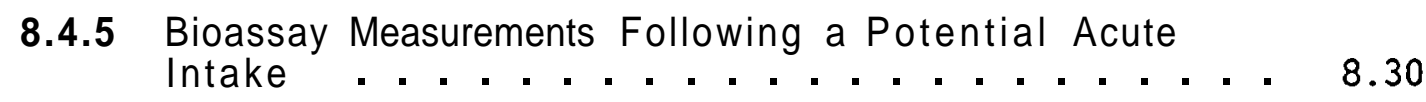

8.5 ASSESSMENT OF INTERNAL DOSE .............. 8.31

8.5.1 Assessment of Dose Equivalent . . . . . . . 8.31

8.5.2 Kidney Burden and Potential Chemical Toxicity .... 8.38 
8.6 MANAGEMENT OF INTERNAL CONTAMINATION CASES . . . . . . . 8.40

8.7 BIOASSAY MONITORING AND INTERNAL DOSIMETRY FOR SPECIFIC

FACILITIES .................. 8.40

8.7.1 Internal Dosimetry for Workers at the Uranium

Oxide Plant ............... 8.41

8.7.2 Bioassay Monitoring and Internal Dosimetry for

Workers at the 300 Area Fuel Production Facility . . . 8.43

8.7.3 Internal Dosimetry for Workers at the

306-W Building . . . . . . . . . . 8.53

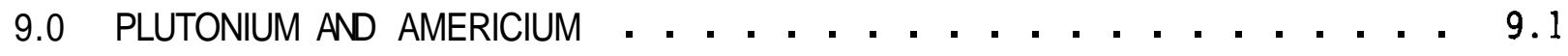

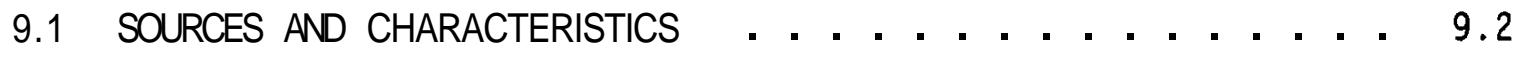

9.1.1 Isotope Decay Data . . . . . . . . . . . 9.3

9.1.2 Reference Plutonium Mixtures . . . . . . . . 9.3

9.2 BIOKINETIC BEHAVIOR . . . . . . . . . . . . . . 9.7

9.2.1 Transportability Class . . . . . . . . . 9.7

9.2.2 Systemic Distribution and Retention ...... 9.9 9.9

9.2.3 Urinary Excretion . . . . . . . . . . . 9.11

9.3 INTERNAL DOSIMETRY FACTORS . . . . . . . . . . . . . . . . 9.13

9.3.1 Intake Excretion Factors . . . . . . . . . 9.13

9.3.2 Dose Conversion Factors . . . . . . . . . . 9.13

9.3.3 Intake Dose Equivalent Factors . . . . . . . . 9.13

9.3.4 Cumulative Dose Equivalents . . . . . . . . . . 9.22

9.4 BIOASSAY MONITORING . . . . . . . . . . . . . . . . . . . 9.22

9.4.1 General Techniques and Applicability . . . . . 9.22

9.4.2 Urine Sample Bioassay . . . . . . . . . . . . . 9.27

9.4.3 Fecal Sample Bioassay . . . . . . . . . . . 9 9.29

9.4 .4 In Vivo Measurement . . . . . . . . . . . . 9.32

9.4.5 Bioassay Monitoring Capability . . . . . . . 9.35 
9.4.6 Recommended Bioassay Monitoring Program . . . . . 9.36

9.4.7 Special Bioassay Monitoring . . . . . . . . . . 9.47

9.4.8 Bioassay Monitoring Capability for Workers with Known Plutonium Depositions . . . . . . . . . 9.47

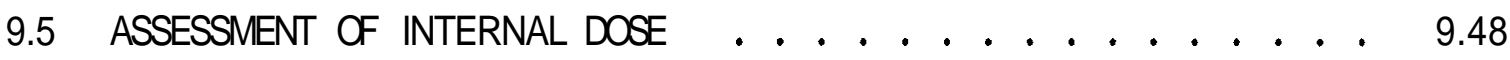

9.5.1 General Approach . . . . . . . . . . 9.48

9.5.2 Estimating Presystemic Deposition . . . . . . 9.49

9.5.3 Estimating Initial Lung Deposition . . . . . . 9.50

9.5.4 Assessing Organ Dose Equivalents . . . . . . . . 9.52

9.5.5 Estimating Intake . . . . . . . . . . . 9.53

9.5.6 Simplified Dose Assessments . . . . . . . . . 9.54

9.6 MANAGEMENT OF INTERNAL CONTAMINATION CASES . . . . . . 9.56

9.6.1 Diagnostic Procedures ........... 9.56

9.6.2 Therapeutic Actions ............. . 9.57

9.6.3 Long-Term Monitoring of Internal Depositions . . . 9.58

10.0 REFERENCES . . . . . . . . . . . . . . . 10.1

APPENDIX A - GEMID INTERNAL DOSIMETRY CONPUIER CODE . . . . . . . . . A.I

APPENDIX B _ ORGANS OR TISSUES OF CONCERN . . . . . . . . . . . B.I

APPENDIX C _ STATISTICAL METHODS FOR INTERPRETING BIOASSAY DATA . . . $\quad$ c.1

APPENDIX D - ICRP LUNG MODE ................ D.I

APPENDIX E - FECAL SAMPLING ............. E.I

APPENDIX F - PUCALC PLUTONIUM EXCRETION COMPUTER CODE . . . . . . . . F.I 



\section{FIGURES}

2.1 Tritium Bioassay Monitoring Program Detection Capability

for Analytical Sensitivity of $10 \mathrm{dpm} / \mathrm{mL}$. . . . . . . . . 2.12

2.2 Tritium Concentration in Urine of Occupational Ty Unexposed

FFTF Workers ..................... 2.17

$4.1{ }^{90} \mathrm{Sr}$ Retention Functions ..................... . . 4.5

$4.2{ }^{90} \mathrm{Sr}$ Excretion Functions for Urinary Excretion Fol lowing an Acute Uptake ........................

4.3 ${ }^{90}$ Sr Intake Excretion Functions for the Urinary Excretion Pathway .......................... 4.8

$4.4{ }^{90}$ Sr Inhalation Intakes Detectable by Urine Sampling . . . . . . 4.17

5.1 Activity in Body Following an Uptake Resulting in a First-Year Effective Dose Equivalent of 100 mrem . . . . . . 5.6

6.1 Stable lodine Retention Model . . . . . . . . . . . 6.3

6.2 Percent of 50-Year Committed Effective Dose Equivalent

Received at Times After Intake .............. 6.5

7.1 ${ }^{154}$ Eu in the Body Following an Inhalation Intake Resulting in a First-Year Effective Dose Equivalent of 10 mrem, Class W . . . 7.4

7.2 ${ }^{154}$ Eu in the Body Following an Inhalation Intake Resulting in a First-Year Effective Dose Equivalent of 10 mrem, Class Y . . 7.5

7.3 ${ }^{154} \mathrm{Eu}$ in the Body Following an Inhalation Intake Resulting in a First-Year Effective Dose Equivalent of 10 mrem, Class W . . 7.5

7.4 ${ }^{155}$ Eu in the Body Following an Inhalation Intake Resulting in a First-Year Effective Dose Equivalent of 10 mrem, Class Y . . 7.6

8.1 Specific Activity for Enriched Uranium . . . . . . . . . . . 8.4

8.2 Urinary Excretion of Uranium in Unexposed Hanford Workers . . 8.7

8.3 Daily Variability in Instantaneous Urinary Excretion from Chronic Inhalation of $1 \mathrm{mg} /$ workday of Class D Uranium . . . . 8.20

8.4 Net Long-Term Urinary Excretion Following an Acute Inhalation of Natural Uranium Resulting in a First-Year Effective Dose

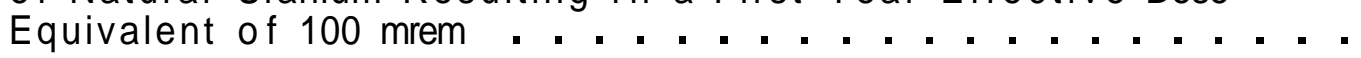


8.5 Predicted Long-Term Retained Quantities in the Lung Following an Acute Inhalation of Class Y Uranium Resulting in a

First-Year Effective Dose Equivalent of $100 \mathrm{mrem}$. . . . . .

8.6 Predicted Long-Term Retained Quantities in the Lung Fol Towing an Acute Inhalation of Class W Uranium Resulting in a First-Year Effective Dose Equivalent of $100 \mathrm{mrem}$. . . . .

8.7 Ratio of Uranium in Kidneys to Daily Excretion in Urine for Chronic Exposure to Class D Uranium .........

8.8 Predicted Urinary Excretion Following an Inhalation of 303-M Building Uranium Resulting in a First-Year Effective Dose Equivalent of $100 \mathrm{mrem} \ldots \ldots . . . . . .$.

8.9 Predicted Urinary Excretion Following an Inhalation of 333 Building Uranium Resulting in a First-Year Effective

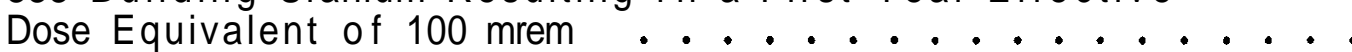

8.10 Predicted urinary Excretion Following an Inhalation of 306-W Building Uranium Resulting in a First-Year Effective Dose Equivalent of $100 \mathrm{mrem}$. . . . . . . . . 8.56

$9.1241_{\mathrm{Pu} /}{ }^{239+240} \mathrm{Pu}$ Ratio as a Function of Time Post Separation . . 9.5

$9.2 \quad 239+240 \mathrm{Pu} /{ }^{241}$ Am Ratio as a Function of Time Post Separation . . 9.6

9.3 Plutonium-Alpha/ ${ }^{241}$ Am Ratio as a Function of Time Post Separation ....................... 9.6

$9.4{ }^{239}$ Pu Acute Intake Urinary Excretion Functions ........ 9.14

9.5 Potentially Undetected First-Year Effective Dose Equivalent for a Single Acute Intake of Fresh 6\% Referenge Plutonium Mixture Based on an MDA of $0.02 \mathrm{dpm} /$ day of 239 Pu Detected

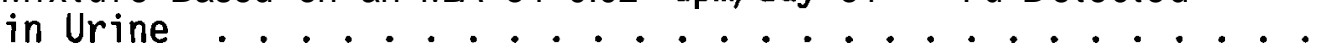

9.6 Potentially Undetected 50-Year Committed Effective Dose Equivalent for a Single Acute Intake of Fresh $6 \%$ Referengce Plutonium Mixture Based on an MDA of $0.02 \mathrm{dpm} /$ day of $239 \mathrm{Pu}$ Detected in Urine

9.7 Potentially Undetected First-Year Effective Dose Equivalent for a Single Acute Intake of Aged 12\% Referenge Plutonium Mixture Based on an MDA of $0.02 \mathrm{dpm} /$ day of 239 Pu Detected

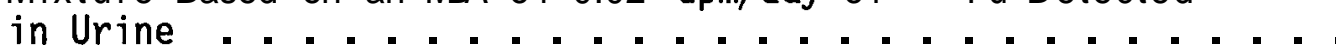

9.8 Potentially Undetected 50-Year Committed Effective Dose Equivalent for a Single Acute Intake of Aged $12 \%$ Referepce Plutonium Mixture Based on an MDA of $0.02 \mathrm{dpm} /$ day of ${ }^{239} \mathrm{Pu}$ Detected in Urine 
9.9 Potentially Undetected First-Year Effective Dose Equivalent for a Single Acute Intake of Fresh 6\% Reference Plutonium Mixture Based on an MDA of $0.18 \mathrm{nCi}$ of ${ }^{241}$ An Detected by Lung Counting

9.10 Potentially Undetected 50-Year Committed Effective Dose Equivalent for a Single Acute Intake of Fresh $6 \%$ Reference Plutonium Mixture Based on an MDA of $0.18 \mathrm{nC} ;{ }^{241}$ Am Detected by Lung Counting ............... 9.45

9.11 Potentiall y Undetected First-Year Effective Dose Equivalent for a Single Acute Intake of Aged 12\% Reference Plutonium Mixture Based on an MDA of $0.18 \mathrm{nC} i$ of ${ }^{241}$ Am Detected by

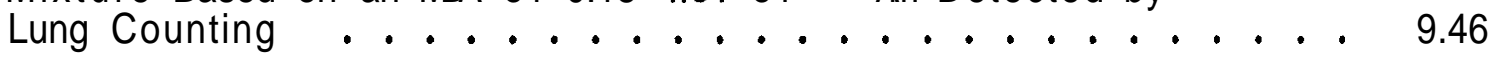

9.12 Potentially Undetected 50-Year Committed Effective Dose Equivalent for a Single Acute Intake of Aged 12\% Befference Plutonium Mixture Based on an MDA of $0.18 \mathrm{nCi}$ of ${ }^{24}$ An Detected by Lung Counting 


\section{$\underline{\text { TABLES }}$}

2.1 ICRP 23 Reference Man Water Balance . . . . . . . . . 2.4

2.2 Tritium Dosimetry Factors . . . . . . . . . . 2.7

2.3 Analytical Sensitivities for Tritium in Urine . . . . . . 2.11

2.4 Detection Capability of Tritium Bioassay Monitoring with a

Sensitivity of $10 \mathrm{dpm} / \mathrm{mL} \ldots \ldots 2.12$

3.1 Minimum Detectable Activity in a Whole Body Count . . . . . 3.4

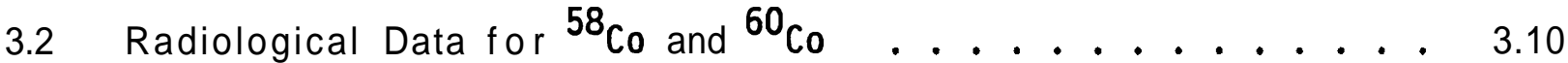

3.3 Total Body Retention Following an Acute Inhalation

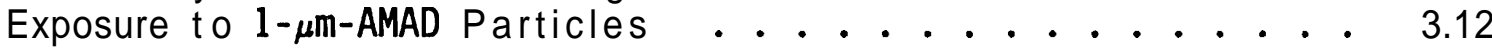

3.4 Dose Conversion Factors for Cobalt . . . . . . . . . 3.13

3.5 Predicted Effective Dose Equivalents Resyllting from an Inhalation Intake of $1-\mu \mathrm{m}-\mathrm{AMAD}{ }^{58} \mathrm{Co}$ or ${ }^{6}$ Co Particles . . . 3.13

3.6 Expected ${ }^{58}$ Co Activity Following an Acute Intake Resulting in a First-Year Effective Dose Equivalent of $10 \mathrm{mrem}$. . . . . 3.14

3.7 Expected ${ }^{60}$ Co Activity Following an Acute Intake Resulting in a First-Year Effective Dose Equivalent of $10 \mathrm{mrem}$..... . 3.14

3.8 Detectable Doses for I $n$ Vivo Measurement of ${ }^{58} \mathrm{Co}$ and ${ }^{60}$ Co Following Inhalation of a $1-\mu \mathrm{m}$-AMAD Aerosol ...... 3.15

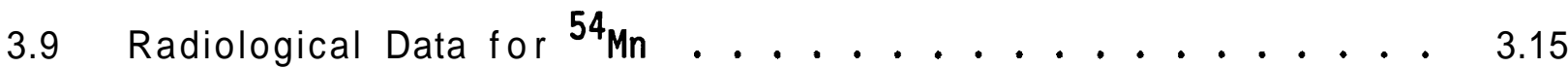

3.10 Dose Conversion Factors for ${ }^{54} \mathrm{Mn} \ldots \ldots . . \ldots 37$

3.11 Predicted Effective Dose Equivalent Resulting from an 3.17

3.12 Expected ${ }^{54}$ Mn Activity Following an Acute Intake Resulting in a First-Year Effective Dose Equivalent of $10 \mathrm{mrem}$.... . 3.18

3.13 Radiological Data for ${ }^{59} \mathrm{Fe} \ldots \ldots . \ldots . \ldots 3 . \ldots$

3.14 Dose Conversion Factors for ${ }^{59} \mathrm{Fe} \ldots \ldots . . \ldots 39$

3.15 Predicted Effective Dose Equivalent Resulting from an
Inhalation Intake of 1- . . . . . 3.20 
3.16 Expected ${ }^{59} \mathrm{Fe}$ Activity Following an Acute Intake Resulting in a First-Year Effective Dose Equivalent of $10 \mathrm{mrem}$. . . . . 3.20

4.1 Historical Documentation of the Hanford Strontium Model and Deposition Evaluation Techniques ........... 4.2

4.2 Fission Product Yields ... . . . . . . . . . . . . 4.2

4.3 Decay Data for Strontium Isotopes . . . . . . . . . . 4.3

4.4 Selected ${ }^{90}$ Sr Urinary Excretion Fractions . . . . . . . 4.9

4.5 Selected ${ }^{89}$ Sr Urinary Excretion Fractions . . . . . . . . 4.10

4.6 Dose Conversion Factors for Strontium Dosimetry . . . . . . . 4.10

4.7 ${ }^{90} \mathrm{Sr}+{ }^{90} \mathrm{Y}$ Intake Dose Equivalent Factors for First-Year and 50-Year Committed Doses . . . . . . . . . . . . . 4.12

4.8 ${ }^{89} \mathrm{Sr}$ Intake Dose Equivalent Factors for First-Year and 50-Year Committed Doses . . . . . . . . . . . . . . 4.13

4.9 Cumulative Effective Dose Equivalent for ${ }^{90}$ Sr Intakes . . . . 4.14

4.10 Contractual Detection Levels for Strontium . . . . . . . . 4.15

4.11 Bioassay Detection Capability for an Acute ${ }^{90}$ Sr Intake Based on a 2-dpm Urine Sample Analysis Sensitivity . . . . . . 4.18

4.12 Simplified Dose Assessment Intakes for a ${ }^{90} \mathrm{Sr}$ Inhalation Intake, nCi ...................... 4.23

4.13 Excretion Associated with ${ }^{90}$ Sr Class D Acute Inhalation of 1 - $\mu \mathrm{m}$-AMAD Particles ................

4.14 Excretion Associated with ${ }^{90}$ Sr Class Y Acute Inhalation

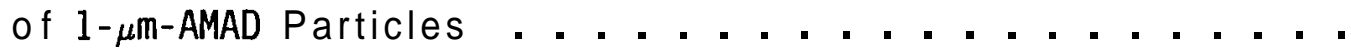

5.1 Predicted Effective Dose Equivalent Resulting from an Inhalation $(a, b)$ or Uptake of Radiocesium, $\mathrm{mrem} / \mathrm{nCi} \ldots . . .5 .4$

5.2 Total Body Activity Following an Acute Uptake or Class D Inhalation Intake Resulting in a First-Year Effective Dose Equivalent of $10 \mathrm{mrem} \ldots \ldots . . . \ldots$

5.3 Bigassay Petsection Capability for an Acute Intake of

6.1 First-Year and 50-Year Committed Effective Dose Equivalent Following an Acute Inhalation Intake of Radioiodine 
6.2 Expected Radioiodine in Thyroid Following an Acute Inhalation Resulting in a First-Year Effective Dose Equivalent of

100 mrem . . . . . . . . . . . . . . . . 6.5

6.3 Dose from a Thyroid Burden of Radioiodine . . . . . . . . . . . 6.6

6.4 Sensjtivities of In Vivo Measurements for ${ }^{125} \mathrm{I}, 131_{\mathrm{I}}$, . . . . . . . . . . . . . . . . . . . . . .

6.5 Detectable Annual Effective Dose Equivalent for Various
Routine In Vivo Monitoring Frequencies . . . . . . . 6.8

7.1 First-Year and Committed Dose Equivalent Following an Acute Inhalation Intake of $1 \mathrm{nCi}$ of $154_{\mathrm{Eu}}$ or $155_{\mathrm{Eu}} \ldots \ldots . . .7 .3$

7.2 Accumulation of Effective Dose Equivalent Following an Acute Inhalation of Europium . . . . . . . . . . . . . . . . 7.4

7.3 Total Body Retention Following an Acute Inhalation Exposure to $0.5-\mu$ m AMAD Particles . . . . . . . . . . 7.7

7.4 Detection Levels for In Vivo Measurements for ${ }^{154}$ Eu and

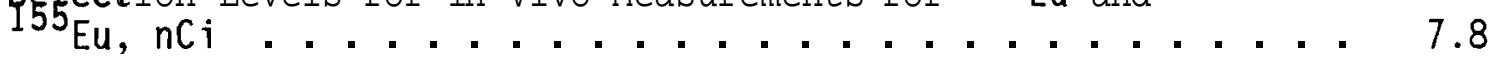

7.5 Expected Whole Body Count Quantities Following an Inhal ation Intake Resulting in a First-Year Effective Dose Equivalent of $10 \mathrm{mrem}$. . . . . . . . . . . . . . . . . . . . . 7.9

7.6 Dose Conversion Factors for Radioisotopes of Europium . . . . . 7.13

8.1 Enrichments of Uranium at Hanford Facilities . . . . . . . . . 8.2

8.2 Radiological Characteristics of Uranium Isotopes . . . . . . . . 8.2

8.3 Radiological Characteristics of Uranium Mixtures . . . . . . . . 8.3

8.4 Impurities in Recycled Uranium at Hanford , . . . . , , . , , , 8.5

8.5 Inhalation Classes and $f_{1}$ Values for Some Uranium Compounds . . 8.8

8.6 Lung Retention Factors Following Inhalation of Uranium . . . . 8.10

8.7 Urinary Excretion Factors Following Inhalation of Uranium . . . 8.11

8.8 Fecal Excretion Factors Following Inhalation of Uranium . . . . 8.12

8.9 Specific Effective Energy Factors for Uranium Isotopes . . . . . 8.14

8.10 Weighted Specific Effective Energy Factors for Hanford Uranium Mixtures . . . . . . . . . . . . . . . . . . . . . . 8.14 
8.11 First-Year and 50-Year Committed Dose Equivalents Following Inhalation of $1 \mathrm{nCi}$ of Natural Uranium ........ 8.15

8.12 Committed Effective Dose Equivalent from Inhalation of Recycled Uranium, Reference Mixture . . . . . . . . 8.16

8.13 Dose Factors from Reference Levels of Non-Uranium Impurities in Recycled Uranium ............... 8.17

8.14 Acute Intake Dose Conversion Factors for 1- $\mu \mathrm{m}$-AMAD Particles . 8.18

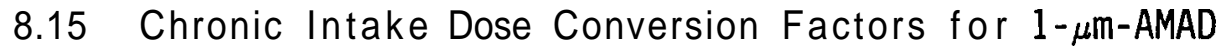
Particles .................. 8.19

8.16 Comparison of Rapid Clearance via the Gastrointestinal Tract with Intake, Initial Long-Term Pulmonary Deposition, and First-Year Effective Dose Equivalent for Class Y Uranium . . . . 8.24

8.17 Sensitivity of an In Vivo Chest Examination for Uranium • • • 8.25

8.18 Sensitivity of an In Vivo Chest Count in Terms of First-Year and 50-Year Committed Effective Dose Equivalent Following Acute Inhalation of 1- $\mu \mathrm{m}$-AMAD, Class Y Uranium . . . . . . . .

8.19 Routine Bioassay Monitoring Capabilities for a Single Acute Inhalation of Natural Uranium . . . . . . . . . . . .

8.20 Routine Urinalysis Monitoring Capabilities for a Single Acute Intake of Class D Uranium in Percent of the Threshold for Acute Toxicity . . . . . . . . . . . . . . . .

8.21 Fraction of Intake Excreted via Feces Following an Acute

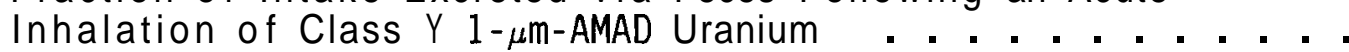

8.22 Ratio of Daily Excretion to Daily Inhalation at 5 Years After the Onset of Chronic Exposure . . . . . . . . . . 8.37

8.23 Urinary Excretion of Uranium Following an Acute Inhalation Resulting in the Uptake of $7 \mathrm{mg}$ of Uranium . . . . . . . . .

8.24 Recommended Follow-Up Levels for Chronic and Acute Intakes, $\mu \mathrm{g} /$ day . . . . . . . . . . . . . . . . . . .

8.25 Predicted Uranium Excretion via Urine Following an Inhalation of U03 Plant Recycled Uranium . . . . . . . . . . . . . .

8.26 In Vitro Solubility Classification of Uranium in the N Reactor Fuel Production Facility . . . . . . . . . . . . . . .

8.27 Expected Deposition Fractions for Airborne Uranium Particulates in the 303-M and 333 Buildings . . . . . . . . 
8.28 Daily Intake Rate of Uranium Yielding an Annual Effective

Dose Equivalent Rate of $100 \mathrm{mrem} / \mathrm{yr}$ by the End of the

Intake Period .......................

8.29 Predicted Uranium Excretion via Urine Following an Inhalation

of 303-M Building Uranium . . . . . . . . . . . . . .

8.30 Predicted Uranium Excretion via Urine Following an Inhalation

of 333-M Building Uranium ...............

8.31 First-Year and 50-Year Committed Dose Following an Acute

Inhalation of $1 \mathrm{mg}$ of $306-W$ Depleted Uranium . . . . . . . .

8.32 Daily Intake Rate of Depleted Uranium Yielding an

Effective Dose Equivalent of $100 \mathrm{mrem} / \mathrm{yr}$ by the End

of the Exposure Period . . . . . . . . . . . . . . . . .

8.33 Predicted Uranium Excretion Via Urine Following an Inhalation

of 306-W Building Uranium .. . . . . . . . . . . . . .

9.1 Plutonium and Americium Decay Data . . . . . . . . . . . . .

9.2 Reference Plutonium Isotope Mixtures Immediately Post

Separation, wt\%

9.3 Activity Composition for Reference Plutonium Mixtures . . . . .

9.4 Selected Lung Retention,Factors Expressed as a Fraction

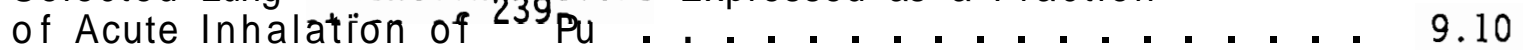

9.5 ICRP 48 Biokinetic Constants for Plutonium . . . . . . . . . . 9.10

9.6 Selected ${ }^{239} \mathrm{Pu}$ Urinary Excretion Fractions Expressed as a

Fraction of Acute Intake..................

9.7 Selected Fecal Excretign Factors Expressed as a Fraction of

Acute Inhalation of 239

9.15

$9.8{ }^{238} \mathrm{Pu}$ Dose Conversion Factors . . . . . . . . . . . . . . .

9.16

$9.9{ }^{239} \mathrm{Pu}$ and/or ${ }^{240} \mathrm{Pu}$ Dose Conversion Factors . . . . . . . . . . .

9.16

9.10

${ }^{241}$ Pu Dose Conversion Factors

9.17

9.11 241Am Dose Conversion Factors . . . . . . . . . . . . . . 9.17

$9.12{ }^{238} \mathrm{Pu}$ Acute Intake Dose Equivalent Factors for First-Year and 50-Year Committed Doses

9.13 ${ }^{239} \mathrm{Pu}$ and/or ${ }^{240} \mathrm{Pu}$ Acute Intake Dose Equivalent Factors for First-Year and 50-Year Committed Doses 
9.14 ${ }^{241}$ Pu Acute Intake Dose Equivalent Factors for First-Year and 50-Year Committed Doses .............. . 9.20

$9.15{ }^{241}$ Am Acute Intake Dose Equivalent Factors for First-Year and 50-Year Committed Doses . . . . . . . . . . 9.21

9.16 Acute Intake Dose Equivalent Factors, Fresh 6\% Plutonium Mixture First-Year and 50-Year Committed Doses . . . . . . . .

9.17 Acute Intake Dose Equivalent Factors, Aged 6\% Plutonium Mixture First-Year and 50-Year Committed Doses . . . . . . . 9.24

9.18 Acute Intake Dose Equivalent Factors, Fresh 12\% Plutonium Mixture First-Year and 50-Year Committed Doses ........

9.19 Acute Intake Dose Equivalent Factors, Aged 12\% Plutonium Mixture First-Year and 50-Year Committed Doses .......

9.20 Cumulative Effective Dose Equivalent for ${ }^{239} \mathrm{Pu}$ Intakes .... .

9.21 Detection Limits for Routine Hanford Analyses of Plutonium

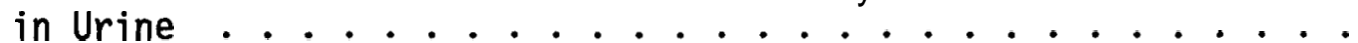

9.22 Contractual Detection Levels for Plutonium in Urine During

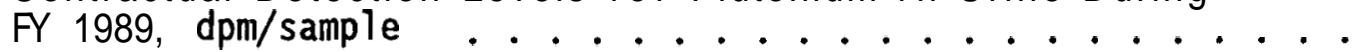

9.23 Contractual Detection Levels for Plutonium in Feces During FY 1989, dpm/sample .................

9.24 Sensitivities of Typical In Vivo Measurements for Plutonium

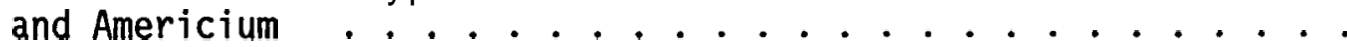

9.25 Acute ${ }^{239} \mathrm{Pu}$ Intake Associated with the Minimum Detectable Activity Urine Bioassay Measurement . . . . . . . . . .

9.26 Potentially Undetected First-Year Effective Dose Equivalent for a Single Acute Intake of Fresh 6\% Referenge Plutonium Mixture Based on an NDA of $0.02 \mathrm{dpm} /$ day of $239 \mathrm{Pu}$ Detected

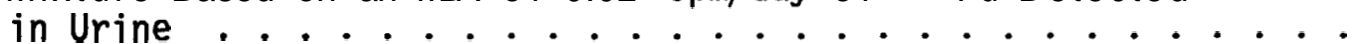

9.27 Potentially Undetected 50-Year Committed Effective Dose Equivalent for a Single Acute Intake of Fresh $6 \%$ Referengce Plutonium Mixture Based on an MDA of $0.02 \mathrm{dpm} /$ day of ${ }^{239} \mathrm{Pu}$ Detected in Urine

9.28 Potentially Undetected First-Year Effective Dose Equivalent for a Single Acute Intake of Aged $12 \%$ Referenge Plutonium Mixture Based on an MDA of $0.02 \mathrm{dpm} /$ day of 239 Pu Detected

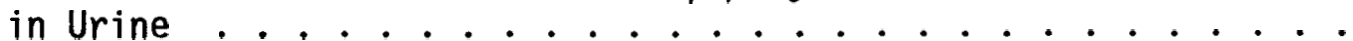


9.29 Potentially Undetected 50-Year Committed Effective Dose Equivalent for a Single Acute Intake of Aged 12\% Referegce Plutonium Mixture Based on an MDA of $0.02 \mathrm{dpm} /$ day of ${ }^{239} \mathrm{Pu}$ Detected in Urine ..................

9.30 Potentially Undetected First-Year Effective Dose Equivalent for a Single Acute Intake of Fresh 6\% Reference Plutonium Mixture Based on an MDA of $0.18 \mathrm{nCi}$ of ${ }^{24}$ Am Detected by Lung Counting ..................

9.31 Potentially Undetected 50-Year Committed Effective Dose Equivalent for a Single Acute Intake of Fresh $6 \%$ Reference
Plutonium Mixture Based on an MDA of $0.18 \mathrm{nCi}$ of 24 Am Detected by Lung Counting ................

9.32 Potentially Undetected First-Year Effective Dose Equivalent for a Single Acute Intake of Aged $12 \%$ Reference Plutonium Mixture Based on an MDA of $0.18 \mathrm{nC} \mathbf{i}$ of ${ }^{24 I}$ An Detected by Lung Counting

9.33 Potentiall y Undetected 50-Year Committed Effective Dose Equivalent for a Single Acute Intake of Aged $12 \%$ Beference
Plutonium Mixture Based on an MDA of $0.18 \mathrm{nCi}$ of Detected by Lung Counting . . . . . . . . . . . . . .

9.34 Intakes for Reference Plutonium Mixtures Resulting in a First-Year Effective Dose Equivalent of $100 \mathrm{mrem}$........ 


\section{ACRONYMS LIST}

\begin{tabular}{|c|c|}
\hline $\begin{array}{l}\text { ALARA } \\
\text { ALI } \\
\text { AMAD } \\
\text { ANS I }\end{array}$ & $\begin{array}{l}\text { as low as reasonably achievable } \\
\text { annual limit on intake } \\
\text { activity median aerodynamic diameter } \\
\text { American National Standards Institute }\end{array}$ \\
\hline BS & bone surface \\
\hline $\begin{array}{l}\text { DCF } \\
\text { D\&D } \\
\text { DIL } \\
\text { DOE } \\
\text { DTPA } \\
D, W, Y\end{array}$ & $\begin{array}{l}\text { dose conversion factor } \\
\text { decontamination and decommissioning } \\
\text { derived investigation level } \\
\text { U.S. Department of Energy } \\
\text { diethylene triamine penta acetate } \\
\text { days, weeks, years (lung classes) }\end{array}$ \\
\hline $\begin{array}{l}\text { EDE } \\
\text { EDF } \\
\text { EDTA } \\
\text { EPA }\end{array}$ & $\begin{array}{l}\text { effective dose equivalent } \\
\text { Emergency Decontamination Facility } \\
\text { ethylene diamine tetraacetic acid } \\
\text { Environmental Protection Agency }\end{array}$ \\
\hline $\begin{array}{l}\text { FETF } \\
\text { FPF } \\
\text { FPF-RU } \\
\text { FY }\end{array}$ & $\begin{array}{l}\text { Fast Flux Test Facility } \\
\text { Fuel Production Facility } \\
\text { Fuel Production Facility recycled urani um } \\
\text { fiscal year }\end{array}$ \\
\hline GI & gastrointestinal \\
\hline $\mathrm{HEHF}$ & Hanford Environmental Health Foundation \\
\hline $\begin{array}{l}\text { IAEA } \\
\text { ICRP } \\
\text { IG } \\
\text { IVRRF }\end{array}$ & $\begin{array}{l}\text { International Atomic Energy Agency } \\
\text { International Commission on Radiological Protection } \\
\text { intrinsic germanium } \\
\text { In Vivo Radioassay and Research Facility }\end{array}$ \\
\hline LLI & lower large intestine \\
\hline $\begin{array}{l}\text { MDA } \\
\text { MKIV } \\
\text { MPBB }\end{array}$ & $\begin{array}{l}\text { minimum detectable activity (or amount) } \\
\text { Mark IV } \\
\text { maximum permissible body burden }\end{array}$ \\
\hline $\begin{array}{l}\text { NA } \\
\text { NBS } \\
\text { NCRP } \\
\text { N-P }\end{array}$ & $\begin{array}{l}\text { not appl icable } \\
\text { National Bureau of Standards } \\
\text { National Counci } 1 \text { on Radiation Protection and Measurements } \\
\text { nasal passage region of the respiratory tract }\end{array}$ \\
\hline $\begin{array}{l}\text { P } \\
\text { PNL } \\
\text { ppmp } \\
\text { ppbp }\end{array}$ & $\begin{array}{l}\text { pulmonary region of the lung } \\
\text { Pacific Northwest Laboratory } \\
\text { parts per million per ... } \\
\text { parts per billion per } \ldots\end{array}$ \\
\hline
\end{tabular}


PUREX Plutonium Uranium Extraction (Facility)

$\begin{array}{ll}\text { RM } & \begin{array}{l}\text { red marrow } \\ \text { RPS }\end{array} \\ \text { radiation protection standard } \\ \text { SEE } & \begin{array}{l}\text { specific effective energy } \\ \text { small intestine }\end{array} \\ \text { TAT } & \text { threshold for acute toxicity } \\ \text { T-B } & \text { tracheal-bronchia1 region of the lung } \\ \text { TGD } & \text { Task Group on Lung Dynamics } \\ \text { ULI } & \text { upper large intestine } \\ \text { UO3 } & \text { Uranium Oxide (PI ant) } \\ \text { U03-R } & \text { Uranium Oxide Plant recycled uranium } \\ \text { WE } & \text { whole body counter } \\ \text { WESF } & \text { Waste Encapsulation and Storage Facility }\end{array}$




\section{MATHEMATICAL SYMBOLOGY $(a)$}

$c(t)$ body water concentration of tritium at time $t$ post intake

$e^{a}(t)$ fractional excretion based on the fraction of uptake to blood

$e^{a}(t) \quad$ fractional uptake urinary excretion

$e_{u}^{a}(t) \quad$ fractional intake urinary excretion

$H_{T, t} \quad$ tissue dose equivalent in year $t$ post intake

$\mathrm{H}_{T, 1}$ first-year tissue dose equivalent

$\mathrm{H}^{\mathrm{c}} \mathrm{T}, \mathrm{t}$ cumulative or committed tissue dose equivalent through year $\mathrm{t}$ post intake

$H_{E, t}$ effective dose equivalent in year $t$ post intake

$H_{E, 50}^{C} \quad 50$-year committed effective dose equivalent

I intake

$\mathrm{L}_{c}$ decision level; the level above which an analyte is determined to be present in a sample

$M_{u}(t)$ measured urinary excretion at time $T$ (not fractional)

$Q(t) \quad$ the retained quantity at time $t$ (not fractional)

$r_{s}{ }_{s}(t)$ fractional uptake systemic retention at time $t$ including systemically fed organs and tissues

$U(t) \quad$ uptake through time $t$

$U(\infty)$ total uptake. Note: concerning uptake to blood, $U(\infty)$ is the presystemic deposition

$W_{T} \quad$ effective dose equivalent weighting factor for tissue $T$

$x_{i} \quad$ result of a measurement

$\sigma_{j} \quad$ uncertainty associated with the result $X_{i}$

(a) The symbology used in this document generally follows that used in Publication 54 of the International Commission on Radiological Protection (1988). 



\section{GLOSSARY}

annual effective dose equivalent, $H_{E}$ : the sum of the products of the annual tissue dose equivalent, $\mathrm{H}_{\mathrm{T}}$, to organs and tissues of the body and the respective weighting factors as designated in DOE 5480.11 (DOE 1988).

annual tissue dose equivalent, $\mathrm{H}_{\mathrm{T}}$ : unweighted dose equivalent to a specific organ or tissue.

a priori: presupposed by experience. In the context of counting statistics, it refers to estimated or general capabilities determined prior to an actual sample count.

bioassay: measurement of amount or concentration of material (usually radioactive material) in the body or in biological material excreted or removed from the body and analyzed for purposes of êstimating the quantity of material in the body (from ANSI 1987). (a)

burden: the instantaneous activity of a radionucl ide in a systemically fed organ or tissue, the lung, or in the whole body excluding the activity at the entry site and lymph system (lung, wound site, and/or in material passing through the GI tract.) For nontransportable activity obtained by inhalation, both the body burden and the lung burden would be required to completely characterize the situation at a given time. Using ICRP 54 (1988) terminology, burden is the same as retained quantity.

committed: refers to a total or time-integrated amount for 50 years post intake or onset of a chronic intake (or for a different period if so specified).

committed dose equivalent, $\mathrm{H}^{\mathrm{C}}$ $50^{\circ}$ : dose equivalent to a organ or tissue committed for a 50-year perriod following an acute intake or onset of chronic intake. It does not include contributions from external dose (DOE 1988).

committed effective dose equivalent, $\mathrm{H}^{\mathrm{C}}{ }_{50}$ : the effective dose equivalent committed for a 50-year period following an acute intake or onset of chronic intake. It does not include contributions from external dose (DOE 1988).

corrosion products: elements that are present in the structure of the reactor or the fuel rods that become activated by neutrons, as opposed to fission products that result from fission.

(a) American National Standards Institute (ANSI). 1987. Performance Criteria for Radiobioassav. Draft ANSI Standard N13.30, New York, New York. 
deposition: the total input to an organ or tissue for a specified period of time. Deposition can also refer to material deposited at an entry site. See also systemic deposition.

detection level: a general term relating to the smallest amount of material detectable as a function of the measurement method and instrument background. (The precise way that detection level has been defined has changed over the years.)

detection 1imit: synonymous with detection level.

injection: any means whereby the radioactive material is placed in direct contact with the blood, excluding through the lung or GI tract.

intake: the amount of material taken into the body by inhalation, absorption through the skin, injection, ingestion or through wounds (from NCRP 1987).

in vivo: refers to measuring radioactivity directly on a living organism. In vivo is synonymous with the word "direct" when used in the phrase "direct bioassay".

minimum detectable activity, MDA: the smallest activity of a radionuclide in a sample (or organ) that will be detected with a specified level of confidence. See Appendix C for details.

positive level: a level of a bioassay measurement at which the Hanford Internal Dosimetry Program considers the analyte to be detected (as opposed to being detectable).

presystemic deposition: a mathematical or schematic component (or components) of the deposition at the entry site that is available for translocation to the blood. It excludes material that is permanently retained at the entry site or by the lymph system.

preview counter: a standup whole body counter consisting of $5 \mathrm{NaI}$ detectors. It is the principal counter used for routine whole body counts and incident screening counts, provided good resolution of photopeaks is not needed.

readily transportable: being readily transferred from the site of initial deposition to the blood. As applied to material in the lung, readily transportable material would be class $D$. It is generally equivalent to the term "soluble" as applied to human physiology, but it is not necessarily equivalent to chemical solubility in aqueous solutions.

retained quantity: synonymous with burden.

retention: the retained quantity (or burden) as a fraction of the uptake or intake. It can apply to an organ or to the whole body. 
specific effective energy, SEE: the energy, suitably modified for quality factor, imparted per gram of a target tissue as a consequence of the emission of a specified radiation from a transformation occurring in a source tissue. The units are Mev per gram-transformation (from ICRP 1979).

super Y: an inhalation class in which the radioactive material is more tenaciously retained in the pulmonary region of the lung than class $Y$ material; i.e., the clearance half-time from the pulmonary region of the lung is greater than 500 days. For purposes of prospective analyses in this document, super $Y$ was assumed to be characterized by a 10,000-day clearance half-time for pathways $a, c, e$, and $i$ as shown in Figure D.1.

systemic deposition: activity retained for an extended period of time in all systemic organs and tissue. Differs from uptake in that activity that stays in the transfer compartment and is ultimately excreted without going to systemic organs (for instance, because of chelation) is included in the term uptake but not in the term systemic deposition.

time-integrated activity or cumulative activity: the integral over time of the instantaneous activity in an organ or in the whole body. The units are activity times time, such as nanocurie-days. When multiplied by the SEE factor and appropriate unit conversion factors, the time-integrated activity provides the dose equivalent to the target organ.

transfer compartment: a mathematical or schematic representation of the blood circulation system through which radioactive material is transported to organs, tissues, or excretion.

uptake: quantity of a radionuclide taken up by the systemic circulation, e.g., by injection into the blood, by absorption from compartments in the respiratory or GI tracts, or by absorption through the skin or through wounds in the skin (from NCRP 1987), or taken up by a specified organ or tissue via the blood. 

SECTION 1.0

INTRODUCTION 



\subsection{INTRODUCTION}

The Hanford Internal Dosimetry Program, administered by Pacific Northwest Laboratory (PNL) for the U.S. Department of Energy (DOE), provides internal dosimetry support services for operations at the Hanford Site. These operations include the production and purification of plutonium, the fabrication of uranium fuel elements, the operation of large thermal (presently in standby status) and fast reactors, the processing of radioactive wastes, and research and development.

Nearly 8,000 of the approximately 15,000 workers employed at Hanford by DOE and its contractors participate in routine bioassay monitoring programs. Radionuclides of particular interest are the fission and activation product radionuclides, uranium, and plutonium.

This report describes the technical basis for the design of the routine bioassay monitoring program and upon which assessment of internal dose is performed. The purposes of this report are to:

provide assurance that the Hanford Internal Dosimetry Program derives from a sound technical base

- promote the consistency and continuity of routine program activities provide a historical record serve as a technical reference for radiation protection personnel aid in identifying and planning for future needs.

Internal dosimetry at Hanford is based on the concepts of effective dose equivalent described in Publications 26 and 30 of the International Commission on Radiological Protection (ICRP 1977, 1979) and modified to apply to annually received dose as prescribed by DOE 5480.11 (DOE 1988). The annually received effective dose equivalent is the basis for evaluating compliance with regard to the $5 \mathrm{rem} / \mathrm{yr}$ DOE Radiation Protection Standard (RPS). Fifty-year committed dose equivalents (both tissue and effective dose equivalents) are also calculated and reported. 


\subsection{DOCUMENT DESCRIPTION}

This document consists of a number of sections and appendixes. Each section deals with a specific radionuclide or a related group of radionuclides. The appendixes provide information that is general to all of the sections. Radionuclides not specifically mentioned are rarely encountered in amounts of dosimetric concern. The basis for dosimetry for other radionuclides will be added to this document (as revisions) if the need arises.

This document was first issued in April 1989. In its first 2 years, the document found a wide audience among the DOE offices, its contractors, and other organizations involved in dosimetry. It not only served well as the intended reference for data, but became a template for other facilities in the development of their own technical basis documents.

This document is a "living" document responsive to the needs of the Hanford Internal Dosimetry Program. A limited number of documents are maintained under controlled distribution at Hanford for the convenience of those Hanford staff having direct responsibilities for site internal dosimetry. Uncontrolled copies are made available to other interested individuals.

\subsection{REVISIONS}

Revisions are made as needed, based on changes in the science and art underlying internal dose assessment, changes in the requirements of the program, and also to incorporate material found to be particularly useful for dose evaluation. These occasional revisions are made via Program Change Records maintained in the Hanford Radiation Protection Historical Files. Affected portions of the document are periodically revised and redistributed or the document is reissued in total as a numbered revision.

The extensive 1991 revision of the Technical Basis document was prompted by the desire to have certain additional information readily available for routine use in dose assessment and bioassay program design. Also, some changes in the presentation of information were identified to make the document easier to use, particularly in light of proposed performance standards for internal dosimetry. Advance drafts of the DOE Performance Standard for 
Changes in the science and art of dosimetry are foreseeable in the future. Such changes might include a new lung model, improved biokinetic models for radionuclides in the body, new recommendations for organs of concern and weighting factors anticipated from ICRP, new implementing computer codes, and performance standards for internal dosimetry. However, at this time the existing "science" appears adequate for the stated purpose of the Hanford Internal Dosimetry Program, namely, evaluating compliance with applicable DOE standards for worker radiation protection as expressed in DOE 5480.11 (1988).

Changes have also occurred in the Hanford mission since the document was originally issued. With the phasing out of plutonium production, the need for dosimetry for freshly processed plutonium has decreased. Likewise, with $\mathrm{N}$ Reactor now in a cold-standby condition, uranium fuel production has ceased and the decay of relatively short-lived fission and activation products has substantially reduced the need for their dosimetry. The continued operation of the Fast Flux Test Facility warrants maintaining well-established internal dosimetry programs for these nuclides, however actual experience has shown little need for internal dose assessments associated with that facility. In addition, the potential need to review or reevaluate past cases of exposure to these nuclides warrants retaining the material in the Technical Basis document. 

SECTION 2.0

TRITIUM 



\section{$2.0 \quad \underline{\text { TRITIUM }}$}

This section provides information on the sources and biokinetics of tritium and summarizes the technical basis used for the internal dosimetry of tritium $\left({ }^{3} \mathrm{H}\right)$ at Hanford. This section is not intended to be an allencompassing technical basis for any type of tritium exposure, but rather to provide the approach to be used for routinely encountered exposures at Hanford. For additional information, models, and approaches suitable for types of tritium exposures other than those addressed here, refer to the references listed in Section 10.0 .

\subsection{SOURCES OF TRITIUM}

Tritium exists as part of the natural background of environmental radiation (National Council on Radiation Protection and Measurements [NCRP] 1979a). It can be assumed that the tritium concentration of the body water of nonoccupationally exposed persons should be reasonably close to that of their drinking water. The Environmental Protection Agency (EPA) has reported that background tritium concentrations in U.S. drinking water range from 100 to $400 \mathrm{pCi} / \mathrm{L}$ (EPA 1985), which corresponds to about 0.2 to $1.0 \mathrm{dpm} / \mathrm{mL}$. In addition, the EPA has promulgated a limit for tritium in drinking water of $20 \mathrm{nCi} / \mathrm{L}$, based on $4 \mathrm{mrem} / \mathrm{yr}$ (EPA 1976), although an upward revision of this limit seems technically justifiable (Moghissi and Cothern 1986).

It is also worth noting that tritium has been widely distributed in the public domain as a source of luminosity for various "glow-in-the-dark" applications, such as the faces of watches, clocks, instruments, and exit signs. Breakage or other loss of containment in such devices could result in tritium levels in urine being substantially above background without occupational exposure.

Tritium at Hanford is encountered at levels of potential occupational dose concern primarily in research associated with tritium production, research associated with tritium production, the decontamination and decommissioning (D\&D) of former tritium production facilities, laboratories associated 
with such facilities, radioluminescent lights being developed by PNL, and as a tracer or labeling compound for biological research projects.

Tritium in the human body can be routinely detected at levels well below those of any dosimetric concern. Therefore, in addition to its use for dosimetry, tritium bioassay can be readily used as a workplace monitoring technique supplemental to air sampling or contamination surveys.

\subsection{BIOKINETIC BEHAVIOR OF TRITIUM}

This section describes the biokinetic models and assumptions used for the behavior of tritium, with the emphasis on tritium in the form of tritiated water.

\subsubsection{Chemical Form}

Unless otherwise specified, exposure to tritium is assumed to occur as exposure to tritiated water. Routine Hanford dosimetry is based on this form of tritium because it is the typical form encountered. Dosimetrically, tritiated water is also substantially more limiting than exposure to elemental tritium.

Organic compounds containing tritium can be substantially more limiting than tritiated water (by as much as a factor of 50). Dosimetry for exposure to elemental tritium or organic forms of tritium requires further knowledge of the nature of the material and the circumstances of exposure. Because elemental and organic forms are not in widespread use at Hanford, they are not addressed in this technical basis. If special circumstances warrant, this technical basis can be expanded.

\subsubsection{Transportability}

Tritium in the form of tritiated water or vapor is assumed to be instantaneously and uniformly mixed with body water immediately following intake. Although the NCRP suggests that 2 or more hours may be required for this distribution and mixing to occur (NCRP 1976), from a practical standpoint the process is quite rapid and an approximate equilibrium condition will probably 
be reached by the time a sample can be collected. The collection of overnight urine samples provides reasonable assurance that an equilibrium condition in the body has been achieved.

\subsubsection{Metabolic Model}

The metabolic model used for tritium is described in ICRP 30 (1979). Tritiated water is assumed to be uniformly distributed among all soft tissues at any time following intake. Its retention $\left(r_{s}^{a}\right)$ is described as a single exponential with an effective clearance half-time of 10 days. Thus, the frac tion of tritium taken into the body as tritiated water, which is retained in the body at time $t$ days later, is given by

$$
r_{s}^{a}(t)=\exp (-0.693 / 10) t=\exp ^{-0.0693 t}
$$

This retention function has been we 11 establ ished and is considered appropriate for exposures to tritiated water. It can be expected that the retention of tritiated water in individuals will vary from this, and if sufficient data are available to establish an alternate model for an individual worker's exposure, they should be used.

In addition to body water, ICRP 30 acknowledges the existence of two organically bound tritium components. However, the ICRP concludes that these could be ignored for radiation protection purposes, and Johnson (1982) estimates that these components would add approximately $10 \%$ to the committed dose equivalent. Unless worker data specifically indicate the existence of significantly longer-term components, the Hanford Internal Dosimetry Program will follow the ICRP recommendation of single compartment retention.

The fraction of the initial uptake eliminated on any given day after intake is derived by differentiating the retention function. Thus, the el imination function based on Equation (2.1) is given by

$$
e(t)=0.0693 \exp ^{-0.0693 t}
$$


where $e(t)$ is the fraction of uptake excreted on day $\mathbf{t}$ and $\mathbf{t}$ is the elapsed time (days) post intake.

It must be recognized that Equation (2.2) describes the total tritium eliminated from the body. This elimination occurs via a number of pathways, notably urine, feces, insensible loss (exhalation), and sweat. The ICRP 23 (1974) Reference Mn water balance, shown in Table 2.1, indicates that $47 \%$ or approximately half of the water loss of the body occurs via urine. In applying the excretion function to uptake estimation based on urine sampling, the fraction of an initial uptake excreted in urine on day ( $t$ ) post intake is then calculated to be

$$
e_{u}^{a}(t)=0.47 \quad e(t)=0.033 \exp -0.0693 t
$$

The uniform concentration of tritium in body water and its single component clearance rate allow for the estimation of uptake based on concentration rather than total daily excretion. Thus, the excretion functions, Equations (2.2) and (2.3), can be generally ignored, and the retention function, Equation (2.1), can be directly used to estimate the initial body water concentration as follows:

TABLE 2.1. ICRP 23 Reference Mn Water Balance

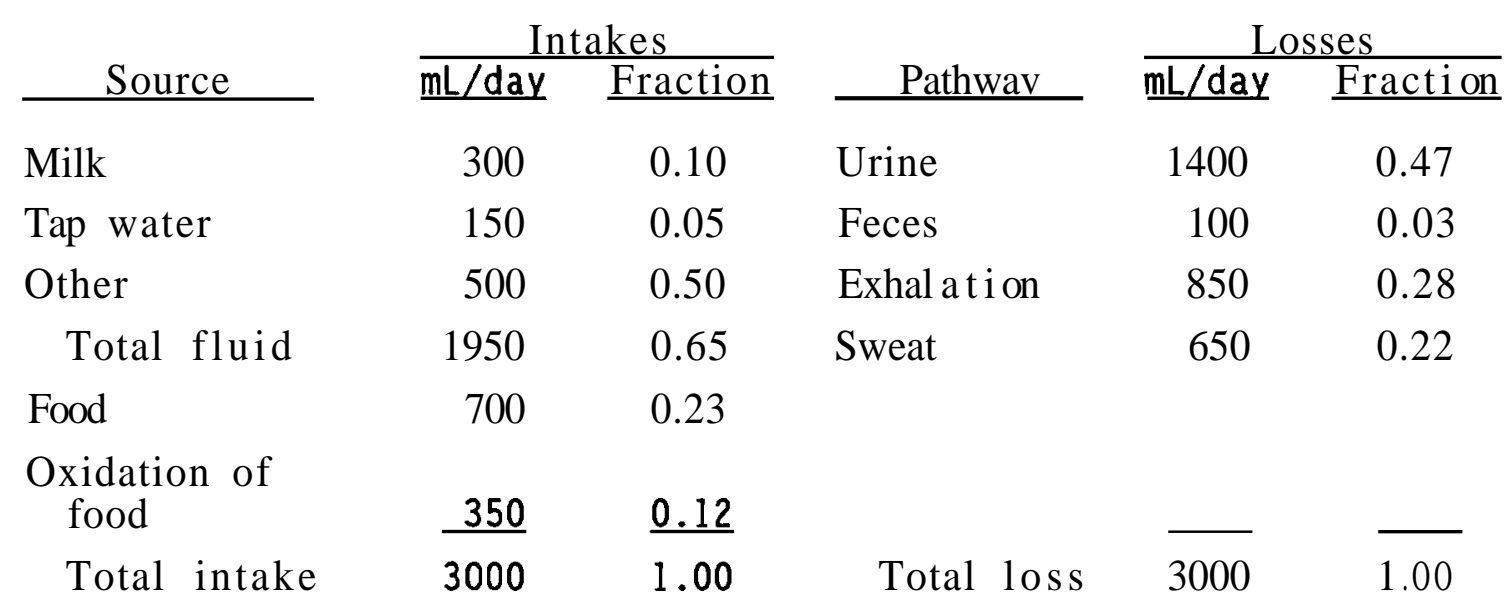




$$
c(t)=c(0) \exp ^{-0.0693 t}
$$

where $C(t)$ is body water concentration on day $t, C(0)$ is initial body water concentration, and $\mathbf{t}$ is elapsed time (days) post intake.

Once $c(0)$ has been determined, the uptake for an acute exposure can be estimated by multiplying $\mathrm{C}(0)$ by the source organ (body water) mass as shown in Equation (2.5):

$$
U(0)=C(0) * M(s)
$$

where $U(0)$ is the uptake in units of activity, $C(0)$ is initial body water concentration, and $M(s)$ is the source organ (body water) mass.

For airborne exposures, ICRP 30 suggests that the uptake rate for tritiated water by inhalation and skin absorption pathways can be approximated by

$$
U^{\prime}=1.8 E+6 * C(a i r)
$$

where $U^{\prime}$ is the uptake rate in $\mu \mathrm{Ci} / \mathrm{h}$, and $\mathrm{C}($ air) is the air concentration in $\mu \mathrm{Ci} / \mathrm{cc}$.

\subsection{TRITIUM INTERNAL DOSIMETRY FACTORS.}

The general approach to tritium dosimetry, including basic dose calculations for acute, chronic, and other exposures to tritium, is discussed in the following subsections.

\subsubsection{General Approach}

Determining the dose from tritium exposures involves calculating the dose to soft tissue from tritium that is assumed to be uniformly distributed throughout the body water. The body water concentration can be determined by the sampling of body fluids (typically urine), followed by direct measurement of tritium using liquid scintillation techniques. For acute exposure situations, the initial body water concentration can be estimated from the retention function, and a total tritium uptake can be calculated using the 
Reference Man body water mass from ICRP 23 (1974). From this uptake, the soft tissue dose equivalent can be calculated for any pertinent time period. For chronic exposure situations, an equilibrium body burden of tritium can be estimated from body water concentration, and a dose equivalent can be calculated for any pertinent time period using a dose rate factor.

Historically, the approach to tritium dosimetry used in ICRP 2, ICRP 10, and American National Standards Institute (ANSI) N13.14-1983 was to calculate the dose to body water as the critical organ (ICRP 1959, 1969; ANSI 1983). A body water mass of 42,000 $\mathrm{g}$ was assumed for ICRP 23 Reference Man (1974). It was assumed that the dose to body water was essentially the same as the dose to soft tissue. This approach was quite conservative.

In ICRP 30, a more realistic approach to tritium dosimetry is recommended. The body water mass of ICRP 23 Reference Man $(42,000 \mathrm{~g})$ is recognized to be essentially uniformly distributed throughout the body mass of soft tissue $(63,000 \mathrm{~g})$. Consequently, tritium is considered to be uniformly distributed throughout soft tissue, and it is the soft tissue mass that is irradiated rather than merely the body water. The net effect is to distribute the decay energy over a larger mass of tissue, resulting in a lowered total dose. Although less conservative, this approach is more accurate from a biological and technical point of view and thus provides a better technical basis for the Hanford Internal Dosimetry Program. Internal dosimetry calculations for tritium at Hanford will henceforth use the ICRP $23 / 30$ soft tissue mass of $63,000 \mathrm{~g}$ as the target organ mass.

As previously noted, there is evidence for an organically bound component of a tritium oxide intake that might add as much as $10 \%$ to the total dose. This factor has been incorporated into Canadian recommendations for dosimetry (EHD 1983; Myers and Johnson 1991) but, due to the relatively low level of doses associated with tritium at Hanford, is not being adopted, pending further national review. If individual worker monitoring data at Hanford show evidence of this organically bound component, it will be factored into the calculations.

Other factors used for tritium dosimetry are shown in Table 2.2. 


\section{TABLE 2.2. Tritium Dosimetry Factors}

$\begin{array}{ll}\text { Radiological half-1ife } & 12.35 \mathrm{yr} \\ \text { Biological half-1ife } & 10 \text { days } \\ \text { Effective half-1ife } & 10 \text { days } \\ \begin{array}{l}\text { Effective energy per } \\ \text { transformation }\end{array} & 5.7 \mathrm{keV}(0.0057 \mathrm{MeV}) \\ \text { SEE factor(a) } & 9.0 \mathrm{E}-08 \mathrm{MeV} / \mathrm{g} \text {-transformation } \\ \text { Quality factor } & 1.0 \\ \text { Weighting factor } & 1.0 \\ \text { Source organ } & \text { Body water } \\ \text { Source organ mass } & 42,000 \mathrm{~g} \\ \text { Target organ } & \text { Soft tissue } \\ \text { Target organ mass } & 63,000 \mathrm{~g} \\ \text { Intake dose equivalent factor } & 0.063 \mathrm{mrem} / \mu \mathrm{Ci} \\ \text { Dose equivalent per unit } & \\ \quad \text { concentration factor } & 2.8 \mathrm{mrem} \mathrm{per} \mu \mathrm{Ci} / \mathrm{L} \\ \text { Dose rate per unit } & 0.19 \mathrm{mrem} / \mathrm{day} \mathrm{per} \mu \mathrm{Ci} / \mathrm{L} \\ \quad \text { concentration factor } & \end{array}$

(a) SEE = specific effective energy.

\subsubsection{Dose Calculation for an Acute Exposure}

The dose calculation for acute uptakes of tritium is as follows:

$$
H_{H, T}=51.15 U(0) \text { SEE }\left(1-\exp ^{-0.0693 t}\right) / 0.0693
$$

where $H_{T, t}=$ the soft tissue dose equivalent in rem

$U(0)=$ the initial uptake in microcuries

SEE $=$ the ICRP 30 specific effective energy per transformation (9.0E-8 MeV/dis-g)

$\mathbf{t}=$ the time interval (in days) following uptake over which the dose is calculated.

Because the weighting factor used for total body soft tissue is 1 , the soft tissue dose equivalent is equal to the effective dose equivalent, or 


$$
H_{E}=H_{T}(2.8)
$$

The 10-day effective half-life of tritium results in the total 50-year committed dose being delivered within about 100 days. Thus, there is no significant difference between the first-year dose and the 50-year committed dose. The 50-year committed dose equivalent from an acute tritium intake can be calculated by solving Equation (2.7) for a period of 18,250 days, giving the following:

$$
H_{E, 50}^{C}=0.064 U(0)
$$

where $H_{E, 50}^{C}$ is in mrem and $U(0)$ is in microcuries or, alternative $7 y$,

$$
H_{E, 50}^{C}=2.8 * C(0)
$$

where $\mathrm{C}(0)$ is in $\mu \mathrm{Ci} / \mathrm{L}$.

Because the dose from tritium is delivered in a relatively short time with regard to a calendar year, it may be a reasonable practice for recordkeeping purposes to credit the total committed dose from an acute tritium exposure to the year of intake.

\subsubsection{Dose Calculation for a Chronic Exposure}

For chronic exposure, or a series of continuing acute exposures, an equilibrium concentration in body water is assumed. The dose equivalent rate during the period when the concentration is maintained can be calculated by

$$
H^{\prime}=51.15 Q(e) \mathrm{SEE}
$$

where $H^{\prime}$ is the dose equivalent rate in rem/day, $Q(e)$ is the equilibrium activity in soft tissue (microcuries), and SEE is the specific effective energy . 
Because $Q(e)$ can be calculated as the product of the body water equilibrium concentration, $\mathrm{C}(\mathrm{e})$, multiplied by the body water mass, M(s), Equation (2.11) can be transformed to

$$
H^{\prime}=51.15 C(e) M(s) \mathrm{SEE}
$$

Substituting constants for body water mass $(42,000 \mathrm{~g})$ and unit conversion factors gives the following relationships for dose equivalent rate to body water concentration:

$$
H^{\prime}=0.19 * C(e)
$$

where $\mathrm{H}^{\prime}$ is in $\mathrm{mrem} / \mathrm{day}$ and $\mathrm{C}(\mathrm{e})$ is in $\mu \mathrm{C} \mathrm{i} / \mathrm{L}$; and,

$$
H^{\prime}=8.7 E-5 C(e)
$$

where $\mathrm{H}^{\prime}$ is in $\mathrm{mrem} /$ day and $\mathrm{C}(\mathrm{e})$ is in $\mathrm{dpm} / \mathrm{mL}$ (the units in which bioassay results are typically reported by the Hanford bioassay laboratory).

The dose equivalent for the time period during which the equilibrium body water concentration is maintained can then be calculated by

$$
H_{T}=H^{\prime} * t
$$

where $t$ is duration of exposure in days.

The total committed dose resulting from a chronic exposure interval consists of the dose incurred during the interval (as calculated by Equation [2.15]) and the dose incurred following the termination of intake. This latter component can be calculated using the equation for an acute exposure (Equation [2.10]) where $C(0)$ is equal to $C(e)$ as follows:

$$
H(\operatorname{total})=\left(H^{\prime}{ }^{*} t\right)+[2.8 C(0)]
$$




\subsubsection{Dosimetry Based on Multiple Sample Results}

When data from routine monitoring indicate that multiple acute intakes or combinations of acute and chronic exposure conditions may exist, dosimetry may be performed by integrating the body water concentration over time and multiplying by the dose rate per unit concentration factor listed in Table 2.2 (as shown in Equation [2.17]). This method is particularly useful if samples are obtained frequently enough to provide an accurate estimate of the integral val ue.

$$
H_{E}^{c}=0.19 \int C(t) d t
$$

where $H_{E}^{C}$ is in mrem and $C(t)$ is in $\mu \mathrm{Ci} / \mathrm{L}$.

\subsubsection{Dosimetry for Other Exposure Conditions}

Dosimetry calculations for other exposure conditions, forms of material, or monitoring techniques will be addressed as specific needs arise. The previously cited references, Brodsky (1983), and the Canadian Environmental Health Directorate's Guidelines for Tritium Bioassay (1983) provide useful models and techniques that can supplement or be adapted to the Hanford dosimetry techniques discussed previously. The NCRP has also addressed the issue of dosimetry for tritium-labeled organic compounds incorporated into genetic material in NCRP 63 (NCRP 1979b).

\subsection{BIOASSAY MONITORING}

The general approaches to routine monitoring, capabilities of bioassay monitoring, and optimum bioassay sampling intervals are discussed in the following subsections.

\subsubsection{General Approach to Bioassay Monitoring}

Bioassay monitoring for tritiated water is relatively simple and involves sampling body fluid. Any body fluid can be used, but from a practical standpoint urine is the medium of choice. Because dosimetry can be readily performed using concentration data and because the models are quite 
simple, a single voiding (spot) urine sample is sufficient to obtain an adequate volume for analysis. Only a few milliliters are actually used in the liquid scintillation analysis procedure. Sufficient time should pass following exposure to allow for uniform distribution throughout body fluids. The NCRP suggests that 2 or more hours may be required for this (NCRP 1976). For this reason, it is usually recommended that tritium samples be collected at home using a multiple voiding sampling protocol to obtain an average concentration.

The Hanford bioassay analysis laboratory's liquid scintillation procedure involves direct mixing of a small quantity $(1 \mathrm{~mL})$ of the urine sample with the scintillation cocktail solution. The sample is then counted in a 1 iquid scintillation analyzer. The sensitivities of the available urine procedures are shown in Table 2.3. It should be noted that the sensitivities of all of the analytical procedures are set at levels above the natural background in urine. More sensitive procedures could be established, if needed.

\subsubsection{Capability of Routine Bioassay Monitoring for Acute Exposures}

The detection capability of a routine tritium bioassay monitoring program for acute exposures has been considered in terms of potentially undetected committed effective dose equivalent per intake and year, using an analytical procedure sensitivity of $10 \mathrm{dpm} / \mathrm{mL}$. In making these calculations, it was assumed that an acute intake occurred on the day immediately following a sample; thus, the time post intake was considered equal to the length of the sample interval. It was also assumed that the pattern of one intake at the

TABLE 2.3. Analytical Sensitivities for Tritium in Urine

\begin{tabular}{lcc} 
Procedure & $\begin{array}{l}\text { Detection } \\
\text { Level, dpm/mL }\end{array}$ & $\begin{array}{c}\text { Nominal Time for Result } \\
\text { (from receipt at lab) }\end{array}$ \\
\cline { 3 - 4 } Routine & 10 & 5 working days \\
Priority & 10 & 3 working days \\
Expedite & 100 & 1 working day \\
Rapid & 500 & 1 hour
\end{tabular}


start of each interval might be maintained for a year. The results of these calculations are listed in Table 2.4 and plotted as the acute intake curve in Figure 2.1.

\section{TABLE 2.4. Detection Capability of Tritium Bioassay Monitoring with a Sensitivity of $10 \mathrm{dpm} / \mathrm{mL}$}

\begin{tabular}{|c|c|c|c|c|}
\hline \multirow{2}{*}{$\begin{array}{l}\text { Sample } \\
\text { Freauency }\end{array}$} & Days Between & Intakes & \multicolumn{2}{|c|}{ Potentially Undetected Dose, mrem } \\
\hline & Samples & per Year & per Intake & per Year \\
\hline Annual & 365 & 1 & $1.2 \mathrm{E}+9$ & $1.2 \mathrm{E}+9$ \\
\hline Semi annual & 180 & 2 & 3300 & 6600 \\
\hline Quarterly & 90 & 4 & 6.4 & 26 \\
\hline Bimonthly & 60 & 6 & 0.81 & 4.8 \\
\hline Monthly & 30 & 12 & 0.10 & 1.2 \\
\hline Biweekly & 14 & 25 & 0.033 & 0.83 \\
\hline Weekly & 7 & 50 & 0.021 & 1.0 \\
\hline
\end{tabular}

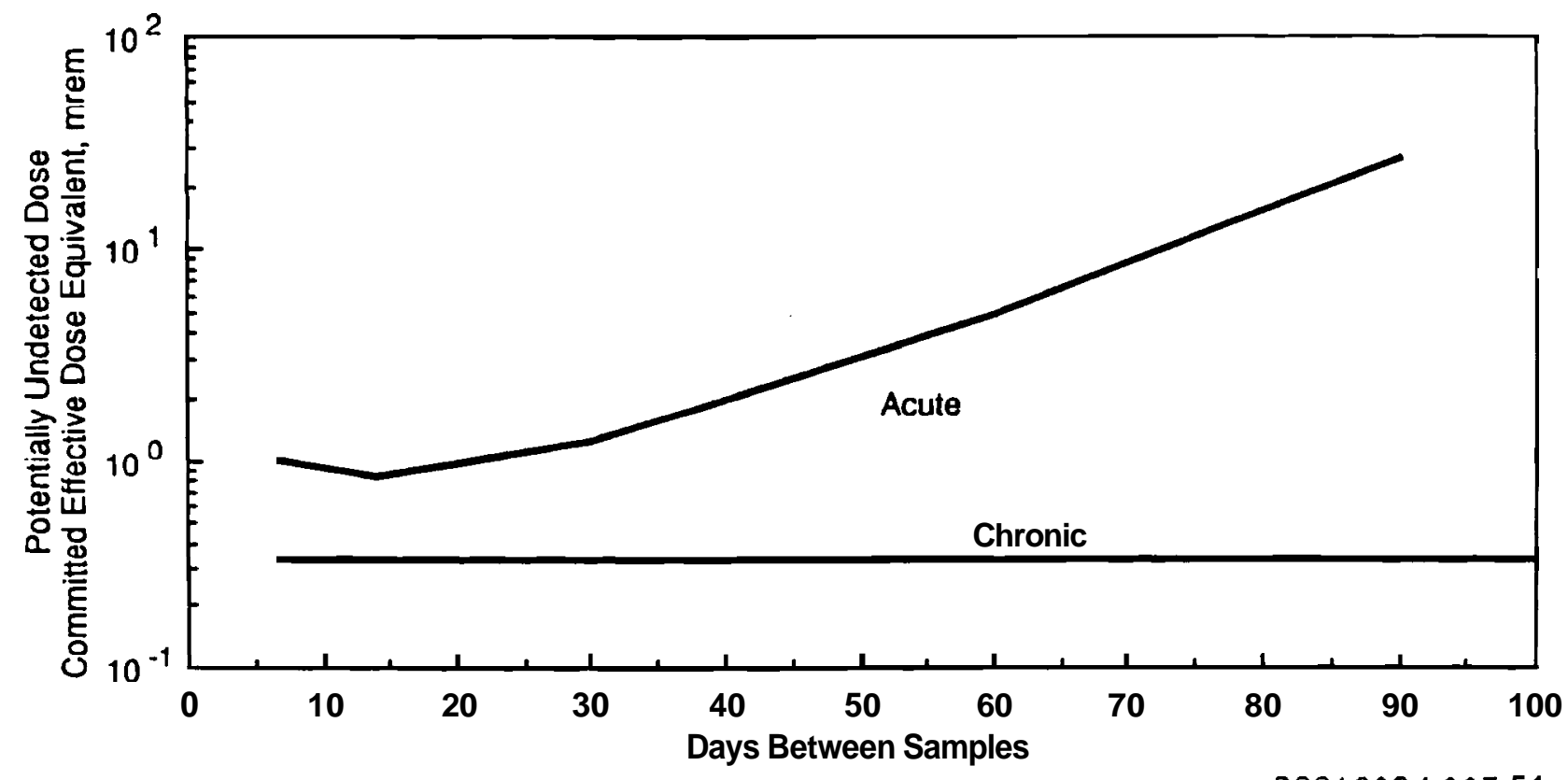

FIGURE 2.1. Tritium Bioassay Monitoring Program Detection Capability for Analytical Sensitivity of $10 \mathrm{dpm} / \mathrm{mL}$ 
From Figure 2.1, it is apparent that a biweekly sampling frequency is optimum for periodic acute intakes of tritium. If the potential exposure to tritium is anticipated only for a very limited interval, starting and ending bioassay samples might be more suitable than participation in a continuing monitoring program.

\subsubsection{Capability of Routine Bioassay Monitoring for Chronic Exposures}

If the exposure condition is chronic and an equilibrium body water concentration of $10 \mathrm{dpm} / \mathrm{mL}$ is assumed (equal to the sensitivity of the analytical procedure and implying a daily intake rate of $14 \mathrm{nCi}$ ), then the resulting committed effective dose equivalent from 365 days of intake would be 0.3 mrem. This estimate is essentially the same as the first-year effective dose equivalent. Because of the assumption of chronic equilibrium conditions, this estimate is independent of sample frequency, and is thus shown as a flat line in Figure 2.1.

\subsubsection{Optimum Bioassay Sampling Intervals}

The optimum routine bioassay sampling frequency for tritium is once every 2 weeks, based on acute exposure conditions. Where exposure conditions are well-established and anticipated exposures are relatively small, longer sampl ing intervals (e.g., monthly) may be suitable. However, the uncertainties with dose estimates associated with longer sampling intervals become much higher. Because of the 10-day effective half-life, sampling intervals greater than 90 days are specifically not recommended.

Based on Table 2.4, a worker monitoring program using screening levels of $110 \mathrm{dpm} / \mathrm{mL}$ for biweekly samples or $80 \mathrm{dpm} / \mathrm{mL}$ for monthly samples is capable of detecting a 10-mrem annual dose based on a series of acute or chronic intakes. At these screening levels, sampling schedules should be reviewed to assure that workers are on an adequate routine monitoring program consistent with their work. If indications are that annual doses may exceed 100 mrem from ongoing work, then a biweekly sampling program is recommended.

\subsubsection{Special Monitoring}

Special monitoring may be required after unplanned or unusual exposures. When an unusual exposure has been suspected or reported, arrangements should 
be made to collect a urine specimen within a reasonably short period of time following the exposure. For potentially high exposures, this sample might be a single voiding sample collected at the workplace. For less serious exposures, an overnight (simul ated 12-hour) or simulated 24-hour sample provides confidence that body equilibrium has been achieved and may be more convenient.

Follow-up sampling should be performed to confirm the initial sample results. Additional follow-up samples may be warranted to verify the applicability of the 10-day retention half-time in the individual, or to assess a more suitable half-time. To adequately determine the degree of agreement between observed and anticipated retention may require only two or three samples over a period of about 3 weeks, or it may involve a more extended sampling program. The evaluator must exercise judgment in determining the number of samples warranted. If the exposed worker is already on a routine (e.g., biweekly) monitoring frequency, additional special sampling for follow-up may not be required.

Once an exposure has been evaluated, elevated urine samples might be expected for some time (several months). If the worker returns to work that involves potential tritium exposure, a more frequent sampling program may be required until normal baselines are re-established. During this time period, consideration may need to be given to the possibility that additional lowlevel uptakes of tritium might occur, which could be undetectable due to tritium retained from the earlier intake.

\subsection{ASSESSMENT OF INTERNAL DOSE}

This section provides summary procedures for the assessment of occupational internal dose. As such, it applies the concepts described in Section 2.3 to the Hanford Internal Dosimetry Program.

\subsubsection{Simplified Dose Assessments}

Simplified dose assessments use the standard models and parameters discussed in the previous sections to provide an estimate of committed effective dose equivalent. Simplified dose assessments may be most suitable when dealing with limited data (e.g., single urine sample results) or when the dose 
estimates are low with regard to radiation protection standards or limits (e.g., 100 mem or less). The simplified dose assessment procedures that follow are based on the discussion contained in Section 2.3, and are adjusted to reflect the units in which Hanford bioassay results are typically reported.

\section{Acute Exposure Simplified Dose Assessment}

To calculate the committed effective dose equivalent from an acute intake of tritium based on a single urine sample result, proceed as follows:

1. Calculate the sample concentration, $C(t)$, in $d p m / m L$

$$
C(t)=\frac{\text { Reported Resul } t, d p m}{\text { Sample Volume, } \mathrm{mL}}
$$

2. Estimate the initial body water concentration, $\mathrm{C}(0)$, in $\mathrm{dpm} / \mathrm{mL}$

$$
C(0)=\frac{C(t)}{\exp \left(-0.0693^{*} t\right)}(t=\text { days post intake })
$$

3. Calculate the committed effective dose equivalent, $H_{E}^{C}$, in mem

$$
H_{E}^{C}=1.3 E-3 * C(0)
$$

Because the committed effective dose equivalent is delivered within a relatively short time following the intake, the first-year and committed dose equivalents are considered equal.

\section{Chronic Exposure Simplified Dose Assessment}

To calculate the dose equivalent resulting from a chronic exposure to tritium (assuming the equilibrium condition), proceed as follows:

1. Calculate the body water equilibrium concentration, $\mathrm{C}(\mathrm{e})$, in $\mathrm{dpm} / \mathrm{mL}$ :

$$
C(e)=\frac{\text { Reported Resul } \mathbf{t}, \text { in dpm }}{\text { Sample Volume, in } \mathrm{mL}}
$$

2. Calculate the committed effective dose equivalent, $H_{E}^{C}$, in mrem, for the interval of exposure ( $t$, in days):

$$
H_{E}^{C}=[(8.7 E-5 * t)+1.3 E-3] * C(e)
$$




\section{Dose Assessment for Periodic Routine Samples}

In situations where periodic routine samples are obtained, not associated with specifically identified intakes but rather with ongoing work practices, an average concentration and dose associated with a sampling interval can be calculated. The choice of an arithmetic mean versus a logarithmic mean has little impact on the dose estimates for intervals of 1 month or less. The dose for the interval can be calculated using Equations (2.14) and (2.15) (see Section 2.3.3) and the total annual dose calculated by summing the interval doses for the year.

\section{Individual-Specific Dose Assessments}

Individual-specific dose assessments are made when there are significant deviations from the metabolic or dosimetric parameters described above. The assumptions or methods used for these assessments are documented as part of the eval uation.

\subsection{MITIGATION OF DOSE FROM TRITIUM}

The primary treatment for reducing internal dose from a tritium uptake is to accelerate the turnover of body water. This can be done by substantially increasing the fluid intake rate of an individual through oral or intravenous means, and/or using diuretics (NCRP 1980; IAEA 1978). Dosemitigating actions should be recommended by the Occupational Medicine Department of the Hanford Environmental Health Foundation (HEHF) with the consultation of Internal Dosimetry.

\subsection{TRITIUM MONITORING PROGRAM FOR THE 400 AREA (FFTF)}

The 400 Area of Hanford Site, which includes the Fast Flux Test Facility (FFTF), obtains its drinking water from groundwater wells. These wells contain low-levels of tritium (below the EPA drinking water standards) originating from aquifer contamination by the past operation of 200 Area fuel processing and waste management facilities (Jaquish and Bryce 1989). Planned operations supporting fusion materials research were expected to produce large quantities of tritium, resulting in the need for a routine tritium bioassay

\subsection{6}


program. In FFTF workers, the existence of potentially detectable tritium, which could be attributable to environmental sources rather than occupational exposure, warranted establishing a screening level to use as a basis for initiating investigations and dose assessments of potential occupational exposure.

A baseline bioassay monitoring program was undertaken for FFTF workers prior to the commencement of the tritium operations (Carbaugh, Sula, and McFadden 1990). Forty-seven urine samples were col lected from FFTF operations personnel over a five-month period in early 1989. The sample data are plotted in Figure 2.2. Based on the curve fit, it was estimated that the geometric mean was $3 \mathrm{dpm} / \mathrm{mL}$ and the tritium concentration corresponding to the 99.9 percentile for environmental exposure at FFTF was $40 \mathrm{dpm} / \mathrm{mL}$. This concentration is similar to the present $20,000 \mathrm{pCi} / \mathrm{L}(44 \mathrm{dpm} / \mathrm{mL})$ EPA Drinking Water Standard for tritium (EPA 1976).

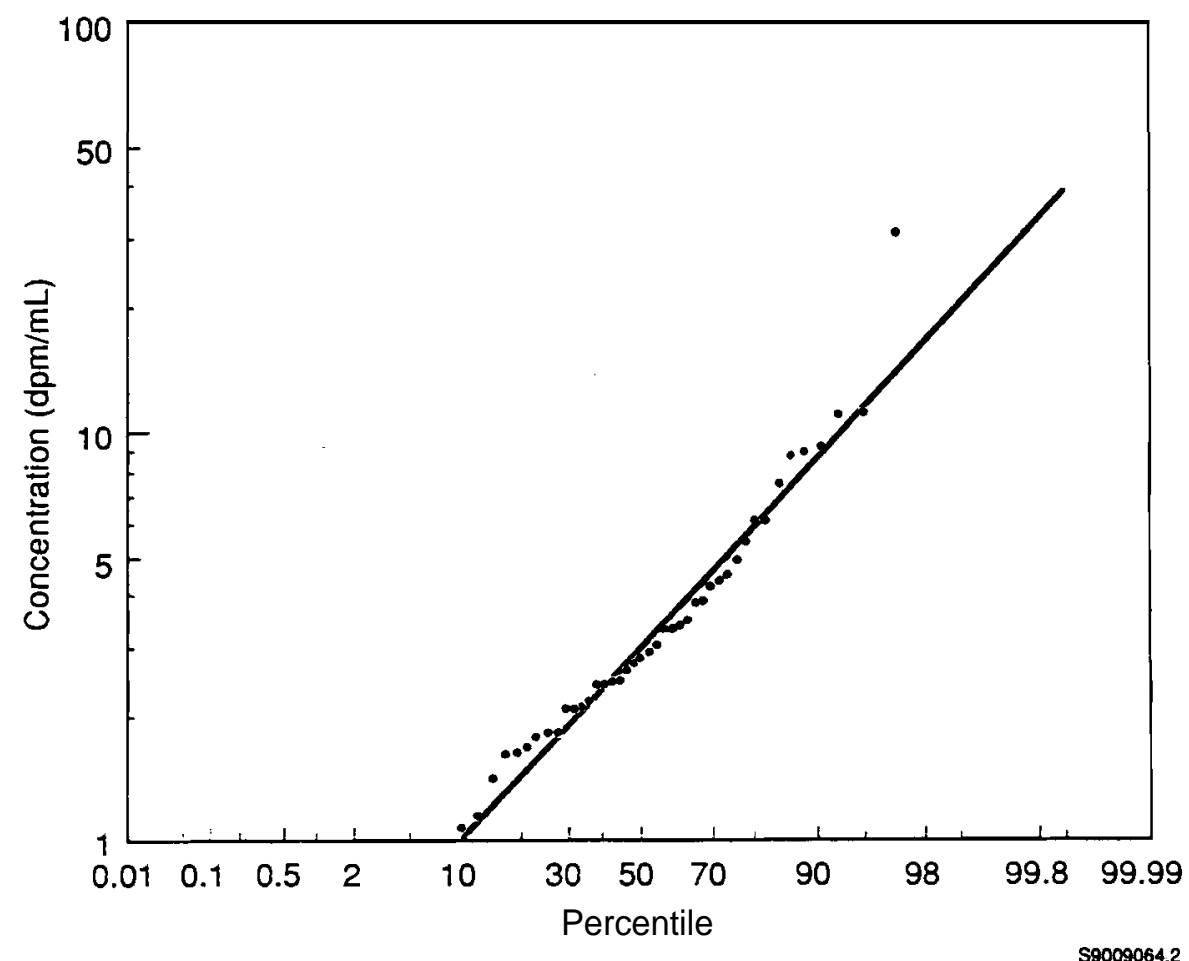

FIGURE 2.2. Tritium Concentration in Urine of Occupationally Unexposed FFTF Workers 
The potentially undetected annual (or 50-year committed) effective dose equivalent associated with a $40-\mathrm{dpm} / \mathrm{mL}$ tritium screening level was estimated to be 1.2 mrem for chronic equilibrium exposure conditions, 5 mrem for acute intakes with weekly to monthly sample intervals (the anticipated range of sampling intervals), and 100 mrem for quarterly intervals.

Because of the low dose potentially associated with chronic exposure or anticipated sampling intervals, use of the 99.9 percentile is justifiable on a cost-benefit basis. Thus, $40 \mathrm{dpm} / \mathrm{mL}$ was selected as a baseline level for tritium in 400 Area workers. Results below $40 \mathrm{dpm} / \mathrm{mL}$ are considered normal for persons working in the 400 Area. Results in excess of $40 \mathrm{dpm} / \mathrm{mL}$ indicate potential occupational exposure and worker data and sampling schedules should be reviewed in light of the criteria in Section 2.4.4. 
SECTION 3.0

COBALT-60 AND OTHER

CORROSION PRODUCT RADIONUCLIDES 



\subsection{COBALT-60 AND OTHER CORROSION PRODUCT RADIONUCLIDES}

Corrosion product radionuclides are created by neutron activation of reactor components such as piping or fuel element cladding. The principal sources of corrosion product radionuclides at Hanford are the $\mathrm{N}$ Reactor and FFTF. Corrosion product radionuclides are generally gamma-emitters; therefore, bioassay monitoring can be readily accomplished by whole body counting. This section provides background on the sources, characteristics, and biokinetic behavior of ${ }^{60} \mathrm{Co}$ and other corrosion product radionuclides and summarizes the technical basis used for their internal dosimetry at Hanford.

\subsection{SOURCES AND CHARACTERISTICS OF CORROSION PRODUCT RADIONUCLIDES}

In recent years, the primary source of corrosion product radionuclides at Hanford has been the $\mathbf{N}$ Reactor, and the most detailed characterization of these radionuclides has been performed for $\mathrm{N}$ Reactor facilities (Weetman and DeHaven 1982a, 1982b). In general, a major characteristic of these corrosion product radionuclides, regardless of origin, is the presence of several radionuclides within a matrix of oxidized metal with ${ }^{60}$ co the predominant radionuclide.

The constituents of most corrosion product mixtures of an internal dosimetry concern at Hanford have historically been ${ }^{58} \mathrm{Co},{ }^{60} \mathrm{Co},{ }^{54} \mathrm{Mn}$, and ${ }^{59} \mathrm{Fe}$. other radionuclides may also be present in trace amounts, but they are generally of little dosimetric significance. These radionuclides are all associated with elements found in steel and alloys used in reactor components. The relative abundance of the radionuclides varies from facility to facility; however, ${ }^{60} \mathrm{Co}$ is generally the predominant radionuclide in terms of both activity and dose significance. With the shutdown of $\mathrm{N}$ Reactor in 1987, the production of corrosion product radionuclides at Hanford is currently limited to FFTF. Based on historical experience, ${ }^{60} C_{0}$ is the best indicator of an intake of mixtures of corrosion product radionuclides.

Studies at $\mathrm{N}$ Reactor indicate that airborne particulates containing corrosion product radionuclides can be characterized by a lognormal distribution with an activity median aerodynamic diameter (AMAD) ranging from 0.5 to $2.5 \mu \mathrm{m}$ 
(Weetman and DeHaven 1982a). Unless specific information is available, the assumption of a 1- $\mu \mathrm{m}$-AMAD particulate is recommended for evaluations of internal exposure.

For mixtures containing corrosion product radionuclides, the pulmonary retention of the individual radionuclides is probably influenced by the contaminant carrier matrix; thus, pulmonary retention for all of the radionuclides within a single carrier matrix will probably be similar. Oxides characteristically represent the least transportable form of an element in the lung. For purposes of a priori calculations of expected dose from intake, the transportability class for the oxide form of the radionuclide is assumed. Nevertheless, retrospective assessment of internal dose following an intake should be based on actual observed retention in the lung.

\subsection{BIOKINETIC BEHAVIOR OF CORROSION PRODUCT RADIONUCLIDES}

The biokinetic behavior of corrosion product radionuclides in the body is influenced by the physical and chemical properties of the host matrix, as well as the individual elements composing the matrix. Thus, the actual behavior of the material following intake is dependent on numerous complex and competing factors. Although there have been several historical cases involving inhalation intakes of corrosion products at Hanford, the intakes involved have been too small to enable the specific radionuclide versus host matrix characteristics to be accurately described. The approach taken here regarding assumptions for distribution and retention of corrosion product radionuclides is to assume that the radionuclide behaves according to the most insoluble form established for the element in ICRP 30 (1979) unless sufficient in vivo data are available and the intake is of sufficient magnitude (e.g., potentially above $100 \mathrm{mrem} / \mathrm{yr}$ ) to warrant evaluation of individual specific retention.

ICRP 30 establishes default inhalation classes $W$ and $Y$ for cobalt, and classes $D$ and W for both manganese and iron. Therefore, for intakes involving a mixture of corrosion products, assumed inhalation classes are $y$ for cobalt and $\mathrm{W}$ for manganese and iron. Other radionuclides identified in the host matrix should be evaluated in the same manner. The GENMOD computer code (Johnson and Carver 1981) implements the biokinetic model prescribed in ICRP 
30 and is used to assess expected bioassay compartment quantities following intakes of the corrosion products. As described in Appendix A, GENMOD also permits modification of biokinetic parameters to provide a better agreement between observed and expected bioassay compartment values.

Section 3.7 summarizes default biokinetic parameters to be used for assessing internal dose equivalents from intakes of corrosion product radionucl ides

\subsection{INTERNAL DOSIMETRY FOR CORROSION PRODUCTS}

Section 3.7 provides radiological and dosimetric data for several corrosion product radionuclides. Tables $3.5,3.11$, and 3.15 provide estimates of the first-year and 50-year committed effective dose equivalents for intakes of the radionuclides and Tables 3.6, 3.7, 3.12, and 3.16 give expected activities remaining in the lung and whole body following an intake sufficient to result in a first-year effective dose equivalent of $10 \mathrm{mrem}$.

Assessments of internal dose equivalents for intakes of mixtures of corrosion product radionuclides must consider the contribution of all radionuclides present in the mixture. The variability of the relative contribution to internal dose equivalent by the various radionuclides precludes the establishment of any specific relationship between effective dose equivalent and organ doses for a generic mixture.

In vivo measurements permit the actual distribution and retention of the radionuclides in the body to be estimated. In vivo measurements are capable of providing estimates of activity in the lung and in the total body following an intake. Subtraction of lung activity from total body activity yields an estimate of the activity in systemic compartments of the body for measurements performed more than 1 week post intake (after clearance of any ingested or inhaled material from the gastrointestinal [GI] tract). Activity in the systemic compartments is distributed among several organs and assessment of the activity in these compartments is normally not feasible using standard in vivo measurement techniques. In lieu of specific information regarding the inter-systemic partitioning of the radionuclides, the organ deposition fractions and retention rates provided in ICRP 30 are used. Thus, successive 
whole body counts yield data from which lung and systemic organ cumulative activities (e.g., $\mathbf{n C i}$-days) can be determined. The dose conversion factors listed in Section 3.7 in Tables 3.4, 3.10, and 3.14 may be applied to these cumulative activities over the time periods of interest to assess organ and effective dose equivalents.

\subsection{BIOASSAY FOR CORROSION PRODUCTS}

The following subsections discuss bioassay monitoring for corrosion product radionuclides.

\subsubsection{Bioassav Methods}

In vivo and excreta measurements comprise the bioassay methods used in monitoring for corrosion product radionuclides.

\section{In Vivo Measurements}

All of the radionuclides included in this section are gamma-emitters; therefore, internally deposited activities can be measured directly using in vivo techniques. Table 3.1 shows the detection levels for the radionuclides using the standard three-minute preview counter measurement (Palmer et al. 1990).

TABLE 3.1. Minimum Detectable Activity in a whole Body Count (preview counter, 3-minute count) (a)

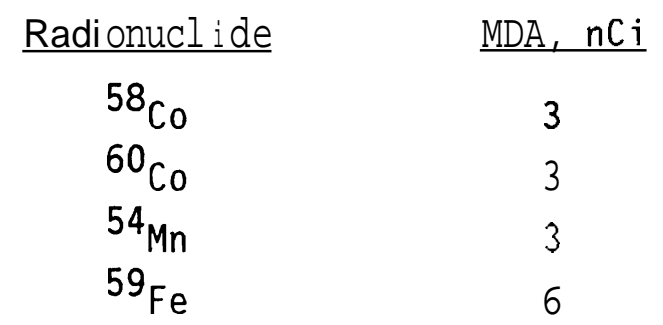

(a) MDA calculated as described by Palmer et a1. (1990) and in Appendix C. 


\section{Excreta Measurements}

Because the radionuclides are easily detectable using in vivo techniques, it is not expected that excreta measurements would be required in most internal exposure situations. Measurement of radionuclides in early fecal excretion can be used as a means for establishing the relative radio-nuclide distribution in a corrosion product mixture; however, analysis of a nasal or appropriate surface contamination smear sample is preferred if the elements present may exhibit different absorption characteristics in the GI tract.

\subsubsection{Routine Bioassay Monitoring Program}

Routine monitoring for gamma-emitting corrosion products is best accomplished by periodic whole body counting. Based on the tables in Section 3.7, which show the capability of periodic bioassay measurements in terms of annual and committed effective dose equivalent, a semiannual frequency provides for detection of intakes in a year resulting in either an annual or committed effective dose equivalent of 100 mrem for the radionuclides specifically covered in this section. An annual frequency would enable detection of annual effective doses of 100 mrem for all radionuclides considered except ${ }^{59} \mathrm{Fe}$.

Because corrosion product mixtures are characterized by the dominant presence of ${ }^{60} \mathrm{Co}$, a bioassay monitoring program for identifying intakes can be based on the identification of ${ }^{60}$ Co. For this approach to be valid, the presence of other radionuclides should be considered whenever ${ }^{60} \mathrm{Co}$ is detected.

Because intakes of activated corrosion products usually involve several radionuclides, it is prudent to assume, upon initial assessment of bioassay measurement results, that the dose incurred from all radionuclides in the corrosion product mixture will exceed somewhat the dose received from ${ }^{60} \mathrm{Co}_{0}$ alone. For example, if ${ }^{60} \mathrm{Co},{ }^{58} \mathrm{Co},{ }^{54} \mathrm{Mn}$, and ${ }^{59} \mathrm{Fe}$ were present at equal activities in a mixture, then the first-year effective dose equivalent from an intake of the mixture would be about 1.4 times the dose equivalent received from the ${ }^{60}$ Co. However, because ${ }^{60}$ Co generally accounts for most of the activity in the mixture, doses from all radionuclides in the mixture are, in actual experience, less than 1.4 times the dose from the ${ }^{60}$ Co alone. 
If ${ }^{60}$ Co or other radionuclides are detected in a routine measurement, follow-up measurements generally should be performed. The measurements can usually be most conveniently performed immediately following the initial measurement, while the subject is at the IVRRF. The use of high-resolution germanium detectors for follow-up measurements is preferred in order to identify other radionuclides possibly associated with the exposure. Detection capabilities for the germanium detectors are comparable to those obtained using the preview counter (Palmer et al. 1990) .

If, at very low indicated activities, a contractor wishes to waive the follow-up measurement, dose equivalents can still be calculated based on the

single initial count. Although the accuracy of a single count performed using the preview counter is somewhat less than that obtained using germanium detector systems, this higher uncertainty is not of much significance at low doses.

\subsubsection{Bioassay Measurements Following an Acute Intake}

An in vivo examination should be performed following any indication of an intake of activated corrosion product radionuclides. However, unless the intake appears to be of such magnitude that medical treatment to aid removal of the material from the body is considered, the exam may be scheduled as convenient, within several days of the intake. All radionuclides potentially involved in the exposure should be considered during the follow-up investigation.

The interpretation of in vivo measurements shortly after intake may be complicated by early transport of material through the lung and GI tract. Measurements performed after about 5 days post intake are more appropriate for dose evaluation. Long-term foll ow-up bioassay measurements should be considered to monitor internal radioactivity levels and establish individualspecific retention characteristics. 


\subsection{ASSESSMENT OF INTERNAL DOSE EQUIVALENT}

The assessment of internal dose equivalent from corrosion products is accomplished by evaluation of in vivo measurement results. Dose equivalents are assessed for any confirmed internal exposure attributed to occupational sources.

Dose assessments include annual and committed dose equivalents, as we11 as dose equivalents to specific organs of concern based on the criteria presented in the Hanford Internal Dosimetry Program Manual. (a) (See also Appendix B). Organs receiving the most dose following intake are those listed in Section 3.7, Tables 3.4, 3.10, and 3.14.

Several methods exist to evaluate in vivo results in order to assess the internal dose equivalent. The simplest method, and one that is recommended for initial evaluation of in vivo results, as well as for final evaluations when doses are very low, involves fitting the in vivo measurement data to the expected internal activity using the biokinetic model prescribed by the ICRP in Publication 30. This model is implemented using GENMOD. Assumptions that are used for this evaluation are that the material is in its most insoluble form, as recommended in ICRP 30; that the intake date, if unknown, is assumed to be the midpoint of the period during which the intake could have occurred; and that the intake consisted of inhalation of an aerosol with 1- $\mu$ m-AMAD particles. The resulting retention function, calculated using GENMOD, is fit to the observed in vivo measurement data using techniques described in Appendix C. Table 3.3 provides a summary of total body retention, expressed as a fraction of a unit acute intake, for selected times post intake. The tables in Section 3.7 that show in vivo retention at various times post intake can be used to estimate internal dose from whole body counting data.

If the intake could potentially result in an annual effective dose equivalent exceeding $100 \mathrm{mrem}$, then an investigation should be performed to determine the radionuclide composition of the involved corrosion product mixture and to assess the dose equivalent from all radionuclides present in the

(a) Pacific Northwest Laboratory. 1989. Hanford Internal Dosimetry Program Manual. PNL-MA-552, Richland, Washington. 
mixture. Additional in vivo measurements to confirm the assumed retention function, or to develop a case-specific retention function, should also be performed.

For the purpose of developing an initial estimate of dose equivalent to determine the extent to which follow-up investigation is warranted, it should be assumed that the total dose received from intake of the corrosion product mixture is $1.4^{(\mathrm{a})}$ times the dose contributed by ${ }^{60} \mathrm{Co}$. This assumption accounts for the fact that ${ }^{60} C_{0}$ is usually part of a mixture of corrosion product radionuclides and not all radionuclides in the mixture may have been detected by the in vivo measurement.

A simplified dose assessment procedure for use in the initial evaluation, and as a final evaluation procedure for cases in which the annual effective dose equivalent is below $100 \mathrm{mrem}$, is as follows:

1. Determine time of intake. Assume the midpoint of the period during which the exposure could have occurred, if a specific intake date is not known. For example, for the evaluation of measured activity in an annual whole body count it might be assumed that the intake occurred at the midpoint of the measurement period, provided the worker could have incurred an intake at any time during the prior year.

2. As an initial evaluation of dose, evaluate the bioassay measurement results for each radionuclide detected using the ICRP 30 biokinetic model and assuming a) the least soluble form of the radionuclide recommended in ICRP 30, b) an acute inhalation intake, and c) an aerosol AMAD of $1 \mu \mathrm{m}$. Table 3.3 provides selected total body retention fractions for various times post intake.

3. If ${ }^{54} \mathrm{Mn}$ and other corrosion product radionuclides were detected by the initial measurement(s), then assess the total annual dose received from these radionuclides. If the calculated dose exceeds a 100-mrem first-year effective dose equivalent, then determine if other radionuclides, not detected by the in vivo measurement, were also present at intake. Also, consider making additional in vivo measurements to confirm the retention characteristics of the material and re-establish baseline internal activity levels.

(a) Assumes equal intake of ${ }^{60} \mathrm{Co}$ and ${ }^{54} \mathrm{Mn}$. While other radionuclides may be involved, experience at Hanford indicates that the first-year dose is contributed most $7{ }_{4}$ by these two radionuclides, and that the activity ratio of ${ }^{\mathrm{CO}}$ to ${ }^{34 \mathrm{Mn}}$ is always greater than 1.0 . 
4. If ${ }^{60}$ Co was the only radionuclide detected and its annual effective dose equivalent multiplied by 1.4 (to account for the possible contribution of other radionuclides present in a mixture) exceeds 100 mrem, then other radionuclides potentially present at intake, but not identified by the in vivo measurement, should be considered in the evaluation.

Observed in vivo retention of the corrosion product radionuclides should be used in place of the ICRP biokinetic model for evaluations of internal doses that potentially exceed $100 \mathrm{mrem} / \mathrm{yr}$ when sufficient in vivo data are available for such an analysis. This can be accomplished by either modifying retention/distribution parameters in GENMOD to achieve better agreement between the model and the observed in vivo measurement data, or by graphically analyzing the in vivo data to identify retention components for the lung and for systemic organs. (a) The retention curves are then integrated to obtain cumulative activity for the calendar years following intake, and the cumulative activity is multiplied by the organ and effective dose equivalent conversion factors in Tables 3.4, 3.10, or 3.14 to obtain annual dose equivalents. In order to provide a true assessment of the effective dose equivalent, the activity deposited in the lung, systemic organs, and tissues must be considered. Modifications to default model parameters must be documented in the internal/dose assessment report.

\subsection{MANAGEMENT OF INTERNAL CONTAMINATION CASES}

Historically, activated corrosion product radionuclides have been the most common type of internal exposure at Hanford. However, exposures have been minor and there is no known instance in which special therapeutic measures have been applied for mitigative purposes. Various options exist for treatment to remove corrosion product radionuclides from the body and these generally involve measures to minimize absorption into the blood, including stomach lavage and administration of purgatives, emetics, or phytates. Use of chelating agents may also be considered in significant exposure cases. A primary consideration for all mitigatory actions is prompt response because

(a) Activity in the systemic compartments of the body can be assumed to be represented by the activity in the total body minus the lung. 
the effectiveness of treatment decreases rapidly with time post intake. Hanford Environmental Health Foundation Occupational Medicine, should be notified immediately upon indication of a severe intake of corrosion product radionucl ides.

\subsection{DOSIMETRY DATA FOR CORROSION PRODUCT RADIONUCLIDES}

This section provides bioassay and dose assessment information for the principal corrosion product radionuclides: ${ }^{58} \mathrm{Co},{ }^{60} \mathrm{Co},{ }^{54} \mathrm{Mn}$, and ${ }^{59} \mathrm{Fe}$. Other radionuclides may sometimes be associated with intakes of mixed corrosion products; however, experience to date at Hanford has shown that they are of negligible dosimetric significance. If radionuclides other than those provided in this section are encountered, dose assessment can be accomplished using the methods discussed in this section.

\subsubsection{Cobalt-58 and Cobalt-60}

Cobalt-60 is the primary corrosion product radionuclide. In essentially all internal exposure cases involving corrosion products at Hanford, the internally deposited activity and the resulting internal dose are both dominated by ${ }^{60}$ Co. Table 3.2 provides radiological data for ${ }^{58} \mathrm{Co}$ and ${ }^{60} \mathrm{Co}$. According to ICRP 30, inhalation classes are assigned as follows:

TABLE 3.2. Radiological, Data for ${ }^{58} \mathrm{Co}$ and ${ }^{60} \mathrm{Co}$

\begin{tabular}{lrr} 
& ${ }^{58} \mathrm{Co}$ & \\
\cline { 2 - 3 } Half-life & & ${ }^{60} \mathrm{Co}$ \\
Annual limit on intake (a) & 70.8 days & $5.27 \mathrm{yr}$ \\
Class W & $1100 \mu \mathrm{Ci}$ & $160 \mu \mathrm{Ci}$ \\
Class Y & $800 \mu \mathrm{Ci}$ & $27 \mu \mathrm{Ci}$ \\
Whole body count MDA (b) & $3 \mathrm{nCi}$ & $3 \mathrm{nCi}$
\end{tabular}

(a) From ICRP 30 (1979).

(b) $\quad \mathrm{MDA}=$ minimum detectable activity (from Palmer et al. 1990). 
- class Y--oxides, halides, nitrates, hydroxides

- class W--all other compounds.

As corrosion products, cobalt particulates exist in the oxide form and are considered to exhibit retention characteristics of class Y compounds. ICRP 30 considers cobalt to be relatively poorly absorbed by the GI tract and therefore assigns an absorption coefficient $\left(f_{1}\right)$ of 0.05 to both class $W$ and $Y$ compounds.

of the cobalt entering the blood stream, about half is excreted directly, with the remaining half distributed in the body. of the amount distributed in the body, $10 \%$ is assumed to go to the liver and the remaining $90 \%$ is distributed throughout the rest of the body. According to ICRP 30, the material deposited in body organs (other than lung) is removed from the organs at several rates. In the absence of retention data on a case-specific basis, the ICRP recommends that the following retention rates be applied to the material in the liver and rest of body:

\section{Fraction Retained, \%}

60

20

20

\section{Biological Half-Life, days}

6

60

800

Because the retention characteristics are considered to be the same for the liver as for the rest of the body, the relative distribution between the two sources can be assumed to be constant at the following percentages of total in the body (except 1ung) :

- liver--10\%

- rest of body--90\%.

Table 3.3 shows ${ }^{58}$ Co and ${ }^{60}$ Co total body retention following an acute exposure to the most limiting ICRP inhalation class (class Y). Table 3.4 provides dose conversion factors (DCFs) (in rem/nCi-day) for ${ }^{58} \mathrm{Co}_{0}$ and ${ }^{60} \mathrm{Co}_{0}$ deposited in the lung and in systemic organs and tissues. Table 3.5 gives predicted first-year and 50-year committed effective dose equivalents per 


\begin{tabular}{|c|c|c|c|c|}
\hline \multirow{2}{*}{$\begin{array}{l}\text { TABLE } 3.3 . \\
\text { Days Post } \\
\text { Intake }\end{array}$} & \multicolumn{4}{|c|}{$\begin{array}{l}\text { Total Body Retention (a) Following an Acute } \\
\text { Inhalation Exposure to } 1-\mu \mathrm{m} \text {-AMAD Particles }\end{array}$} \\
\hline & $\begin{array}{r}{ }^{58} \text { Co } \\
\text { Class Y }\end{array}$ & $\begin{array}{l}{ }^{60} \mathrm{Co} \\
\mathrm{Class} Y \\
\end{array}$ & $\begin{array}{c}{ }^{54_{M n}} \\
\text { Class W } \\
\end{array}$ & $\begin{array}{c}{ }^{59} \mathrm{Fe} \\
\text { Class W } \\
\end{array}$ \\
\hline 0 & $6.30 \mathrm{E}-1$ & $6.30 \mathrm{E}-1$ & $6.30 \mathrm{E}-1$ & $6.30 \mathrm{E}-1$ \\
\hline 1 & $5.71 \mathrm{E}-1$ & $5.76 \mathrm{E}-1$ & $5.88 \mathrm{E}-1$ & $5.83 \mathrm{E}-1$ \\
\hline 2 & $4.14 \mathrm{E}-1$ & $4.22 \mathrm{E}-1$ & $4.63 \mathrm{E}-1$ & $4.59 \mathrm{E}-1$ \\
\hline 5 & $1.82 \mathrm{E}-1$ & $1.91 \mathrm{E}-1$ & $2.58 \mathrm{E}-1$ & $2.63 \mathrm{E}-1$ \\
\hline 7 & $1.55 \mathrm{E}-1$ & $1.66 \mathrm{E}-1$ & $2.27 \mathrm{E}-1$ & $2.34 \mathrm{E}-1$ \\
\hline 14 & $1.36 \mathrm{E}-1$ & $1.55 \mathrm{E}-1$ & $1.93 \mathrm{E}-1$ & $1.98 \mathrm{E}-1$ \\
\hline 30 & $1.13 \mathrm{E}-1$ & $1.49 \mathrm{E}-1$ & $1.51 \mathrm{E}-1$ & $1.45 \mathrm{E}-1$ \\
\hline 60 & $8.10 \mathrm{E}-2$ & $1.42 \mathrm{E}-1$ & $9.77 \mathrm{E}-2$ & $8.20 \mathrm{E}-2$ \\
\hline 90 & $5.85 E-2$ & $1.36 \mathrm{E}-1$ & $6.34 \mathrm{E}-2$ & $4.76 \mathrm{E}-2$ \\
\hline 180 & $2.21 \mathrm{E}-2$ & $1.20 \mathrm{E}-1$ & $1.73 \mathrm{E}-2$ & $1.03 \mathrm{E}-2$ \\
\hline 365 & $3.03 E-3$ & $9.37 \mathrm{E}-2$ & $1.17 \mathrm{E}-3$ & $5.21 \mathrm{E}-4$ \\
\hline 730 & $6.20 \mathrm{E}-5$ & $5.85 E-2$ & $5.43 E-6$ & $1.35 \mathrm{E}-6$ \\
\hline 1,825 & $0.00 \mathrm{EtO}$ & $1.62 E-2$ & $2.83 E-0$ & $2.14 \mathrm{E}-0$ \\
\hline 3,650 & 0.00 Eto & $2.86 E-3$ & 0.00 EtO & $\mathbf{0 . 0 0 E t O}$ \\
\hline 7,300 & 0.00 EtO & $3.11 \mathrm{E}-4$ & $\mathbf{0 . 0 0 E t O}$ & $0.00 E+0$ \\
\hline 18,250 & 0.00 EtO & $4.86 E-6$ & $\mathbf{0 . 0 0 E t O}$ & $\mathbf{0 . 0 0 \mathrm { EtO }}$ \\
\hline
\end{tabular}

(a) Expressed as fraction of a unit intake.

nanocurie of intake, and Tables 3.6 and 3.7 give the activity remaining in the lung and the total activity in the body at various times after an acute inhalation intake. Table 3.8 gives the detectable first-year effective dose equivalent for measurements performed at various times post intake.

\subsubsection{Manqanese-54}

Manganese-54 ( $\mathrm{T}_{1 / 2}=312.5$ days $)$ is the principal radioactive isotope of manganese at Hanford from an internal exposure standpoint. However, because of its relatively short effective half-life, it is usually only of minor importance in cases involving intakes of activation products. In essentially all internal exposure cases observed at Hanford that involve mixtures of 
TABLE 3.4. Dose Conversion Factors for Cobalt

\begin{tabular}{|c|c|c|c|}
\hline Site of Deposition & Tarqet $\operatorname{Orqan}(a)$ & $\begin{array}{l}{ }^{58} \text { Co DCF, } \\
\mathrm{rem} / \mathrm{nCi} \text {-day }\end{array}$ & $\begin{array}{l}{ }^{60}{ }_{C o} \mathrm{DCF}, \\
\mathrm{rem} / \mathrm{nC} i-\mathrm{day}\end{array}$ \\
\hline \multirow[t]{2}{*}{ Lung } & Lung & $4.2 \mathrm{E}-6$ & $1.1 E-5$ \\
\hline & Effective & $5.0 \mathrm{E}-7$ & $1.3 E-6$ \\
\hline \multirow[t]{6}{*}{ Body (b) } & Gonad & $2.6 \mathrm{E}-7$ & $7.2 \mathrm{E}-7$ \\
\hline & Breast & $2.6 \mathrm{E}-7$ & $6.4 E-7$ \\
\hline & Red marrow & $2.8 \mathrm{E}-7$ & $6.8 E-7$ \\
\hline & Lung & $2.8 \mathrm{E}-7$ & $6.5 E-7$ \\
\hline & Liver & $8.0 \mathrm{E}-7$ & $2.0 \mathrm{E}-6$ \\
\hline & Effective & $3.1 \mathrm{E}-7$ & $7.9 E-7$ \\
\hline
\end{tabular}

(a) Organ doses included for organs contributing more than $10 \%$ to the total effective dose equivalent.

(b) Excludes lung and assumes $10 \%$ in liver and $90 \%$ in the rest of the body. Factors can be applied directly to whole body count data from which the contribution due to activity in the lung has been subtracted.

TABLE 3.5. Predicted Effective Dose Equivalents Resy'l'iing from an Inhalation Intake of $1-\mu \mathrm{m}-A M A D{ }^{58} \mathrm{Co}$ or ${ }^{6}$ Co Particles

\begin{tabular}{|c|c|c|c|}
\hline & $\frac{\text { mrer }}{\sigma}$ & & $\begin{array}{r}\text { Fraction of } \\
50-Y r \text { Committ } \\
\text { Effective Dos }\end{array}$ \\
\hline & $\begin{array}{l}\text { First-Yr Effective } \\
\text { Dose Equivalent }\end{array}$ & $\begin{array}{l}50-Y r \text { Committed } \\
\text { Dose Equivalent }\end{array}$ & $\begin{array}{c}\text { Equivalent Rece } \\
\text { in First Yea }\end{array}$ \\
\hline${ }^{58} \mathrm{Co}$ & & & \\
\hline Class W & 0.0065 & 0.0066 & $99 \%$ \\
\hline $\begin{array}{l}\text { Class Y } \\
{ }^{60}{ }_{\mathrm{Co}}\end{array}$ & 0.011 & 0.011 & $>99 \%$ \\
\hline Class W & 0.028 & 0.034 & $81 \%$ \\
\hline Class $\mathrm{Y}$ & 0.080 & 0.22 & $37 \%$ \\
\hline
\end{tabular}



TABLE 3.6. Expected ${ }^{58}$ Co Activity Following an Acute Intake Resutyting
in a First-Year Effective Dose Equivalent of 10 mrem

Days Post
Intake

7

14

30

60

90

180

365

730
Activitv $\mathrm{nCi}$

\begin{tabular}{lll}
\hline \multicolumn{2}{c}{ Class W } & Class Y \\
\hline Lung & $\underline{\text { Whole Bodv }} \quad \underline{\text { Lung }}$
\end{tabular}

200

260

130

140

170

200

120

120

120

140

98

100

60

76

71

74

30

42

52

50

3.9

7.9

19

20

(b)

0.5

3.0

3.0

(b)

(b)

(b)

(b)

(a) Intake $=1500 \mathrm{nCi}$ class $\mathrm{W}$ or $910 \mathrm{nCi}$ class $\mathrm{Y}$, assuming 1- $\mu \mathrm{m}$-AMAD particles.

(b) Negligible.

TABLE 3.7. Expected ${ }^{60}$ Co Activity Following an Acute Intake Res 1 ting in a First-Year Effective Dose Equivalent of 10 mrem(a)

Days Post
Intake

7

14

30

60

90

180

365

730

1825

\begin{tabular}{llll}
\multicolumn{4}{c}{ Activity, $\mathrm{nCi}$} \\
\hline \multicolumn{2}{c}{ Class W } & \multicolumn{2}{c}{ Class Y } \\
\hline Lung & Whole Body & Lung & Whole Body
\end{tabular}

50

64

19

21

45

55

18

19

37

44

18

19

25

32

23

5.1

10

17

17

15

11

6.7

1.9

4.0

(b)

2.0

(b)

1.0

(a) Intake $=360 \mathrm{nCi}$ class $W$ or $125 \mathrm{nCi}$ class $\mathrm{Y}$, assuming $1-\mu \mathrm{m}-$ AMAD particles.

(b) Negligible. 
TABLE 3.8. Detectable Doses for In Vivo Measurement of ${ }^{58}$ Co $a a_{n} d$
Co Following Inhalation of a $1-\mu m-A M A D$ Aerosol $(a)$

Days Post
Intake

7

14

30

60

90

180

365

\begin{tabular}{|c|c|}
\hline${ }^{i r s t}=\frac{y}{58} \mathrm{Co}$ & 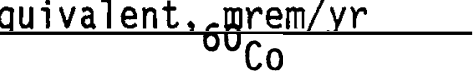 \\
\hline Class W & $\begin{array}{ll}\text { Class W } & \text { Class } Y \\
\end{array}$ \\
\hline
\end{tabular}

$<1$

$<1$

$<1$

$<1$

$<1$

4

60
$<1$

$<1$

$<1$

$<1$

$<1$

2

10
$<1$

$<1$

$<1$

$<1$

1

3

8
1

2

2

2

2

2

3

(a) Based on an MDA of $3 \mathrm{nCi}$.

activation products produced in reactors, the activation product ${ }^{60} \mathrm{Co}$ is the predominant radionuclide, both in terms of activity and resulting dose.

Table 3.9 provides radiological data for ${ }^{54} \mathrm{Mn}$.

According to ICRP 30, compounds of manganese are assigned the following inhalation classes:

- class W--oxides, hydroxides, halides, nitrates

- class D--all other compounds.

TABLE 3.9. Radiological Data for ${ }^{54} \mathrm{Mn}$

$\begin{array}{ll}\text { Half-life } & 313 \text { days } \\ \text { Annual Timit on intake (a) } & \\ \text { Class D } & 810 \mu \mathrm{Ci} \\ \text { Class W } & 810 \mu \mathrm{Ci}\end{array}$

Whole body count MDA (b) $3 \mathrm{nCi}$

(a) From ICRP 30 (1979).

(b) $\mathrm{MDA}=$ minimum detectable activity (from Palmer et al. 1990). 
Although the transportability of manganese present in a mixture of corrosion products is likely to be influenced by the solubility, physical, and chemical characteristics of the host matrix, it is appropriate to assume in a priori dose calculations, an inhalation class $W$ for corrosion product manganese. ICRP 30 assigns a $G$ I tract absorption coefficient, $f_{1}$, of 0.1 for both classes of manganese.

Once manganese enters the blood stream, it is distributed to the bone surfaces, liver, and soft tissues of the body. ICRP 30 suggests that $65 \%$ of the deposited material is retained in soft tissues, including the liver, with half-lives of 4 days for half of the material and 40 days for the other half. The other $35 \%$ is retained in the bone surfaces with a half-life of 40 days. For dosimetry purposes the 40-day component is most significant; its distribution in the body is as follows:

- bone surfaces--50\%

- 1iver--20\%

soft tissue- $-30 \%$

Thus, the above distribution would pertain to ${ }^{54} \mathrm{Mn}$ observed in the body (excluding lung) about 2 weeks post intake.

Table 3.10 provides DCFs (in rem/nCi-day) for ${ }^{54} \mathrm{Mn}$ deposited in the lung and in systemic organs and tissues. Table 3.11 gives the predicted firstyear and 50-year committed effective dose equivalent per nanocurie of intake, and Table 3.12 shows the expected activity remaining in the lung and the total activity in the body for various times after an acute inhalation intake. Table 3.4 includes the fractional total body retention following an acute class $W$ inhalation (the most limiting ICRP 30 case).

\section{$3.7 .3 \quad \underline{\text { Iron }-59}$}

Iron-59 is a relatively minor component of typical corrosion product mixtures--contributing, for example, about $10 \%$ of the activity at $\mathrm{N}$ Reactor. Because of its relatively short half-life (44.5 days), its relatively greater 
TABLE 3.10. Dose Conversion Factors for ${ }^{54} \mathrm{Mn}$

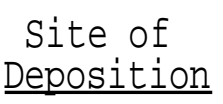

Lung

Body $(b)$

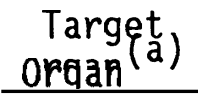

Lung

Effective

Gonad

Breast

Red marrow

Lung

Liver

Effective

\section{$\mathrm{DCF}$, rem/nCi-day}

$2.3 \mathrm{E}-6$

$3.7 \mathrm{E}-7$

$8.7 \mathrm{E}-7$

$5.4 \mathrm{E}-7$

$3.3 \mathrm{E}-7$

$1.7 \mathrm{E}-7$

$1.5 \mathrm{E}-7$

2. $6 \mathrm{E}-7$
(a) Organ doses included for organs contributing more than $10 \%$ to the total effective dose equivalent.
(b) Excludes lung and assumes a tissue distri- bution of $50 \%$ bones surfaces, $20 \%$ liver, and $30 \%$ soft tissue. TABLE 3.11. Predicted Effective Dose Equivalent Resulting from
an Inhalation Intake of $1-\mu \mathrm{m}-\mathrm{AMAD} 5 \mathrm{Mn}$ Particles

$\begin{array}{ll}\frac{\mathrm{mrem} / \mathrm{nCi}}{\text { First-Yr Effective }} & 50 \text {-Yr Committed } \\ \text { Dose Equivalent } & \text { Dose Equivalent }\end{array}$

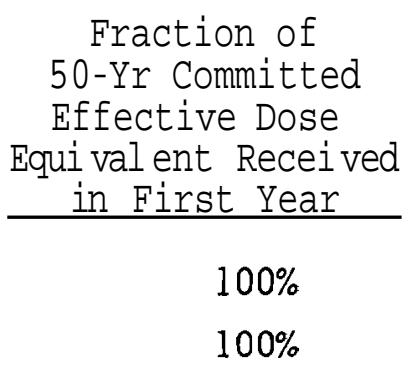

transportability from the lung, and its general distribution throughout the body, it contributes less than $10 \%$ of the total effective dose equivalent in most corrosion product exposure cases.

Table 3.13 lists radiological data for ${ }^{59} \mathrm{Fe}$.

According to ICRP 30, inhalation classes are assigned to compounds of iron as follows: 
TABLE 3.12. Expected ${ }^{54}$ Mn Activity Following an Acute Intake Res 4 lting
in a First-Year Effective Dose Equivalent of 10 mrem(a)

\begin{tabular}{|c|c|c|c|c|}
\hline \multirow{3}{*}{$\begin{array}{l}\text { Days Post } \\
\text { Intake }\end{array}$} & \multicolumn{4}{|c|}{ Activity, $\mathrm{nC}$} \\
\hline & \multicolumn{2}{|c|}{ Class D } & \multicolumn{2}{|c|}{ Class W } \\
\hline & Lung & Whole Body & Lung & Whole Body \\
\hline 7 & (b) & 660 & 200 & 330 \\
\hline 14 & (b) & 520 & 180 & 280 \\
\hline 30 & (b) & 360 & 140 & 220 \\
\hline 60 & (b) & 200 & 89 & 140 \\
\hline 90 & (b) & 110 & 57 & 92 \\
\hline 180 & (b) & 19 & 15 & 25 \\
\hline 365 & (b) & 0.5 & 0.9 & 1.7 \\
\hline
\end{tabular}

(a) Intake $=1.8 \mu \mathrm{Ci}$ class $\mathrm{D}$ or $1.4 \mu \mathrm{Ci}$ class $\mathrm{W}$, assuming inhalation of $1-\mu \mathrm{m}-A M A D$ particles.

(b) Negligible.

TABLE 3.13. Radiological Data for ${ }^{59} \mathrm{Fe}$

Half-1ife

Annual limit on intake $(a)$

44.5 days

Class D

$270 \mu \mathrm{Ci}$

Class W

$540 \mu \mathrm{Ci}$

Whole body count MDA $(b)$

$6 \mathrm{nCi}$

(a) From ICRP 30

(b) $\quad \mathrm{MDA}=$ minimum detectable activity (from Palmer et a1. 1990).

- class W--oxides, ha7ides, hydroxides

class D--all other common compounds.

The extent of absorption of iron by the GI tract depends on a number of factors, including the amount of iron in the diet, its chemical form, the body's iron needs, and the presence of interfering substances in the diet. For the a priori calculation of dose from iron intakes, ICRP 30 recommends an absorption coefficient $\left(f_{1}\right)$ of 0.1 to both class $D$ and $W$ compounds. 
Of iron entering the blood stream, the assumption of the following organ distribution is recommended:

- 1 iver- $-8 \%$

- $\quad$ spleen- $-1.3 \%$

- rest of body--90.7\%.

Regardless of the site of deposition, iron is assumed to have a biological half-life of 2000 days. Thus, the above organ distribution can be assumed to remain fixed following intake.

Table 3.14 provides DCFs (in rem/nCi-day) for ${ }^{59} \mathrm{Fe}$ deposited in the lung and in systemic organs and tissues. Table 3.15 gives the predicted firstyear and 50-year committed dose equivalent per nanocurie of intake, and Table 3.16 shows the expected activity remaining in the lung and the total activity in the body for various times after an acute inhalation intake.

TABLE 3.14. Dose Conversion Factors for ${ }^{59} \mathrm{Fe}$

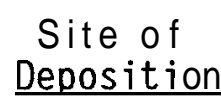

Lung

$\operatorname{Body}(b)$

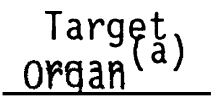

Lung

Effective

Gonad'

Breast

Liver

Spleen

Effective
DCF, $\mathrm{rem} / \mathrm{nC} \mathrm{i}$-day

8.6 E-6

$1.1 \mathrm{E}-6$

$3.7 \quad$ E-7

3.5 E-7

1.0 E-6

1.1 E-6

4.6 E-7

(a) Organ doses included for organs contributing more than $10 \%$ to the total effective dose equivalent.

(b) Excludes lung and assumes $8 \%$ in 1 iver, $1.3 \%$ in spleen, and $90.7 \%$ in the rest of the body. Factors can be applied directly to whole body count data from which the contribution due to activity in the lung has been subtracted. 
TABLE 3.15. Predicted Effective Dose Equivalent Resulting from an Inhalation Intake of 1 - $\mu \mathrm{m}$-AMAD ${ }^{59} \mathrm{Fe}$ Particles

\begin{tabular}{|c|c|c|c|}
\hline & mrer & & $\begin{array}{c}\text { Fraction of } \\
50-\text { Yr Committed } \\
\text { Effective Dose }\end{array}$ \\
\hline & $\begin{array}{l}\text { First-Yr Effective } \\
\text { Dose Equivalent } \\
\end{array}$ & $\begin{array}{l}50-Y r \text { Committed } \\
\text { Dose Eauivalent }\end{array}$ & $\begin{array}{l}\text { Equivalent Received } \\
\text { in First Year }\end{array}$ \\
\hline Class D & 0.016 & 0.016 & $100 \%$ \\
\hline Class W & 0.013 & 0.013 & $100 \%$ \\
\hline
\end{tabular}

TABLE 3.16. Expected ${ }^{59} \mathrm{Fe}$ Activity Following an Acute Intake Res 4 1ting

Days Post

Intake

14

30

60

90

180

365
7

7

4

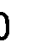

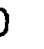

$(80$
in a First-Year Effective Dose Equivalent of 10 mrem(a)

$$
\text { in a First- }
$$

\begin{tabular}{llll}
\multicolumn{4}{c}{ Activitv, $\mathrm{nCi}$} \\
\multicolumn{2}{c}{ Class $\mathrm{D}$} & \multicolumn{2}{c}{ Class W } \\
\hline$\underline{\text { Lung }}$ & $\underline{\text { Whole Bodv }}$ & Lung & Whole Bodv
\end{tabular}

(b)

$$
280
$$

97

180

(b)

250

79

160

(b)

190

51

110

(b)

120

21

64

(b)

74

9.2

37

(b)

18

0.7

8.0

(b)

0.9

(b)

0.4 
SECTION 4.0

STRONTIUM 



\subsection{STRONTIUM}

This section summarizes the technical basis and provides some historical perspective for the internal dosimetry of strontium at Hanford.

Historically, Hanford internal dosimetry for strontium was based on estimating the long-term systemic deposition, using urine data and Dolphin's excretion model (Dolphin and Eve 1963a, 1963b), and comparing it with the 2- $\mu \mathrm{Ci}$ ICRP 2 maximum permissible body burden (MPBB) (ICRP 1959). The longterm (formerly referred to as "permanent") deposition was defined as the amount remaining in the body at 1 year post intake, which was calculated to be 15\% of the initial systemic uptake. This evaluation technique was described in several short explanations, the most recent being Appendix $G$ of the Hanford Dosimetry Evaluation Manual (PNL-MA-575). (a) Earlier versions are listed in Table 4.1.

In April 1985, the practice of investigating all positive ${ }^{90} \mathrm{Sr}$ results regardless of their dose implication was discontinued, and only results potentially indicating long-term systemic depositions in excess of $1 \%$ of the abovedescribed level were investigated. This change in practice was made due to increased sensitivity of the analytical procedure and the indication of potential background levels in the range of the minimum detection level for the analytical procedure. Using the above model, derived investigation levels were calculated for various times post intake, and these were documented by letter to the Hanford Radiation Protection Historical Files as referenced in Table 4.1 .

This technical basis incorporates the ICRP 26 and 30 (1977, 1979) concepts of tissue and effective doses, the ICRP alkaline earth model (1973) as implemented using the GENMOD computer code (Johnson and Carver 1981; see Appendix A), and supersedes the previously documented techniques for assessing internal exposure to strontium at Hanford.

(a) Pacific Northwest Laboratory. 1982. Hanford Dosimetry Evaluation Manual. PNL-MA-575, Richland, Washington. 
TABLE 4.1. Historical Documentation of the Hanford Strontium Model and Deposition Evaluation Techniques

\begin{tabular}{|c|c|c|}
\hline Date & Author & Title \\
\hline Pre 1966 & Various & Deposition Evaluations $(a)$ \\
\hline $11-66$ & Not Specified & Appendix I $-{ }^{90} S r(a)$ \\
\hline $08-01-68$ & R. C. Henle & ${ }^{90}$ Sr Calculation Factors $(a)$ \\
\hline $07-26-76$ & R. D. Glenn & Appendix I- ${ }^{90} S r(a)$ \\
\hline $09-17-80$ & D. P. Hickman & Appendix I $-{ }^{90}$ Sr Dose Evaluation (a) \\
\hline $11-82$ & & $\begin{array}{l}\text { PNL-MA-575 Appendix G- }{ }^{90} \text { Sr Dose } \\
\text { Evaluation }\end{array}$ \\
\hline $04-01-85$ & E. H. Carbaugh & Derived Investigation Levels $-{ }^{90} \mathrm{Sr}$ (b) \\
\hline
\end{tabular}

(a) Unpublished Hanford evaluation procedures, guides, and evaluations.

(b) Carbaugh E. H., and M. J. Sula. 1985. "Derived Investigation Levels-- ${ }^{5}$ Sr." Letter to the Hanford Radiation Protection Historical Files, April 1, 1985, Pacific Northwest Laboratory, Richland, Washington.

For incidents involving potential intakes of mixed fission products, it is often a common practice to use ${ }^{137} \mathrm{Cs}$ as an indicator of ${ }^{90} \mathrm{Sr}$. This can be a valid assumption, because both nuclides have comparable yields from the fissioning of ${ }^{235} \mathrm{U}$ (see Table 4.2). However, it must be noted that some Hanford chemical processes have separated cesium from strontium. Thus, caution must

TABLE 4.2. Fission Product Yields (a)

\begin{tabular}{cccc} 
Fissionable Nuclide & FP Mass $90, \%$ & & FP Mass 137, \% \\
\cline { 2 - 3 } $233_{\mathrm{U}}$ & 6.9 & 6.81 \\
$235_{\mathrm{U}}$ & 5.91 & 6.22 \\
${ }^{239} \mathrm{Pu}$ & 2.11 & 6.70
\end{tabular}

(a) From General Electric Co. (1983). 
be exercised because the ${ }^{90} \mathrm{Sr} /{ }^{137} \mathrm{Cs}$ ratio is highly variable between and within facilities. This use of a ratio can be valid if the nature of facility contamination is known.

\subsection{SOURCES AND CHARACTERISTICS OF STRONTIUM}

This section provides general information on the isotopes of strontium and related decay products that can be found at Hanford. The information compiled in this section was taken directly from, or calculated based on, information in ICRP 30 and 38 (1979, 1983).

The isotopes of dominant concern for strontium internal dosimetry are ${ }^{90} \mathrm{Sr}$ and its decay product ${ }^{90} \mathrm{Y}$. These nuclides may be found in almost any facility that deals with fission products. Most facilities that have strontium may also be expected to have other fission products present, notably cesium ( $\left.{ }^{137} \mathrm{Cs}\right)$. However, at certain facilities, notably B-Plant (221-B Building) and the Waste Encapsulation and Storage Facility (WESF) (225-B Building), strontium may be found in an essentially pure form.

In facilities where freshly irradiated fuel is being handled or processed, ${ }^{89}$ Sr may also be a concern. Due to its short radiological half-1ife, it is not likely to be found. At Hanford, N Reactor, fuel storage basins, FFTF, and the Plutonium Uranium Extraction (PUREX) Plant are considered the facilities most 1 ikely to have ${ }^{89} \mathrm{Sr}$. Immediately after irradiation, there may be substantially more ${ }^{89} \mathrm{Sr}$ than ${ }^{90} \mathrm{Sr}$, but by 1 year of decay the residual ${ }^{89} \mathrm{Sr}$ is insignificant compared to ${ }^{90} \mathrm{Sr}$ for internal dosimetry purposes. Selected decay data for these three nuclides are in Table 4.3.

TABLE 4.3. Decay Data for Strontium Isotopes

\begin{tabular}{|c|c|c|c|}
\hline Parameter & ${ }^{90} \mathrm{Sr}$ & $90_{Y}$ & ${ }^{89} \mathrm{Sr}$ \\
\hline Half-life & $29.12 \mathrm{y} \mathrm{r}$ & $64.0 \mathrm{~h}$ & 50.5 days \\
\hline Decay constant & $6.5 E-5 \mathrm{day}^{-1}$ & $0.26 \mathrm{day}^{-1}$ & 1.4E-2 $\mathrm{day}^{-1}$ \\
\hline Decay mode & $\begin{array}{c}\text { Beta } \\
\text { (no gamma) }\end{array}$ & $\begin{array}{c}\text { Beta } \\
\text { (no gamma) }\end{array}$ & $\begin{array}{c}\text { Beta } \\
\text { (no gamma) }\end{array}$ \\
\hline
\end{tabular}


For most internal dosimetry purposes, ${ }^{90} \mathrm{Sr}$ and ${ }^{90} \mathrm{Y}$ are the nuclides of concern. These nuclides are found in equilibrium to each other in virtually all circumstances under which exposure is likely. Although strontium separation operations have been performed in which pure ${ }^{90} \mathrm{Sr}$ might be obtained, the rapid ingrowth of the ${ }^{90} \mathrm{Y}$ decay product would result in the secular equilibrium condition being achieved within about 2 weeks after separation. Thus, even if an exposure to pure ${ }^{90} \mathrm{Sr}$ occurred involving significant metabolic uptake and internal deposition, within about 2 weeks of exposure there would be equal quantities of both nuclides present.

Strontium-89 decays to a stable decay product and, due to its short (50-day) radiological half-1ife, is only a concern in facilities that handle freshly irradiated fuel or the associated wastes from processing freshly irradiated fuel. The ORIGEN computer code (Hedengren 1985) indicates that, for $N$ Reactor, 6\%, Mark IV (MKIV) fuel at discharge, there may be about 90 times as much ${ }^{89} \mathrm{Sr}$ as ${ }^{90} \mathrm{Sr}$. Exposure to such material may be more limiting in terms of internal dose than exposure to ${ }^{90} \mathrm{Sr}$. Because of the rapid decay of ${ }^{89} \mathrm{Sr}$, within about 6 months ${ }^{90} \mathrm{Sr}$ becomes the dominant isotope of concern. At that time there may still be seven times as much ${ }^{89} \mathrm{Sr}$ as ${ }^{90} \mathrm{Sr}$; however, the potential first-year dose from the ${ }^{89} \mathrm{Sr}$ is only about $20 \%$ of that from the ${ }^{90} \mathrm{Sr}$. Less than $1 \%$ of the ${ }^{89} \mathrm{Sr}$ produced in fuel remains at 1 year after exposure, and, for practical purposes, that nuclide ceases to be a dosimetric concern by that time.

\subsection{BIOKINETIC BEHAVIOR OF STRONTIUM}

The biokinetic behavior of strontium is a composite of the intake mode, the chemical form, the inhalation class, the internal distribution and retention, the excretion, and the radiological half-life of the strontium isotope.

\subsubsection{Inhalation Class}

All intakes of strontium at Hanford are considered to be inhalation class $D$, in accordance with the recommendations of ICRP 30 . It is noted that strontium titanate is the only compound identified by the ICRP as belonging to inhalation class $Y$. However, that compound of strontium is not present at Hanford. 


\subsubsection{Uptake to Blood}

The absorption coefficient $\left(f_{1}\right)$ used for the $G$ I tract absorption of readily transportable (inhalation class D) forms of strontium is 0.3 , which is consistent with the recommendation of ICRP 30. Where evaluation of poorly transportable (class $Y$ ) forms may be required, the ICRP 30 value of $0.01 \mathrm{will}$ be used. These values have been incorporated into the GMOD computer code used for derivation of many of the values and factors used in this technical basis.

\subsubsection{Internal Distribution and Retention}

The biokinetic model used for the distribution, retention, and excretion of stable strontium is the alkaline earth model of the ICRP $(1973,1979)$ as implemented by the GEMOD computer code (see Appendix A). It is assumed that stable strontium is uniformly distributed throughout the bone volume, where it is retained and internally recycled according to a series of exponential terms modeled by Johnson and Myers (1981), which show good agreement with the ICRP alkaline earth model. The uptake retention function of GEMOD is shown in Figure 4.1 along with the Dolphin mode1 that has been used for Hanford strontium evaluations prior to this technical basis.

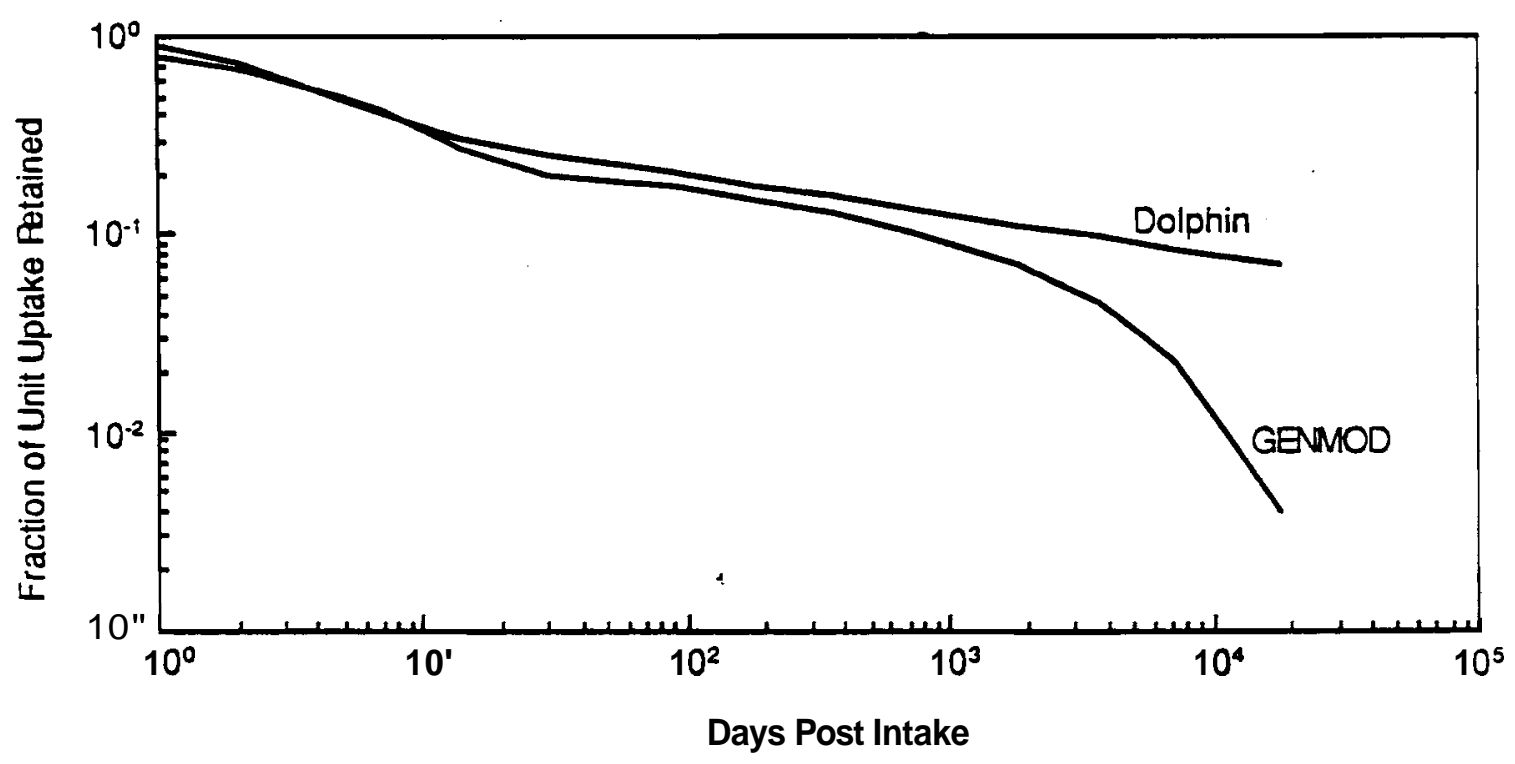

FIGURE 4.1. $\quad{ }^{90} \mathrm{Sr}$ Retention Functions 
The use of the GENMOD code marks a departure from the past Hanford use of the Dolphin model described previously. This departure is made to allow for the adoption of tools consistent with ICRP 30 recommendations and DOE 5480.11 radiation protection standards. Past ${ }^{90} \mathrm{Sr}$ evaluations compared the residual systemically retained quantity at 1 year post intake with the ICRP 2 (1959) MPBB as a measure of compliance and assumed that this retained quantity was permanent. In fact, the 29 -year radiological half-1ife for ${ }^{90}$ Sr combined with biological clearance results in a continuing decrease in the systemically retained quantity, which becomes significant with regard to the annual tissue and effective doses at long times post intake. The transition from the Dolphin to the ICRP alkaline earth model as implemented by GENMOD is noted here for historical purposes.

For dosimetry purposes, it is assumed that the intake is the pure isotope of ${ }^{90} \mathrm{Sr}$. The dose contribution from any ${ }^{90} \gamma$ present at the time of intake due to equilibrium with the ${ }^{90} \mathrm{Sr}$ parent makes no significant difference in the total dose.

\subsubsection{Excretion of Strontium}

The alkaline earth excretion model assumes that the fraction of excreted uptake occurring by the urinary pathway and by the fecal pathway is 0.8 and 0.2 , respectively. This is consistent with past Hanford practices and represents generally accepted excretion fractionation.

Urine sample analysis is the easiest and most common bioassay method for both ${ }^{89} \mathrm{Sr}$ and ${ }^{90} \mathrm{Sr}$, and therefore the urinary excretion function becomes the key for internal dosimetry evaluations of strontium. The GENMOD ${ }^{90}$ Sr urinary excretion function is used in this technical basis for strontium evaluations. This function, expressed as the fractional excretion rate for an acute uptake of transportable ${ }^{90} \mathrm{Sr}$, is plotted in Figure 4.2. Also shown is the excretion function derived from the Dolphin model that was formerly used for Hanford ${ }^{90} \mathrm{Sr}$ evaluations without correction for radiological decay.

Despite the differences in formulation and the lack of decay correction in the Dolphin-based function, it can be concluded from Figure 4.2 that the two models will provide roughly comparable estimates of an acute uptake, when 


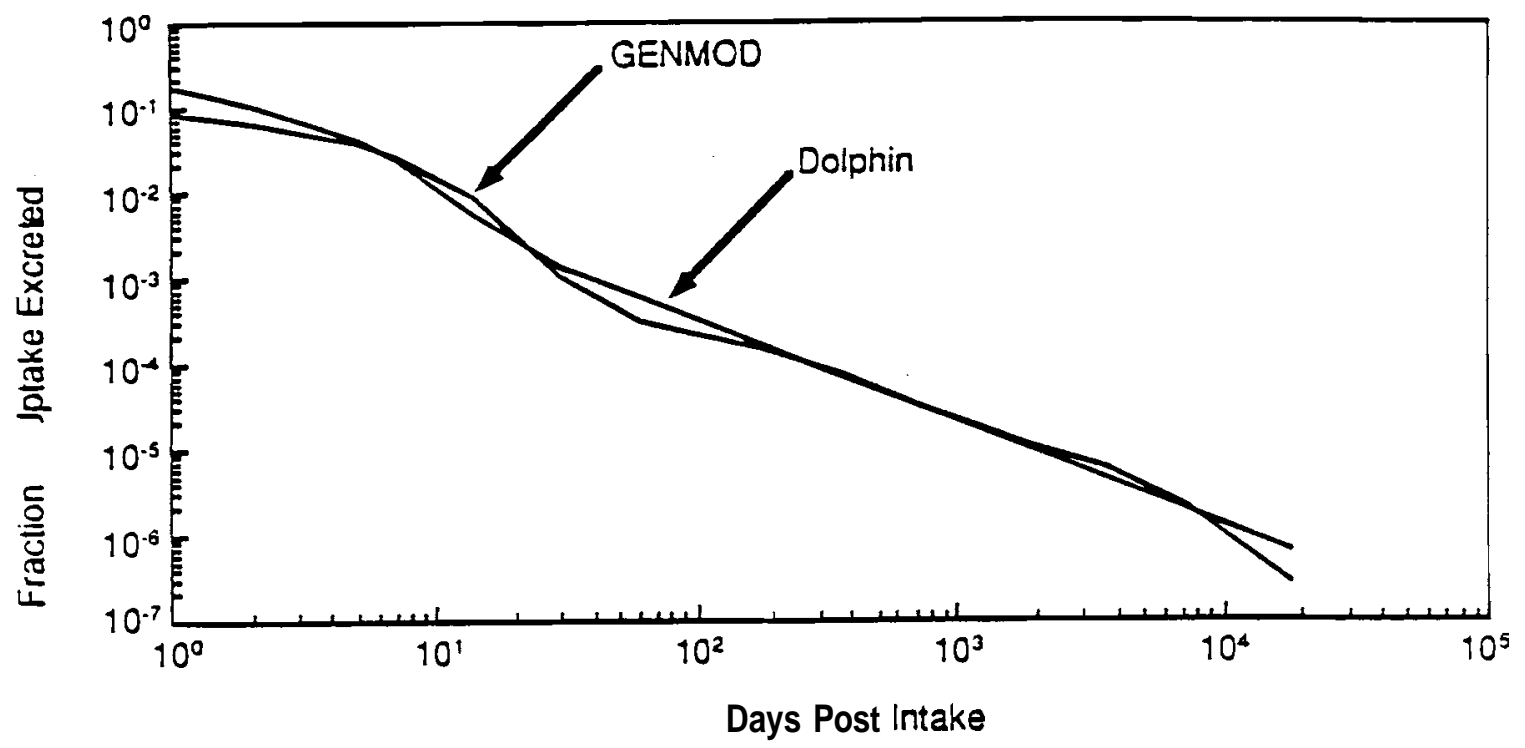

FIGURE 4.2. ${ }^{90}$ Sr Excretion Functions for Urinary Excretion Following an Acute Uptake

evaluations are based on multiple data points spread over many days to weeks post intake and undue emphasis is not given to single data points. The excretion models are not significantly different between about 150 and several thousand days post uptake, and thus, where long-term data are available, the models should give comparable results. For evaluations based primarily on data from times less than 150 days post uptake, the uptake estimates based on GEMOD are likely to be more conservative than those based on the Dolphin model, because the GEMOD code predicts lower excretion rates for about twothirds of that period. For the typical case, the data fits for the two models should not make an appreciable difference in the estimated uptake.

The GEMDD excretion function for ${ }^{89} \mathrm{Sr}$ uses the same stable element retention function with corrections based on the radiological decay of ${ }^{89} \mathrm{Sr}$. This function is addressed in the next section.

\subsection{STRONTIUM INTERNAL DOSIMETRY FACTORS}

The following subsections detail factors useful for making internal dosimetry calculations. These factors are derived from the GEMOD computer code. 


\subsubsection{Intake Excretion Functions}

The fractional intake excretion functions for transportable injection, class $D$ inhalation, and class $Y$ inhalation intakes of ${ }^{90} \mathrm{Sr}$ (as calculated by GEMOD) are shown in Figure 4.3. Selected values for these functions are listed in Table 4.4. For readily transportable injection intakes (i.e., wounds), the total uptake to blood occurs very quickly. In these cases, the calculated intake and uptake are essentially synonymous. For a class $D$ inhalation, the only significant difference from a transportable injection excretion function is the positioning of the curve relative to the $y$-axis. The difference is due simply to the ratio of total uptake to total intake $(0.48$ for $1-\mu \mathrm{m}$, class $D$ particles), where total uptake includes the contributions from both the respiratory and $G I$ tracts. For class $Y$ material, the uptake to blood occurs over a long period, nominally characterized by the clearance rate from the lung. As is apparent in Figure 4.3, urinary excretion following an acute class $Y$ intake can be expected to be relatively constant from about 50 to 1000 days post intake.

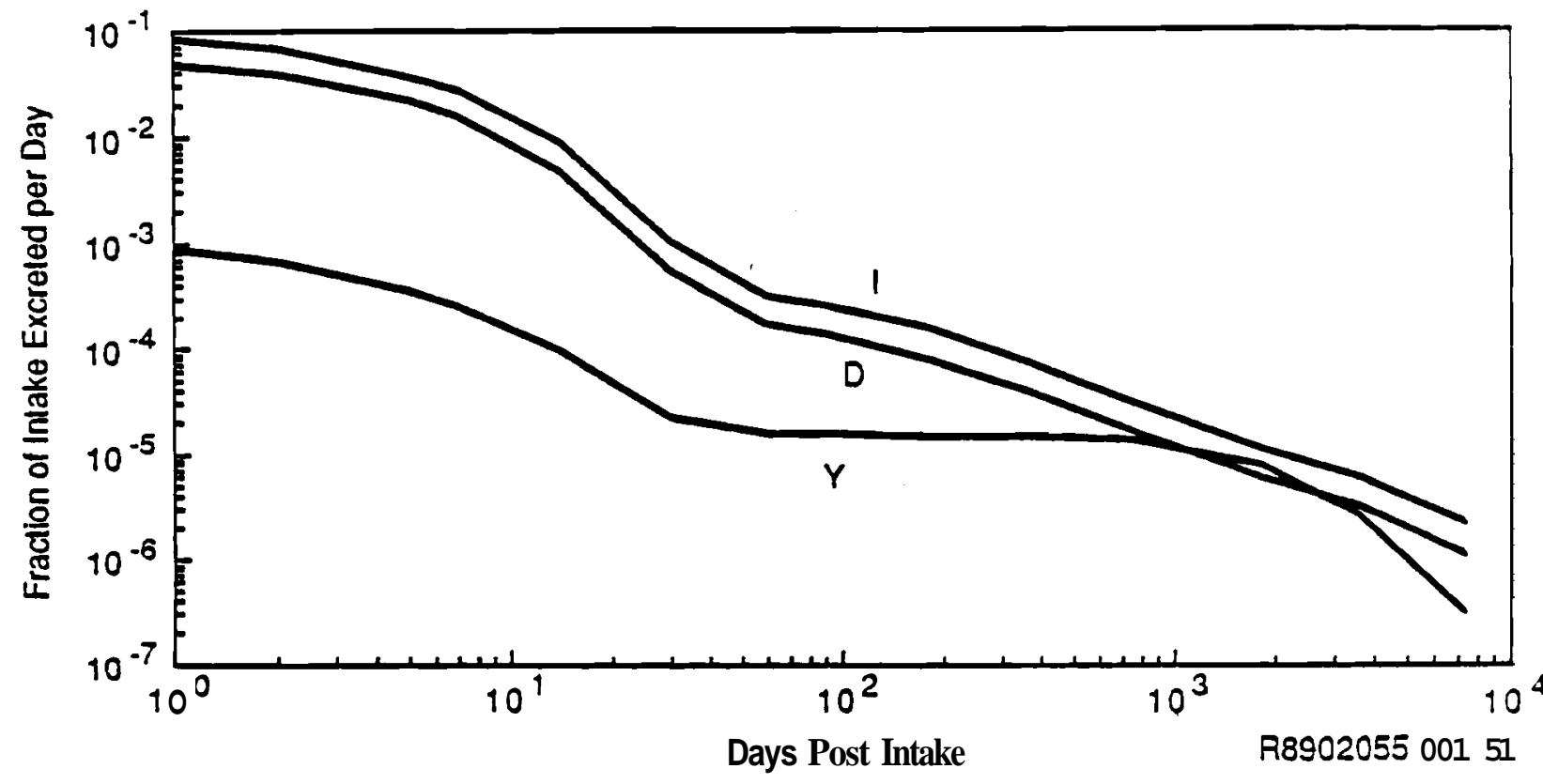

FIGURE 4.3. ${ }^{90} \mathrm{Sr}$ Intake Excretion Functions for the Urinary Excretion Pathway (Johnson and Carter 1981). I = transportable injection, $D=$ class $D$ inhalation, $Y=$ class $Y$ inhalation . 


\begin{tabular}{|c|c|c|c|}
\hline $\begin{array}{l}\text { Days Post } \\
\text { Intake }\end{array}$ & $\begin{array}{l}\text { Transportable } \\
\text { Injection } \\
\end{array}$ & $\begin{array}{l}\text { Class D } \\
\text { Inhalation } \\
\end{array}$ & $\begin{array}{l}\text { Class Y } \\
\text { Inhalation }\end{array}$ \\
\hline 1 & $8.2 E-2$ & $4.8 E-2$ & $8.4 E-4$ \\
\hline 2 & $6.5 E-2$ & $3.8 \mathrm{E}-2$ & $6.4 \mathrm{E}-4$ \\
\hline 5 & $3.6 \mathrm{E}-2$ & $2.1 E-2$ & $3.6 E-4$ \\
\hline 7 & $2.6 \mathrm{E}-2$ & $1.5 E-2$ & $2.5 E-4$ \\
\hline 14 & $8.5 E-3$ & $4.8 E-3$ & $9.1 \mathrm{E}-5$ \\
\hline 30 & $1.0 \mathrm{E}-3$ & $5.5 E-4$ & $2.1 \mathrm{E}-5$ \\
\hline 60 & $3.0 \mathrm{E}-4$ & $1.6 \mathrm{E}-4$ & $1.5 \mathrm{E}-5$ \\
\hline 90 & $2.4 \mathrm{E}-4$ & $1.3 \mathrm{E}-4$ & $1.5 \mathrm{E}-5$ \\
\hline 180 & $1.5 \mathrm{E}-4$ & $7.6 \mathrm{E}-5$ & $1.4 \mathrm{E}-5$ \\
\hline 365 & $7.3 \mathrm{E}-5$ & $3.8 \mathrm{E}-5$ & $1.4 \mathrm{E}-5$ \\
\hline 730 & $3.1 \mathrm{E}-5$ & $1.6 \mathrm{E}-5$ & $1.3 \mathrm{E}-5$ \\
\hline 1825 & $1.1 \mathrm{E}-5$ & $5.9 E-6$ & $7.5 E-6$ \\
\hline 3650 & $5.9 \mathrm{E}-6$ & $3.1 \mathrm{E}-6$ & $2.4 \mathrm{E}-6$ \\
\hline 7300 & $2.1 \mathrm{E}-6$ & $1.1 \mathrm{E}-6$ & $3.0 \mathrm{E}-7$ \\
\hline
\end{tabular}

Values of the intake excretion functions for days other than those indicated in Table 4.4 can be obtained directly from running the GENMOD code, or can be reasonably approximated by linear interpolation between the data points of Table 4.4.

Table 4.5 provides similar values for the ${ }^{89} \mathrm{Sr}$ urinary excretion function.

\subsubsection{Source-to-Target-Orqan Dose Conversion Factors}

The DCFs used by the GENMOD computer code to calculate dose equivalent to a target organ from radioactive decay in a source organ are shown in Table 4.6. These factors agree with those of ICRP 30 to within a few percent, which is consistent with the expected rounding error. 
TABLE 4.5.
Selected ${ }^{89}$ Sr Urinary Excretion Fractions
(expressed as fraction of intake)

\begin{tabular}{|c|c|c|c|}
\hline $\begin{array}{l}\text { Days Post } \\
\text { Intake }\end{array}$ & $\begin{array}{l}\text { Transportable } \\
\text { Injection } \\
\end{array}$ & $\begin{array}{l}\text { Class D } \\
\text { Inhalation }\end{array}$ & $\begin{array}{l}\text { Class Y } \\
\text { Inhalation }\end{array}$ \\
\hline 1 & 8. $1 \mathrm{E}-2$ & $4.9 E-2$ & $8.3 E-4$ \\
\hline 2 & $6.3 \mathrm{E}-2$ & $3.8 \mathrm{E}-2$ & $6.2 \mathrm{E}-4$ \\
\hline 5 & $3.4 \mathrm{E}-2$ & $2.0 \mathrm{E}-2$ & $3.3 \mathrm{E}-4$ \\
\hline 7 & $2.3 \mathrm{E}-2$ & $1.3 \mathrm{E}-2$ & $2.3 \mathrm{E}-4$ \\
\hline 14 & $7.0 \mathrm{E}-3$ & $4.0 E-3$ & $7.6 \mathrm{E}-5$ \\
\hline 30 & $6.7 \mathrm{E}-4$ & $3.7 \mathrm{E}-4$ & $1.4 \mathrm{E}-5$ \\
\hline 60 & 1. $3 \mathrm{E}-4$ & $6.9 E-5$ & $6.6 \mathrm{E}-6$ \\
\hline 90 & $7.0 \mathrm{E}-5$ & $3.7 E-5$ & $4.3 \mathrm{E}-6$ \\
\hline 180 & $1.2 \mathrm{E}-5$ & $6.5 \mathrm{E}-6$ & $1.4 \mathrm{E}-6$ \\
\hline 365 & $5.0 \mathrm{E}-7$ & $2.6 \mathrm{E}-7$ & $1.1 \mathrm{E}-7$ \\
\hline
\end{tabular}

TABLE 4.6. Dose Conversion Factors for Strontium Dosimetry

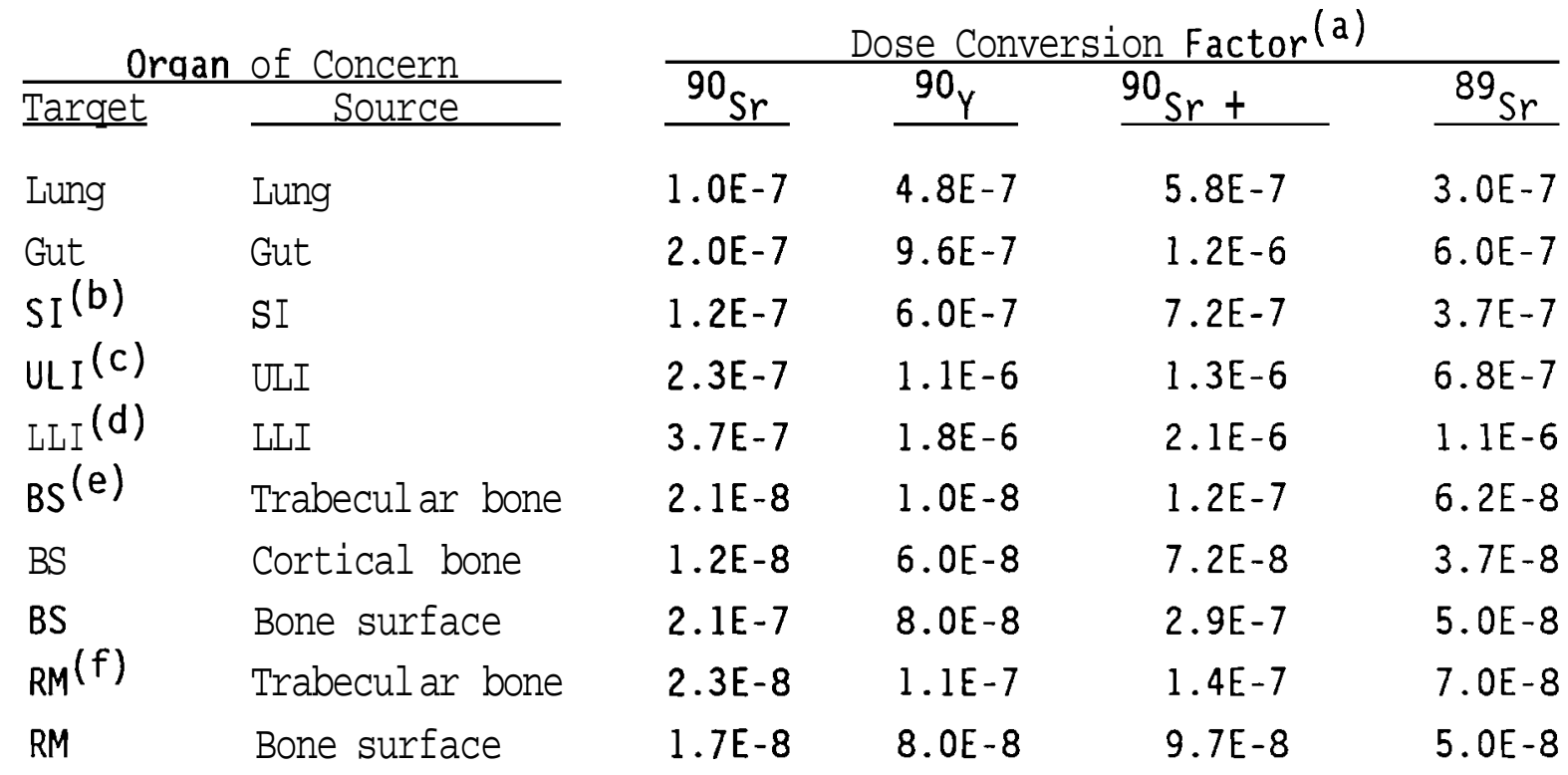
(a) Units of rem(target)/nCi-day (source).
(b) $\mathrm{SI}=$ small intestine.
(c) ULI = upper large intestine.
(d) LLI = lower large intestine.
(e) $\mathrm{BS}=$ bone surface.
(f) $\quad$ RM = red marrow. 


\subsubsection{Intake Dose Equivalent Factors}

Intake dose equivalent factors express the dose to an organ from a unit intake of radioactivity. Because of the mathematical formulation of the strontium retention function, with its incorporation of bone-to-blood recycling, these factors are difficult to derive by hand calculation, but they can be readily obtained from the GENMOD computer code. Tables 4.7 and 4.8 provide first-year and 50-year committed organ and effective dose equivalent factors for transportable injection, and inhalations of 1- $\mu$ m-AMAD class D and class $Y$ particles. Intake dose equivalent factors for any year post intake can be obtained from the GENMOD code. For ${ }^{90} \mathrm{Sr}$ cases, it was assumed that the intake was pure ${ }^{90} \mathrm{Sr}$ with ${ }^{90} \mathrm{Y}$ rapidly growing to equilibrium. If the intake consisted of ${ }^{90} \mathrm{Sr}$ and ${ }^{90} \mathrm{Y}$ in equilibrium at the time of intake, the resulting factors would not be noticeably different.

\subsubsection{Cumulative Dose Equivalents}

The cumulative dose equivalent from an intake through various times post intake is frequently of interest with regard to tenaciously retained radionuclides. The most commonly referenced cumulative dose is the committed dose equivalent through a 50 -year period following an intake. For ${ }^{89} \mathrm{Sr}$, virtually all of this dose is received during the first year after intake, and the committed dose is essentially the same as the first-year dose. The dose from a ${ }^{90} \mathrm{Sr}$ intake is delivered over a much longer period of time, due to its long radiological and biological half-lives.

The cumulative effective dose equival ents (expressed as a percentage of the 50-year committed effective dose equivalent) through various times post intake are shown in Table 4.9 for transportable injection, class D inhalation, and class $Y$ inhalation intakes. These values were derived from the GENMOD computer code.

The ICRP 30 annual limits on intakes (ALIs) for ${ }^{90} \mathrm{Sr}$ are $19,000 \mathrm{nCi}$ and $2700 \mathrm{nCi}$ for class $\mathrm{D}$ and class $\mathrm{Y}$ inhalations, respectively. These intakes correspond to a 50-year committed effective dose equivalent of $5 \mathrm{rem}$. 
TABLE 4.7. ${ }^{90} \mathrm{Sr}+90_{Y}$ Intake Dose Equivalent Factors (a) for First-Year and 50-Year Committed Doses

\begin{tabular}{|c|c|c|c|}
\hline Tissue & $\begin{array}{l}\text { Transportable (b) } \\
\text { Injection }\end{array}$ & $\begin{array}{l}\text { Class } D^{(c)} \\
\text { Inhalation }\end{array}$ & $\begin{array}{l}\text { Class } Y(c) \\
\text { Inhalation }\end{array}$ \\
\hline $\begin{array}{l}\text { Effective } \\
\text { First-year } \\
50 \text {-year }\end{array}$ & $\begin{array}{l}5.9 \mathrm{E}-5 \\
4.1 \mathrm{E}-4\end{array}$ & $\begin{array}{l}3.2 \mathrm{E}-5 \\
2.2 \mathrm{E}-4\end{array}$ & $\begin{array}{l}3.2 \mathrm{E}-4 \\
1.3 \mathrm{E}-3\end{array}$ \\
\hline $\begin{array}{l}\text { Bone Surface } \\
\text { First-year } \\
50 \text {-year }\end{array}$ & $\begin{array}{l}5.5 \mathrm{E}-4 \\
4.6 \mathrm{E}-3\end{array}$ & $\begin{array}{l}2.9 \mathrm{E}-4 \\
2.4 \mathrm{E}-3\end{array}$ & $\begin{array}{l}7.0 \mathrm{E}-6 \\
2.3 \mathrm{E}-4\end{array}$ \\
\hline $\begin{array}{l}\text { Red Marrow } \\
\text { First-year } \\
50 \text {-year }\end{array}$ & $\begin{array}{l}3.1 \mathrm{E}-4 \\
2.0 \mathrm{E}-3\end{array}$ & $\begin{array}{l}1.6 \mathrm{E}-4 \\
1.1 \mathrm{E}-3\end{array}$ & $\begin{array}{l}3.9 \mathrm{E}-6 \\
1.0 \mathrm{E}-4\end{array}$ \\
\hline $\begin{array}{l}\text { Lung } \\
\text { First-year } \\
50 \text {-year }\end{array}$ & $\begin{array}{l}\mathrm{NA}(\mathrm{d}) \\
\mathrm{NA}\end{array}$ & $\begin{array}{l}3.9 \mathrm{E}-6 \\
4.1 \mathrm{E}-6\end{array}$ & $\begin{array}{l}2.6 \mathrm{E}-3 \\
1.1 \mathrm{E}-2\end{array}$ \\
\hline $\begin{array}{l}\text { Gut } \\
\text { First-year } \\
\text { 50-year }\end{array}$ & $\begin{array}{l}N A(d) \\
N A(d)\end{array}$ & $\begin{array}{l}2.1 \mathrm{E}-7 \\
2.1 \mathrm{E}-7\end{array}$ & $\begin{array}{l}9.1 \mathrm{E}-7 \\
1.2 \mathrm{E}-6\end{array}$ \\
\hline $\begin{array}{l}\text { Small Intestine } \\
\text { First-year } \\
50 \text {-year }\end{array}$ & $\begin{array}{l}\mathrm{NA}(\mathrm{d}) \\
\mathrm{NA}\end{array}$ & $\begin{array}{l}4.0 \mathrm{E}-7 \\
4.0 \mathrm{E}-7\end{array}$ & $\begin{array}{l}2.4 \mathrm{E}-6 \\
3.1 \mathrm{E}-6\end{array}$ \\
\hline $\begin{array}{l}\text { Upper Large Intestine } \\
\text { First-year } \\
50 \text {-year }\end{array}$ & $\begin{array}{l}N A(d) \\
N A\end{array}$ & $\begin{array}{l}3.1 \mathrm{E}-6 \\
3.1 \mathrm{E}-6\end{array}$ & $\begin{array}{l}1.8 \mathrm{E}-5 \\
2.2 \mathrm{E}-5\end{array}$ \\
\hline $\begin{array}{l}\text { Lower Large Intestine } \\
\text { First-year } \\
50 \text {-year }\end{array}$ & $\begin{array}{l}N A(d) \\
N A \\
N(d)\end{array}$ & $\begin{array}{l}1.2 \mathrm{E}-5 \\
1.2 \mathrm{E}-5\end{array}$ & $\begin{array}{l}6.3 E-5 \\
7.5 E-5\end{array}$ \\
\hline $\begin{array}{l}\text { Other } \\
\text { First-year } \\
50 \text {-year }\end{array}$ & $\begin{array}{l}2.1 \mathrm{E}-6 \\
2.4 \mathrm{E}-6\end{array}$ & $\begin{array}{l}1.3 \mathrm{E}-6 \\
1.3 \mathrm{E}-6\end{array}$ & $\begin{array}{l}3.9 \mathrm{E}-8 \\
1.7 \mathrm{E}-7\end{array}$ \\
\hline $\begin{array}{l}\text { (a) Units are rem/nCi } \\
\text { (b) Assumes all stron } \\
\text { (c) Assumes } 1-\mu \mathrm{m}-\mathrm{AMAD} \\
\text { (d) Not appl i cable. }\end{array}$ & $\begin{array}{l}\text { acute intake. } \\
\text { and yttrium is re } \\
\text { ticle size. }\end{array}$ & ansportable & \\
\hline
\end{tabular}


TABLE 4.8. ${ }^{89}$ Sr Intake Dose Equivalent Factors (a) for First-Year and 50-Year Committed Doses

\begin{tabular}{|c|c|c|c|}
\hline Tissue & $\begin{array}{c}\text { Transportable (b) } \\
\text { Injection }\end{array}$ & $\begin{array}{l}\text { Class } D^{(c)} \\
\text { Inhalation }\end{array}$ & $\begin{array}{l}\text { Class } y(c) \\
\text { Inhalation }\end{array}$ \\
\hline $\begin{array}{l}\text { Effective } \\
\text { First-year } \\
50 \text {-year }\end{array}$ & $\begin{array}{l}7.0 E-6 \\
8.7 E-6\end{array}$ & $\begin{array}{l}6.2 \mathrm{E}-6 \\
6.3 \mathrm{E}-6\end{array}$ & $\begin{array}{l}4.2 E-5 \\
4.2 E-5\end{array}$ \\
\hline $\begin{array}{l}\text { Bone Surface } \\
\text { Firs t-year } \\
50 \text {-year }\end{array}$ & $\begin{array}{l}6.5 E-5 \\
6.6 E-5\end{array}$ & $\begin{array}{l}3.4 \mathrm{E}-5 \\
3.4 \mathrm{E}-5\end{array}$ & $\begin{array}{l}6.4 \mathrm{E}-7 \\
6.5 \mathrm{E}-7\end{array}$ \\
\hline $\begin{array}{l}\text { Red Marrow } \\
\text { First-year } \\
50 \text {-year }\end{array}$ & $\begin{array}{l}4.1 \mathrm{E}-5 \\
1.1 \mathrm{E}-6\end{array}$ & $\begin{array}{l}2.1 \mathrm{E}-5 \\
2.2 \mathrm{E}-5\end{array}$ & $\begin{array}{l}\text { 4. } 1 E-7 \\
4.1 E-7\end{array}$ \\
\hline $\begin{array}{l}\text { Lung } \\
\text { First-year } \\
50 \text {-year }\end{array}$ & $\begin{array}{l}\text { NA (d) } \\
N A(d)\end{array}$ & $\begin{array}{l}6.4 \mathrm{E}-6 \\
6.4 \mathrm{E}-6\end{array}$ & $\begin{array}{l}3.1 \mathrm{E}-4 \\
3.1 \mathrm{E}-4\end{array}$ \\
\hline $\begin{array}{l}\text { Gut } \\
\text { First-year } \\
50 \text {-year }\end{array}$ & $\begin{array}{l}\text { NA (d) } \\
\text { NA }(d)\end{array}$ & $\begin{array}{l}3.8 \mathrm{E}-7 \\
3.8 \mathrm{E}-7\end{array}$ & $\begin{array}{l}1.2 \mathrm{E}-6 \\
1.2 \mathrm{E}-6\end{array}$ \\
\hline $\begin{array}{l}\text { Small Intestine } \\
\text { First-year } \\
50 \text {-year }\end{array}$ & $\begin{array}{l}N A \text { (d) } \\
N A \text { (d) }\end{array}$ & $\begin{array}{l}6.7 \mathrm{E}-7 \\
6.7 \mathrm{E}-7\end{array}$ & $\begin{array}{l}3.0 \mathrm{E}-6 \\
3.0 \mathrm{E}-6\end{array}$ \\
\hline $\begin{array}{l}\text { Upper Large Intestine } \\
\text { First-year } \\
50 \text {-year }\end{array}$ & $\begin{array}{l}\text { NA (d) } \\
\text { NA (d) }\end{array}$ & $\begin{array}{l}4.0 E-6 \\
4.0 E-6\end{array}$ & $\begin{array}{l}1.8 \mathrm{E}-5 \\
1.8 \mathrm{E}-5\end{array}$ \\
\hline $\begin{array}{l}\text { Lower Large Intestine } \\
\text { First-year } \\
50 \text {-year }\end{array}$ & $\begin{array}{l}\mathrm{NA}(\mathrm{d}) \\
\mathrm{NA}(\mathrm{d})\end{array}$ & $\begin{array}{l}1.1 \mathrm{E}-5 \\
1.1 \mathrm{E}-5\end{array}$ & $\begin{array}{l}5.1 E-5 \\
5.1 E-5\end{array}$ \\
\hline $\begin{array}{l}\text { Other } \\
\text { First-year } \\
50 \text {-year }\end{array}$ & $\begin{array}{l}1.4 \mathrm{E}-6 \\
1.4 \mathrm{E}-6\end{array}$ & $\begin{array}{l}7.1 \mathrm{E}-7 \\
7.1 \mathrm{E}-7\end{array}$ & $\begin{array}{l}1.4 \mathrm{E}-8 \\
1.4 \mathrm{E}-8\end{array}$ \\
\hline $\begin{array}{l}\text { (a) Units are rem/nCi } \\
\text { (b) Assumes all stront } \\
\text { (c) Assumes 1- }-\mu \mathrm{m}-\mathrm{AMAD} \\
\text { (d) Not applicable. }\end{array}$ & $\begin{array}{l}\text { cute intake. } \\
\text { is readily transh } \\
\text { icle size. }\end{array}$ & & \\
\hline
\end{tabular}


TABLE 4.9. Cumulative Effective Dose Equivalent (a) for ${ }^{90} \mathrm{Sr}$ Intakes

Cumulative Time Post Intake, days years

$90 \quad 0.25$

180

365

730

1,825

3,650

7,300

18,250

\begin{tabular}{|c|c|c|}
\hline & e of Intake & \\
\hline $\begin{array}{c}\text { Transportable } \\
\text { Injection }\end{array}$ & Class D & Class Y \\
\hline
\end{tabular}

$5.5 \%$

$4.8 \%$

$8.9 \%$

$8.2 \%$

$15 \%$

$14 \%$

$24 \%$

$41 \%$

$25 \%$

$25 \%$

$67 \%$

$48 \%$

$48 \%$

$81 \%$

$71 \%$

$71 \%$

$90 \%$

$89 \%$

$89 \%$

$100 \%$

$100 \%$

$100 \%$

(a) Expressed as a percentage of $\mathrm{H}_{E}^{\mathrm{C}}, 50^{\text {. }}$

\subsection{BIOASSAY TECHNIQUES FOR STRONTIUM}

The general techniques and applicability of bioassay for strontium, urine and fecal sample bioassay, in vivo measurement of ${ }^{90} \mathrm{Sr}$, bioassay monitoring program capability, a recommended program, and special monitoring needs are discussed in the following subsections.

\subsubsection{General Techniques and Applicability}

The standard method of bioassay for strontium is by analysis of urine excreta samples. Because strontium at Hanford is a class D material, its rapid transport to the systemic compartment makes urine sampling an accurate, reliable, and convenient means for bioassay monitoring. In addition, the lack of any readily detectable gamma emissions makes in vivo detection somewhat ineffective, although if sufficient strontium is present, the brernsstrahlung can be detected by in vivo counting. Fecal samples can also be analyzed; however, their collection is more difficult, and analysis of fecal samples is more costly than analysis of urine samples. 


\subsubsection{Urine and Fecal Sample Bioassav}

Minimum detectable activities for radiostrontium analyses from 1980 through 1991 are shown in Table 4.10. Other procedures have been available, however their actual use has been quite limited.

Prior to the June 1990 termination of the analytical support laboratory contract, the laboratory performed a strontium chemical separation followed by a total radiostrontium $\left({ }^{89+90} \mathrm{Sr}\right)$ count. If the result was below $1 \mathrm{dpm}$, then no further analysis was performed and the result was reported as either total strontium or ${ }^{90} \mathrm{Sr}$ depending on the request. For ${ }^{90} \mathrm{Sr}$ analyses in which the first count exceeded $1 \mathrm{dpm}$, the sample preparation would be aged to allow $90_{Y}$ ingrowth to occur. Chemical separation and measurement of the $900_{Y}$ would then be used to determine the ${ }^{90} \mathrm{Sr}$ present.

Following the June 1990 contract termination, arrangements were made for ${ }^{90} \mathrm{Sr}$ analyses to be provided by an interim analytical laboratory pending

\section{TABLE 4.10. Contractual Detection Level s for Strontium}

Sampl e Media

Uri ne
Anal vsis

Pre-June 1990 Routine and prijority $^{90} \mathrm{Sr}$ Expedite $\left({ }^{89+9}(r)\right.$ Emergency $\left({ }^{89+90} \mathrm{Sr}\right)$

Post-June

Routine Expedite Emergency
Detection Level, $\mathrm{dpm} / \mathrm{sample}$

$$
\begin{aligned}
& 2.0 \\
& 10 \\
& 80 \\
& \\
& 30(a) \\
& 40 \\
& 400
\end{aligned}
$$

Feces

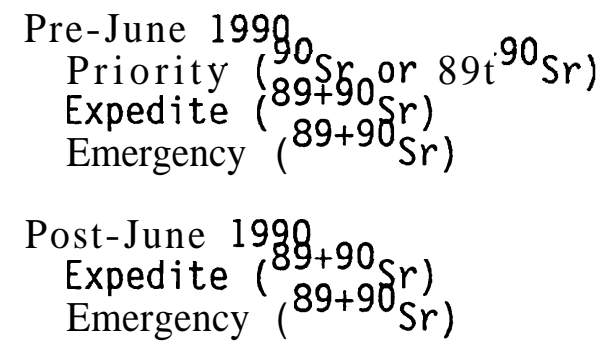

10 150 450

400

2000

(a) Results greater than the critical level $\left(L_{c}\right)$ of 15 dpm are considered to be positive detection and are investigated. 
completion of the bidding process for a permanent replacement laboratory. As of this writing (June 1991) these arrangements are continuing. The interim laboratory provides a minimum detection level of $30 \mathrm{dpm}$, and any results greater than the 15 dpm critical level $\left(L_{c}\right)$ are investigated.

\subsubsection{In Vivo Measurement of ${ }^{90} \mathrm{Sr}$}

Direct in vivo measurement of ${ }^{90} \mathrm{Sr}$ in the skeleton is possible by counting the bremsstrahlung from its decay. This procedure is subject to substantial interference by any other gamma- and beta-emitting nuclides that might be present. Indications are that a retained quantity in the skeleton of about $100 \mathrm{nCi}$ might be detectable by head counting, however, there is no calibration for this measurement.

If isotope activity relationships are known, in vivo whole body counting can be an effective indicator for the potential presence of strontium. Cesium-137 is the nuclide frequently used as the indicator, because its fission product yield is comparable to that of ${ }^{90} \mathrm{Sr}$. For some circumstances, it can be assumed that ${ }^{90} \mathrm{Sr}$ is present at intake in amounts equal to ${ }^{137} \mathrm{Cs}$. However, this method is not conclusive and caution must be exercised in its use as a rule-of-thumb, because there are processes at Hanford where strontium and cesium undergo chemical separation from each other. Use of ${ }^{137} \mathrm{Cs}$ as an indicator of ${ }^{90} \mathrm{Sr}$ is more fully described in Section 5.0.

It is generally recommended that in vivo measurements be used only as indicators of the potential for strontium being present, and that evaluations of any strontium uptake be based on urine samples.

\subsubsection{Bioassay Monitoring Program Capability}

The ${ }^{90}$ Sr class $D$ and $Y$ acute inhalation intakes (for 1- $\mu$ m-AMAD particles) that are potentially detectable using the $2 \mathrm{dpm} / \mathrm{sample}$ analytical procedure sensitivity are shown in Figure 4.4. This assumes that the samples represent 24-hour excretion. Capabilities for selected times post intake are shown in Table 4.11, and include the magnitudes of intake, first-year effective dose equivalent, and committed effective dose equivalents. 


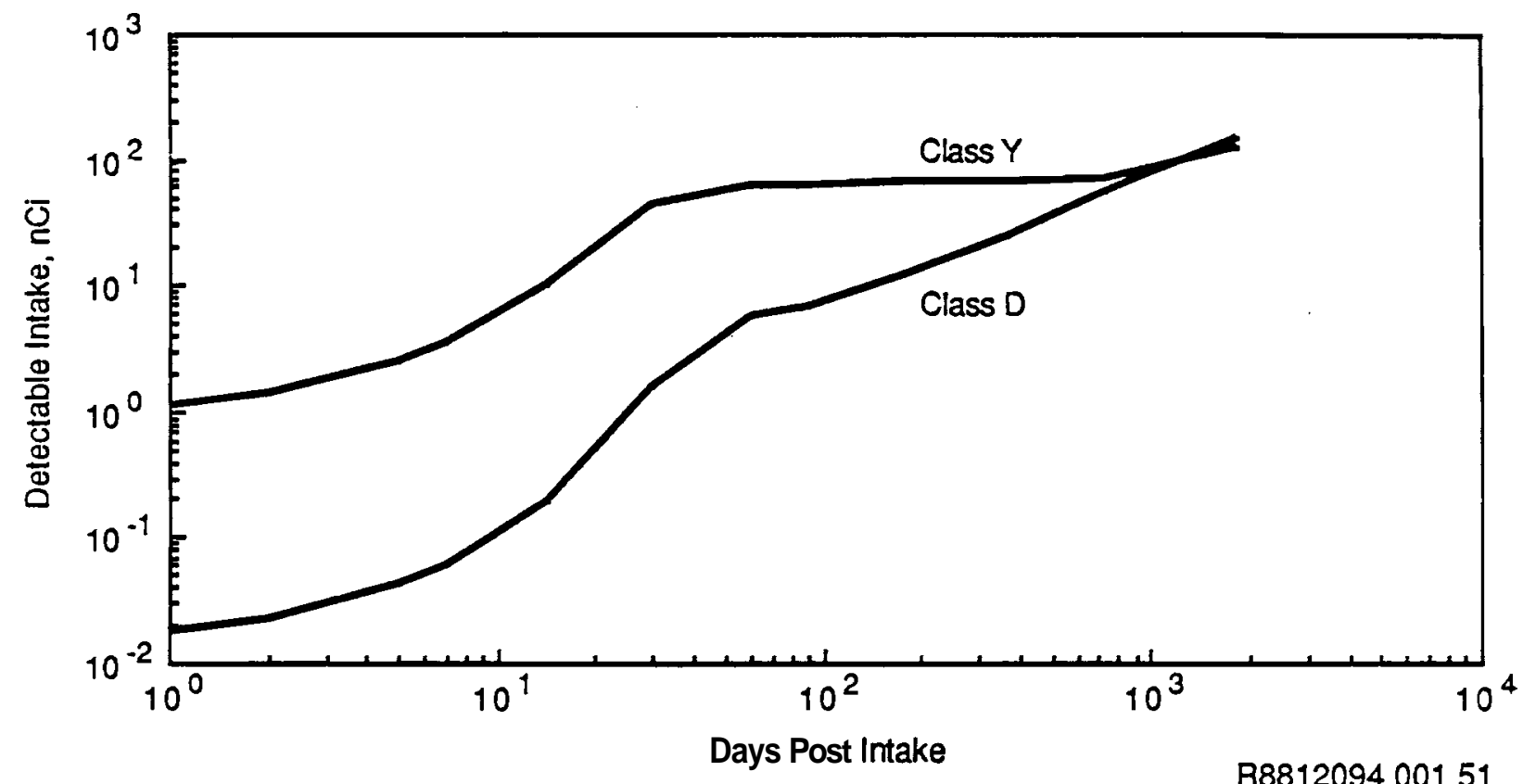

FIGURE 4.4. ${ }^{90} \mathrm{Sr}$ Inhalation Intakes Detectable by Urine Sampling $(\mathrm{D}=$ class $\mathrm{D}$ inhalation, $\mathrm{Y}=$ class $\mathrm{Y}$ inhalation . Assumes 1- $\mu$ m-AMAD particles and a 2-dpm/day detection level.)

\subsubsection{Recommended Routine Bioassay Monitoring Program}

Workers potentially exposed to radiostrontium should be on an annual bioassay program including urine sample analysis for radiostrontium and whole body counting for high-energy gamma-emitting nuclides as additional indicators of potential intake of mixed fission products. A worker scheduled only for a whole body exam may not be recognized as having potential exposure to radiostrontium.

Extrapolating Table 4.11 to the present 30-dpm urine sample analysis sensitivity indicate that a routine bioassay monitoring program with an annual urine sampling frequency will be capable of detecting an approximate 80-mrem committed effective dose equivalent for class $\mathrm{D}{ }^{90} \mathrm{Sr}$, with the first-year effective dose equivalent being about $11 \mathrm{mrem}$. For class $Y$ material, such 
TABLE 4.11. Bioassay Detection Capability for an Acute ${ }^{90}$ Sr Intake ${ }^{(a)}$ Based on a 2-dpm Urine Sample Analysis Sensitivity

\begin{tabular}{|c|c|c|c|c|c|c|}
\hline $\begin{array}{l}\text { Days Post } \\
\text { Intake }\end{array}$ & $\stackrel{\mathrm{I}}{\mathrm{nC} i}$ & $\begin{array}{l}\mathrm{H}_{\mathrm{E}, 1}, \\
\text { mrem } \\
\end{array}$ & $\begin{array}{l}\mathrm{H}_{\mathrm{E}, 50}^{\mathrm{C}}, \\
\text { mrem } \\
\end{array}$ & $\begin{array}{c}\mathrm{I} \\
\mathrm{nC} i\end{array}$ & $\begin{array}{l}{ }_{E, 1}, \\
\underline{\text { mrem }}\end{array}$ & $\begin{array}{l}{ }^{H_{E}^{C}, 50} \\
\text { mrem } \\
\end{array}$ \\
\hline 1 & 0.018 & $6.1 E-4$ & $4.0 E-3$ & 1.1 & 0.35 & 1.4 \\
\hline 2 & 0.023 & $7.4 \mathrm{E}-4$ & $5.1 E-3$ & 1.4 & 0.45 & 1.8 \\
\hline 5 & 0.043 & $1.4 E-3$ & $9.5 E-3$ & 2.5 & 0.80 & 3.3 \\
\hline 7 & 0.060 & $1.9 E-3$ & 0.013 & 3.6 & 1.2 & 4.7 \\
\hline 14 & 0.19 & $6.0 \mathrm{E}-3$ & 0.041 & 9.9 & 3.2 & 13 \\
\hline 30 & 1.6 & 0.053 & 0.36 & 43 & 14 & 56 \\
\hline 60 & 5.6 & 0.18 & 1.2 & 60 & 19 & 78 \\
\hline 90 & 6.9 & 0.22 & 1.5 & 60 & 19 & 78 \\
\hline 180 & 12 & 0.38 & 2.6 & 64 & 21 & 83 \\
\hline 365 & 24 & 0.76 & 5.2 & 64 & 21 & 84 \\
\hline 730 & 56 & 1.8 & 12 & 69 & 22 & 90 \\
\hline 1830 & 153 & 4.9 & 34 & 120 & 38 & 156 \\
\hline
\end{tabular}

(a) Assumes 1- $\mu$ m-AMAD particle size.

a program would only be capable of detecting a 1300-mrem committed effective dose equivalent and a 310-mrem first-year effective dose equivalent. Although some increase in the program capability can be achieved by more frequent Sampling, the relatively small improvements so indicated in Table 4.11 imply that a more sensitive analytical procedure might be more cost effective than changes in sampling frequency. A biennial sampling frequency for Class D material would be capable of detecting a 50-year committed effective dose equivalent of 230 mrem with a first-year dose of 27 mrem.

If gamma-emitting nuclides such as ${ }^{137} \mathrm{Cs}$ are also of potential concern, the impact of mixtures on potentially undetected effective dose equivalent must also be addressed. If other means (e.g., in vivo measurements) are used to monitor for other nuclides, then annual urine samples should be sufficient to monitor the ${ }^{90} \mathrm{Sr}$ contribution to dose. 


\subsubsection{Special Monitoring for Suspected Exposures}

If exposure to ${ }^{90} \mathrm{Sr}$ has occurred or is suspected to have occurred, one or more urine samples should be scheduled for investigation purposes. Because of the high sensitivity of the urine sample analysis, even slight intakes of ${ }^{90} \mathrm{Sr}$ resulting in small fractions of a mill irem annual or 50-year committed effective dose equivalent can be detected if prompt sampling is performed. This also permits the use of less sensitive analytical procedures (i.e., rapid processing analyses) for reasonably accurate dose estimates.

Isotopic strontium analyses should be considered for any potential exposures to ${ }^{89} \mathrm{Sr}$. However, if more than 1 year has elapsed since the production of ${ }^{89} \mathrm{Sr}$, that isotope is unlikely to be a dosimetric concern due to its short radiological half-life.

In vivo measurements should also be considered following potential ${ }^{90} \mathrm{Sr}$ exposures because generally ${ }^{90} \mathrm{Sr}$ is likely to be mixed with other nuclides.

For relatively small intakes, fecal samples for strontium are not likely to be warranted because of the high degree of systemic uptake and the ease of detection by urine sampling. If major intakes are suspected, fecal samples combined with urine samples may provide more accurate estimates of intake, particularly if the intake is thought to contain some nontransportable strontium.

\subsection{INTERNAL DOSE ASSESSMENT FOR STRONIIUM NTAKES}

The following subsections discuss the general approach to strontium internal dosimetry, including how to estimate intake based on urine excretion data, specification of organs of concern, and dose equivalent calculations.

\subsubsection{General Approach}

For Hanford applications, ${ }^{90} \mathrm{Sr}$ and its ${ }^{90} \mathrm{Y}$ decay product have generally been the isotopes of greatest concern for strontium dosimetry. As noted in the previous sections, ${ }^{89} \mathrm{Sr}$ ma also be a concern under some conditions. This section outlines a general approach for any strontium dosimetry evaluation. Estimates of the magnitude of a strontium intake can be made using urine data and the excretion function. However, because of the sophistication of the 
strontium retention function, hand calculation of doses is quite complex, requiring the integration of simultaneous differential equations. Therefore, for practical purposes the organ and effective dose equivalent calculations are made using factors obtained from the GENMOD computer code.

Both ${ }^{89} \mathrm{Sr}$ and ${ }^{90} \mathrm{Sr}-\mathrm{Y}$ are essentially pure beta-emitters; therefore, the dosimetry for them must generally be based on excreta sample analysis. In vivo measurements can be of some use if the activity relationship relative to a gamma-emitter, such as ${ }^{137} \mathrm{Cs}$, is known, or if sufficient strontium activity is present to produce measurable bremsstrahlung radiation.

The general protocol for strontium dosimetry proceeds as follows:

- Estimate the intake based on urine excreta analyses and the appropriate intake excretion function.

- Estimate annual tissue and effective doses using factors from the GENMOD computer code.

When estimated intakes and associated doses are a relatively small fraction of the applicable radiation protection limit, direct application of the biokinetic models and dosimetry factors without modification for individualspecific considerations is appropriate. As intakes and doses become more significant, it is appropriate to give correspondingly greater attention to those individual-specific details.

\subsubsection{Estimating Intake}

The intake for strontium is estimated by fitting the urinary excretion data to the appropriate intake excretion function, using manual or computerized techniques. For single data points, the intake can be estimated by dividing the measured excretion by the value of the intake excretion function on the day post intake that the sample represents, as shown in Equation (4.1):

$$
I=M_{u}(t) / e_{u}^{i}(t)
$$

where $I$ is the intake, $\mathbf{M}_{\mathbf{u}}(t)$ is the observed urinary excretion of strontium on day $t$, and $e_{u}^{\prime}(t)$ is the fractional intake excretion function (for urine) on day $t$ (obtained from Figure 4.3, Table 4.4, or directly from the GENMOD 
computer code). For multiple data points, a least-squares fit of the data to the expected excretion function should be used, as described in Appendix C.

In addition to their use for dose calculations, class $D$ or $Y$ inhalation intakes calculated by the above techniques may also be compared with the ICRP Annual Limits on Intake (ALIs) or intake estimates based on air sample results.

\subsubsection{Calculating Orqan and Effective Dose Equivalents}

Dose assessments include calculation of annual and committed effective dose equivalents, as well as dose equivalents to specific organs of concern based on criteria presented in the Hanford Internal Dosimetry Program Manual. (a) (See also Appendix B.)

Doses to the organs of interest can be calculated for any given time post intake by multiplying the intake by the appropriate intake dose equivalent factor. The intake dose equivalent factors may be those in Tables 4.7 or 4.8 , or may be obtained directly from the GEMOD computer code.

\subsubsection{Systemic Deposition Estimate}

With the advent of the new requirements for organ and effective dose equivalent assessment, the calculation and reporting of strontium systemic depositions for comparison to the ICRP 2 (1959) MPBB is no longer required. By using the intake excretion function technique described in this section, the calculation of systemic deposition is bypassed. Previous evaluations of systemic deposition performed using the previously discussed Dolphin technique can be converted to a readily transportable injection intake (or total uptake) by dividing the long-term (or permanent) systemic deposition by 0.15 . If the mode of intake was inhalation, then the total uptake must also be divided by the ratio of total uptake to class $D$ inhalation intake $(0.48$, for 1- $\mu \mathrm{m}$-AMAD particles).

(a) Pacific Northwest Laboratory. 1989. Hanford Internal Dosimetrv Program Manual. PNL-MA-552, Richland, Washington. 


\subsubsection{Simplified Dose Assessments}

Simplified dose assessments use the techniques and biokinetic models described previously and assume ICRP 23 (1974) Reference Man parameters, without correction for individual-specific characteristics. These assessments provide a basis for prospective bioassay program design and retrospective evaluation of doses that are small relative to the occupational exposure limits. In addition, the excretion associated with simplified assessments can be used as a trigger point for more in-depth measurements or dose assessments.

The procedure for performing a .simplifieddose assessment is as follows:

1. Normalize the result to daily excretion rate.

2. Select the intake date (known or assumed).

3. Estimate intake by fitting the data to excretion model.

4. Calculate dose equivalents by multiplying the estimated intake by the appropriate intake dose equivalent factor from GENMOD.

Intakes and the associated urinary excretions have been evaluated using simplified dose assessments on a prospective basis for class D and $Y$ inhalations of ${ }^{90} \mathrm{Sr}$ resulting in the following doses:

- First-year effective dose equivalent of $10 \mathrm{mrem}$. Below this level the annual organ dose equivalents for each organ of concern are less than $100 \mathrm{mrem}$, and the 50-year committed effective dose equivalent is also less than 100 mrem.

- First-year effective dose equivalent of $100 \mathrm{mrem}$. Doses that exceed this level may merit attention to the individual-specific circumstances of the exposure. As higher doses are evaluated, the importance of these individual-specific details increases.

- 50-year committed effective dose equivalent of $100 \mathrm{mrem}$. Below this level it may be reasonable for compliance monitoring and record-keeping purposes to record the committed dose in the year of intake rather than the year in which it is actually incurred. Such recording is unlikely to significantly impact a worker's standing with regard to the stochastic and nonstochastic radiation protection limits.

The intakes associated with these doses are shown in Table 4.12. These intakes were then multiplied by the appropriate excretion function value 
TABLE 4.12. Simplified Dose Assessment Intakes for a 90 S. I Inhalation Intake, nCi

\begin{tabular}{ccccc} 
Associated Dose Equivalent & & Class D & & Class Y \\
\cline { 1 - 1 } 10 mrem First-Year Effective & & 310 & & 31 \\
100 mrem First-Year Effective & & 3100 & & 310 \\
100 mrem 50-Year Committed & & 460 & & 77
\end{tabular}

from Table 4.4 to calculate the expected urinary excretion. The anticipated urinary excretions resulting from these intakes are shown for selected times post intake in Tables 4.13 and 4.14.

Based on the preceding discussions, action levels for tailoring dose assessments based on individual-specific characteristics can be established for routine bioassay monitoring. By assuming that an inhalation intake occurs immediately following a routinely scheduled sample, the number of days post intake becomes the same as the number of days between samples.

TABLE 4.13. Excretion Associated with ${ }^{90}$ Sr Class D Acute Inhalation of $1-\mu \mathrm{m}$-AMAD Particles

\begin{tabular}{|c|c|c|c|}
\hline $\begin{array}{l}\text { Days Post } \\
\text { Intake }\end{array}$ & $\begin{array}{l}10 \text { mrem } \\
\text { First Year, } \\
\text { dpm/day } \\
\end{array}$ & $\begin{array}{l}100 \text { mrem } \\
\text { First Year, } \\
\text { dpm/day }\end{array}$ & $\begin{array}{c}100 \text { mrem } \\
\text { Committed } 50-\text { Year, } \\
\text { dpm/day }\end{array}$ \\
\hline 1 & 35,000 & 350,000 & 50,000 \\
\hline 2 & 27,000 & 270,000 & 39,000 \\
\hline 5 & 15,000 & 150,000 & 21,000 \\
\hline 7 & 10,000 & 100,000 & 15,000 \\
\hline 14 & 3,300 & 33,000 & 4,800 \\
\hline 30 & 380 & 3,800 & 560 \\
\hline 60 & 110 & 1,100 & 160 \\
\hline 90 & 90 & 900 & 130 \\
\hline 180 & 53 & 530 & 77 \\
\hline 365 & 26 & 260 & 38 \\
\hline 730 & 11 & 110 & 17 \\
\hline 1825 & 4.1 & 41 & 6.0 \\
\hline
\end{tabular}




\begin{tabular}{|c|c|c|c|}
\hline \multirow[b]{2}{*}{$\begin{array}{l}\text { Days Post } \\
\text { Intake }\end{array}$} & \multicolumn{3}{|c|}{$\begin{array}{l}\text { Excretion Associated with }{ }^{90} \text { Sr Class Y } \\
\text { Acute Inhalation of } 1-\mu \mathrm{m}-\mathrm{AM} A \mathrm{D} \text { Particles } \\
\text { Effective Dose Equivalent }\end{array}$} \\
\hline & $\begin{array}{c}10 \text { mrem } \\
\text { First Year, } \\
\text { dpm/day } \\
\end{array}$ & $\begin{array}{c}100 \text { mrem } \\
\text { First Year, } \\
\text { dpm/day } \\
\end{array}$ & $\begin{array}{c}100 \text { mrem } \\
\text { Committed } 50-\text { Year, } \\
\mathrm{dpm} / \mathrm{day} \\
\end{array}$ \\
\hline 1 & 58 & 580 & 140 \\
\hline 2 & 45 & 450 & 100 \\
\hline 5 & 25 & 250 & 62 \\
\hline 7 & 17 & 170 & 43 \\
\hline 14 & 6.3 & 63 & 16 \\
\hline 30 & 1.5 & 15 & 3.6 \\
\hline 60 & 1.0 & 10 & 2.6 \\
\hline 90 & 1.0 & 10 & 2.6 \\
\hline 180 & 1.0 & 9.7 & 2.4 \\
\hline 365 & 1.0 & 9.7 & 2.4 \\
\hline 730 & 0.90 & 9.0 & 2.2 \\
\hline 1825 & 0.52 & 5.2 & 1.3 \\
\hline
\end{tabular}

The class $D$ inhalation is suitable for monitoring potential transportable injection uptakes because the excretions associated with identical doses are not significantly different.

\subsection{MANAGEMENT OF POTENTIAL INTERNAL CONTAMINATION CASES}

The diagnostic procedures, therapeutic actions, and long-term monitoring of internal deposition are discussed in the following subsections on the management of potential internal contamination cases.

\subsubsection{Diagnostic Procedures}

A worker who may have received an internal contamination of strontium should be scheduled for a whole body count and a single voiding or an overnight urine sample. These initial measurements can be used to confirm an intake and provide preliminary estimates of the magnitude of potential doses. However, as noted in previous sections, the in vivo measurements are for the 
detection of gamma-emitting nuclides, which may or may not be indicative of ${ }^{90} \mathrm{Sr}$. A potential intake of ${ }^{90} \mathrm{Sr}$ is best indicated by the results of the overnight or single voiding sample.

The evaluation of the magnitude of a ${ }^{90} \mathrm{Sr}$ intake should be based on two or more urine samples (representing actual or simulated 24-hour periods) collected over several days or weeks following the intake. The sample results should be evaluated using the techniques of Section 4.5.

\subsubsection{Therapeutic Actions}

Therapeutic actions to prevent the uptake of strontium are based primarily on reducing GI tract absorption and accelerating the passage of material through the GI tract. These measures are addressed in NCRP 65 (1980) and require administration under medical supervision. Aluminum phosphate gel and sodium alginate are the drugs identified by NCRP 65 as being potentially effective in reducing the GI tract uptake of strontium. Accelerating the passage of material through the GI tract can be accomplished by use of laxatives and enemas. These measures can only be taken at the direction of HEHF Occupational Medicine.

\subsubsection{Lonq-Term Monitoring of Internal Deposition}

Long-term monitoring of urinary excretion fol lowing a ${ }^{90} \mathrm{Sr}$ intake may be required to validate the excretion model or to ensure that potential additional intakes do not go undetected. The establishment of a sampling frequency for such monitoring is dependent upon the nature of the exposure, magnitude of deposition, and likelihood for additional exposure. Appropriate long-term follow-up monitoring should be determined as part of the exposure evaluation. 

SECTION 5.0

\section{CESIUM}





\subsection{CESIUM}

This section provides technical information on the sources, characteristics, and biokinetics of radiocesium and summarizes the technical basis used for its internal dosimetry at Hanford.

\subsection{SOURCES AND CHARACTERISTICS OF RADIOCESIUM}

The most important radionuclides of cesium at Hanford from an internal exposure standpoint are ${ }^{134} \mathrm{Cs}$ and ${ }^{137} \mathrm{Cs}$. Cesium-137 ( $\mathrm{T} 1 / 2=30.0 \mathrm{yr}$ ), a fission product, is the primary cesium isotope of interest with respect to internal exposure. Cesium-134 ( $\left.\mathrm{T}_{1 / 2}=2.1 \mathrm{yr}\right)$, produced by neutron activation of ${ }^{133}$ Cs (stable), is usually observed at activities on the order of less than $5 \%$ of the ${ }^{137}$ Cs activity.

Because of its relatively high fission yield and its long half-life, ${ }^{137} \mathrm{Cs}$, along with ${ }^{90} \mathrm{Sr}$, is one of the most abundant radionuclides in aged fission product mixtures. More volatile than most of the longer-1ived fission product radionuclides, cesium is more apt to escape containment or confinement and is commonly the most abundant radionuclide found in fission product releases within a facility. As discussed later, ${ }^{137} \mathrm{Cs}$ is easily detected using in vivo bioassay techniques and thus serves as a good indicator of internal exposure to fission products.

In addition to its presence in fission product mixtures, ${ }^{137} \mathrm{Cs}$ exists in relatively pure form at the waste fractionation facility (B-Plant) and the WESF. Encapsulation programs in WESF have been terminated; however, cesiumbearing capsules and cesium-contaminated equipment are stored in the facility.

Cesium has been found to be more dispersible than strontium, and therefore in most internal exposure situations involving ${ }^{137} \mathrm{Cs}$ and ${ }^{90} \mathrm{Sr},{ }^{137} \mathrm{Cs}$ will constitute the major component of intake. In cases where it is suspected that ${ }^{90} \mathrm{Sr}$ may be present along with ${ }^{137} \mathrm{Cs}$ but no radionuclide ratio information exists, it is prudent to consider the ${ }^{137} \mathrm{Cs} /{ }^{90} \mathrm{Sr}$ activity ratio to be 1.0 and to determine the need for specific assessment of strontium exposure accordingly. 


\subsection{BIOKINETIC BEHAVIOR OF RADIOCESIUM}

ICRP 30 (1979) classifies all isotopes of cesium as class D, indicating that inhaled material will be absorbed rapidly from the respiratory tract into the circulatory system. This is consistent with observations at Hanford. From the blood, cesium is distributed uniformly in the body with no organ showing a higher concentration than muscle. For dose assessment purposes, cesium is assumed to be completely and rapidly absorbed into systemic circulation from both the respiratory tract and the GI tract. The soluble nature of cesium makes aerosol particle size of little importance from a bioassay and dosimetric standpoint. For purposes of biokinetic modeling, airborne particulates are assumed to have an AMAD of $1 \mu \mathrm{m}$.

ICRP 30 recommends the following equation for the retention of cesium following systemic uptake:

$$
r_{s}^{a}(t)=0.1 \exp ^{-}\left(\frac{0.693 t}{2}\right)+0.9 \exp ^{-}\left(\frac{0.693 t}{110}\right)
$$

where $r_{s}^{a}(t)$ is the fraction of the initial uptake that is present in the body at $\mathbf{t}$ days post uptake.

\subsection{INTERNAL DOSIMETRY FOR RADIOCESIUM}

Because cesium is assumed to be distributed evenly throughout soft tis sues in the body, the stochastic dose equivalent (effective dose equivalent) will be limiting for compliance purposes. Dose conversion factors for the radiocesiums were developed by Snyder et a1., and published in ORNL-5000 (1975). These factors include the "total body dose" from activity deposited in the total body. Dosimetrically, this represents the most straightforward and technically appropriate way to express the total dose equivalent to the body when a radionuclide is uniformly distributed. The effective dose equivalent is derived from the "total body dose" by using a weighting factor of 1.0 for the total body as an organ. That is, the effective dose equivalent is equal to the "total body dose." The computer code GEMOD is used for internal dose calculations at Hanford (Johnson and Carver 1981; see Appendix A). The 
code employs the dose factors in ORNL-5000 for radiocesiums and the biokinetic model of the ICRP. In contrast, effective dose equivalents for radiocesiums calculated and published in supplements to ICRP 30 are based on the summing of weighted doses to specific organs meeting the ICRP criteria for inclusion in the effective dose equivalent (Watson and Ford 1980). Dose factors calculated in this way are slightly higher (about 10\%) than those obtained using GEMOD and this difference is attributed to conventions used by the ICRP rather than to technical merit. Thus, the use of total body dose factors is considered to be more appropriate for assessing effective dose equivalent to radiocesiums. These dose factors, from ORNL-5000, are

$$
\begin{aligned}
& \operatorname{DCF}\left({ }^{134} \mathrm{Cs}\right)=5.1 \mathrm{E}-7 \mathrm{rem} / \mathrm{nC} \mathrm{i}-\mathrm{day}, \\
& \mathrm{DCF}\left({ }^{137} \mathrm{Cs}\right)=3.2 \mathrm{E}-7 \mathrm{rem} / \mathrm{nC} \mathrm{i}-\text { day } .
\end{aligned}
$$

Because cesium distributes relatively uniformly in the body, the dose received by individual organs and tissues is about the same as the total body dose. Thus, the dose received by specific organs and tissues can be assumed to be equivalent to the total body dose equivalent.

Integrating the retention function (Equation 5.1) with respect to time yields the cumulated internal activity in activity-days, and multiplying this times the DCF and the initial uptake $\left(U_{0}\right)$ yields the effective dose equivalent over the time period of interest:

$$
H_{E, t}^{C}(\text { rem })=U_{0} \cdot \operatorname{DCF} \cdot\left[0.1\left(\frac{1-\exp ^{-\lambda} e_{f f 1}^{t}}{\lambda_{\text {eff1 }}}\right)+0.9 \frac{\left(1-\exp ^{-\lambda} e_{f f 2}^{t}\right)}{\lambda_{e f f 2}}\right]
$$

where $\quad \mathbf{t}=$ days post initial deposition

$$
\begin{aligned}
& \lambda_{\text {eff1 }}(134)=0.35 / \text { day } \\
& \lambda_{\text {eff1 }}(137)=0.35 / \text { day } \\
& \lambda_{\text {eff2 }}(134)=0.0072 / \text { day } \\
& \lambda_{\text {eff2 }}(137)=0.0064 / \text { day }
\end{aligned}
$$


The $\lambda_{\text {eff }}$ values provided above are based on ICRP recommendations. However, for retrospective dose assessments, $\lambda_{\text {eff }}$ values may be empirically determined from whole body counts as described in Section 5.4.

Equations 5.1 and 5.2 are specifically for the calculation of internal dose equivalent following acute uptakes of ${ }^{134} \mathrm{Cs}$ or ${ }^{137} \mathrm{Cs}$. In actuality, most uptakes occur following inhalation of airborne contamination and deposition in the lung precedes systemic uptake. Nevertheless, for exposures to readily transportable forms of cesium (class D) the dose received by the lung is negligible in comparison to the total body dose and can generally be ignored for dose assessment purposes. The exception to this is in cases where actual retention in the respiratory tract exceeds a few days. In these situations, and as a general application, the computer code GENMOD includes the lung in the effective dose equivalent.

Table 5.1 gives the first-year and 50-year committed effective dose equivalents following an intake or uptake of radiocesium calculated using Equation 5.2. About 90\% of the 50-year committed effective dose equivalent is received within the first year after intake.

Table 5.2 gives the activity of ${ }^{134} \mathrm{Cs}$ and ${ }^{137} \mathrm{Cs}$ in the body following an uptake sufficient to result in a first-year effective dose equivalent of 10 mrem. The table also gives the internal activity of ${ }^{137} \mathrm{Cs}$ following an intake of equal activities of ${ }^{137} \mathrm{Cs}$ and ${ }^{90} \mathrm{Sr}$ resulting in a first-year

TABLE 5.1. Predicted Effective Dose Equivalent Resulting from an Inhal at ion $(a, b)$ or Uptake of Radiocesium, $\mathrm{mrem} / \mathrm{nCi}$

\begin{tabular}{|c|c|c|c|c|}
\hline \multirow[b]{3}{*}{ Nucl ide } & \multicolumn{2}{|c|}{$\begin{array}{l}\text { First-Year Effective } \\
\text { Dose Eaui valent } \\
\end{array}$} & \multicolumn{2}{|c|}{$\begin{array}{l}\text { 50-Year Committed } \\
\text { Dose Eaui valent }\end{array}$} \\
\hline & & & & ion \\
\hline & Intake & Uptake & Intake & Uptake \\
\hline${ }^{134} \mathrm{Cs}$ & 0.043 & 0.068 & 0.046 & 0.073 \\
\hline${ }^{137} \mathrm{Cs}$ & 0.026 & 0.041 & 0.028 & 0.045 \\
\hline
\end{tabular}

(a) Assuming an inhalation of class D, 1- $\mu \mathrm{m}-\mathrm{AMAD}$ aerosol.

(b) Organ dose equivalents are assumed to be the same as the effective dose equivalent. 
TABLE 5.2. Total Body Activity Following an Acute Uptake or Class D Inhalation Intake Resulting in a First-Year Effective Dose Equivalent of $10 \mathrm{mrem}$

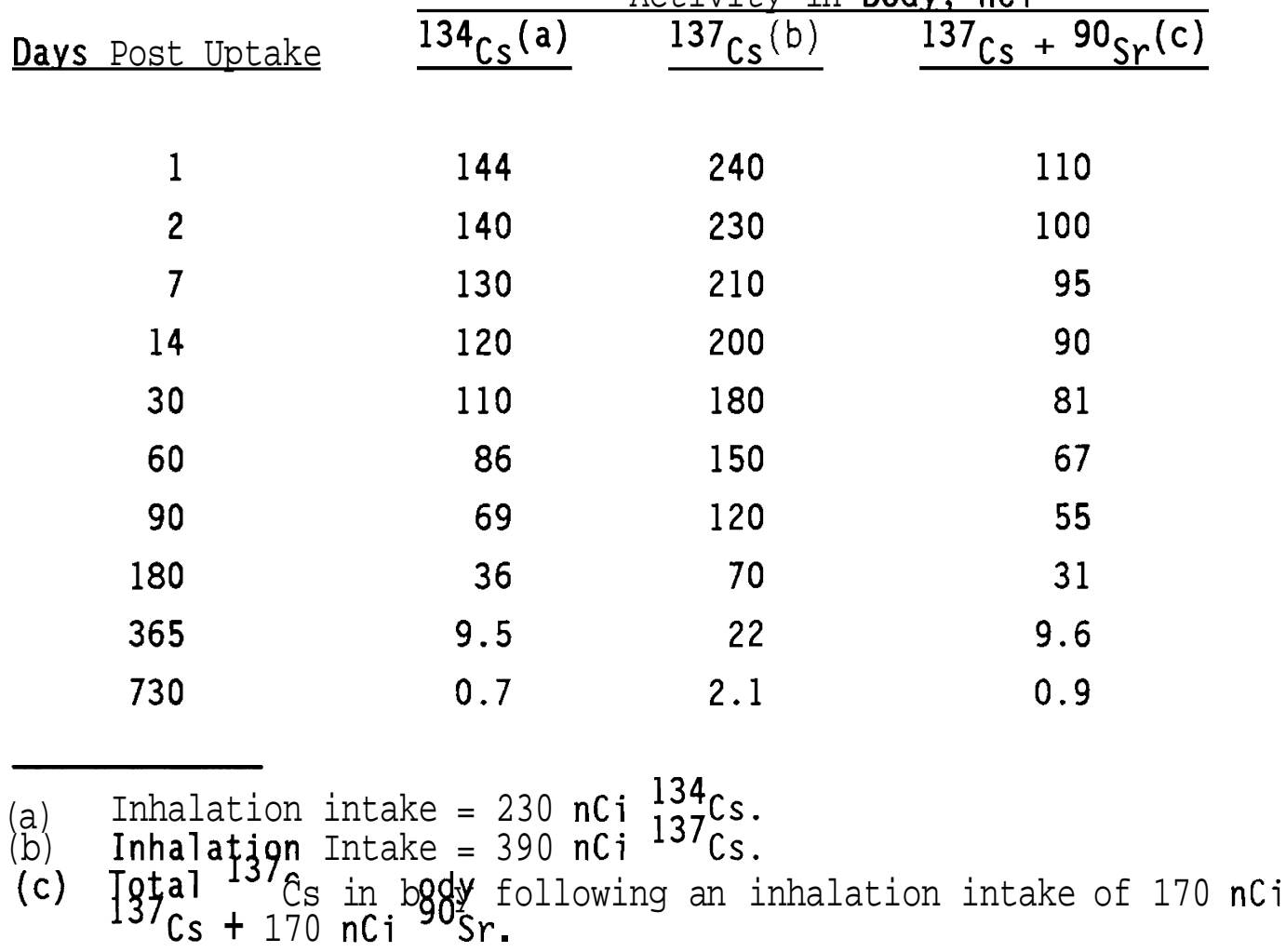

effective dose equivalent of $10 \mathrm{mrem}$. This information is presented graphically in Figure 5.1. Because fission product mixtures may include ${ }^{90} \mathrm{Sr}$, as well as ${ }^{137} \mathrm{Cs}$, the detection of the presence of ${ }^{137} \mathrm{Cs}$ in the body should be regarded as an indication of a potential exposure to ${ }^{90} \mathrm{Sr}$ as wel1. Thus, if internal levels exceed those for cesium/strontium in Table 5.2, bioassay measurement and assessment for ${ }^{90} \mathrm{Sr}$ as described in section 4.0 is recom-mended. Consideration should be given to the individual's routine bioassay monitoring schedule for ${ }^{90} \mathrm{Sr}$ when deciding action to be taken regarding ${ }^{90} \mathrm{Sr}$ bioassay following detection of ${ }^{137} \mathrm{Cs}$ in the body.

The ICRP 30 annual 1 imits on intake (ALIs) for class $D{ }^{137} \mathrm{Cs}$ and ${ }^{134} \mathrm{Cs}$ are $200 \mu \mathrm{C}$ and $100 \mu \mathrm{C}$, respectively. 


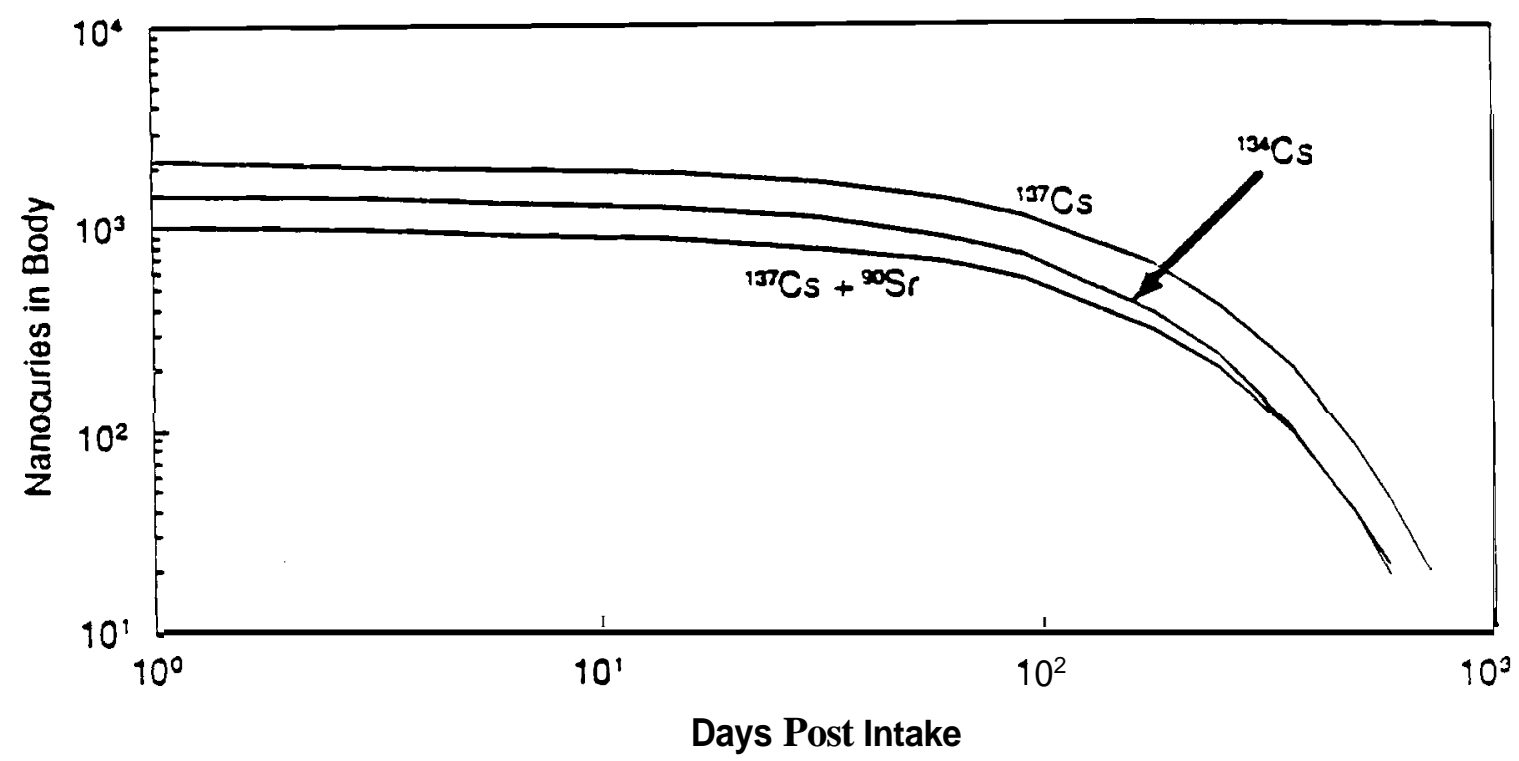

FIGURE 5.1. Activity in Body Following an Uptake Resulting in a First-Year Effective Dose Equivalent of 100 mrem

\subsection{BIOASSAY FOR RADIOCESIUM}

The bioassay techniques, the recommended routine program, and the measurements required for monitoring radiocesium after an acute intake, are discussed in the following subsections.

\subsubsection{Bioassay Methods}

The presence of radiocesium is detected by in vivo measurements and in some cases excreta analysis.

\section{$\underline{\text { In Vivo Measurements }}$}

Whole body counting using the 5-Nal detector preview counter for a 3-minute count will detect the presence of $3 \mathrm{nCi}$ of ${ }^{137} \mathrm{Cs}$ in the body of a male subject of average size (Palmer et al. 1990).

Table 5.3 summarizes the capability of a standard whole body count for various times after a single acute intake. From the table, it is evident that an annual in vivo measurement with a detection level of $3 \mathrm{nCi}$ for ${ }^{134} \mathrm{Cs}$ or ${ }^{137}$ Cs would be capable of detecting an intake resulting in an annual or a committed effective dose equivalent of less than $4 \mathrm{mrem}$. Similarly, an intake 
TABLE 5.3. Bioassay Detection Capability for an Acute Intake
of ${ }^{34} C_{S}$ or $137 \mathrm{CS}(a)$ First-Year and Fiftv-Year Committed Effective Dose Eq., mrem

Days Post

Intake

30
90
180
365
730

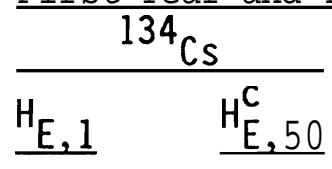

0.27

0.43

0.83

3.2

43.0
0.29

0.47

0.90

3.4

46.0

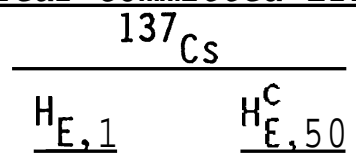

0.17

0.24

0.43

1.4

14
$-{ }^{137} \mathrm{Cs}^{9}{ }^{90} \mathrm{Sr}$ (b) $\underline{H_{E, 1}} \quad \underline{H_{E, 50}^{C}}$

$0.37 \quad 1.6$

$0.54 \quad 2.3$

$0.96 \quad 4.1$

$3.1 \quad 13.0$

$32 \quad 14$

(a) Detectable dose for a single intake of class D, 1- $\mu \mathrm{m}-\mathrm{AMAD}$ particles

(b) Assuming equal intakes of ${ }^{137} \mathrm{Cs}$ and ${ }^{90} \mathrm{Sr}$.

involving a $1: 1$ mixture of ${ }^{137} \mathrm{Cs}$ and ${ }^{90} \mathrm{Sr}$ would be detectable at the 13 -mrem committed effective dose equivalent level.

\section{Excreta Anal vsis}

Urine measurements may be used to detect internal cesium; however, because of the sensitivity of in vivo detection methods, there are no likely circumstances where urine sampling will improve the sensitivity or accuracy of internal dose assessment. Urine sampling for ${ }^{90} \mathrm{Sr}$ should be considered if there is reason to suspect its presence along with cesium.

\subsubsection{Routine Bioassay Monitoring Program}

Annual in vivo measurements are recommended for periodic retrospective bioassay monitoring of workers potentially exposed to mixtures of radionuclides containing radiocesium. Even though in vivo measurement capabilities are sufficiently sensitive for a biennial frequency (see Table 5.3), the longer time between measurements makes investigation of potential exposures more difficult, and thus a minimum annual frequency is recommended.

If radiocesium is detected through a routine measurement, then followup measurements to confirm the initial indication should generally be performed. Follow-up measurements can usually be most conveniently performed 
immediately following the initial measurement, while the subject is at the IVRRF. Follow-up measurements should be performed as promptly as practical following an indication of an intake in order to facilitate any health physics investigation associated with the potential exposures. However, because of the high sensitivity of the in vivo measurement, confirmatory measurements are technically capable of detecting a 100-mrem first-year effective dose equivalent for up to 3 years following the intake.

Follow-up in vivo measurements using high-resolution germanium detectors are preferred in order to identify other radionuclides possibly associated with the exposure and because the germanium detectors are considered to provide a more precise and accurate measurement. Detection capabilities for the germanium detectors are comparable to those obtained using the preview counter (Palmer et al. 1990). In addition to follow-up in vivo measurements, urinalysis for ${ }^{90} \mathrm{Sr}$ should be considered if internal levels of ${ }^{137} \mathrm{Cs}$ exceed those shown for the cesium/strontium mixture in Table 5.2.

\subsubsection{Bioassav Measurements Following an Acute Intake}

An in vivo examination should be performed following any indication of an intake of radiocesium. Unless the exposure appears to be of such magnitude that medical treatment to aid removal is considered, the exam may be scheduled as convenient within several days of the intake. All radionuclides potentially involved in the exposure should be considered in the follow-up investigation. Urinalysis for ${ }^{90} \mathrm{Sr}$ should also be considered.

The interpretation of in vivo measurements performed shortly after intake may be complicated by early transport of material through the lung and GI tract. Measurements performed after about 5 days post intake are more appropriate for dose evaluation. For intakes potentially above $100 \mathrm{mrem} / \mathrm{yr}$ (considering all radionuclides contributing), long-term follow-up bioassay measurements should be considered to monitor internal radioactivity levels and establish individual retention characteristics.

For the purposes of determining the dose from a radiocesium intake, excreta analysis is generally not necessary. 


\subsection{ASSESSMENT OF INTERNAL DOSE EQUIVALENT}

The assessment of the internal dose equivalent from ${ }^{137} \mathrm{Cs}$ is accomplished by evaluation of in vivo measurement results. Dose equivalents are assessed for any confirmed internal exposure not attributed to environmental or other non-occupational sources.

Table 5.2 provides whole body count levels for several routine in vivo monitoring frequencies that could be expected following an inhalation intake resulting in a first-year effective dose equivalent of $100 \mathrm{mrem}$. The values in the table were calculated assuming a single acute inhalation intake. The table provides values for ${ }^{134} \mathrm{Cs},{ }^{137} \mathrm{Cs}$, and a mixture of ${ }^{137} \mathrm{Cs}$ and ${ }^{90} \mathrm{Sr}$; and it was assumed that the inhaled aerosol consisted entirely of class D particulate with an AMAD of $1 \mu \mathrm{m}$. Because ${ }^{137} \mathrm{Cs}$ is often associated with mixtures of fission product radionuclides, it is prudent, upon the initial review of bioassay measurement results, to assume that the intake consisted of a mixture of ${ }^{137} \mathrm{Cs}$ and ${ }^{90} \mathrm{Sr}$ with an activity ratio of 1.0 . Assessment of internal deposition of ${ }^{90} \mathrm{Sr}$ using urinalysis is recommended when ${ }^{137} \mathrm{Cs}$ levels are above those shown in Figure 5.1 for intakes of cesium/strontium mixtures. This conservative approach is not necessary when it is known that only ${ }^{137} \mathrm{Cs}$ is available for intake or when actual ${ }^{90}$ Sr urinalysis results are available.

Equations $5.3 \mathrm{a}$ and $5.3 \mathrm{~b}$ give the 50 -year committed effective dose equivalent, $H_{E, 50}^{\mathrm{C}}$ for ${ }^{134} \mathrm{Cs}$ and ${ }^{137} \mathrm{Cs}$ as a function of total body activity, $Q(t)$, at time $\mathbf{t}$ post intake.

$$
\begin{aligned}
& H_{E, 50}^{C}\left({ }^{134} C s\right)=0.073^{*} Q(t) / r_{s}^{a}(t) \text { mrem } \\
& H_{E, 50}^{C}\left({ }^{137} C s\right)=0.045^{*} Q(t) / r_{s}^{a}(t) \text { mrem }
\end{aligned}
$$

where $r_{s}^{a}(t)$ is the retention function given by Equation 5.1.

The equation is appropriate for use to assess internal dose equivalents for radiocesium intakes that do not exceed $100 \mathrm{mrem} / \mathrm{yr}$. It is also appropriate for the assessment to assume, in the absence of a known date of intake, that the intake was an acute inhalation occurring at the midpoint of the 
period during which an intake is considered to be possible. Thus, for an annual routine in vivo measurement, a positive ${ }^{137}$ Cs result would be assessed assuming the intake occurred 6 months prior to the measurement. For assessments involving intake times not shown in the table, doses may be calculated using the GENMOD code.

Assessments of internal dose equivalent that potentially exceed an annual effective dose equivalent of $100 \mathrm{mrem} / \mathrm{yr}$ should be based on observed retention to the extent practicable. The ICRP 30 model for uptake and retention of cesium has been described previously. The rapidly clearing compartment has little effect on the total dose equivalent received from an intake and can be ignored in retrospective dose assessments based on observed in vivo retention. Cumulated activity, obtained by integrating the observed retention curve based on repeated in vivo measurements, is multiplied by the DCF given for Equation 5.2 to obtain the effective dose equivalent for the period covered. As an alternative approach, default biokinetic assumptions regarding internal deposition and retention of cesium can be modified to obtain a better fit between the observed retention data and the model. The modified model is then used to calculate annual dose equivalents. The computer code GENMOD is used for this type of assessment.

Because cesium distributes relatively uniformly in the body, the dose received by individual organs and tissues is about the same as the effective dose equivalent. To simplify the recording of doses to specific organs and tissues, the dose to uniformly distributed radionuclides is ascribed to a single organ category called "total body." That is, assessments of exposure to radiocesium will include the annual effective dose equivalent, which is the weighted composite organ dose equivalent, and the total body dose equivalent, which is the dose received by any organ. The total body dose equivalent is numerically equal to the effective dose equivalent. The "total body" designation thus serves as a surrogate for any specific organ or tissue in the body.

\subsection{MANAGEMENT OF INTERNAL CONTAMINATION CASES}

Although one of the most prevalent radionuclides at Hanford, historically ${ }^{137} \mathrm{Cs}$ has not contributed significantly to internal exposures. 
Cesium-134+137 are easily detected by whole body counting and therefore early measurement and assessment of internal depositions can be made readily. Primary considerations for interpretation of initial in vivo measurements are possible external contamination on the subject and the rapid translocation and elimination that occurs shortly after intake.

Being a major fission product radionuclide, ${ }^{137} \mathrm{Cs}$ is often accompanied by other fission product radionuclides. Thus, investigation of internal exposures involving ${ }^{137}$ Cs should also consider that other radionuclides may be involved.

The most effective measure for removal of cesium from the body is by oral administration of Prussian Blue. Prussian Blue is not absorbed from the intestine and $i t$ binds the cesium ions that are enterically cycled into the $G$ I tract, so that the cesium is not reabsorbed. The treatment can reduce the biological half-1ife to about one-third of its usual value. The effectiveness of the treatment is dependent on how soon after exposure it is started (NCRP 1980).

\subsection{ENVIRONMENTAL LEVELS OF CESIUM}

Cesium-137 is present throughout the world environment as a result of atmospheric testing of nuclear weapons and releases from the 1986 Chernobyl nuclear accident in the Ukraine. Elevated levels of ${ }^{137}$ Cs in caribou and reindeer have long been recognized as contributing to detectable levels in people who consume such meats, and fish have also been identified as concentrators of environmental cesium (NCRP 1977). Following the Chernobyl accident, levels of ${ }^{137} \mathrm{Cs}$ were widely reported in the literature (for example, Tarroni et al., 1990; Strand, et al. 1989; Lloyd 1990; and Kang 1989). Generally these levels were in the range of a few nanocuries, although Strand et al. indicated microcurie quantities in Lapps who breed reindeer.

Potential transfer of radioactivity through the food chain received wide attention following the Chernobyl accident. In 1989 the joint World Health Organization/Food and Agriculture Organization established a guideline level of $1000 \mathrm{~Bq} / \mathrm{kg}(27 \mathrm{nCi} / \mathrm{kg})$ for cesium contamination in foods moving in international trade (Health Phvsics 1989). 
The possible existence of ${ }^{137} \mathrm{Cs}$ at the foregoing levels complicates interpretation of the source of low-level cesium that might be detected in routine whole body examinations. An attempt should be made to ascertain whether the detected levels are most likely of occupational or environmental origin: if occupational, then dose assessment may be warranted; if environmental, then occupational dose assessment is not warranted.

For workers who consume large wild game on a regular basis it might be reasonable to conclude that a few nanocuries of ${ }^{137} \mathrm{Cs}$ may represent nonoccupuational intake. This can be further investigated if samples of meat can be obtained for direct assessment. However, even then conclusions may be tenuous because only limited data are available regarding expected variation throughout the Pacific Northwest and these data indicate over 3 orders of magnitude of variability.

Likewise, for a worker who has spent time in a location known to be potentially affected by elevated cesium levels (e.g., Europe, the Scandianvian countries, or Russia), it may also be reasonable to assume environmental exposure. Such exposure would probably result from consumption of locally obtained meat, dairy products, or produce. Consideration should be given to the location where one was exposed, length of time there, food consumption, and elapsed time since exposure in determining the likelihood that environmental sources were responsible for cesium intake.

For unknown sources of intake and circumstances where occupational intake seems unlikely, it may be prudent to estimate a dose as a matter of interest for the worker but not to assign it as an occupational dose. However, it should be emphasized that nonoccupational estimates based on measurements likely to be available through a routine occupational monitoring program are subject to large uncertainties regarding onset, duration, and nature of intake, and that standard assumptions used for occupational assessment are not necessarily applicable. Any in-depth assessment of nonoccupational exposure is usually beyond the scope of an occupational monitoring program. 
SECTION 6.0

\section{IODINE}





\subsection{IODINE}

Radioiodines generated or used at Hanford include isotopes with halflives ranging from minutes to millions of years in various physical and chemical forms. Internal radiation protection is achieved through the use of containment, ventilation, radioactive decay, and respiratory protection. Thus, exposures to radioiodines should only occur as a result of accident situations. This section provides information on the sources, characteristics and biokinetics of radioiodine and summarizes the technical basis used for its internal dosimetry at Hanford.

\subsection{SOURCES AND CHARACTERISTICS OF RADIOIODINE}

At Hanford the radioiodines of principal interest are ${ }^{131} \mathrm{I}$, associated with reactor operations, and ${ }^{125} \mathrm{I}$, associated with biological experimentation.

Although historically radioiodines were generated in large quantities during the operation of production reactors, the FFTF is currently the only generator of fission product radioiodine at Hanford. Iodine-131 is considered the most significant iodine radionuclide from an internal exposure standpoint. Several other radioactive isotopes of iodine are generated by the fission process; however, with the exception of the long-1ived ${ }^{129}$ I, the others are short-lived and of potential interest only during or within several days of reactor operation. Iodine-129 has, for practical purposes, an infinite half-life and is contained in irradiated fuel and associated separations and waste management facilities. However, unless concentrated by some means such as in the PUREX air treatment system, it is present in negligibly small quantities.

Iodine-125 is not generated at Hanford, but it is purchased for use in various biological research experiments. Thus, its use is generally limited to biology laboratories operated by PNL. Quantities of the isotope in use at one time are generally limited to amounts that could not result in significant internal exposures. 


\subsection{BIOKINETIC BEHAVIOR OF RADIOIODINE}

The distribution and retention model described in ICRP 30 (1979) and ICRP 54 (1988) can be used to predict the uptake, retention, and resulting doses following an intake of a radioiodine. Using the ICRP assumptions for iodine intakes (class D transportability and 100\% solubility in the GI tract), it is assumed that, for a 1- $\mu$ m-AMAD aerosol, 63\% of the intake is taken up into the circulatory system. The ICRP metabolic model, essentially the same one described by Riggs (1952), describes the deposition and retention of iodine in systemic compartments of the body. Of the iodine entering the systemic compartment, a fraction, 0.3 , is assumed to be translocated to the thyroid, while the remainder is assumed to go directly to excretion. Iodine in the thyroid is assumed to be retained with a biological half-1ife of 80 days and to be lost from the thyroid in the form of organic iodine. Organic iodine is assumed to be uniformly distributed among all organs and tissues of the body other than the thyroid and to be retained there with a biological half-life of 12 days. One-tenth of this organic iodine is assumed to go directly to fecal excretion and the rest is assumed to be returned to the transfer compartment as inorganic iodine so that the effective half-life in the thyroid is 120 days.

The above model was implemented using the computer code GENMOD (Johnson and Carver 1981; see Appendix A). Several modifications to the iodine "default" compartment parameters in the Iodine Model of GENMOD 3.2 were made to provide for better agreement with dose values in ICRP 30 and retention values in ICRP 54 (1988). Figure 6.1 diagrams the iodine model employed by GENMOD and shows the model setup parameters used for the calculations in this section. The GENMOD variables that are set to the model parameters are provided in parentheses. The ICRP's lung and GI tract models are incorporated without change into GENMOD and, for simplicity, are represented by a single box in Figure 6.1.

As shown in Figure 6.1, material leaving the inorganic compartment is split $30 / 70$ between the thyroid and bladder by setting the stable iodine removal rates to $1.9 \mathrm{day}^{-1}$ and $0.87 \mathrm{day}^{-1}$, respectively. The material leaving the organic compartment is either recycled back to the inorganic 


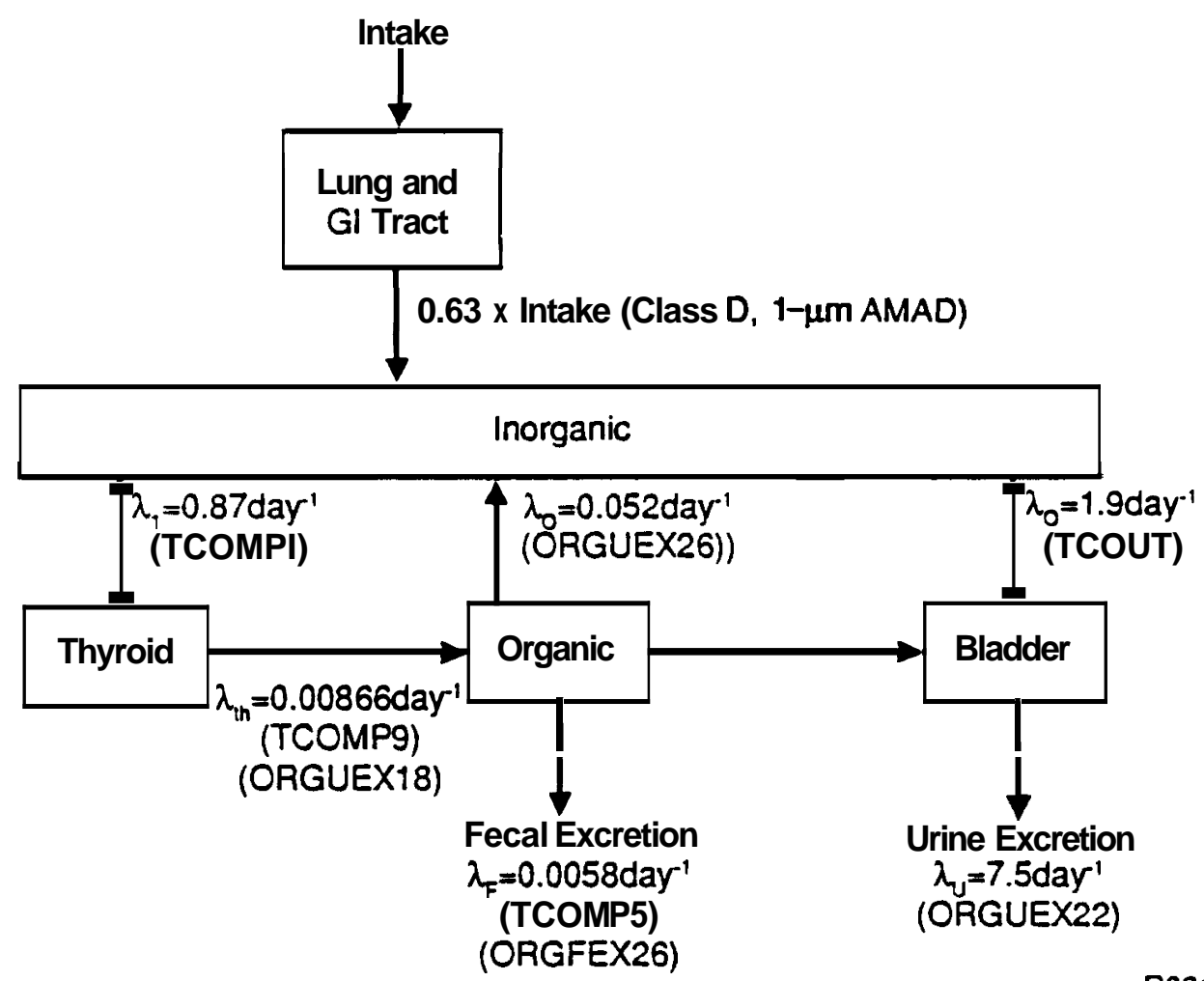

R881209422

FIGURE 6.1. Stable Iodine Retention Model

compartment or it goes directly to the feces. ICRP recommends a 90/10 split for this material, and this is achieved by setting the stable iodine removal rates in the organic compartment to $0.052 \mathrm{day}^{-1}$ for removal to the inorganic compartment and $0.0058 \mathrm{day}^{-1}$ for removal via fecal excretion. The recycling of the iodine back to the thyroid, along with stable iodine's fundamental half-life of 80 days in the thyroid, results in an apparent effective halflife of 120 days in the thyroid. Use of GENMOD allows for comparison of thyroid to total body iodine at various times after intake. However, for simplicity, ICRP 54 (1988) provides a thyroid retention function that effectively provides expected thyroid quantities following uptake:

$$
\begin{aligned}
\mathrm{r}_{\text {thy }}^{\mathrm{a}}(\mathrm{t})= & -0.33 \exp (-0.693 \mathrm{t} / 0.24)+0.018 \exp (-0.693 \mathrm{t} / 11) \\
& +0.31 \exp ^{(-0.693 \mathrm{t} / 120)}
\end{aligned}
$$


where $\mathbf{t}$ is in days post uptake.

For class $D$ material, translocation from the lung to the blood is rapid and the above equation will provide an accurate thyroid retention value for the model after several days after acute inhalation.

\subsection{INTERNAL DOSIMETRY FOR RADIOIODINE}

The thyroid is the principally exposed organ following an intake of radioiodine and can be considered to be the only organ contributing to the effective dose equivalent for radioiodines with half-lives greater than a few days. Because of the low weighting factor for the thyroid $(W=0.03)$, the limiting dose from a regulatory standpoint is the nonstochastic limit of $50 \mathrm{rem} / \mathrm{yr}$.

Table 6.1 gives first-year and 50-year committed effective dose equivalents per nanocurie for acute inhalation intakes of radioiodines (class $D$, 1- $\mu \mathrm{m}$ AMAD). The 50-year committed effective dose equivalent will be received within a few weeks for ${ }^{131} \mathrm{I}$, within a few months for ${ }^{125} \mathrm{I}$, and within a few years for ${ }^{129} \mathrm{I}$ as shown in Figure 6.2.

Table 6.2 gives expected thyroid activity following an acute intake sufficient to result in a first-year effective dose equivalent of $100 \mathrm{mrem}$. Conversion from effective dose equivalent to thyroid dose is made by multiplying the effective dose equivalent by 33.3 . TABLE 6.1. First-Year and 50-Year Committed Effective Dose Equi'valent
Following an Acute Inhalation Intake of Radioiodinela)

\begin{tabular}{|c|c|c|c|c|}
\hline Nucl ide & Half-Life & $\begin{array}{l}\frac{m r e n}{\text { First-Yr Eff. }} \\
\text { Dose Eg. }\end{array}$ & $\begin{array}{l}\text { Intake } \\
50-Y_{r} \text { Comm } \\
\text { Dose Ea. }(b)^{f f}\end{array}$ & $\begin{array}{r}\text { Fraction } \\
\text { Received } \\
\text { First Year } \\
\end{array}$ \\
\hline${ }^{125}$ I & 60 days & 0.023 & 0.023 & $99 \%$ \\
\hline${ }^{129}{ }_{I}$ & $1.6 \mathrm{E}+7 \mathrm{yr}$ & 0.15 & 0.16 & $89 \%$ \\
\hline $131_{I}$ & 8 days & 0.032 & 0.032 & $100 \%$ \\
\hline
\end{tabular}

(a) Assuming 1- $\mu$ m-AMAD particles.

(b) Thyroid dose equivalent is 33 times the effective dose equivalent. 


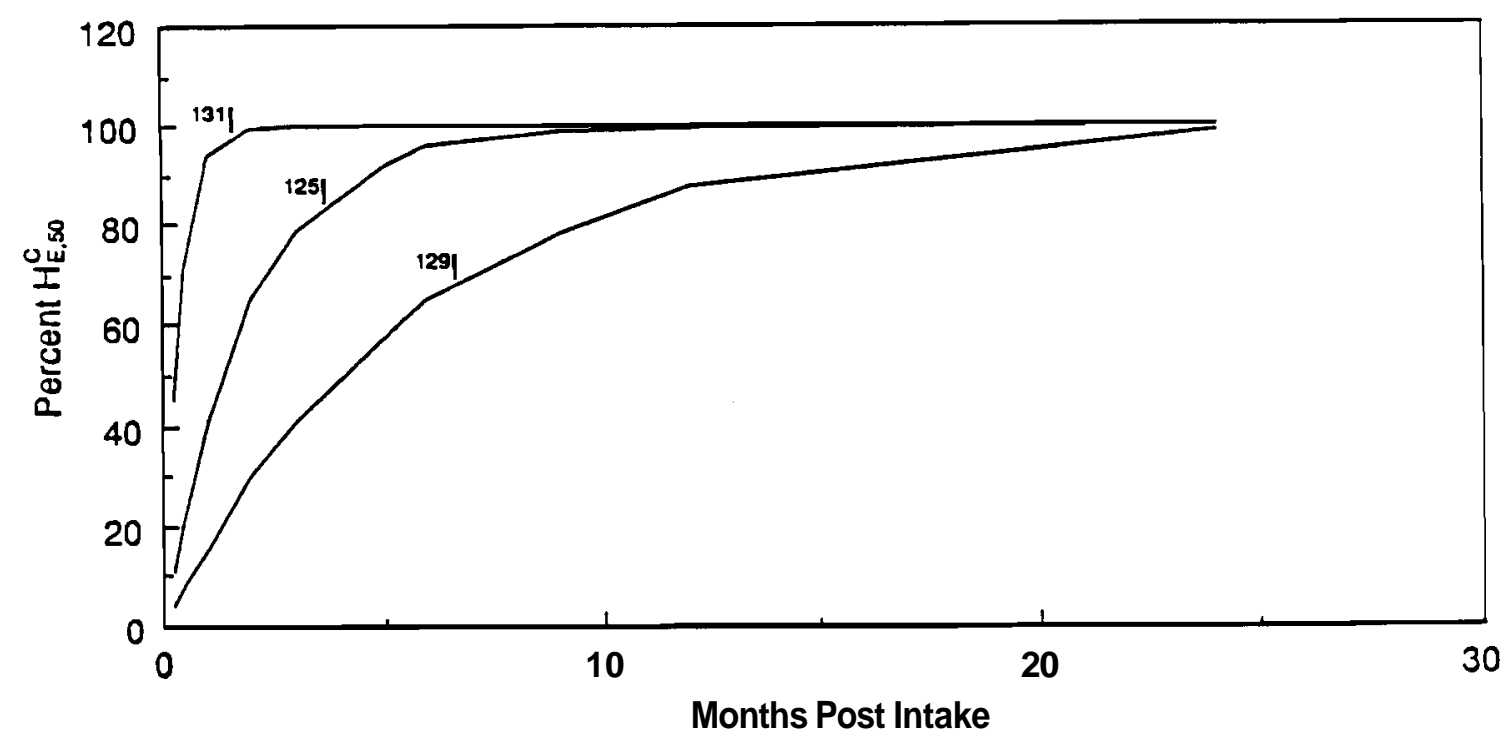

FIGURE 6.2. Percent of 50-Year Committed Effective Dose Equivalent Received at Times After Intake

TABLE 6.2. Expected Radioiodine in Thyroid Following an Acute Inhalation Resulting in a First-Year Effective Dose Equivalent of 100 mrem (Class D, 1- $\mu$ m AMAD)

Days Post Intake

1

2

5

7

14

30

60

90

180

365

730

Activity, $\mathrm{nCi}$

\begin{tabular}{|c|c|c|}
\hline $125_{\mathrm{I}}$ & ${ }^{129} \mathrm{I}$ & ${ }^{131}{ }_{\mathrm{I}}$ \\
\hline 650 & 100 & 430 \\
\hline 780 & 120 & 480 \\
\hline 790 & 130 & 390 \\
\hline 760 & 130 & 320 \\
\hline 670 & 120 & 170 \\
\hline 500 & 110 & 38 \\
\hline 290 & 91 & 2.4 \\
\hline 170 & 76 & (a) \\
\hline 36 & 45 & (a) \\
\hline 1.4 & 15 & (a) \\
\hline (a) & 1.7 & (a) \\
\hline
\end{tabular}

(a) Much less than $1 \mathrm{nCi}$. 
Table 6.3 gives the relationship between retained activity in the thyroid and effective dose equivalent.

Although the biokinetic models described in this section can be used to provide initial estimates of intake and dose following an exposure, in vivo measurements permit the actual retention in the thyroid to be determined. Thus, successive thyroid counts following an internal exposure yield data from which cumulated thyroid activity (in $\mathbf{n C i}$-days) can be calculated. The dose conversion factors in Table 6.3 are applied to the calculated cumulative activities over time periods of interest to assess thyroid and effective dose equivalent.

The stochastic ALIs for class D ${ }^{125} \mathrm{I},{ }^{129} \mathrm{I}$, and ${ }^{131} \mathrm{I}$ are $2 \mathrm{E5}, 3 \mathrm{E} 4$, and $2 \mathrm{E} 5 \mathrm{nCi}$, respectively; and the nonstochastic ALIs, based on thyroid dose, are $5 \mathrm{E} 4,8 \mathrm{E} 3$, and $5 \mathrm{E} 4 \mathrm{nCi}$, respectively.

\subsection{BIOASSAY}

In vivo measurements and a routine monitoring program for radioiodine isotopes are the main bioassay considerations.

\subsubsection{Bioassay Methods}

All radioiodine isotopes can be detected by in vivo measurements. Iodine-131 and the other short-lived iodine radionuclides can be detected readily using the $\mathrm{NaI}$-detector-based preview counter (Palmer et al. 1987). Because of their low-energy photon emissions, ${ }^{125}$ I and ${ }^{129}$ I can only be measured using the intrinsic germanium(IG) detector systems in the thyroidcounting configuration.

\section{TABLE 6.3. Dose from a Thyroid Burden of Radioiodine}

\begin{tabular}{|c|c|c|c|}
\hline \multirow[b]{2}{*}{ Nucl ide } & \multicolumn{2}{|c|}{$\begin{array}{c}\text { Dose Conversion Factor, } \\
\text { rem/nCi-day }\end{array}$} & \multirow{2}{*}{$\begin{array}{l}\text { Activity in Thyroid } \\
\text { Yielding Eff. Dose Eq. } \\
\text { Rate of } 100 \mathrm{mrem} / \mathrm{vr}, \quad{ }^{2} \mathrm{C}\end{array}$} \\
\hline & Thvroid & Eff. Dose Ea. & \\
\hline${ }^{125}{ }_{I}$ & $7.1 \mathrm{E}-5$ & $2.1 E-6$ & 0.13 \\
\hline${ }^{129}$ I & $1.7 \mathrm{E}-4$ & $5.2 E-6$ & 0.053 \\
\hline${ }^{131}{ }_{I}$ & $5.1 E-4$ & $1.5 E-5$ & 0.018 \\
\hline
\end{tabular}


In vivo measurement detection capabilities are summarized in Table 6.4.

\subsubsection{Routine Bioassay Monitoring Program}

It is recommended that routine bioassay measurements be performed at intervals not exceeding four to five effective half-lives of the radionuclide because of uncertainties associated with the assumed retention characteristics. In addition, a minimum annual bioassay frequency is recommended regardless of the effective half-life, so that adequate documentation of the internal exposure status is provided.

Thus, based on the above recommendations, the measurement frequency for the minimum recommended routine monitoring program for workers potentially exposed to ${ }^{131} \mathrm{I},{ }^{125} \mathrm{I}$, and ${ }^{129} \mathrm{I}$, respectively, is monthly, semiannually, and annually. Because of their short physical half-lives, it is generally not practicable to perform routine bioassay monitoring for ${ }^{132-135}$ I. Instead, assessment of exposures to these nuclides is normally accomplished by facility monitoring (e.g., air sampling).

Table 6.5 provides estimates of the annual effective dose equivalent potentially missed for several measurement frequencies. The doses are calculated assuming a worst-case scenario in which the individual receives an intake on the first day of each monitoring period that would be just below the

\section{TABLE 6.4. Sensjtivitjess of In Yiyo Measurements
for 125 I,}

\begin{tabular}{|c|c|c|c|}
\hline \multirow{2}{*}{$\frac{\text { Type of Measurement }}{\text { Whole body count }}$} & \multicolumn{3}{|c|}{ Minimum Detectable Activity. $\mathrm{nC}(\mathrm{a})$} \\
\hline & $\underline{125_{I}}$ & ${ }^{131_{\mathrm{I}}}$ & ${ }^{129} 9_{\mathrm{I}}(\mathrm{b})$ \\
\hline Preview counter & (c) & $4.5^{(d)}$ & (c) \\
\hline Thyroid count & & & \\
\hline Germanium detectors & 0.004 & 0.03 & 0.004 \\
\hline $3 \times 3 \mathrm{NaI}$ detectors & (c) & 0.02 & (c) \\
\hline
\end{tabular}
(a) From Palmer et a1. (1987). (See also Appendix C.)
(b) Sensitivity is about the same as for ${ }^{125}$ I.
(c) Not detectable using these systems.
(d) Using the detectors located over the chest region. 
TABLE 6.5. Detectable Annual Effective Dose Equivalent for
Various Routine In Vi vo Monitoring Frequenci es $(a)$

Measurement

Frequency

Weekly

Biweekly

Monthly

Bimonthly

Quarterly

Semi annual

Annual

Detectable First-Yr and 50-Yr Gommitted Dose Equivalent, mem $(b)$

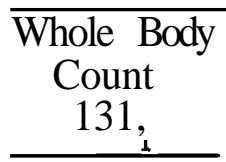

73

69

140

(c)

(c)

(c)

(c)
Thyroid Count (using $\mathrm{Ge}$ detector)

\begin{tabular}{ccc}
\hline 125 I & $129_{\text {I }}$ & 131 \\
\cline { 2 - 3 } & $<1$ & $<1$ \\
$<1$ & $<1$ & $<1$ \\
$<1$ & $<1$ & $<1$ \\
$<1$ & $<1$ & $($ c) \\
$<1$ & $<1$ & $($ c) \\
$<1$ & $<1$ & (c) \\
(c) & $<1$ & (c)
\end{tabular}

(a) Assumes an acute intake occurs on the first day of each monitoring period during the year. Thus the detectable dose is $\mathrm{N}$ times the dose detectable during each monitoring period, where $\mathrm{N}$ is the number of monitoring periods per year. Based on detection capabilities for thyroid counts from Table 6.4.

(b) The 50-year committed effective dose equivalent is essential1y equal to the first-year effective dose equivalent for ${ }^{25}$ I and I3I I and is about 1.1 times the first-year effective dose equival ent for ${ }^{129} \mathrm{I}$.

(c) Surveillance frequency exceeds five times the effective thyroid residence time.

detection level of the next routine measurement. This approach was taken because of the relatively short retention time of ${ }^{131} \mathrm{I}$ in the body and thus the need to perform routine bioassay measurements frequently during the year. $\mathrm{N}$ credit was taken for the long-term buildup of radioiodine in the thyroid that would decrease the doses reported in the table. Although values for ${ }^{129}$ I were similarly calculated, an annual frequency is possible in that case.

From Table 6.5 , it is apparent that for ${ }^{131}$ I the routine whole body count provided by the preview counter $(\mathrm{MDA}=4.5 \mathrm{nCi}$ ) could ensure detection of a 100-mrem annual dose if performed biweekly, whereas a monthly germanium thyroid count could detect as low as a 1-mrem dose. The most appropriate 
monitoring program for ${ }^{131}$ I would thus be a whole body count every 2 weeks (or a thyroid count once every month) during the potential exposure period.

If a radioiodine isotope is detected in a routine measurement, followup measurements to confirm the intake should be performed. The measurements can usually be conveniently performed immediately following the initial measurement while the subject is at the whole body counting facility. The use of the high resolution germanium detectors for follow-up measurements is preferred in order to accurately quantify the thyroid deposition.

\subsubsection{Bioassay Measurements Following an Acute Intake}

Thyroid counts should be performed to assess the significance of an acute intake of radioiodine. The deposition of iodine in the thyroid following an acute intake is not instantaneous; rather, buildup of iodine in the thyroid will occur over a period of about 3 days following the intake. Results of thyroid counts obtained within a day or so of an intake may thus underestimate the maximum retained quantity that will be achieved following the exposure. Measurements made 2 to 3 days post intake will likely provide the best indication of the maximum retained quantity in the thyroid from the intake.

If significant quantities of short-lived iodine isotopes are possibly associated with an exposure, then in vivo measurements should be performed within a day of the intake. The measurements should be made using a germanium detector to achieve optimum resolution. Follow-up counts, if needed, should be performed. Data from facility monitoring may be used to identify the relative activities of the various radioiodines present at the time of intake. Caution should be exercised when analyzing in vivo data for shortlived iodine isotopes, to ensure that activity within the thyroid and not external contamination is being measured.

\subsection{ASSESSMENT OF INTERNAL DOSE EOUIVALENT}

Radioiodines can be detected and quantified in the thyroid using in vivo techniques. Thyroid counts are sufficiently sensitive to enable detection of activity in the thyroid at levels well below that of any dosimetric 
consequence (see Table 6.5). Measurement of ${ }^{125} \mathrm{I}$ and ${ }^{129} \mathrm{I}$ requires the use of the low-energy germanium counting system.

Several methods exist to evaluate in vivo results in order to assess the internal dose equivalent. The simplest method, and one that is recommended for initial evaluation of in vivo results as well as for final evaluations when doses are very low, involves fitting the in vivo measurement data to the expected internal activity using the biokinetic model prescribed in this section. This model is implemented using GEMOD, and values of thyroid activity at various times following a given intake are provided in Table 6.2.

Assumptions that are used for this evaluation are that the material is inhaled in class $D$ form, that the intake date, if unknown, is assumed to be the midpoint of the period during which the intake could have occurred, and that the intake consisted of the inhalation of an aerosol with an AMAD of $1 \mathrm{~m}$. The resulting retention function, calculated using GMOD, is fit to the observed in vivo measurement data using techniques described in Appendix $C$.

A simplified dose assessment procedure for use in cases when annual effective dose equivalents are below 100 mrem is as follows:

1. Determine the time of intake. Assume the midpoint of the period during which the exposure could have occurred if a specific intake date is not known. For example, evaluation of measured activity in an annual count might assume that the intake occurred at the midpoint of the measurement period provided the worker could have incurred an intake at any time during the prior year.

2. Evaluate the bioassay measurement result using the biokinetic model described above.

3. If the calculated dose exceeds a 100-mrem first-year effective dose equivalent, then consider taking additional in vivo measurements to confirm the retention characteristics of the material and re-establish baseline internal activity levels.

If the intake could potentially result in an annual effective dose equivalent exceeding 100 mrem, then an investigation should be performed to determine whether other radionuclides were involved to review the validity of the above assumptions and to develop a case-specific retention function. 
Observed in vivo retention should be used in place of the ICRP biokinetic model for evaluations of internal doses that potentially exceed $100 \mathrm{mrem} / \mathrm{yr}$ when sufficient in vivo data are available for such an analysis. This can be most easily accomplished by graphically analyzing the in vivo data to identify retention components. The retention curves are then integrated to obtain cumulative activity for calendar years following intake, and the cumulative activity is multiplied times the organ and effective dose equivalent conversion factors in Table 6.3 to obtain annual dose equivalents.

\subsection{MANAGEMENT OF INTERNAL CONTAMINATION CASES}

In an accident exposure situation, iodine will likely be taken in by inhalation, ingestion, and absorption through the skin. If the iodine is very soluble, it will reach the thyroid relatively quickly; however, maximum thyroid activity may not occur until 2 or 3 days post intake. Thus, thyroid counts performed shortly after intake may underestimate the deposition. Also of concern for in vivo measurements made shortly after intake are contributions to the count from radioiodine located outside the body or in other regions of the body. However, if thyroid measurements are made with a collimated germanium detector, these interferences can most likely be reduced to negligible levels.

The adult thyroid gland is considered to be a relatively radioresistant organ (weighting factor $=0.03$ ) with respect to the risk of fatal malignancies. However, thyroid nodules, cancer, and hypothyroidism are all associated with radiation exposure to the thyroid. NCRP 65 (1980) recommends immediate administration of $300 \mathrm{mg} \mathrm{KI}$ or $\mathrm{NaI}$ tablets, regardless of the route of exposure, and daily administrations for 7 to 14 days (to prevent recycling back into the thyroid as a mitigative action following a large intake). For individuals receiving greater than a 100 -rem dose equivalent to the thyroid, an estimate of residual thyroid function should be made within 2 or 3 months after exposure (NCRP 1980). Occupational Medicine (at HEHF) should be immediately notified of a potentially severe intake of radioiodine. 

SECTION 7.0

EUROPIUM 



\subsection{EUROPIUM}

This section provides technical information on the sources, characteristics, biokinetics, and dosimetry of ${ }^{154} \mathrm{Eu}$ and ${ }^{155} \mathrm{Eu}$--the principal europium radionuclides of concern from an internal exposure standpoint at Hanford.

\subsection{SOURCES AND CHARACTERISTICS OF EUROPIUM}

Europium-154 $\left(\mathrm{T}_{1 / 2}=8.8 \mathrm{yr}\right)$ and ${ }^{155} \mathrm{Eu}\left(\mathrm{T}_{1 / 2}=4.96 \mathrm{yr}\right)$ have been produced historically at Hanford by the $\mathrm{N}$ Reactor through neutron activation of samarium oxide marbles used in the reactor's safety system. The samariumoxide marbles were replaced in 1978 with marbles made of boron carbide; however, a few of the old samarium-oxide marbles remained lodged in the graphite block moderator and continued to be activated during operation of the reactor until its shutdown in 1986.

The principal locations where exposures to europium radionuclides may occur are the 100-N Area and the waste management facilities in the 200 Areas where contaminated waste from $\mathrm{N}$ Reactor is handled.

\subsection{BIOKINETIC BEHAVIOR OF EUROPIUM}

ICRP 30 (1979) recommends that all compounds of europium (including nitrates, chlorides, and oxides) be assigned to inhalation class W. Experience at Hanford suggests that europium oxide may occasionally be more tenaciously retained in the lung than would be expected for a class W material. However, at this time data are insufficient to establish a case for class $Y$ europium at Hanford.

Based on numerous measurements made at various $\mathrm{N}$ Reactor locations (Weetman and DeHaven 1982a) a particle size of $0.5 \mu \mathrm{m} \mathrm{AMAD} \mathrm{should} \mathrm{be} \mathrm{assumed,}$ unless specific particle size data are available. According to the Task Group on Lung Dynamics (TGLD 1966) model of the respiratory tract, an inhaled aerosol, lognormally distributed with an AMAD of $0.5 \mu \mathrm{m}$, will be deposited as follows: $16 \%$ in the nasal-passage (N-P) region of the respiratory tract, $8 \%$ in the tracheal-bronchial (T-B) region of the lung, and $33 \%$ in the pulmonary (P) region of the lung (see Appendix D). 
According to ICRP 30, europium that enters the bloodstream is deposited and tenaciously retained in the liver and on bone surfaces. The distribution of europium entering the blood is given by ICRP 30 as follows:

- 1 iver- $-40 \%\left(T_{1 / 2}=3500\right.$ days $)$

- bone--40\% surfaces $\left(\mathrm{T}_{1 / 2}=3500\right.$ days $)$

- kidney- $-6 \%\left(T_{1 / 2}=10\right.$ days $)$

- unabsorbed and excreted directly--14\%.

\subsection{INTERNAL DOSIMETRY FOR EUROPIUM}

Using the computer code GEMDD (Johnson and Carver 1981; see Appendix A), an evaluation of the resulting internal organ doses following an intake of europium shows that the dose incurred by the kidney is negligible with respect to the liver and bone surface doses and does not contribute to the effective dose equivalent. Also, because of the short retention time in the kidney, europium observed in the body (excluding the lung) can be assumed to be distributed evenly between the liver and the bone surfaces.

Because of the long retention time for europium in the bone and liver, internal dose may accumulate for years following an intake. In most exposure cases (either class W or class $Y$ ), the lung can be expected to be the primary contributor to the effective dose equivalent during the first year following an intake. For the more soluble forms of europium (class $W$ ), the liver eventually becomes the principal contributor to effective dose equivalent. Table 7.1 gives first-year and the 50-year committed dose equivalent per nanocurie of inhalation intake of ${ }^{154} \mathrm{Eu}$ and ${ }^{155} \mathrm{Eu}$, assuming the physical and biokinetic characteristics discussed previously. Table 7.2 shows the time over which the internal dose from an inhalation intake of ${ }^{154} \mathrm{Eu}$ or ${ }^{155} \mathrm{Eu}$ is accumulated.

Figures 7.1 through 7.4 show the activity of ${ }^{154} \mathrm{Eu}$ and ${ }^{155} \mathrm{Eu}$ in the total body, the lung, and the bones or liver following an acute inhalation resulting in a first-year effective dose equivalent of $10 \mathrm{mrem}$. From the graphs, it is apparent that from about 6 months to 2 years after intake the total body activities for class $W$ and class $Y$ compounds are of roughly similar magnitude. 
TABLE 7.1. First-Year and Committed Dose Equivalent Following an
Acute Inhalation Intake of $1 \mathrm{nCi}$ of

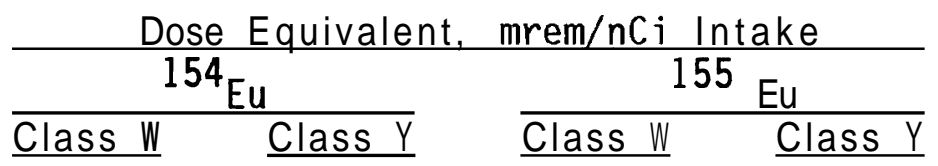

$\begin{array}{lllll}\begin{array}{l}\text { Effective Dose } \\ \text { Equivalent }\end{array} & & & & \\ \text { 1st-year } & 0.073 & 0.15 & 0.013 & 0.026 \\ \text { 50-year } & 0.30 & 0.55 & 0.044 & 0.080 \\ \text { Lung } & & & & \\ \begin{array}{l}\text { 1st-year } \\ \text { 50-year }\end{array} & 0.29 & 1.1 & 0.054 & 0.20 \\ \text { Bone Surface } & 0.36 & 3.4 & 0.057 & 0.54 \\ \text { 1st-year } & 0.24 & 0.029 & 0.096 & 0.0078 \\ \text { 50-year } & 2.0 & 0.79 & 0.57 & 0.19 \\ \begin{array}{l}\text { Bone Marrow } \\ \text { 1st-year }\end{array} & 0.053 & 0.019 & 0.0095 & 0.0024 \\ 50 \text {-year } & 0.40 & 0.20 & 0.054 & 0.022 \\ \text { Kidney } & & & & \\ \text { 1st-year } & 0.024 & 0.014 & 0.0022 & 0.00071 \\ 50 \text {-year } & 0.13 & 0.087 & 0.0064 & 0.0035 \\ \text { Liver } & & & & \\ \text { 1st-year } & 0.20 & 0.042 & 0.031 & 0.0039 \\ 50 \text {-year } & 1.6 & 0.71 & 0.18 & 0.063\end{array}$

(a) Acute inhalation of $0.5-\mu \mathrm{m}-\mathrm{AMAD}$ aerosol.

Table 7.3 shows fractional retention values for selected days post intake. Retention fractions for other organs or times post intake can be obtained using the GEMOD Code.

The ALI for class $W{ }^{154} \mathrm{Eu}$ is $20 \mu \mathrm{Ci}$. The stochastic ALI for class W

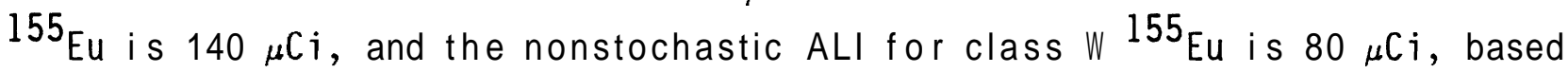
on dose to bone surfaces. 
AABLE 7.2. Accumulation of Effective Dose Equivalent
Following an Acute Inhalation of Europium

\begin{tabular}{|c|c|c|c|c|}
\hline \multirow[b]{3}{*}{ Years Post Intake } & \multicolumn{4}{|c|}{$\begin{array}{c}\text { Percent of } 50 \text {-Year Committed } \\
\text { Effective Dose Eauivalent Received }\end{array}$} \\
\hline & \multicolumn{2}{|c|}{$154 \mathrm{Eu}$} & \multicolumn{2}{|c|}{$155_{\mathrm{Eu}}$} \\
\hline & Class W & $\underline{\text { Class Y }}$ & Class W & Class Y \\
\hline 1 & 24 & 26 & 30 & 32 \\
\hline 2 & 35 & 44 & 44 & 52 \\
\hline 5 & 59 & 71 & 70 & 80 \\
\hline 10 & 81 & 87 & 89 & 94 \\
\hline 20 & 96 & 96 & 98 & 99 \\
\hline 50 & 100 & 100 & 100 & 100 \\
\hline
\end{tabular}

(a) Acute inhalation of $0.5-\mu \mathrm{m}-\mathrm{AMAD}$ aerosol.

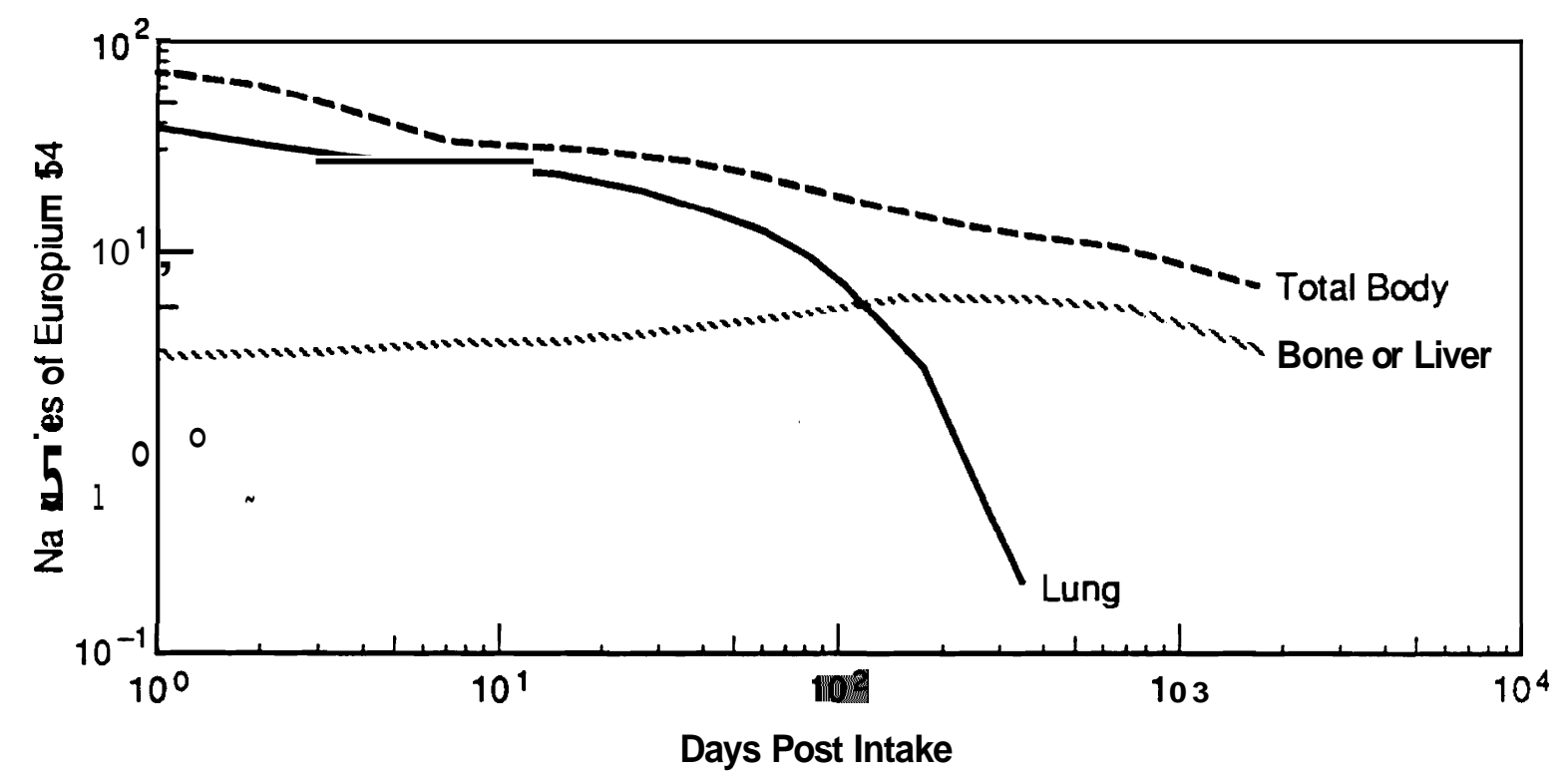

59106061.1

FIGURE 7.1. ${ }^{154}$ Eu in the Body Following an Inhalation Intake Resulting in a First-Year Effective Dose Equivalent of 10 mrem, Class W 


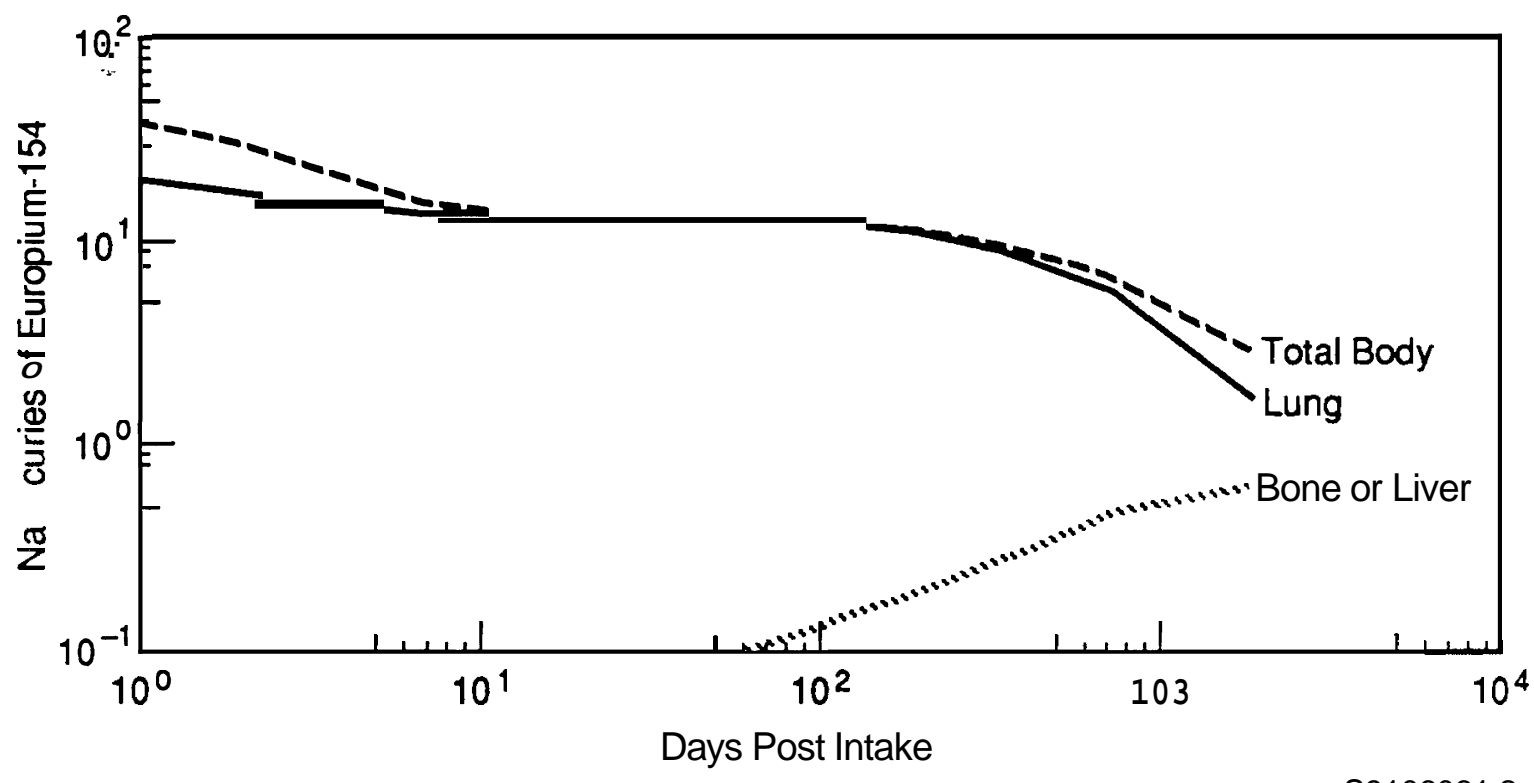

FIGURE 7.2. $\quad{ }^{154}$ Eu in the Body Following an Inhalation Intake Resulting a First-Year Effective Dose Equivalent of 10 mrem, Class Y

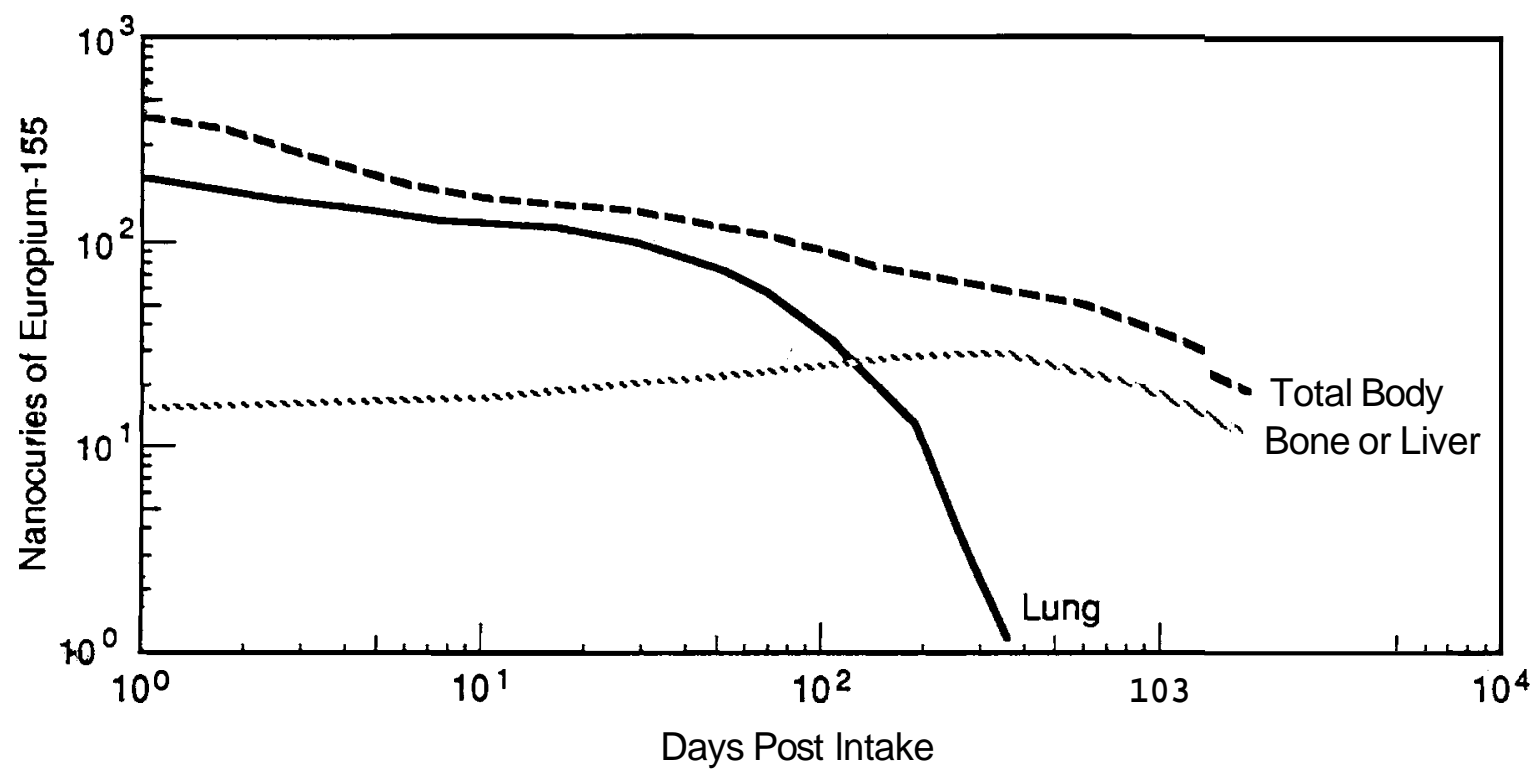

$\$ 9106061.3$

FIGURE 7.3. $\quad{ }^{154}$ Eu in the Body Following an Inhalation Intake Resulting a First-Year Effective Dose Equivalent of 10 mrem, Class W 


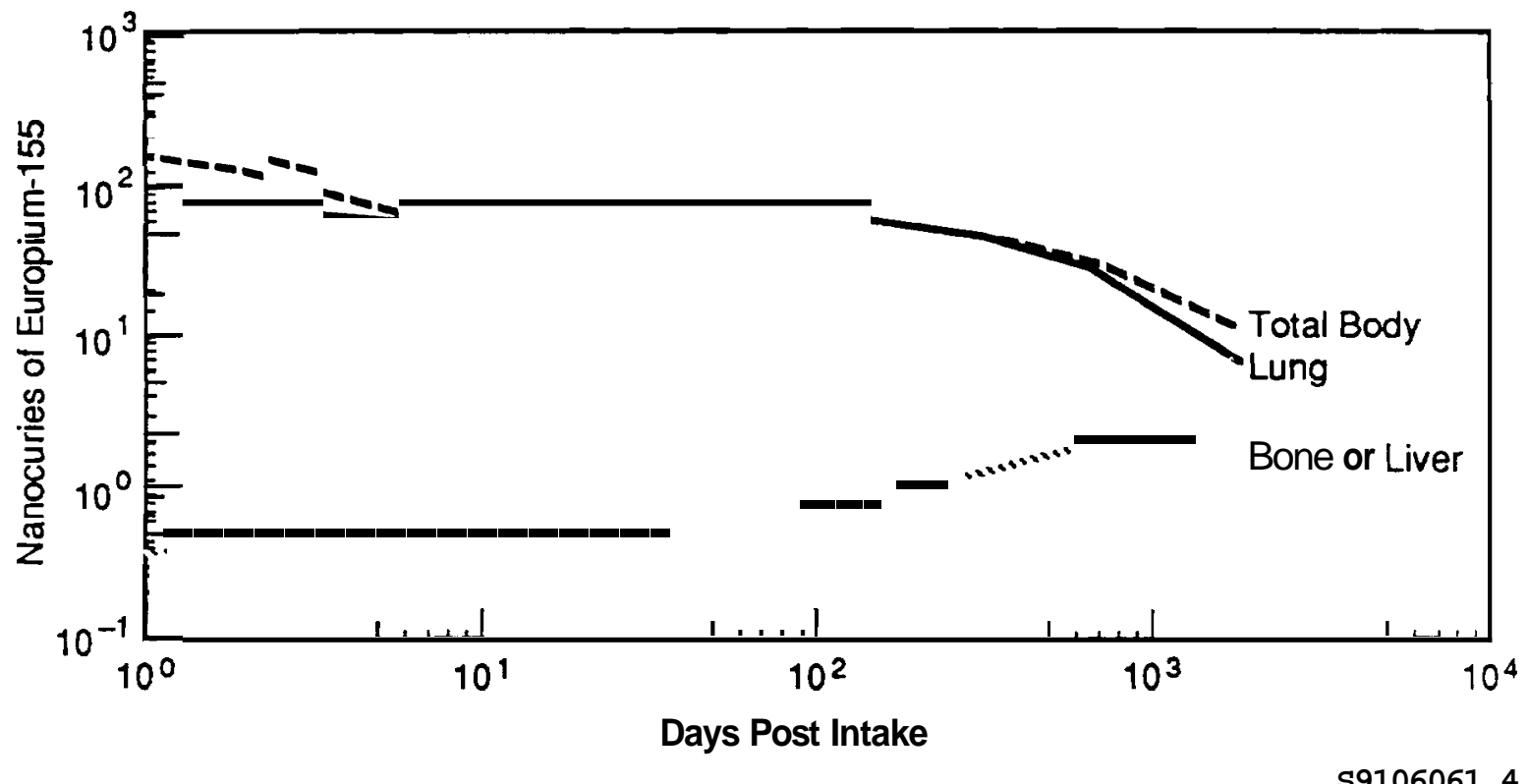

FIGURE 7.4. $\quad{ }^{155} \mathrm{Eu}$ in the Body Following an Inhalation Intake Resulting in a First-Year Effective Dose Equivalent of 10 mrem, Class Y

\subsection{BIOASSAY}

In vivo measurements and excreta analysis and their use in a routine bioassay monitoring program and following an acute intake are discussed in the following subsections.

\subsubsection{Bioassay Measurements}

Both ${ }^{154} \mathrm{Eu}$ and ${ }^{155} \mathrm{Eu}$ are readily measured by in vivo bioassay techniques.

\section{In Vivo Measurements}

Europium-154 is the predominant long-lived europium radioisotope in europium isotope mixtures at Hanford. During the operating lifetime of $\mathrm{N}$ Reactor, the ${ }^{154} \mathrm{Eu} /{ }^{155} \mathrm{Eu}$ activity ratio has generally been about 2.0 . This ratio will increase now that europium is no longer produced due to the longer half-1ife of ${ }^{154} \mathrm{Eu}$. Because ${ }^{154} \mathrm{Eu}$ is also more easily detectable in vivo than ${ }^{155} \mathrm{Eu}$, it is the best indicator of an intake of europium radionuclides. 
TABLE 7.3. Total Body Retention Following an Acute Inhalation Exposure to 0.5- $\mu$ m AMAD Particles (expressed as fraction of intake)

\begin{tabular}{|c|c|c|c|c|}
\hline \multirow{2}{*}{$\begin{array}{r}\text { Days } \\
\text { Post } \\
\text { Intake } \\
\end{array}$} & \multicolumn{2}{|c|}{${ }^{154} \mathrm{Eu}$} & \multicolumn{2}{|c|}{${ }^{155} \mathrm{Eu}$} \\
\hline & Class W & $\underline{\text { Class } Y}$ & Class W & Class Y \\
\hline 0 & $5.70 \mathrm{E}-1$ & $5.70 \mathrm{E}-1$ & $5.70 \mathrm{E}-1$ & $5.70 \mathrm{E}-1$ \\
\hline 1 & $5.35 \mathrm{E}-1$ & $5.34 \mathrm{E}-1$ & $5.35 E-1$ & $5.34 \mathrm{E}-1$ \\
\hline 2 & $4.42 \mathrm{E}-1$ & $4.21 E-1$ & $4.42 E-1$ & $4.21 E-1$ \\
\hline 5 & $2.70 \mathrm{E}-1$ & $2.32 \mathrm{E}-1$ & $2.70 \mathrm{E}-1$ & $2.32 \mathrm{E}-1$ \\
\hline 7 & $2.43 E-1$ & $2.07 E-1$ & $2.43 \mathrm{E}-1$ & $2.07 \mathrm{E}-1$ \\
\hline 14 & $2.22 \mathrm{E}-1$ & $1.98 \mathrm{E}-1$ & $2.22 \mathrm{E}-1$ & $1.97 E-1$ \\
\hline 30 & $1.96 \mathrm{E}-1$ & $1.94 \mathrm{E}-1$ & $1.95 \mathrm{E}-1$ & $1.93 E-1$ \\
\hline 60 & $1.62 \mathrm{E}-1$ & $1.87 \mathrm{E}-1$ & $1.60 \mathrm{E}-1$ & $1.85 E-1$ \\
\hline 90 & 1. $38 \mathrm{E}-1$ & $1.81 \mathrm{E}-1$ & $1.36 \mathrm{E}-1$ & $1.78 \mathrm{E}-1$ \\
\hline 180 & $1.04 \mathrm{E}-1$ & $1.64 \mathrm{E}-1$ & $1.01 E-1$ & $1.59 \mathrm{E}-1$ \\
\hline 365 & $8.58 E-2$ & $1.35 \mathrm{E}-1$ & $8.09 \mathrm{E}-2$ & $1.27 \mathrm{E}-1$ \\
\hline 730 & $7.27 \mathrm{E}-2$ & $9.49 \mathrm{E}-2$ & $6.47 \mathrm{E}-2$ & $8.44 E-2$ \\
\hline 1,825 & $4.58 E-2$ & $4.34 E-2$ & $3.43 E-2$ & $3.24 E-2$ \\
\hline 3,650 & $2.12 E-2$ & $1.85 E-2$ & $1.19 E-2$ & $1.03 E-2$ \\
\hline 7,300 & $4.56 E-3$ & $4.46 \mathrm{E}-3$ & $1.42 \mathrm{E}-3$ & $1.39 E-3$ \\
\hline 18,250 & $4.55 E-5$ & $1.19 E-4$ & $2.57 \mathrm{E}-6$ & $6.48 E-6$ \\
\hline
\end{tabular}

Europium-155 is more difficult to detect in vivo because its predominant gamma emission falls in the low-energy noise region of the standard whole body count.

Whole body counting for ${ }^{154} \mathrm{Eu}$ is conveniently performed using the 5-Nal-detector preview counter (Palmer et al. 1990). The standard 3-minute count performed using the system will detect the presence of $4.5 \mathrm{nC} i$ in the total body or about $3.4 \mathrm{nC}$ i in the chest region. The preview counter provides a quantitative indication of the presence of radioactivity in the body. Nevertheless, it is routine practice to establish internal deposition 
quantities for radionuclides detected with the preview counter by using the high-resolution large-volume coaxial germanium detector system described by Palmer et a1. (1990).

Total body content of ${ }^{155}$ Eu cannot be directly measured with the Hanford whole body counter. It can be estimated by establishing a ${ }^{155}$ Eu-to- ${ }^{154} \mathrm{Eu}$ ratio using chest or skeleton counts and then applying that ratio to the ${ }^{154} \mathrm{Eu}$ whole body count result. Skeleton counting would provide more sensitive ratio for ${ }^{155}$ Eu estimation.

Special measurements of lung, skeleton, or liver content may be desired to establish individual-specific patterns of distribution and retention.

Because europium is a bone-seeking radionuclide, chest counts performed more than several weeks after intake may be detecting activity in the bones of the chest, as well as in the lung. Therefore, any quantification of lung activity should consider the contribution from the bones.

Skeleton activity is estimated from a head count. A correction factor can then be derived for obtaining lung activity from a chest count. These calculations are performed by the PNL Whole Body counter (WBC) group.

Table 7.4 summarizes in vivo detection capabilities.

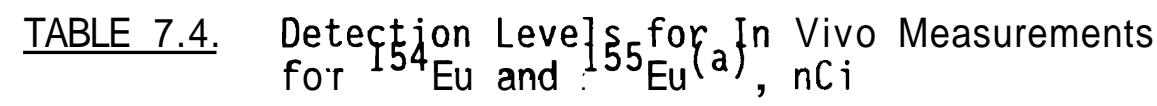

\begin{tabular}{|c|c|c|c|c|}
\hline Count Type & Orqan/Tissue & ${ }^{154} \mathrm{Eu}$ & ${ }^{155_{\mathrm{Eu}}}$ & $\begin{array}{l}\text { Length of } \\
\text { Count, s }\end{array}$ \\
\hline Preview & Whole body & 4.5 & NA & 200 \\
\hline Coaxial germanium & Chest & 3.4 & NA & 1200 \\
\hline Chest & Lung & 0.07 & 0.18 & 2000 \\
\hline Sku11 & Skeleton & 0.22 & 0.37 & 3000 \\
\hline
\end{tabular}

(a) From Palmer et al. (1990). (See also Appendix C.)

(b) NA = not applicable. 


\section{Excreta Analysis}

Europium intakes can be detected and assessed through collection and analysis of urine and fecal samples. However, because in vivo measurements provide a direct and sensitive method for assessing internal depositions of europium radionuclides, excreta measurements are generally not necessary.

\subsubsection{Routine Bioassay Monitoring Program}

Routine bioassay monitoring for ${ }^{154} \mathrm{Eu}$ and ${ }^{155} \mathrm{Eu}$ is accomplished by in vivo measurements, principally for ${ }^{154} \mathrm{Eu}$ because of its predominance in europium mixtures and its easy detectability. Table 7.5 shows the activity of ${ }^{154} \mathrm{Eu}$ and ${ }^{155} \mathrm{Eu}$ in the body at various times after acute inhalation intake of a quantity that would result in a first-year effective dose equivalent of 10 mrem.

From Table 7.5, it is evident that an annual in vivo measurement frequency using the preview counter $\left(\mathrm{MDA}=4.5 \mathrm{nC}\right.$ i for $\left.{ }^{154} \mathrm{Eu}\right)$ is sufficient to

TABLE 7.5. Expected Whole Body Count Quantitiés Following an Inhalation Intake Resultjng in a First-Year Effective Dose Equivalent of 10 mrem $(a, b)$

\begin{tabular}{|c|c|c|c|c|}
\hline \multirow{3}{*}{$\begin{array}{l}\text { Days Post } \\
\text { Intake }\end{array}$} & \multicolumn{4}{|c|}{ Activity in the Total Body nCi $_{\text {. }}$} \\
\hline & \multicolumn{2}{|c|}{${ }^{154} \mathrm{Eu}$} & \multicolumn{2}{|c|}{${ }^{15 b_{E u}}$} \\
\hline & Class W & Class Y & $\overline{\mathrm{Class} \mathrm{W}}$ & Class Y \\
\hline 7 & 29 & 14 & 180 & 80 \\
\hline 14 & 27 & 14 & 165 & 76 \\
\hline 30 & 27 & 13 & 145 & 75 \\
\hline 60 & 26 & 13 & 119 & 72 \\
\hline 90 & 25 & 12 & 101 & 69 \\
\hline 180 & 23 & 11 & 75 & 62 \\
\hline 365 & 19 & 9.3 & 60 & 49 \\
\hline 730 & 13 & 6.5 & 48 & 33 \\
\hline
\end{tabular}

(a) The expected total body activity values were calculated

(b) Issuming a $0.5-\mu \mathrm{m}$-AMAD particle size.

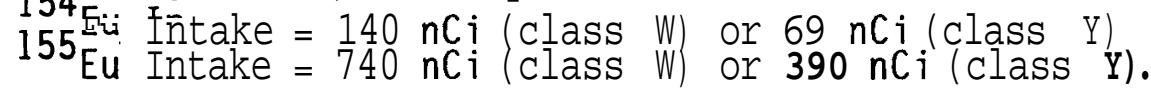


detect an intake of ${ }^{154} \mathrm{Eu}$ at a 10 -mrem first-year effective dose equivalent. A supplemental skeleton count to establish the ${ }^{155} \mathrm{Eu}$-to- ${ }^{154} \mathrm{Eu}$ ratio would. allow determination of the total body content of ${ }^{155^{2}} \mathrm{Eu}$ also at a level corresponding to a 10-mrem first-year effective dose equivalent. The first-year effective dose implied by an $\mathrm{MDA}{ }^{155} \mathrm{Eu}$ measurement of $4.5 \mu \mathrm{Ci}$ and an MDA skeleton count is 6.4 mrem for the combined isotopes of ${ }^{154} \mathrm{Eu}$ and ${ }^{155} \mathrm{Eu}$. An annual in vivo measurement frequency would also be capable of detecting a 50 year committed effective dose equivalent of $100 \mathrm{mrem}$, as can be determined using the ratios of first-year to 50-year effective dose equivalents from Table 7.1.

Routine measurements in which a europium radionuclide is detected should be confirmed by follow-up in vivo measurements. The recommended protocol is to use high-resolution germanium detector whole body counting to confirm the identity and magnitude of the activity indicated by the preview counter. Because of the adequate sensitivity of whole body counting, supplemental chest and skeleton measurements are not generally warranted for intake or dose assessment unless unusual retention or distribution is suspected.

\subsubsection{Bioassav Measurements Following An Acute Intake}

An in vivo whole body examination should be performed following a suspected intake. However, unless the exposure appears to be of such magnitude that actions to hasten the removal of the material from the body are considered, the initial examination can be at the earliest convenient time during normal working hours. A measurement of the chest or skeleton is warranted to establish the ${ }^{155}$ Eu-to- ${ }^{154}$ Eu ratio.

Because there is much movement of inhaled material in the body during the first hours following an inhalation intake, early in vivo measurements should be considered semiquantitative. Measurements to determine total body retention for dose assessment purposes should not be performed until after about 5 days to allow for the early elimination of material via the GI tract. Likewise specialized measurements to estimate clearance rates from specific organs (i .e., chest counts and skeleton counts) should also be delayed until early GI tract clearance is complete. 


\subsection{ASSESSMENT OF INTERNAL DOSE}

Europium radionuclides of concern can be readily detected and quantified by in vivo measurements. Several methods exist to evaluate in vivo measurement results in order to assess internal dose equivalent. The simplest method, and one that is recommended for initial evaluation of in vivo results as well as for final evaluations when annual effective doses are 100 mrem or less, involves fitting the expected internal activity using the biokinetic model prescribed in this section to whole body measurement data. This model is implemented using GENMOD (see Appendix A), and Table 7.3 and Figures 7.1 through 7.4 provide the expected retention values after an intake.

Assumptions used for this simplified evaluation are that the material is inhaled in class W or $Y$ form, that the intake date, if unknown, is assumed to be the midpoint of the period during which the intake could have occurred, and that the inhaled aerosol had an AMAD of $0.5 \mu \mathrm{m}$. The expected retention values per unit of intake are fit to the observed data using methods described in Appendix $\mathrm{C}$ to determine the intake. Intake dose equivalent factors, such as those in Table 7.1, may then be applied to compute dose equivalent.

If it is determined that the intake could potentially result in an annual effective dose equivalent in excess of $100 \mathrm{mrem}$, then an investigation should be performed to determine whether other radionuclides were involved, to review the validity of the above-stated. assumptions, and to develop specific retention functions for the lung and body.

The objective of bioassay measurements performed for the purpose of assessing the internal dose based on observed retention and distribution is to establish, on a calendar-year basis, the integrated activity (in nCi-days) for the lung, the bone, and the liver. Because the bones of the chest interfere with the assessment of the pulmonary retained quantity, a combination chest and head count is advisable for estimating the true activity in the lung. The activity in the rest of the body can be estimated from a whole body count with subtraction of the true lung activity, or by direct counting of the skeleton and the liver. 
Retention observed in vivo can be graphically analyzed to determine the cumulative activity by integrating under the observed retention curve. Once the annual integrated activity (in $\mathbf{n C i}$-days) is established, the DCFs in Table 7.6 can be applied to derive the organ and effective dose equivalent. The internal effective dose equivalent is the sum of the effective dose equivalent contribution from activity in the lung and the effective dose equivalent contribution from activity in the bone plus liver.

Dose assessments include annual and committed effective dose equivalents, as well as dose equivalents to specific organs of concern based on the criteria presented in the Hanford Internal Dosimetry Program Manual. (a) (See also Appendix B). Dose factors for organs receiving the greatest dose equivalent are provided in Tables 7.1 and 7.5.

\subsection{MANAGEMENT OF INTERNAL CONTAMINATION CASES}

Although, historically, there have been internal exposure cases involving europium radionuclides at Hanford, in no case have the exposures resulted in significant internal doses relative to occupational exposure limits. Because europium radionuclides are no longer produced, the concentrations of europium radionuclides at Hanford are slowly diminishing.

In vivo measurements performed following a potential intake provide an initial indication of the significance of an intake, although external contamination and rapid translocation of the material through the body may interfere with the accuracy of the measurement. If a significant intake is indicated, then various mitigative actions are possible. Purgatives or laxatives, as well as enemas or colonic irrigations, may reduce the residence time of the radionuclide in the GI tract, thereby reducing absorption by the blood (NCRP 1980). Once absorbed, diethylene triamine penta acetate (DTPA) may be considered (NCRP 1980). Hanford Environmental Health Foundation Occupational Medicine should be notified immediately upon indication of a severe intake potentially requiring mitigative action.

(a) Pacific Northwest Laboratory. 1989. Hanford Internal Dosimetry Proaram Manual. PNL-MA-552, Richland, Washington. 
TABLE 7.6. Dose Conversion Factors for Radioisotopes of Europium(a)

\begin{tabular}{|c|c|c|c|}
\hline \multirow{2}{*}{$\begin{array}{c}\text { Site of } \\
\text { Deposition } \\
\end{array}$} & \multirow{2}{*}{$\begin{array}{l}\text { Target } \\
\text { Organ } \\
\end{array}$} & \multicolumn{2}{|c|}{$\begin{array}{l}\text { DCF, rem/nCi-day } \\
\text { in Source Orqan } \\
\end{array}$} \\
\hline & & $\overline{154} \mathrm{Eu}$ & ${ }^{155_{\mathrm{Eu}}}$ \\
\hline \multirow[t]{2}{*}{ Lungs } & Lungs & $1.8 \mathrm{E}-5$ & $3.4 \mathrm{E}-6$ \\
\hline & Effective & $2.1 \mathrm{E}-6$ & $4.1 E-7$ \\
\hline \multirow[t]{4}{*}{ Body (b) } & Bone surface & $8.2 E-6$ & $3.3 E-6$ \\
\hline & Bone marrow & $1.6 \mathrm{E}-6$ & $3.1 E-7$ \\
\hline & Liver & $6.6 \mathrm{E}-6$ & $1.1 \mathrm{E}-6$ \\
\hline & Effective & $1.3 E-6$ & $2.2 E-7$ \\
\hline \multirow[t]{4}{*}{ Bone surface ${ }^{(c)}$} & Bone surface & $1.7 E-5$ & $6.7 E-6$ \\
\hline & Bone marrow & $5.6 E-6$ & $1.2 E-6$ \\
\hline & Liver & $1.5 E-7$ & $7.6 E-9$ \\
\hline & Effective & $7.3 E-7$ & $2.5 E-7$ \\
\hline \multirow[t]{4}{*}{ Liver $(c)$} & Bone surface & $1.6 \mathrm{E}-7$ & $1.8 E-8$ \\
\hline & Bone marrow & $2.2 \mathrm{E}-7$ & $1.7 \mathrm{E}-8$ \\
\hline & Liver & $1.3 E-5$ & $2.2 E-6$ \\
\hline & Effective & $8.0 E-7$ & $1.3 \mathrm{E}-7$ \\
\hline
\end{tabular}

(a) Based on SEE factors in ICRP 30.

(b) Excludes lung and assumes $50 \%$ in liver and $50 \%$ on bone surfaces. Organs shown contribute $10 \%$ or more to the effective dose equivalent, but the calculated effective dose equivalent considers all organs.

(c) To be used when assumption (b) does not hold. 



\section{SECTION 8.0}

\section{URANIUM}





\subsection{URANIUM}

This section provides technical information on uranium sources, characteristics, biokinetics, and internal dosimetry for general application at Hanford. Also included are special sections that apply to exposures in specific facilities where uncontained uranium is routinely handled.

Bioassay monitoring and internal dosimetry for uranium at Hanford pose relatively unique problems, primarily because, except for highly enriched uranium, total containment is not provided. Thus, low-level chronic airborne contamination levels are assumed to exist in facilities in which uncontained uranium is routinely handled.

Additional difficulties with uranium dosimetry are caused by the relatively low sensitivity of direct (in vivo) measurement capabilities for depleted and low-enrichment uranium, and the presence of environmental uranium in urine as background interference.

\subsection{SOURCES AND CHARACTERISTICS OF URANIUM}

The sources, isotopic composition, transportability, particle size, environmental background, chemical toxicity, and biokinetic characteristics of uranium 'at Hanford are discussed in the following subsections.

\section{1 .1 Sources}

Historically, at Hanford uranium has been used primarily as feed material in the plutonium production process. The uranium was received as slightly enriched metallic uranium in the form of large billets and extruded into fuel elements at the 300 Area Fuel Production Facility (FPF). After irradiation in production reactors, the elements are shipped to the PUREX facility for processing. The final operating plutonium production reactor (N Reactor) and its associated fuels production facility were shut down in 1987; however, the extraction of plutonium and uranium from the irradiated fuels will continue for several more years at the PUREX facility. The recovered uranium, as uranylnitrate-hexahydrate, is shipped to the Uranium Oxide (U03) Plant in 200 West Area for conversion to uranium trioxide. 
Uranium is also used in fuel elements for the FFTF reactor. The FFTF fuel consists of a mixture of plutonium and uranium oxide, with plutonium being the primary concern.

Depleted uranium metal is machined in shops in the 306-W Building in support of a long-term research and development program.

Uranium isotopes are stored and handled in several laboratories in the 200 and 300 Areas.

\subsubsection{Isotopic Composition}

Uranium handled at Hanford generally ranges from depleted to slightly enriched. Table 8.1 summarizes ${ }^{235} \mathrm{U}$ enrichment levels in several Hanford facilities. Table 8.2 gives radiological data for uranium isotopes.

Uranium that is used in the plutonium production process is recycled uranium and is subject to the ingrowth of impurities during the irradiation phase of the fuel cycle (Rich et al. 1988). These impurities are not

TABLE 8.1. Enrichments of Uranium at Hanford Facilities

\begin{tabular}{llll} 
Area & \multicolumn{1}{c}{ Facility } & & \multicolumn{1}{c}{$235 \mathrm{U}$ Enrichment } \\
100 & N Reactor fuel & & $0.8-1.25 \% 23{ }^{20}$ \\
200 & PUREX, U03 Plant & & $0.8 \% 235 \mathrm{U}$ \\
300 & $306-W$ Building (PNL) & & Depleted $(0.3 \%){ }^{235} \mathrm{U}$ \\
& N Reactor FPF & $0.95-1.25 \% 235 \mathrm{U}$
\end{tabular}

TABLE 8.2. Radiological Characteristics of Uranium Isotopes

\begin{tabular}{|c|c|c|c|}
\hline \multirow[b]{2}{*}{ Isotopes } & \multirow[b]{2}{*}{ Specific Activity, $\mu \mathrm{Ci} / \mathrm{g}$} & \multicolumn{2}{|c|}{ Half-Life, $y r$} \\
\hline & & Years & Days \\
\hline $232 v$ & $2.1 E+7$ & 72 & $2.63 E+5$ \\
\hline $233 U$ & $9.69 \mathrm{E}+3$ & $1.59 E+5$ & $5.80 E+7$ \\
\hline $234 u$ & $6.25 E+3$ & $2.45 E+5$ & $8.94 E+7$ \\
\hline $235 U$ & 2.16 & $7.03 E+8$ & $2.57 E+11$ \\
\hline $236_{U}$ & 64.7 & $2.34 E+7$ & $8.54 E+9$ \\
\hline $238 U$ & 0.336 & $4.47 E+9$ & $1.63 \mathrm{E}+12$ \\
\hline
\end{tabular}


completely removed during the reprocessing and plutonium extraction phases of the production cycle and thus contribute to internal dose along with uranium. The impurities include ${ }^{236} \mathrm{U},{ }^{239} \mathrm{Pu},{ }^{99} \mathrm{Tc},{ }^{237} \mathrm{~Np}$, and other, shorter-1ived, fission products.

Table 8.3 gives the isotopic composition of various types of uranium at Hanford. Recycled uranium is present in the FPF and in the U03 Plant. Figure 8.1 shows how the specific activity of virgin (unirradiated) uranium

TABLE 8.3. Radiological Characteristics of Uranium Mixtures

\begin{tabular}{|c|c|c|c|c|c|}
\hline \multirow{2}{*}{\multicolumn{2}{|c|}{ Specific Activity }} & \\
\hline & & $234_{U}$ & $235 U$ & $236 U$ & $238_{U}$ \\
\hline Natural & 0.687 & 0.000054 & 0.0072 & (a) & 0.9927 \\
\hline Depleted & 0.364 & 0.0000037 & 0.0025 & (a) & 0.9975 \\
\hline U03-RU & 0.90 & 0.000080 & 0.0083 & 0.00074 & 0.991 \\
\hline$F P F-R U^{(b)}$ & 0.92 & 0.000084 & 0.011 & 0.00062 & 0.988 \\
\hline \multirow{2}{*}{\multicolumn{2}{|c|}{ Mixture }} & \multicolumn{4}{|c|}{$\begin{array}{c}\text { Fraction of Total Uranium } \\
\text { Activity of Mixture }\end{array}$} \\
\hline & & ${ }^{234} U$ & ${ }^{235} \mathrm{U}$ & $236 \mathrm{U}$ & $238 U$ \\
\hline Natural & & 0.492 & 0.023 & (a) & 0.486 \\
\hline Depleted & & 0.064 & 0.015 & (a) & 0.922 \\
\hline U03-RU & & 0.56 & 0.020 & 0.053 & 0.37 \\
\hline FPF-RU & & 0.57 & 0.026 & 0.044 & 0.36 \\
\hline \multirow{2}{*}{\multicolumn{2}{|c|}{ Mixture }} & \multicolumn{4}{|c|}{$\begin{array}{c}\text { Activity Per Microgram of Material, } \\
\mathrm{dpm} / \mu \mathrm{q} \text { of Mixture }\end{array}$} \\
\hline & & $\overline{234} \mathrm{U}$ & $236_{U}$ & $238 \mathrm{U}$ & U-Total \\
\hline \multicolumn{2}{|l|}{ Natural } & 0.74 & (a) & 0.73 & 1.5 \\
\hline \multicolumn{2}{|l|}{ Depleted } & 0.05 & (a) & 0.74 & 0.8 \\
\hline \multicolumn{2}{|l|}{ U03-RU } & 1.1 & 0.11 & 0.74 & 2.0 \\
\hline \multicolumn{2}{|l|}{ FPF-RU } & 1.2 & 0.09 & 0.74 & 2.0 \\
\hline
\end{tabular}

\footnotetext{
(a) Negligible

(b) Average atom fraction based on range expected for facility. Uranium-235 enrichment varies from $0.95 \%$ to $1.25 \%$.
} 


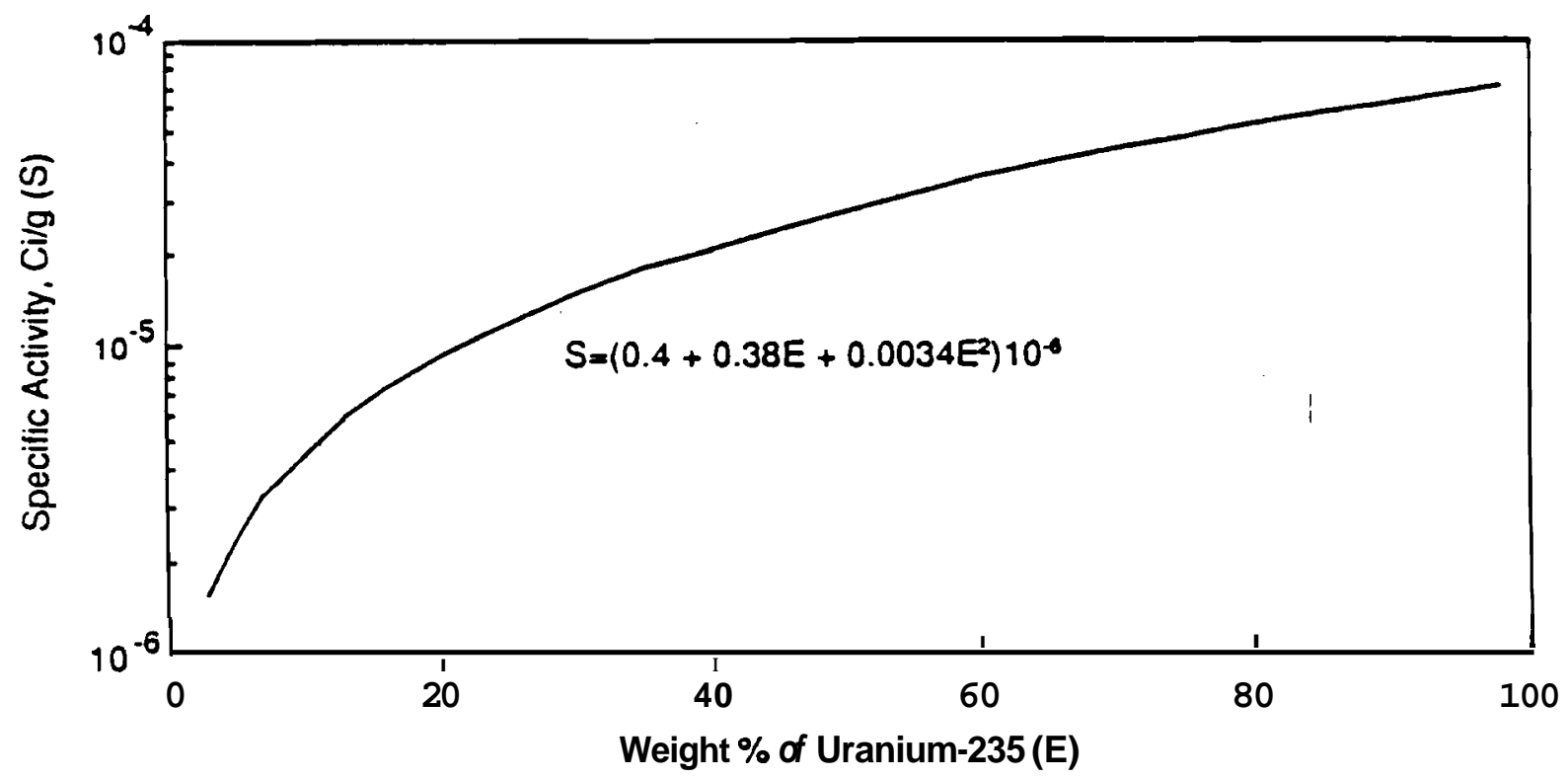

FGURE 8.1. Specific Activity for Enriched Uranium (from WASH-1251 [Alexander 19741)

increases with $235 \mathrm{U}$ enrichment. Table 8.3 shows that the specific alpha activity of the recycled uranium exceeds that of virgin uranium for corresponding $235 U$ weight percentages. This increase is due primarily to higher levels of ${ }^{234} \mathrm{U}$ and ${ }^{236} \mathrm{U}$ in the recycled uranium. The atom ratios used to calculate specific activity in Table 8.3 are based on operational data obtained from facility operating records and represent a reference recycled uranium mixture. Although the isotope ratios vary slightly between UOB Plant recycled uranium (U03-RU) and FPF recycled urani um (FPF-RU), the total specific activity for the two mixtures is the same at $2.0 \mathrm{dpm} / \mu \mathrm{g}$ uranium.

Other impurities in recycled uranium include plutonium, neptunium, technicium, and other fission products. Table 8.4 gives maximum allowed levels of these impurities in uranium handled at the U03 Plant. These levels can be considered to represent the maximum impurity levels for recycled uranium at Hanford. Actual operational experience shows that levels of impurities in recycled uranium at Hanford are substantially below the maximum allowed levels. Default reference levels for these impurities are also established in the table. 
TABLE 8.4. Impurities in Recycled Uranium at Hanford

\begin{tabular}{|c|c|c|c|}
\hline Constituent & $\begin{array}{c}\text { Maximum }(a) \\
\text { Allowed } \\
\end{array}$ & $\begin{array}{c}\text { Observed (b) } \\
\text { Range }\end{array}$ & Reference Level (c) \\
\hline Plutonium & $10 \mathrm{ppbp} U$ & $<1-2$ ppbp $U$ & $0.4 \mathrm{nCi} P u-a 1 p h a / g-U(d)$ \\
\hline Neptunium & $N E^{(e)}$ & 0.04-0.16 ppmp U & $0.4 \mathrm{nCi}^{237} \mathrm{~Np} / \mathrm{g}-\mathrm{U}^{(f)}$ \\
\hline Thorium & 750 ppmp U & 8-10 ppmp U & $5 \mathrm{pCi}{ }^{232} \mathrm{Th} / \mathrm{g}-\mathrm{U}^{(\mathrm{g})}$ \\
\hline${ }^{99} \mathrm{Tc}$ & $N E^{(e)}$ & 3-4 ppmp U & $0.2 \mu \mathrm{C} i{ }^{99} \mathrm{Tc} / \mathrm{g}-\mathrm{U}^{(h)}$ \\
\hline $103,{ }^{106} \mathrm{Ru}$ & $<20 \mu \mathrm{Ci} / \mathrm{Ib}-\mathrm{U}$ & $<6 \mu \mathrm{Ci} / \mathrm{Tb}-\mathrm{U}$ & $40 \mathrm{nCi}{ }^{106} \mathrm{Ru} / \mathrm{g}-\mathrm{U}^{(\mathrm{i})}$ \\
\hline${ }^{95} \mathrm{ZrNb}$ & $<10 \mu \mathrm{Ci} / \mathrm{Ib}-\mathrm{U}$ & $<4 \mu \mathrm{Ci} / 1 \mathrm{~b}-\mathrm{U}$ & $20 \mathrm{nCi}^{95} \mathrm{Zr} / \mathrm{g}-\mathrm{U}^{(\mathrm{j})}$ \\
\hline
\end{tabular}

(a) From U03 Plant operating specifications, OSD-U-185-0001 (Thompson 1986).

(b) From analysis of uranium lots 88-1, 88-2, 88-3 that were processed in 1988.

(c) A reference level is chosen for determining bioassay monitoring needs and for use as an initial assumption in evaluating intakes. The use of the reference levels is expected to result in a slight overestimate of dose compared to levels actually observed in 1988.

(d) Based on 5 ppbp U and assuming plutonium is represented by aged $6 \div 240 \mathrm{Pu}$ grade material (per Section 9.0).

(e) $\mathrm{NE}=$ not established.

(f) Based on 0.5 ppmp U of $237 \mathrm{~Np}$.

(g) Based on 50 ppmp $U$ of ${ }^{232} \mathrm{Th}$.

(h) Based on 10 ppmp U of 99 Ic.

(i) Based on $20 \mu \mathrm{Ci} / 1 \mathrm{~b}$ of $106_{\mathrm{Ru}}$.

(j) Based on $10 \mu \mathrm{Ci} / \mathrm{lb}$ of ${ }^{95} \mathrm{ZrNb}$.

\subsubsection{Environmental Backsround}

The sensitivity of urine sampling as a uranium bioassay tool is limited by the presence of environmental levels of uranium, which is subject to some uncertainty in interpretation. In ICRP 30 (1979) the average daily ingestion intake of natural uranium in food and water is estimated to be $1.9 \mu \mathrm{g}$. Assuming that the GI tract absorption of uranium at environmental levels is about 1\% (Wrenn 1985) at equilibrium, about $0.02 \mu \mathrm{g}$ /day could be expected in the urine of occupationally unexposed workers. Two studies at Hanford, performed in 1985 and 1990, indicated that the concentrations of uranium in urine in the Hanford area are similar but slightly higher than the foregoing estimates 
(Carbaugh, Sula, and McFadden 1990). The ICRP Reference Man Report (1974) lists urinary excretion from 0.05 to $0.5 \mu \mathrm{g} /$ day and fecal excretion from 1.4 to $1.8 \mu \mathrm{g} /$ day, although the range reported in its cited literature is much greater.

Urine samples were collected in mid-1985 from 21 occupationally unexposed Hanford workers who resided in various locations around Hanford, including Yakima, Benton City, Kennewick, and Richland. Both municipal drinking water and individual well-water systems were represented by the sampling. The results ranged from below detectable levels $(0.03 \mu \mathrm{g} /$ day $)$ to $0.12 \mu \mathrm{g} /$ day. For seven of the individuals, three samples were collected over a 2-week period, and the daily excretion remained fairly constant for each individual over the period. Data for this group are shown as the 1985 curve in Figure 8.2. The median daily uranium output for the 1985 study group was 0.06 ug and $0.2 \mu \mathrm{g} /$ day was estimated to be the 99.9 percentile (one in a thousand samples collected from unexposed workers would be expected to exceed that value). Based on this study, samples containing less than $0.2 \mu \mathrm{g}$ /day of uranium were considered to be within the expected environmental range, and results above $0.2 \mu \mathrm{g} /$ day were considered to contain occupationally derived uranium. The net amount attributed to occupational sources was calculated as the total observed amount minus the average expected environmental level of $0.06 \mu \mathrm{g} /$ day.

A second study of background uranium levels in urine commenced in 1990. Urine samples were collected from 20 nonoccupationally exposed workers in early 1990 with the intent of collecting quarterly samples from each worker throughout the year, as well as samples of their drinking water. The workers were selected to provide an indication of the possible correlation between drinking water sources and urinary excretion. Due to the cancellation of the analytical support services laboratory contract this study was terminated following collection of the first samples. However, the data are useful as a comparison with the 1985 data and, as can be seen in Figure 8.2, show some very interesting variations. The geometric mean of this sample group was $0.024 \mu \mathrm{g} /$ day with a 99.9 percentile of $2.8 \mu \mathrm{g} /$ day. The $0.2-\mu \mathrm{g} /$ day value used as the 99.9 percentile for the 1985 data corresponds more closely to a 99 


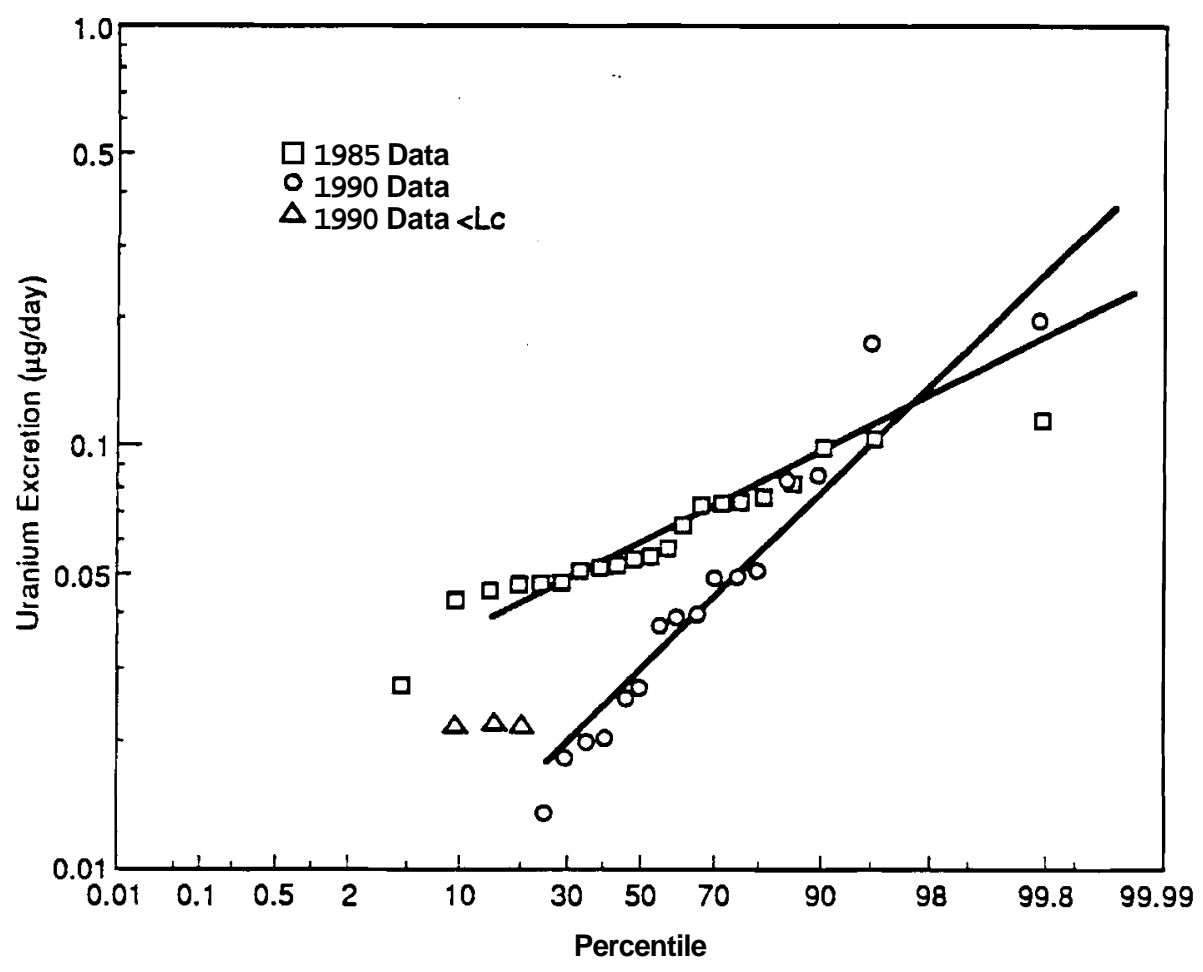

58009064.1

FIGURE 8.2. Urinary Excretion of Uranium in Unexposed Hanford Workers

percentile for the 1990 data, implying that one in a hundred (rather than one in a thousand) samples from occupationally unexposed workers might exceed it.

At least two factors contribute to these apparent differences. First, the workers sampled were a substantially different subset than the first group; whereas the 1985 subjects were primarily from two large municipal water systems, the 1990 subjects were carefully selected to provide an indication of possible impact from water consumption in numerous outlying communities around Hanford. Second, a significant change in the analytical process occurred during the time that elapsed between the two sets of samples - namely, the practice of subtracting reagent blanks from sample results was initiated. Interpretation of the 1990 data is still considered preliminary.

Fecal excretion of uranium from ingestion of nonoccupational sources of uranium in the Hanford environs has not been studied in a manner similar to 
that of urine excretion. Lacking Hanford-specific information, it is assumed that the ICRP Reference Man values of 1.4 to $1.8 \mu \mathrm{g} /$ day are reasonable.

\subsection{BIOKINETIC BEHAVIOR OF URANIUM}

The inhalation class, particle size, distribution, retention, excretion and chemical toxicity of uranium are included here in the discussion of its biokinetic behavior.

\subsubsection{Inhalation Class}

Table 8.5 provides transportability classifications for uranium compounds as recommended in ICRP 30 . Unless special dissolution analysis is performed, these assigned classifications are used. Special dissolution studies have been performed for uranium handled in the U03 Plant, the FPF, and the 306-W Building. (See Section 8.7.)

\subsubsection{Particle Size}

Unless determined by specific measurements, it is assumed that the AMAD for uranium particulates is $1 \mu \mathrm{m}$. Particle sizing has been performed in several facilities using a cascade impactor and, where available, the results of the measurements are provided in Section 8.7.2.

\subsubsection{Distribution. Retention, and Excretion}

For the design of monitoring programs and for the assessment of dose equivalents when there is insufficient bioassay measurement data to develop

TABLE 8.5. Inhalation Classes and $f_{1}$ Values for Some Uranium Compounds (a)

$\underline{\text { Class }}$

D

W
Compounds

$\mathrm{UF}_{6}, \mathrm{UO}_{2} \mathrm{~F}_{2}, \mathrm{UO}_{2}\left(\mathrm{NO}_{3}\right)_{2}$

$\mathrm{UO}_{3}, \mathrm{UF}_{4}, \mathrm{UCT}_{4}$

$\mathrm{UO}_{2}, \mathrm{U}_{3} \mathrm{O}_{8}$ $f_{1}$

0.05

0.05

0.002

(a) Dissolution studies of uranium at Hanford have resulted in some modification to the values shown in this table. Hanford specific values are given in Section 8.7. 
individual-specific characteristics, the distribution, retention, and excretion of uranium are assumed to follow the biokinetic model described in ICRP 30. This model assigns the transportability classes shown in Table 8.5. For material entering the systemic circulation, fractions 0.2 and 0.023 are assumed to go to mineral bone and be retained there with half-lives of 20 and 5000 days, respectively; fractions 0.12 and 0.00052 are assumed to go to the kidneys and to be retained with half-1ives of 6 and 1500 days, respectively; and fractions 0.12 and 0.00052 are assumed to go to all other tissues of the body and be retained with half-lives of 6 and 1500 days, respectively. Uranium is assumed to be uniformly distributed among these other tissues. Fraction 0.54 of the uranium entering the systemic circulation is assumed to go directly to excretion. Long-lived uranium isotopes entering the bone are assumed to be distributed uniformly throughout the bone volume.

Selected lung retention, urinary, and fecal excretion functions for acute and chronic inhalations are tabulated in Tables 8.6, 8.7, and 8.8. These factors were calculated using the computer code GENMOD (Johnson and Carver 1981; see Appendix A).

\subsubsection{Chemical Toxicity}

Because of the comparatively high mass-to-activity ratio at low enrichments $\left(<10 \%{ }^{235} U\right)$, consideration is given to the potential toxicological effects of an intake in addition to the radiological effects. For readily transportable uranium of low enrichment, concerns about chemical toxicity predominate; and for slowly transportable uranium, concerns about the radiation dose received by the lung following inhalation predominate.

The following subsections provide additional guidance for evaluating bioassay data to determine the potential toxicological effects of chronic and acute exposure.

\section{Chronic Exposure}

A chronic kidney burden of $3 \mu \mathrm{g} / \mathrm{g}$ of kidney has historically been the basis for development of action levels for bioassay monitoring of workers who are chronically exposed to uranium (Hursh and Spoor 1973). Recent studies with the most highly transportable and toxic form of uranium, $\mathrm{UO}_{2} \mathrm{~F}_{2}$, indicate 
TABLE 8.6. Lung Retention Factors Following Inhalation of Uranium $(a, b, c)$

\begin{tabular}{|c|c|c|c|c|c|c|}
\hline \multirow{3}{*}{$\begin{array}{l}\text { Days } \\
\text { Post } \\
\text { Intake }\end{array}$} & \multicolumn{3}{|c|}{ Acute Inhalation } & \multicolumn{3}{|c|}{ Chronic Inhalation } \\
\hline & $\overline{\text { Class D }}$ & Class W & Class $Y$ & $\overline{\text { Class D }}$ & Class W & Class Y \\
\hline & Lunq & Lunq & Lunq & Lung & Lunq & Luna \\
\hline 0 & $3.3 \mathrm{E}-1$ & $3.3 \mathrm{E}-1$ & $3.3 \mathrm{E}-1$ & $0.0 \mathrm{E}-0$ & $0.0 \mathrm{E}-0$ & $0.0 \mathrm{E}-0$ \\
\hline 1 & $1.4 \mathrm{E}-1$ & $2.2 \mathrm{E}-1$ & $2.2 \mathrm{E}-1$ & $2.7 \mathrm{E}-1$ & $2.7 E-1$ & $2.6 \mathrm{E}-1$ \\
\hline 2 & $4.3 \mathrm{E}-2$ & $1.8 \mathrm{E}-1$ & $1.8 \mathrm{E}-1$ & $3.6 \mathrm{E}-1$ & $4.7 \mathrm{E}-1$ & $4.5 \mathrm{E}-1$ \\
\hline 5 & $1.1 \mathrm{E}-3$ & $1.5 \mathrm{E}-1$ & $1.5 \mathrm{E}-1$ & $3.9 \mathrm{E}-1$ & $9.4 E-1$ & $9.4 \mathrm{E}-1$ \\
\hline 7 & $8.1 \mathrm{E}-5$ & $1.4 \mathrm{E}-1$ & $1.5 \mathrm{E}-1$ & $3.9 \mathrm{E}-1$ & $1.2 \mathrm{E}+0$ & $1.2 \mathrm{E}+0$ \\
\hline 14 & 0.0 EtO & $1.3 \mathrm{E}-1$ & $1.5 \mathrm{E}-1$ & $3.9 \mathrm{E}-1$ & $2.2 E+0$ & $2.3 E+0$ \\
\hline 30 & $0.0 \mathrm{EtO}$ & $1.0 \mathrm{E}-1$ & $1.4 \mathrm{E}-1$ & $3.9 \mathrm{E}-1$ & 4. OEtO & $4.6 \mathrm{E}+0$ \\
\hline 60 & 0.0 EtO & $7.0 \mathrm{E}-2$ & $1.4 \mathrm{E}-1$ & $3.9 \mathrm{E}-1$ & $6.5 \mathrm{E}+0$ & $8.9 \mathrm{E}+0$ \\
\hline 90 & $0.0 \mathrm{EtO}$ & $4.8 E-2$ & $1.4 \mathrm{E}-1$ & $3.9 \mathrm{E}-1$ & $8.3 E+0$ & $1.3 E+1$ \\
\hline 180 & $0.0 \mathrm{EtO}$ & $1.5 \mathrm{E}-2$ & $1.3 \mathrm{E}-1$ & $3.9 \mathrm{E}-1$ & $1.1 E+1$ & $2.5 E+1$ \\
\hline 365 & 0. OEtO & $1.4 \mathrm{E}-3$ & $1.0 \mathrm{E}-1$ & $3.9 \mathrm{E}-1$ & $1.2 \mathrm{E}+1$ & $4.6 \mathrm{E}+1$ \\
\hline 730 & 0.0 EtO & $1.1 \mathrm{E}-5$ & $7.3 \mathrm{E}-2$ & $3.9 \mathrm{E}-1$ & $1.2 \mathrm{E}+1$ & $7.8 \mathrm{E}+1$ \\
\hline 1825 & $0.0 \mathrm{EtO}$ & $1.3 \mathrm{E}-9$ & $2.9 \mathrm{E}-2$ & $3.9 \mathrm{E}-1$ & $1.2 \mathrm{E}+1$ & $1.3 E+2$ \\
\hline 3650 & 0.0 EtO & 0.0 EtO & $9.6 \mathrm{E}-3$ & $3.9 \mathrm{E}-1$ & $1.2 \mathrm{E}+1$ & $1.6 \mathrm{E}+2$ \\
\hline 7300 & $0.0 \mathrm{EtO}$ & 0.0 EtO & $4.2 E-3$ & $3.9 \mathrm{E}-1$ & $1.2 \mathrm{E}+1$ & $1.8 E+2$ \\
\hline 18,250 & $0.0 \mathrm{EtO}$ & 0.0 EtO & $3.8 \mathrm{E}-3$ & $3.9 \mathrm{E}-1$ & $1.2 \mathrm{E}+1$ & $2.2 E+2$ \\
\hline
\end{tabular}

(a) Factors are expressed as a fraction (or multiple) of acute intake or

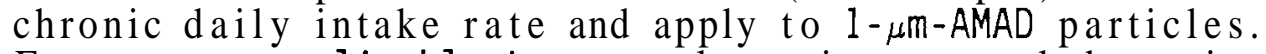

(b) Factors a applifable to natural uranium, recycled uranium, depleted uranium, $234 \mathrm{~d}, 235_{U}, 238 \mathrm{U}$, or any combination thereof.

(c) Lung includes pulmonary lymph nodes.

that steady-state kidney concentrations of $3 \mu \mathrm{g} / \mathrm{g}$ in dogs were sufficient to produce indications of uranium poisoning (Morrow et al. 1982). Although $\mathrm{UO}_{2} \mathrm{~F}_{2}$ is not handled at Hanford, it is prudent for bioassay monitoring purposes to assume a renal toxicity threshold of less than $3 \mu \mathrm{g} / \mathrm{g}$ of kidney. Based on recent studies by a number of investigators, current consensus is that the "no effect" threshold for uranium in kidney is $1.1 \mu \mathrm{g} / \mathrm{g}$ (Rich et al. 1988). As an additional conservative measure, this technical basis uses $0.4 \mu \mathrm{g} / \mathrm{g}$ (onethird of the $1.1-\mu \mathrm{g} / \mathrm{g}$ value, rounded to one significant figure) for routine bioassay monitoring as described in Sections 8.5.2, 8.7.1, and Table 8.20. 
TABLE 8.7. Urinary Excretion Factors Following Inhalation of Uranium(a,b)

\begin{tabular}{|c|c|c|c|c|c|c|}
\hline Days & & te Inhal & & & ic Inhal & \\
\hline Post & $\overline{\text { Class D }}$ & Class W & Class Y & $\overline{\text { Class D }}$ & Class W & Class Y \\
\hline$\underline{\text { Intake }}$ & $\underline{\text { Urinary }}$ & $\underline{\text { Urinary }}$ & $\underline{\text { Urinary }}$ & Urinary & Urinary & Urinary \\
\hline 0 & $0.0 E+0$ & $0.0 E+0$ & $0.0 E+0$ & $0.0 \mathrm{E}-0$ & $0.0 \mathrm{E}-0$ & $0.0 \mathrm{E}-0$ \\
\hline 1 & $1.0 \mathrm{E}-1$ & $1.6 \mathrm{E}-2$ & $8.0 \mathrm{E}-4$ & $1.9 \mathrm{E}-1$ & $4.2 \mathrm{E}-2$ & $2.2 \mathrm{E}-3$ \\
\hline 2 & $4.1 \mathrm{E}-2$ & $5.5 E-3$ & $2.7 E-4$ & $2.6 \mathrm{E}-1$ & $5.1 \mathrm{E}-2$ & $2.7 \mathrm{E}-3$ \\
\hline 5 & $1.2 \mathrm{E}-2$ & $2.5 E-3$ & $1.2 E-4$ & $3.2 \mathrm{E}-1$ & $6.1 \mathrm{E}-2$ & $3.2 \mathrm{E}-3$ \\
\hline 7 & $9.4 \mathrm{E}-3$ & $2.1 \mathrm{E}-3$ & $1.0 \mathrm{E}-4$ & $3.4 \mathrm{E}-1$ & $6.6 \mathrm{E}-2$ & $3.4 \mathrm{E}-3$ \\
\hline 14 & $5.1 \mathrm{E}-3$ & $1.4 \mathrm{E}-3$ & $6.3 E-5$ & $3.8 \mathrm{E}-1$ & $7.7 \mathrm{E}-2$ & $4.0 \mathrm{E}-3$ \\
\hline 30 & $1.7 \mathrm{E}-3$ & $7.2 E-4$ & $3.2 E-5$ & $4.3 \mathrm{E}-1$ & $9.3 \mathrm{E}-2$ & $4.7 \mathrm{E}-3$ \\
\hline 60 & $4.5 E-4$ & $4.1 \mathrm{E}-4$ & $2.2 E-5$ & $4.6 \mathrm{E}-1$ & $1.1 \mathrm{E}-1$ & $5.4 \mathrm{E}-3$ \\
\hline 90 & $1.5 \mathrm{E}-4$ & $2.7 E-4$ & $1.9 \mathrm{E}-5$ & $4.7 \mathrm{E}-1$ & $1.2 \mathrm{E}-1$ & $6.0 \mathrm{E}-3$ \\
\hline 180 & $8.5 E-6$ & $9.4 E-5$ & $1.8 \mathrm{E}-5$ & $4.7 \mathrm{E}-1$ & $1.3 \mathrm{E}-1$ & $7.7 E-3$ \\
\hline 365 & $1.7 \mathrm{E}-6$ & $1.1 \mathrm{E}-5$ & $1.8 \mathrm{E}-5$ & $4.7 \mathrm{E}-1$ & $1.4 \mathrm{E}-1$ & $1.1 \mathrm{E}-2$ \\
\hline 730 & $1.6 \mathrm{E}-6$ & $5.8 \mathrm{E}-7$ & $1.7 \mathrm{E}-5$ & $4.7 \mathrm{E}-1$ & $1.4 \mathrm{E}-1$ & $1.7 \mathrm{E}-2$ \\
\hline 1825 & $1.3 \mathrm{E}-6$ & $3.9 \mathrm{E}-7$ & $1.1 \mathrm{E}-5$ & $4.7 \mathrm{E}-1$ & $1.4 \mathrm{E}-1$ & $3.3 E-2$ \\
\hline 3650 & $9.7 \mathrm{E}-7$ & $2.9 \mathrm{E}-7$ & $3.8 E-6$ & $4.8 \mathrm{E}-1$ & $1.4 \mathrm{E}-1$ & $4.5 \mathrm{E}-2$ \\
\hline 7300 & $5.7 \mathrm{E}-7$ & $1.7 \mathrm{E}-7$ & $3.7 \mathrm{E}-7$ & $4.8 \mathrm{E}-1$ & $1.4 \mathrm{E}-1$ & $5.0 \mathrm{E}-2$ \\
\hline 18,250 & $1.2 \mathrm{E}-7$ & $3.7 \mathrm{E}-8$ & $1.7 \mathrm{E}-8$ & $4.8 \mathrm{E}-1$ & $1.5 \mathrm{E}-1$ & $5.1 \mathrm{E}-2$ \\
\hline
\end{tabular}

(a) Factors are expressed as a fraction (or multiple) of acute intake or chronic daily intake rate and apply to $1-\mu \mathrm{m}-\mathrm{AMAD}$ particles. (b) Factors are applicable to natural uranium, recycled uranium, depleted
uranium, $234 \mathrm{U}, 235_{U}, 238$, or any combination thereof.

\section{Acute Exposure}

Guidance for a maximum single acute intake of uranium has been provided in ICRP 6 (1964), based on work by Eve (1964). Eve's analysis was derived from the assumption that a daily intake of $2.5 \mathrm{mg}$ of uranium could be tolerated without harm. Of more relevance for acute intakes are the results of human injection studies that have shown that an uptake of $0.07 \mathrm{mg}$ of hexavalent uranium per kilogram of body weight produced transient injury and $0.1 \mathrm{mg} / \mathrm{kg}$ produced catal asuria and proteinuria (Hursh and Spoor 1973). More recent studies of the highly soluble uranyl fluoride $\left(\mathrm{UO}_{2} \mathrm{~F}_{2}\right)$ showed that 
TABLE 8.8. Fecal Excretion Factors Following Inhal ation of Uranium $(a, b)$

\begin{tabular}{|c|c|c|c|c|c|c|}
\hline \multirow{3}{*}{$\begin{array}{r}\text { Days } \\
\text { Post } \\
\text { Intake } \\
\end{array}$} & \multicolumn{3}{|c|}{ Acute Inhalation } & \multicolumn{3}{|c|}{ Chronic Inhalation } \\
\hline & $\overline{C l a s s ~ D}$ & Class W & $\overline{\text { Class Y }}$ & Class D & Class N & Class Y \\
\hline & Fecal & Fecal & Fecal & Fecal & Fecal & Fecal \\
\hline 0 & $0.0 E+0$ & $0.0 \mathrm{E}+0$ & $0.0 E+0$ & $0.0 \mathrm{E}-0$ & $0.0 \mathrm{E}-0$ & $0.0 \mathrm{E}-0$ \\
\hline 1 & $6.8 \mathrm{E}-2$ & $1.0 \mathrm{E}-1$ & $1.3 \mathrm{E}-1$ & $4.1 E-2$ & $3.9 E-2$ & $5.0 E-2$ \\
\hline 2 & $4.2 \mathrm{E}-2$ & $1.3 \mathrm{E}-1$ & $1.6 \mathrm{E}-1$ & $9.8 \mathrm{E}-2$ & $1.6 \mathrm{E}-1$ & $2.1 \mathrm{E}-1$ \\
\hline 5 & $2.7 \mathrm{E}-3$ & $2.2 \mathrm{E}-2$ & $2.4 \mathrm{E}-2$ & $1.4 \mathrm{E}-1$ & $3.6 \mathrm{E}-1$ & $4.4 \mathrm{E}-1$ \\
\hline 7 & $3.7 E-4$ & $6.0 \mathrm{E}-3$ & $5.5 E-3$ & $1.5 \mathrm{E}-1$ & $3.9 \mathrm{E}-1$ & $4.7 E-1$ \\
\hline 14 & $0.0 \mathrm{E}+0$ & $1.2 \mathrm{E}-3$ & $1.7 \mathrm{E}-4$ & $1.5 \mathrm{E}-1$ & 4. $\mathrm{OE}-1$ & $4.8 E-1$ \\
\hline 30 & $0.0 E+0$ & $8.9 E-4$ & $1.3 E-4$ & $1.5 \mathrm{E}-1$ & $4.2 \mathrm{E}-1$ & $4.8 \mathrm{E}-1$ \\
\hline 60 & $0.0 E+0$ & $5.9 E-4$ & $1.3 \mathrm{E}-4$ & $1.5 \mathrm{E}-1$ & $4.4 \mathrm{E}-1$ & $4.8 E-1$ \\
\hline 90 & $0.0 \mathrm{E}+0$ & $3.9 E-4$ & $1.2 \mathrm{E}-4$ & $1.5 \mathrm{E}-1$ & $4.6 \mathrm{E}-1$ & $4.9 E-1$ \\
\hline 180 & $0.0 E+0$ & $1.1 E-4$ & $1.1 \mathrm{E}-4$ & $1.5 \mathrm{E}-1$ & $4.8 \mathrm{E}-1$ & $5.0 E-1$ \\
\hline 365 & $0.0 E+0$ & $8.6 \mathrm{E}-6$ & $8.4 E-5$ & $1.5 \mathrm{E}-1$ & $4.8 \mathrm{E}-1$ & $5.2 \mathrm{E}-1$ \\
\hline 730 & $0.0 E+0$ & $5.6 E-8$ & $5.0 \mathrm{E}-5$ & $1.5 \mathrm{E}-1$ & $4.8 E-1$ & $5.4 E-1$ \\
\hline 1825 & $0.0 E+0$ & $0.0 E+0$ & $1.1 E-5$ & $1.5 \mathrm{E}-1$ & $4.8 E-1$ & $5.7 \mathrm{E}-1$ \\
\hline 3650 & $0.0 E+0$ & $0.0 E+0$ & $1.4 \mathrm{E}-6$ & $1.5 \mathrm{E}-1$ & $4.8 E-1$ & $5.7 \mathrm{E}-1$ \\
\hline 7300 & $0.0 E+0$ & $0.0 E+0$ & $4.5 \mathrm{E}-0$ & $1.5 \mathrm{E}-1$ & $4.8 \mathrm{E}-1$ & $5.7 \mathrm{E}-1$ \\
\hline 18,250 & $0.0 E+0$ & $0.0 \mathrm{E}+0$ & $0.0 E+0$ & $1.5 \mathrm{E}-1$ & $4.8 \mathrm{E}-1$ & $5.7 \mathrm{E}-1$ \\
\hline
\end{tabular}

(a) Factors are expressed as a fraction (or multiple) of acute intake or chronic daily intake rate and apply to 1- $\mu$ m-AMAD particles.

(b) Factors are applíable $338^{\text {to }}$ natural uranium, recycled uranium, depleted uranium, ${ }^{234} \mathrm{U} ;{ }^{235},{ }^{238} \mathrm{U}$, or any combination thereof.

intravenous doses of $0.01 \mathrm{mgU} / \mathrm{kg}$ of body weight for dogs and $0.1 \mathrm{mg} / \mathrm{kg}$ of body weight for rats were nephrotoxic, and that the threshold for injury in man was thought to be about $0.07 \mathrm{mgU} / \mathrm{kg}$ of body weight (Morrow et al. 1982). The renal toxicity of uranium varies with the compound form, with toxicity increasing with chemical solubility (Morrow et al. 1982).

Uranium compounds encountered during production operations at Hanford range from the highly soluble uranyl nitrate, $\mathrm{UO}_{2}\left(\mathrm{NO}_{3}\right)_{2}$, to somewhat less soluble uranium trioxide, $\mathrm{UO}_{3}$, to relatively insoluble uranium oxides, $\mathrm{UO}_{2}$ and $\mathrm{U}_{3} \mathrm{O}_{8}$. The highly reactive uranium hexafluoride, $\mathrm{UF}_{6}$, and uranyl fluoride, 
$\mathrm{UO}_{2} \mathrm{~F}_{2}$, are not handled at Hanford. For the purpose of establishing action levels for bioassay monitoring, a renal toxicity threshold of $0.1 \mathrm{ng}$ acute uptake to blood per kilogram of body weight or a 7-mg acute uptake for Reference Mn is established. This corresponds to an acute inhalation of $15 \mathrm{mg}$ of Class D uranium.

\section{Update on Chemical Toxicity}

Since the foregoing discussion on chemical toxicity of uranium was written in 1989, additional publications have appeared on the subject, raising some question as to the appropriate assumption for a "no effects threshold level" of uranium intake, uptake, or kidney burden. In an extensive review article, Leggett (1989) noted that results and conclusions of studies have varied widely and that "apparent discrepancies may be due largely to differences in 1) perceptions and/or definitions of toxicity, 2) sensitivity of the measurements of kidney damage or dysfunction, 3) patterns of exposure (for example, acute versus chronic), and 4) sensitivity to renal $U$ in different species." Leggett concluded that "it may be prudent to lower this longstanding guidance level [of $3 \mu \mathrm{gU} / \mathrm{g}$ ] by roughly an order of magnitude until more is known about subtle physiological effects of small quantities of $U$ in the kidneys." Similar sentiment was expressed by SuLu and Zhao (1990) in recommending a maximum safe uranium burden in the kidney of $0.26 \mu \mathrm{g} / \mathrm{g}$, based on a 10-fold safety factor below mild kidney impairment observed in one human case at $2.6 \mu \mathrm{gU} / \mathrm{g}$. McGuire (1990) concluded that an intake of soluble uranium of $10 \mathrm{ng}$ or less is unlikely to have any detectable (even transient) effects, and that a $40 \mathrm{ng}$ intake (possibly as high as $100 \mathrm{mg}$ ) is likely to be below the level of any permanent effects. These levels are all within a factor of 2 to 3 of those proposed in the first release of this document (Sula, Carbaugh, and Bihl 1989).

Considering that Leggett noted that the early researchers cited ranges of "much less than $5 \mu \mathrm{g} / \mathrm{g}$, probably 2 to $3 \mu \mathrm{g} / \mathrm{g}$ " rather than absolute values, the question of a $1.1 \mu \mathrm{g} / \mathrm{g}$ versus a $0.3 \mu \mathrm{g} / \mathrm{g}$ "no effects" threshold relates more to a matter of an assumed factor for conservativeness rather than actual linkage to identifiable effects. 


\subsection{INTERNAL DOSIMETRY FOR URANIUM}

Specific effective energy (SEE) factors for uranium isotopes are provided in Table 8.9, and weighted SEE factors for reference uranium isotope mixtures are shown in Table 8.10. From the tables it is seen that doses are essentially the same on a "per nanocurie" basis for natural uranium, recycled uranium, and ${ }^{236} U$. Thus, for a rough "rule of thumb," dose from intakes of recycled or natural uranium can be evaluated on a per alpha activity basis using dosimetry factors for ${ }^{236} U$. Table 8.11 gives first-year and 50 -year committed doses from an acute inhalation intake of $1 \mathrm{nCi}$ of "natural" uranium without any other radio-nuclide impurities. These dose factors can also be used directly for evaluating intakes of recycled uranium if consideration is also given to the presence of impurity radionuclides as discussed below.

TABLE 8.9. Specific Effective Energy Factors for Uranium Isotopes(a)

\begin{tabular}{llcc} 
& \multicolumn{3}{c}{ Mev/q-transformation (source=target) } \\
\cline { 2 - 4 } & $\underline{\text { Lunq }}$ & $\underline{\text { Bone Surfaces }}$ & $\underline{\text { Kidney }}$ \\
$234_{U}$ & 0.097 & 0.014 & 0.31 \\
$235_{U}$ & 0.089 & 0.013 & 0.29 \\
$236_{U}$ & 0.092 & 0.013 & 0.30 \\
$238_{U}$ & 0.085 & 0.012 & 0.28
\end{tabular}

(a) From ICRP 30 (1979).

TABLE 8.10. Weighted Specific Effective Energy Factors for Hanford Uranium Mixtures

Uranium

Mixture

Natural

Depleted

U03-RU

FPF-RU
$\mathrm{MeV} / \mathrm{q}$-Transformation

\begin{tabular}{lcc}
\hline$\underline{\text { Lung }}$ & Bone Surfaces & Kidney \\
0.091 & 0.013 & 0.30 \\
0.085 & 0.012 & 0.28 \\
0.092 & 0.013 & 0.30 \\
0.092 & 0.013 & 0.30
\end{tabular}


TABLE 8.11. First-Year and 50-Year Commitfed Dose Equivalents Following Inhalation of $1 \mathrm{nCi}$ (a) of Natural Uranium

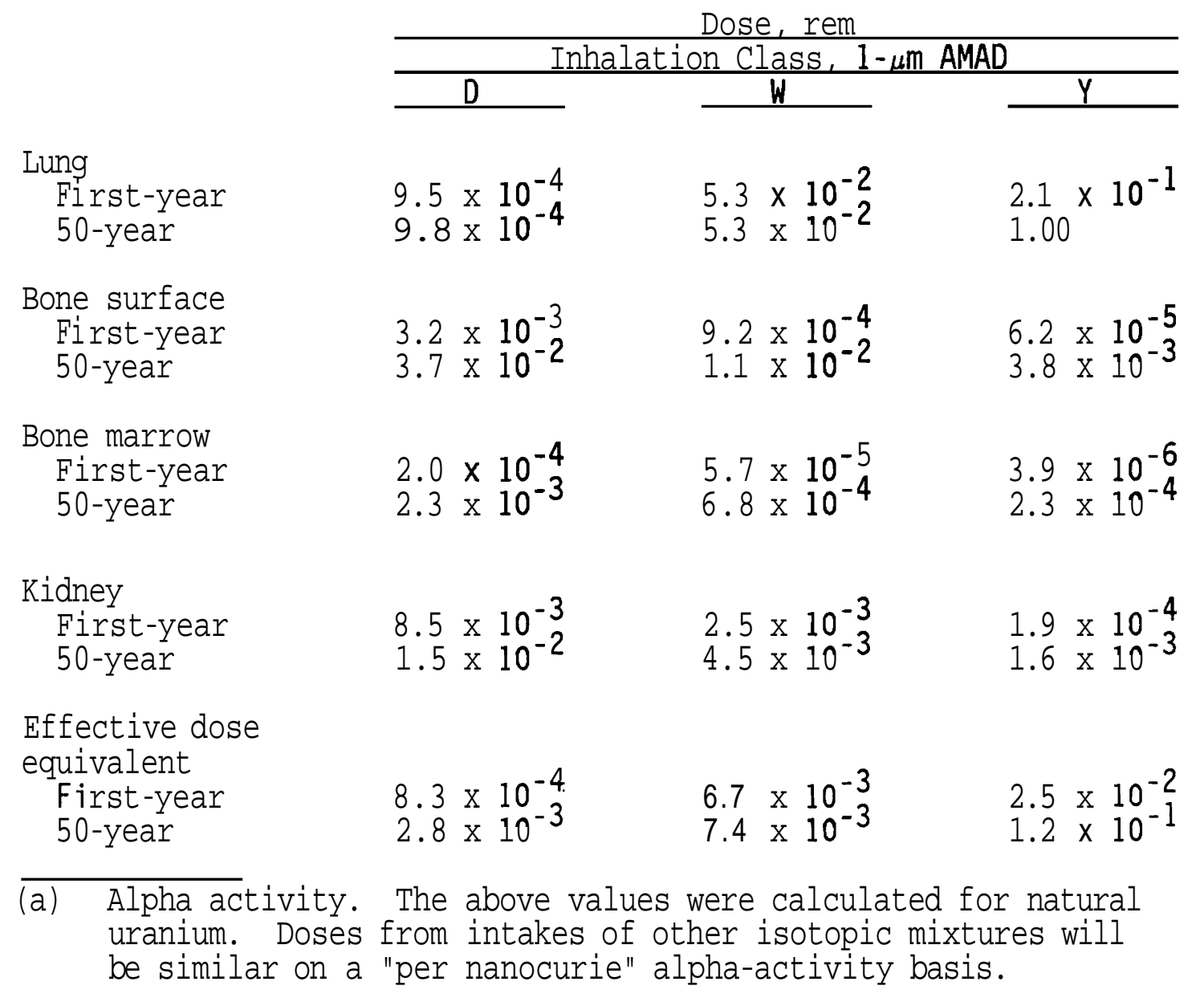

Impurity radionuclides present in recycled uranium must be considered in dose assessments. Table 8.12 summarizes the contributions to the 50-year committed effective dose equivalent from the presence of reference levels of impurities in recycled uranium. From the table, it is seen that impurities do not significantly affect doses from class y recycled uranium intakes, but do contribute sufficiently to doses of class $D$ and class $W$ intakes to warrant their consideration. Table 8.13 shows the factors that can be used to modify the doses from recycled uranium mixtures present in the U03 Plant and the $\mathrm{N}$ Reactor FPF. 
TABLE 8.12. Committed Effective Dose Equivalent from Inhalation of Recycled Uranium, ${ }^{(a)}$ Reference Mixture

Committed Effective Dose Equivalent

\begin{tabular}{|c|c|c|c|}
\hline & $\begin{array}{r}\text { Comm } \\
\text { Per Gram }\end{array}$ & $\begin{array}{l}\text { ective Dc } \\
\text { n Inhalec }\end{array}$ & $\begin{array}{l}\text { valent } \\
\text { uranium }\end{array}$ \\
\hline Constituent & $\underline{\text { Class D }}$ & Class W & Class-Y \\
\hline Recycled Uranium & 2.5 & 6.6 & 110 \\
\hline Pu-alpha(b) & $0.2^{(c)}$ & 0.2 & 0.14 \\
\hline${ }^{237} \mathrm{~Np}$ & $0.2^{(c)}$ & 0.2 & $0.2^{(d)}$ \\
\hline${ }^{232} \mathrm{Th}$ & 0.008 & 0.008 & 0.006 \\
\hline${ }^{99} \mathrm{Tc}$ & 0.0002 & 0.002 & $0.002^{(d)}$ \\
\hline${ }^{106} \mathrm{Ru}$ & 0.003 & 0.004 & 0.018 \\
\hline${ }^{95} \mathrm{Zr}$ & $\underline{0.0004}$ & $\underline{0.0003}$ & $\underline{0.0004}$ \\
\hline Total & 2.9 & 7.0 & 110 \\
\hline $\begin{array}{l}\text { Ratio of total } \\
\text { to U only dose }\end{array}$ & 1.16 & 1.06 & 1.00 \\
\hline
\end{tabular}

(a) Assuming 1- $\mu$ m-AMAD particulate.

(b) Assuming aged 6\% grade plutonium (see Section 9.0).

(c) Class Dinhalation characteristics are generally considered to not exist for this nuclide, thus class $W$ behavior is assumed.

(d) Class $Y$ inhalation characteristics are generally considered to not exist for this nuclide, thus class $W$ behavior is assumed.

Contributions to total dose from non-uranium impurity radionuclides may be estimated by multiplying the annual and committed dose from uranium isotopes by the ratio of the total 50-year committed effective dose equivalent to the committed dose from uranium activity alone, as given in Table 8.12 or Table 8.13. This represents an adequate assessment of the total dose for cases involving annual effective dose equivalents on the order of $100 \mathrm{mrem} / \mathrm{yr}$ or less. If annual effective doses significantly exceed $100 \mathrm{mrem} / \mathrm{yr}$, then consideration should be given to evaluating the annual dose for impurity radionuclides separately and adding to the dose from uranium isotopes. If intakes are sufficiently high that depositions of impurity radionuclides may be observable via bioassay measurements, then such measurements should be performed. 
TABLE 8.13. Dose Factors from Reference Levels of Non-Uranium Impurities in Recycled Uranium

\begin{tabular}{|c|c|c|}
\hline Material & $\begin{array}{c}\text { Inhalation } \\
\text { Class } \\
\end{array}$ & $\begin{array}{l}\text { Total to Uranium Only } \\
\text { Dose Factor }\end{array}$ \\
\hline $\mathrm{U} 03-\mathrm{RU}$ & $80 \% \quad D, 20 \% W$ & 1.14 \\
\hline FPF-RU (333 Bldg) & $30 \% \mathrm{D}, 70 \% \mathrm{Y}$ & 1.04 \\
\hline FPF-RU (303-M B1dg) & $10 \% \mathrm{D}, 90 \% \mathrm{Y}$ & 1.02 \\
\hline
\end{tabular}

Tables 8.14 and 8.15 give intake effective dose equivalent factors for acute or chronic intakes of uranium isotopes and reference mixtures, including the contribution from reference levels of impurities.

\subsection{BIOASSAY FOR URANIUM}

Bioassay monitoring procedures for uranium include excreta analysis and in vivo measurements. Urinalysis is an indicator of systemically deposited uranium; fecal analysis provides an indication of the amount of uranium that is being cleared from the lung; and in vivo counting provides a direct measurement of the quantity of uranium in the lung. The following subsections discuss urine sampling, fecal excretion, in vivo measurement, the routine bioassay monitoring program, and bioassay measurements following a potential acute intake.

\subsubsection{Urine Sampling}

The interpretation of urinalysis measurements is highly dependent on knowledge of the time and duration of the intake and on assumptions regarding the biokinetic transport and excretion of systemically absorbed uranium. Standard biokinetic models provide estimated uranium excretion rates in terms of daily output (i.e., micrograms per day). The influence of diurnal variations in urination frequency and volume may be lessened if a full 24-hour collection is obtained rather than a single grab sample.

According to ICRP 30, studies of the metabolism of uranium in man show that a significant amount of uranium entering the circulatory system (54\%) is not deposited in body tissue but instead passes directly to excretion. The 
TABLE 8.14. Acute Intake Dose Conversion Factors for 1- $\mu \mathrm{m}$-AMAD Particles

\begin{tabular}{|c|c|c|c|c|}
\hline \multirow[b]{2}{*}{ Class D } & \multicolumn{2}{|c|}{$\begin{array}{c}\text { Activity Intake DCF, } \\
\mathrm{rem} / \mathrm{nCiU} / \mathrm{day}\end{array}$} & \multicolumn{2}{|c|}{$\begin{array}{c}\text { Mass Intake DCF. } \\
\mathrm{rem} / \mathrm{mqU} / \mathrm{day}\end{array}$} \\
\hline & First-Year & $50-Y e a r$ & First-Year & 50-Yea \\
\hline $\begin{array}{l}238 U \\
236 U \\
235 U \\
234 U \\
\text { U-Nat } \\
\text { U-Dep } \\
\text { U-Rec }\end{array}$ & $\begin{array}{l}8.0 \mathrm{E}-4 \\
8.6 \mathrm{E}-4 \\
8.4 \mathrm{E}-4 \\
9.0 \mathrm{E}-4 \\
8.3 \mathrm{E}-4 \\
7.8 \mathrm{E}-4 \\
1.0 \mathrm{E}-3\end{array}$ & $\begin{array}{l}2.7 \mathrm{E}-3 \\
2.9 \mathrm{E}-3 \\
2.8 \mathrm{E}-3 \\
3.1 \mathrm{E}-3 \\
2.8 \mathrm{E}-3 \\
2.6 \mathrm{E}-3 \\
3.2 \mathrm{E}-3\end{array}$ & $\begin{array}{l}2.7 \mathrm{E}-4 \\
5.5 \mathrm{E}-2 \\
1.8 \mathrm{E}-3 \\
5.6 \mathrm{E}+0 \\
5.7 \mathrm{E}-4 \\
2.8 \mathrm{E}-4 \\
9.1 \mathrm{E}-4\end{array}$ & $\begin{array}{l}9.0 \mathrm{E}-4 \\
1.9 \mathrm{E}-1 \\
6.1 \mathrm{E}-3 \\
1.9 \mathrm{E}+1 \\
1.9 \mathrm{E}-3 \\
9.1 \mathrm{E}-4 \\
2.9 \mathrm{E}-3\end{array}$ \\
\hline $\begin{array}{l}\text { Class W } \\
238 \mathrm{U} \\
236_{U} \\
235_{U} \\
234_{U} \\
\text { U-Nat } \\
\text { U-Dep } \\
\text { U-Rec }\end{array}$ & $\begin{array}{l}6.4 \mathrm{E}-3 \\
7.0 \mathrm{E}-3 \\
6.8 \mathrm{E}-3 \\
7.3 \mathrm{E}-3 \\
6.7 \mathrm{E}-3 \\
6.4 \mathrm{E}-3 \\
7.4 \mathrm{E}-3\end{array}$ & $\begin{array}{l}7.1 \mathrm{E}-3 \\
7.6 \mathrm{E}-3 \\
7.4 \mathrm{E}-3 \\
8.0 \mathrm{E}-3 \\
7.4 \mathrm{E}-3 \\
7.2 \mathrm{E}-3 \\
7.8 \mathrm{E}-3\end{array}$ & $\begin{array}{l}2.2 \mathrm{E}-3 \\
4.5 \mathrm{E}-1 \\
1.5 \mathrm{E}-2 \\
4.6 \mathrm{E}+1 \\
4.6 \mathrm{E}-3 \\
2.3 \mathrm{E}-3 \\
6.7 \mathrm{E}-3\end{array}$ & $\begin{array}{l}2.4 \mathrm{E}-3 \\
4.9 \mathrm{E}-1 \\
1.6 \mathrm{E}-2 \\
5.0 \mathrm{E}+1 \\
5.1 \mathrm{E}-3 \\
2.6 \mathrm{E}-3 \\
7.0 \mathrm{E}-3\end{array}$ \\
\hline $\begin{array}{l}\text { Class Y } \\
238_{U} \\
236_{U} \\
235_{U} \\
234 U \\
\text { U-Nat } \\
\text { U-Dep } \\
\text { U-Rec }\end{array}$ & $\begin{array}{l}2.4 \mathrm{E}-2 \\
2.6 \mathrm{E}-2 \\
2.5 \mathrm{E}-2 \\
2.8 \mathrm{E}-2 \\
2.5 \mathrm{E}-2 \\
2.3 \mathrm{E}-2 \\
2.6 \mathrm{E}-2\end{array}$ & $\begin{array}{l}1.2 \mathrm{E}-1 \\
1.3 \mathrm{E}-1 \\
1.2 \mathrm{E}-1 \\
1.3 \mathrm{E}-1 \\
1.2 \mathrm{E}-1 \\
1.1 \mathrm{E}-1 \\
1.2 \mathrm{E}-1\end{array}$ & $\begin{array}{l}8.1 \mathrm{E}-3 \\
1.7 \mathrm{E}+0 \\
5.5 \mathrm{E}-2 \\
1.7 \mathrm{E}+2 \\
1.7 \mathrm{E}-2 \\
8.3 \mathrm{E}-3 \\
2.3 \mathrm{E}-2\end{array}$ & $\begin{array}{l}4.9 \mathrm{E}-2 \\
8.2 \mathrm{E}+0 \\
2.7 \mathrm{E}-1 \\
8.4 \mathrm{E}+2 \\
9.2 \mathrm{E}-2 \\
4.0 \mathrm{E}-2 \\
1.1 \mathrm{E}-1\end{array}$ \\
\hline $\begin{array}{l}\text { Facility Spec } \\
221-U \text { B1dg(a) } \\
\text { U03-RU }\end{array}$ & $2.3 E-3$ & $4.3 E-3$ & $2.1 E-3$ & $3.9 \mathrm{E}-3$ \\
\hline $\begin{array}{l}333 \mathrm{Bldg}(\mathrm{b}) \\
\text { FPF-RU }\end{array}$ & $1.8 \mathrm{E}-2$ & $8.7 E-2$ & $1.6 \mathrm{E}-2$ & $7.8 E-2$ \\
\hline $\begin{array}{l}\text { 303-M Bldg (c) } \\
\text { FPF-RU }\end{array}$ & $2.3 E-2$ & $1.1 \mathrm{E}-1$ & $2.1 E-2$ & $9.9 E-2$ \\
\hline $\begin{array}{l}306-W \text { Bldg }(d) \\
306 W-D U\end{array}$ & $1.9 \mathrm{E}-2$ & $8.9 E-2$ & $6.7 \mathrm{E}-3$ & $3.2 E-2$ \\
\hline
\end{tabular}

\footnotetext{
(a) U03-RU (221-U Building) is $80 \%$ class D and $20 \%$ class W (see Section 8.7).

(b) FPF-RU (333 Building) is $30 \%$ class D and $70 \%$ class $Y$ (see Section 8.7 ).

(c) FPF-RU (303-M Building) is $10 \%$ class $D$ and $90 \%$ class $Y$ (see Section 8.7).

(d) 306W-DU (306-W Building) is $20 \%$ class D and $80 \%$ class $Y$ (see Section 8.7).
} 
TABLE 8.15. Chronic (365 days/year) Intake Dose Conversion Factors for 1- $\mu \mathrm{m}$-AMAD Particles

Activity Intake DCF, rem oer nCiU/d

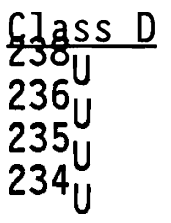

$\mathrm{U}-\mathrm{Nat}$

U-Dep

$\mathrm{U}-\operatorname{Rec}$

Class W

$236 U$
235
234

U-Nat

U-Dep

U-Rec

Class $Y$

236

235

$234 \mathrm{U}$

$\mathrm{U}-\mathrm{Nat}$

$U$-Dep

U-Rec
$\underline{50-Y e a r}$

9.6E-1

1. $0 \mathrm{E}+0$

1. $0 E+0$

$1.1 \mathrm{E}+0$

1. $0 \mathrm{EtO}$

9.1E-0

$1.0 E+0$

2. $4 \mathrm{E}+0$

$2.5 \mathrm{E}+0$

2. $5 \mathrm{E}+0$

$2.6 \mathrm{E}+0$

2. $5 \mathrm{E}+0$

$2.4 \mathrm{E}+0$

2. $9 \mathrm{E}+0$
Mass Intake DCF, rem per mqU/d

First-Year 50-Year

$8.7 E-2$

$3.5 \mathrm{E}-1$

1.7E+1

$6.8 \mathrm{E}+1$

$5.8 \mathrm{E}-1$

2. $3 \mathrm{E}+0$

7. $2 \mathrm{E}+3$

$7.2 \mathrm{E}-1$

$3.3 \mathrm{E}-1$

$9.4 \mathrm{E}-1$

$1.8 \mathrm{E}-1$

2. $4 \mathrm{E}-1$

$6.4 \mathrm{E}-1$

$7.8 \mathrm{E}-1$

$1.6 \mathrm{E}+2$

$5.2 E+0$

$1.6 \mathrm{E}+4$

$1.7 \mathrm{E}+0$

$8.7 \mathrm{E}-1$

$2.6 \mathrm{E}+0$

4. $3 \mathrm{E}+0$

$1.3 \mathrm{E}+4$

$1.4 \mathrm{E}+0$

7.2E-1

2. $1 \mathrm{E}+0$

$1.4 \mathrm{E}+1$

3. $0 E+3$

$9.7 E+1$

3. $0 E+5$

3. $0 \mathrm{E}+1$

1. $5 \mathrm{E}+1$

4. $1 E+1$

Facility Specific Data 221-U B1dg(d)

\begin{tabular}{|c|c|c|c|c|}
\hline U03-RU & $7.4 \mathrm{E}-1$ & $1.4 \mathrm{E}+0$ & $6.7 \mathrm{E}-1$ & 1. $3 E+0$ \\
\hline $\begin{array}{l}333 \mathrm{Bldg}(\mathrm{b}) \\
\text { FPF-RU }\end{array}$ & $3.7 E+0$ & $3.2 E+1$ & $3.4 \mathrm{E}+0$ & $2.9 \mathrm{E}+1$ \\
\hline $\begin{array}{l}303-M \text { B1dg(c) } \\
\text { FPF-RU }\end{array}$ & $4.6 \mathrm{E}+0$ & $4.0 E+1$ & $4.3 \mathrm{E}+0$ & $3.7 E+1$ \\
\hline $\begin{array}{l}306-W \text { Bldg } \\
306 W-D U\end{array}$ & $3.7 E+0$ & $1.3 \mathrm{E}+1$ & $1.4 \mathrm{E}+0$ & $1.2 \mathrm{E}+1$ \\
\hline
\end{tabular}

(a) U03-RU (221-U Building) is $80 \%$ class $D$ and $20 \%$ class W (see Section 8.7).

(b) FPF-RU (333 Building) is $30 \%$ class $D$ and $70 \%$ class $Y$ (see Section 8.7 )

(c) FPF-RU (303-M Building) is $10 \%$ class D and $90 \%$ class $Y$ (see Section 8.7).

(d) $306 \mathrm{~W}-\mathrm{DU}$ (306-W Building) is $20 \%$ class D and $80 \%$ class $Y$ (see Section 8.7). 
excretion of this unabsorbed fraction can result in highly variable urinary levels under conditions of ongoing repeated or chronic exposure as depicted in Figure 8.3. Table 8.1 (Section 8.2.3) shows urine excretion factors for selected days following acute or chronic intake of 1- $\mu$ m-AMAD particles.

Because of the possible large time variability in uranium excretion rates due to this unabsorbed fraction, quantitative interpretation of bioassay data is best accomplished by either collecting all of the unabsorbed fraction (i.e., that voided during the first several days after exposure) or by collecting samples after the unabsorbed fraction has been eliminated. For routine sampling of potentially chronically exposed workers, it is desirable to collect the urine sample several days after any possible exposure. For the initial evaluation of potentially significant uptakes of uranium, a single void sample within 3 to 4 hours of the exposure is appropriate.

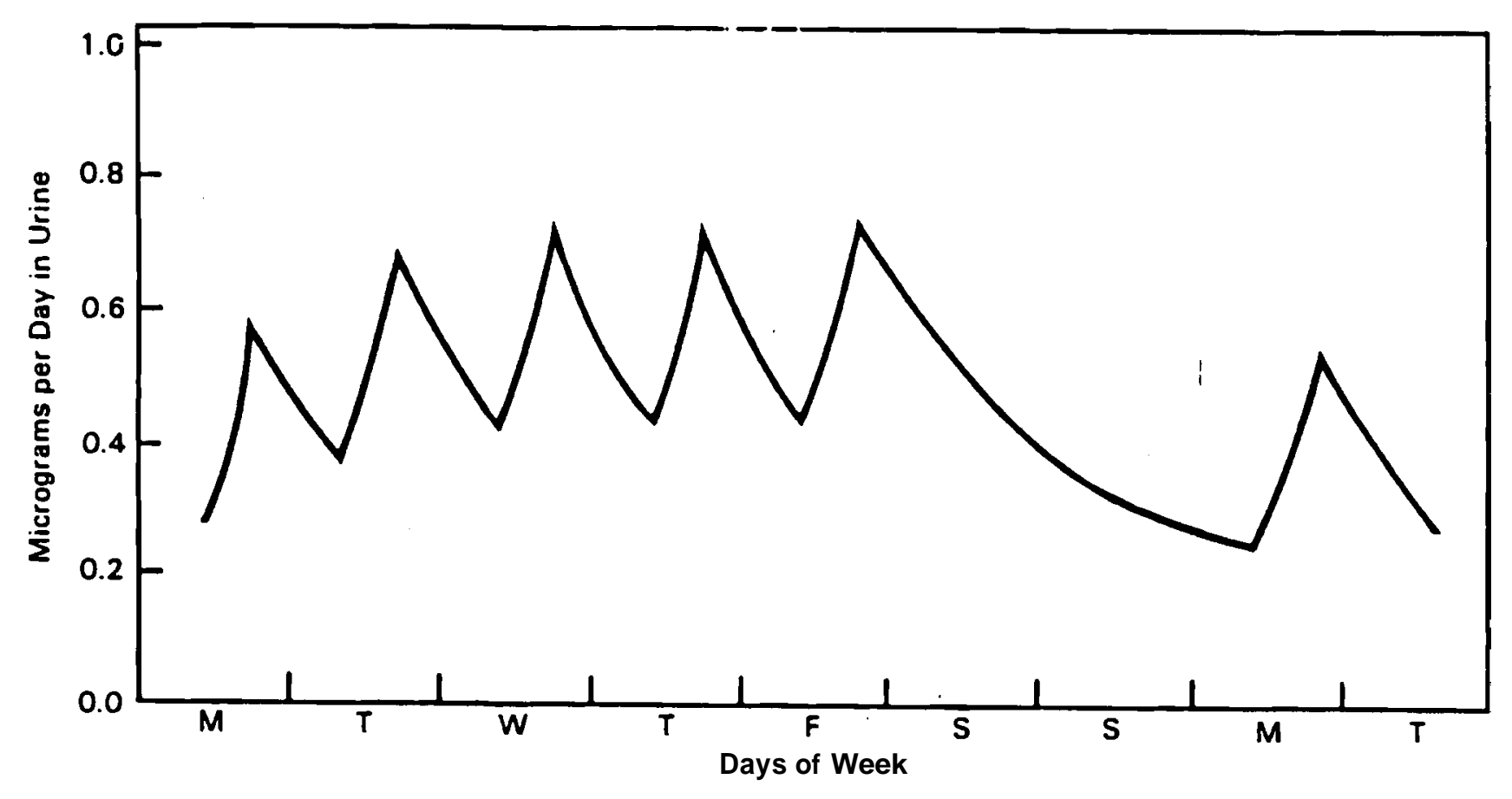

FIGURE 8.3. Daily Variability in Instantaneous Urinary Excretion from Chronic Inhalation of $1 \mathrm{mg} /$ workday of Class 0 Uranium (Curve shown is for 52nd week of exposure.) 
For the reasons stated above, the optimum urine sample for a routine uranium bioassay sampling program is a 24-hour total urine collection following several days' absence from any source of intake. Because this is not always practicable to implement on a large scale, simulated 24-hour or simulated 12-hour samples are commonly used. The simulated 12-hour sample consists of urine voided between one-half hour of retiring to bed in the evening and one-half hour after rising. The 24-hour simulated sample consists of two 12-hour simulated samples collected on consecutive days. For the initial evaluation of bioassay measurement results, the result in terms of $\mu \mathrm{g} / \mathrm{sample}$ may be normalized to a single day's excretion using reference volumes of $1400 \mathrm{~mL} /$ day for males and $1000 \mathrm{~mL} /$ day for females.

The sensitivity of urine sampling is limited by the presence of environmental levels of uranium. As discussed previously, it is estimated that environmental levels in urine locally average $0.06 \mu \mathrm{g} /$ day and range from $<0.03 \mu \mathrm{g} /$ day to $0.2 \mu \mathrm{g} /$ day. The net occupationally derived uranium in urine can be approximated by subtracting $0.06 \mu \mathrm{g} /$ day from the observed total daily excretion.

Figure 8.4 shows expected excretion rates following an acute inhalation of natural uranium resulting in a first-year effective dose equivalent of 100 mrem. Samples containing less than $0.2 \mu \mathrm{g}$ /day of uranium are generally considered to be within the expected environmental range. As such, any result above $0.2 \mu \mathrm{g} /$ day is considered to contain occupationally derived uranium and the net amount attributed to occupational sources is generally calculated as the total observed amount minus the averaqe expected environmental level of $0.06 \mu \mathrm{g} /$ day. Thus, $0.14 \mu \mathrm{g} /$ day becomes the de facto minimum detectable occupational urine excretion rate. From Figure 8.4, it can be seen that this means that acute inhalation intakes of class W material at the 100-mrem firstyear effective dose equivalent level could be detected via urinalysis measurements for a year after intake. Class $D$ intakes at this level could be detectable for about 10 months, and class $Y$ intakes could be detectable for only about 2 months. 


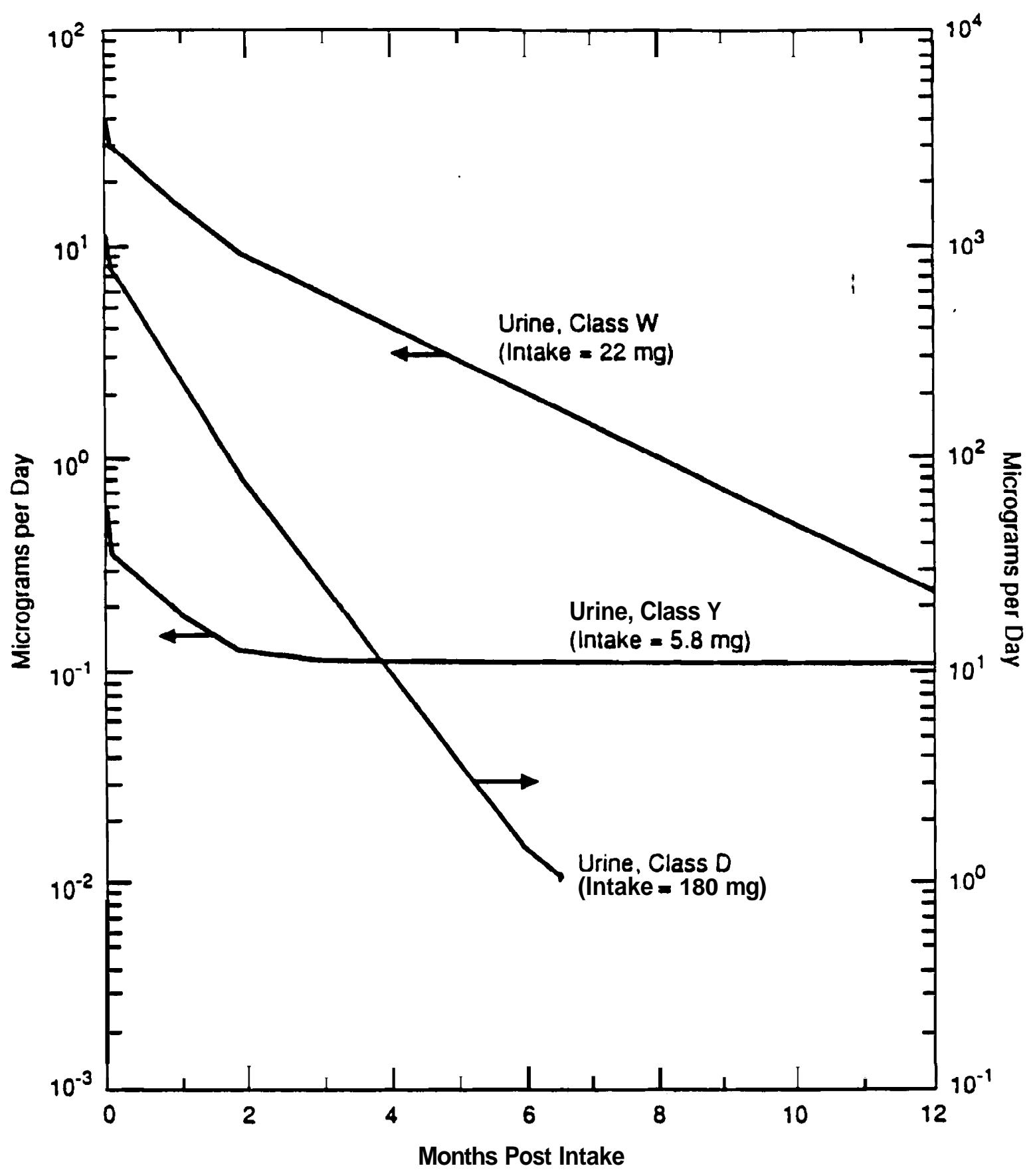

FIGURE 8.4. Net Long-Term Urinary Excretion Following an Acute Inhalation of Natural Uranium Resulting in a First-Year Effective Dose Equivalent of 100 mrem (curves exclude excretion of environmental uranium) 
Of special importance in the evaluation of bioassay measurement capability is the potential for chronic intakes. Any chronic exposure subsequent to an acute intake could significantly affect the interpretation of the urinalysis measurement. In facilities where uncontained uranium is handled, urinalysis as a means for monitoring for acute intakes is acceptable, but quantitative assessment of intake or dose equivalent based on the results of routine urine samples is subject to large uncertainties. Assessment of intakes of poorly transportable uranium using urinalysis should be cautiously performed and should consider available in vivo measurement results and other information regarding the exposure.

\subsubsection{Fecal Excretion Measurements}

Through the application of the TGLD model (ICRP 1979; see Appendix D), estimates can be made of the expected daily fecal excretion of uranium following an inhalation intake. Clearance of uranium via feces can be divided into two components: that which represents rapid clearance from the respiratory tract and that which represents longer-term clearance from the pulmonary region and systemic circulation. For evaluation of an inhalation of slowly transportable uranium, the measurement of the quantity of uranium excreted via feces during the first few days following the intake can provide a basis for estimating the significance of the intake, when levels are below that detectable using in vivo techniques. Table 8.16 gives the ratio of intake and in $\mathrm{i}$ tial, long-term pulmonary deposition to the rapidly clearing component of the intake for three particle sizes of class Y material. The table also provides the estimated ratio between this component and the first-year effective dose equivalent. Table 8.8 (Section 8.2.3) provides fecal excretion factors for selected days post intake following an acute or chronic intake of 1 - $\mu \mathrm{m}$-AMAD particles.

Because the quantity of uranium ingested daily through food is about $2 \mu \mathrm{g}$, it is generally not practicable to use fecal sampling as a routine bioassay monitoring technique. However, it can be used effectively following incidents or for monitoring of potential intakes of enriched uranium. 
TABLE 8.16. Comparison of Rapid Clearance(a) via the Gastrointestinal Tract with Intake, Initial Long-Term Pulmonary Deposition, and First-Year Effective Dose Equivalent for Class Y Uranium

\begin{tabular}{|c|c|c|c|}
\hline & \multicolumn{3}{|c|}{$\begin{array}{c}\text { Quantity per Nanocurie Cleared } \\
\text { Rapidly via the GI Tract }\end{array}$} \\
\hline & $\underline{0.30 \mu \mathrm{m}}$ & $1.0 \mu \mathrm{m}$ & $3.0 \mu \mathrm{m}$ \\
\hline $\begin{array}{l}\text { Intake/ } \\
\text { Rapid Clearance }\end{array}$ & $3.0 \mathrm{nCi}$ & $2.1 \mathrm{nCi}$ & $1.4 \mathrm{nCi}$ \\
\hline $\begin{array}{l}\text { Pulmonary Deposition/ } \\
\text { Rapid Clearance }\end{array}$ & $0.76 \mathrm{nCi}$ & $0.31 \mathrm{nCi}$ & $0.11 \mathrm{nCi}$ \\
\hline $\begin{array}{l}\text { First-Year EDE }{ }^{(b)} / \\
\text { Rapid Clearance }\end{array}$ & $130 \mathrm{mrem}$ & $53 \mathrm{mrem}$ & $18 \mathrm{mrem}$ \\
\hline $\begin{array}{l}50-\text { Year Committed EDE/ } \\
\text { Rapid Clearance }\end{array}$ & 620 mrem & 250 mrem & 87 mrem \\
\hline
\end{tabular}
(a) Rapid clearance means complete clearance from all short-lived compartments in the respiratory tract.
(b) $E D E$ = effective dose equivalent.

\subsubsection{In Vivo Measurements}

Uranium is detectable in the lung using in vivo techniques. Detection is achieved by measuring photon emissions from ${ }^{235} U$ and ${ }^{234} \mathrm{Th}$. Thorium-234 is a decay product of ${ }^{238} \mathrm{U}$ in secular equilibrium. Techniques for in vivo measurements are discussed by Palmer et al. (1990).

Table 8.17 gives the MDAs of ${ }^{235} U$ and ${ }^{238} U$ by some typical in vivo chest counts using an array of six germanium detectors. These MDAs are derived from the three-sigma MDA data by Palmer et al. (1990) and adjusted to the ANSI N13.30 (1989) definition of MDA (4.65-sigma). Table 8.18 shows the capability of chest counting in terms of detectable dose.

Figures 8.5 and 8.6 show the expected activity of natural and depleted uranium in the lung following an acute intake resulting in a 100-mrem annual effective dose equivalent. Figure 8.5 illustrates that in vivo counting would not be able to detect activity in the lung resulting from an acute intake of class $Y$ uranium of 100-mrem first-year effective dose equivalent, even for a 4000-second count. Figure 8.6 shows that detection of an intake of class $W$ 
TABLE 8.17. Sensitivity of an In Vivo Chest Examination for Uranium

\begin{tabular}{|c|c|c|}
\hline Count Time, sec & ${ }^{235} \mathrm{U}, \mathrm{nCi}$ & $\left.{ }^{238} \mathrm{U}_{-}{ }^{234} \mathrm{Th}\right),(\mathrm{a})$ \\
\hline 1000 & 0.17 & $2.6\left(7.6 \mathrm{mg}{ }^{238} \mathrm{U}\right)$ \\
\hline 2000 & 0.12 & $1.8\left(5.4 \mathrm{mg}{ }^{238} \mathrm{U}\right)$ \\
\hline 4000 & 0.085 & $1.3\left(3.8 \mathrm{mg}{ }^{238} \mathrm{U}\right)$ \\
\hline
\end{tabular}

(a) Assuming secular equilibrium with $238_{U}$

TABLE 8.18. Sensitivity of an In Vivo Chest Count in Terms of First-Year and 50-Year Committed Effective Dose Equivalent Following Acute Inhalation of 1- $\mu \mathrm{m}-\mathrm{AMAD}$, Class Y Uranium(a)

\begin{tabular}{|c|c|c|c|c|c|c|}
\hline \multirow{3}{*}{$\begin{array}{l}\text { Days Post } \\
\text { Intake }\end{array}$} & \multicolumn{6}{|c|}{ Effective Dose Equivalent, rem } \\
\hline & \multirow{3}{*}{$\frac{\text { U-Nat }}{0.57}$} & \multirow{2}{*}{\multicolumn{2}{|c|}{$\begin{array}{l}\text { First-Year } \\
\underline{U \text {-Dep }} \quad \underline{U-R e c}(b)\end{array}$}} & \multicolumn{3}{|c|}{ 50-Year Committed } \\
\hline & & & & $\underline{\text { U-Nat }}$ & $\underline{\text { U-Dep }}$ & $\underline{U-\operatorname{Rec}(b)}$ \\
\hline 7 & & 0.28 & 0.76 & 2.7 & 1.3 & 3.6 \\
\hline 30 & 0.57 & 0.28 & 0.76 & 2.7 & 1.3 & 3.6 \\
\hline 60 & 0.61 & 0.30 & 0.81 & 2.9 & 1.4 & 3.9 \\
\hline 90 & 0.61 & 0.30 & 0.81 & 2.9 & 1.4 & 3.9 \\
\hline 180 & 0.66 & 0.33 & 0.88 & 3.2 & 1.6 & 4.3 \\
\hline 365 & 0.85 & 0.42 & 1.1 & 4.1 & 2.0 & 5.5 \\
\hline 730 & 1.1 & 0.55 & 1.5 & 5.3 & 2.7 & 7.1 \\
\hline 1825 & 2.8 & 1.4 & 3.7 & 13.0 & 6.7 & 17.0 \\
\hline Constant burden & 0.66 & 0.33 & 0.88 & 3.2 & 1.6 & 4.3 \\
\hline
\end{tabular}

(a) 2380 -secpnd count for natural and recycled uranium, but much poorer for depleted uranium.

(b) Recycled uranium, specific activity of $2.0 \mathrm{dpm} / \mu \mathrm{g}$.

uranium at the 100-mrem first-year dose equivalent level is possible only for depleted uranium--and then only if the measurement was performed within a week or so of the intake. Because of the relatively rapid removal of readily transportable (class D) forms of uranium from the lung, in vivo measurements do not provide a useful bioassay technique for these materials. 


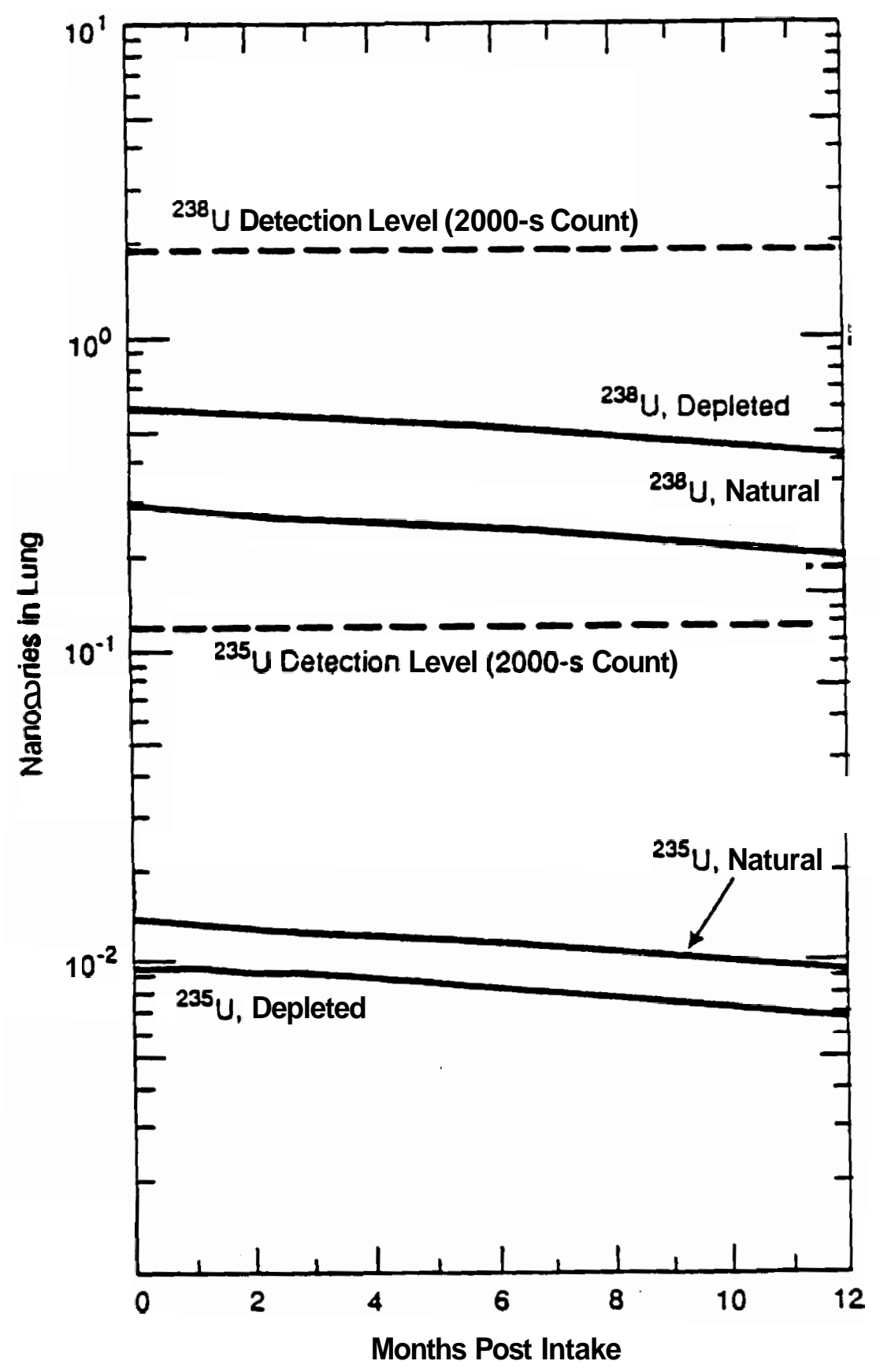

FGURE 8.5. Predicted Long-Term Retained Quantities in the Lung Following an Acute Inhalation of Class Y Uranium Resulting in a First-Year Effective Dose Equivalent of 100 mrem 


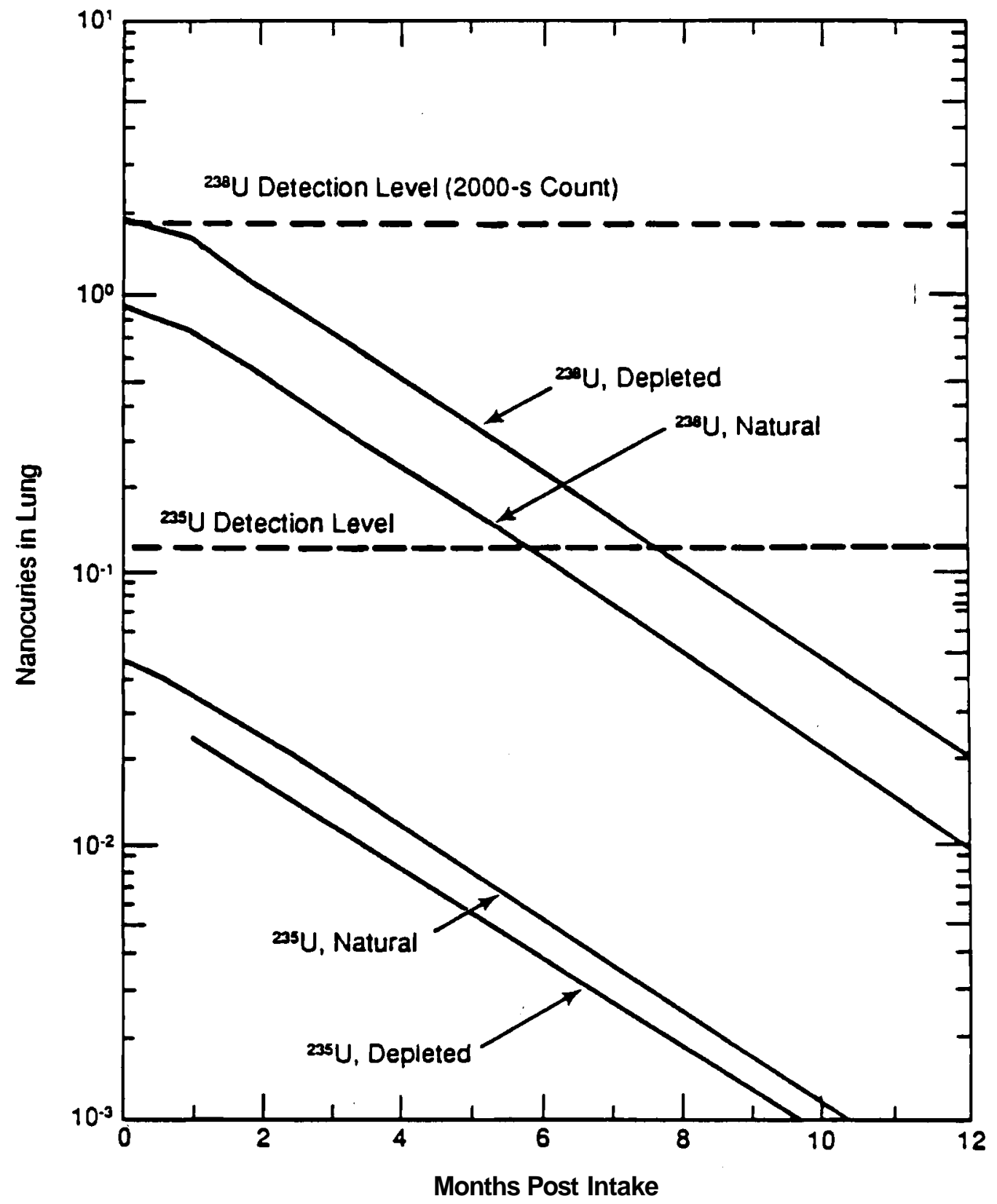

FIGURE 8.6. Predicted Long-Term Retained Quantities in the Lung Following an Acute Inhalation of Class W Uranium Resulting in a First-Year Effective Dose Equivalent of 100 mrem

In vivo measurements of ${ }^{235} U$ and ${ }^{234}$ Th are used as indicators of natural and recycled uranium based on the isotopic compositions shown in Table 8.3. These compositions and the MOAs of Table 8.17 show that ${ }^{234}$ Th is a more sensitive indicator of natural uranium than ${ }^{235} U$ and a comparably sensitive 
indicator of recycled uranium. These two results, obtained from a single in vivo chest measurement, can be used as independent verification of the presence of uranium, or alternatively as a method of identifying potential false-positive detections. For example, the relative isotopic activity abundance of ${ }^{238} U$ to ${ }^{235} U$ for a mixture can be multiplied by the detected amount of ${ }^{235} \mathrm{U}$. This result (the ${ }^{238} \mathrm{U}$ implied by the ${ }^{235} \mathrm{U}$ measurement) can then be compared with the ${ }^{234} \mathrm{Th}$ (assumed to be in equilibrium with the ${ }^{238} \mathrm{U}$ ) to determine if the measurements reasonably agree.

\subsubsection{Routine Bioassay Monitoring Proqram}

The preceding section discusses the capabilities and limitations of bioassay for uranium in terms of limits of detection and interpretation of results. In particular, it is evident that current routine bioassay measurement programs are generally not sensitive enough for desired prospective monitoring for poorly transported forms of uranium. As such, it is generally necessary to rely on workplace monitoring to detect potential internal exposures. Follow-up urine and fecal sampling, initiated promptly upon indication of a potential internal exposure, can detect intakes resulting in a firstyear effective dose equivalent of $100 \mathrm{mrem}$. Routine bioassay monitoring should thus be considered to supplement the facility monitoring program and provide backup verification that significant (relative to the occupational exposure standards) internal exposures are not occurring.

Table 8.19 summarizes routine bioassay monitoring capabilities based on radiological considerations for several monitoring frequencies when it can be assumed that exposures will be acute and infrequent. The doses shown are for natural uranium; however, capabilities for both depleted and recycled uranium can be easily obtained as described in the footnotes to the table. Table 8.19 gives routine monitoring capabilities for readily transportable uranium based on consideration of chemical toxicity. The values in Table 8.20 are independent of specific activity or impurity radionuclide levels.

In vivo measurements are the preferred routine bioassay monitoring method for poorly transportable (class Y) forms of uranium, because they measure the lung deposition directly and because urine samples are easily biased by low level intakes of relatively soluble uranium. However, due to the 
TABLE 8.19. Routine Bioassay Monitoring Capabilities $\mathrm{f} g \vec{r}$ a Single Acute Inhalation of Natural Uranium(a)

\begin{tabular}{|c|c|c|c|c|}
\hline \multirow{2}{*}{$\begin{array}{c}\text { Inhalation } \\
\text { Class } \\
\end{array}$} & \multirow{2}{*}{$\begin{array}{c}\text { Type of } \\
\text { Measurement } \\
\end{array}$} & \multirow[b]{2}{*}{ Frequency } & \multicolumn{2}{|c|}{$\begin{array}{c}\text { Dose Eaui val ent } \\
\end{array}$} \\
\hline & & & First-Year & 50-Yr Committed \\
\hline \multirow[t]{9}{*}{$Y$} & In vivo(b) & Annual & 850 mrem & $4100 \mathrm{mrem}$ \\
\hline & & Semiannual & 660 mrem & 3200 mrem \\
\hline & & Quarterly & 610 mrem & 2900 mrem \\
\hline & & Monthly & 570 mrem & 2700 mrem \\
\hline & Urinalysis $(\mathrm{c})$ & Annual & 125 mrem & 600 mrem \\
\hline & & Semi annual & 125 mrem & $600 \mathrm{mrem}$ \\
\hline & & Quarterly & 125 mrem & $600 \mathrm{mrem}$ \\
\hline & & Monthly & 70 mrem & 340 mrem \\
\hline & & Biweekly & 40 mrem & 190 mrem \\
\hline \multirow[t]{6}{*}{ W } & In vivo(b) & Quarterly & 670 mrem & 740 mrem \\
\hline & $r)$ & Monthly & 360 mrem & 400 mrem \\
\hline & Urinalysis $(\mathrm{C})$ & Annual & 69 mrem & 76 mrem \\
\hline & & Semi annual & 7 mrem & 8 mrem \\
\hline & & Quarterly & $2 \mathrm{mrem}$ & $2 \mathrm{mrem}$ \\
\hline & & Monthly & $<1$ mrem & $<1$ mrem \\
\hline \multirow{6}{*}{ D } & In vivo & & Recommended & \\
\hline & Urinalysis (d) & Quarterly & 4 mrem & 14 mrem \\
\hline & & Bimonthly & $1 \mathrm{mrem}$ & 3 mrem \\
\hline & & Monthly & $<1$ mrem & $1 \mathrm{mrem}$ \\
\hline & & Biweekly & $<1$ mrem & $<1$ mrem \\
\hline & & Weekly & $<1$ mrem & $<1$ mrem \\
\hline
\end{tabular}

(a) This is a summary table for natural uranium. Bioassay capabilities for depleted and recycled uranium can be easily derived from the information in this table as follows:

- for depleted uranium, multiply the doses in the table by 0.5 .

- for recycled uranium, multiply the doses in the table by:

- 1.5 for class D

- 1.4 for class W

- 1.3 for class $Y$

These factors account for impurity radionuclides in recycled uranium as well as for specific activity differences in natural, depleted, and recycled uranium.

(b) 2000-second chest count.

(c) Sample is a simulated 24-hour excretion. Threshold of detection is $0.14 \mu \mathrm{g} /$ day, based on the assumption that daily excretion greater than $0.2 \mu \mathrm{g}$ can be attributed primarily to occupationally derived sources and that $0.06 \mu \mathrm{g}$ is the average daily environmental uranium in urine.

(d) Sample is a simulated 12-hour excretion. The minimum detectable activity is $1 \mu \mathrm{g} /$ day. 
TABLE 8.20. Routine Urinalysis Monitoring Capabilities for a Single Acute Intake of Class D Uranium in Pêrcent of the Threshold for Acute Toxicity (TAT) (a,b)

\begin{tabular}{lc} 
Sample Frequency & Percent TAT \\
\cline { 2 - 2 } Quarterty & 50 \\
Bimonthly & 17 \\
Monthly & 4 \\
Biweekly & 1 \\
Weekly & $<1$ \\
& \\
(a) Based on a minimum detectable \\
(b) TAT is a acute of $1 \mu \mathrm{gU} / \mathrm{d}$. \\
of 7 mgU.
\end{tabular}

limited ability to detect uranium in vivo, urinalysis is useful as a supplementary method and is recommended when in vivo measurements are unable to detect exposures at the $100-\mathrm{mrem} / \mathrm{yr}$ level.

The interpretation of routine urinalysis measurements is highly dependent on the nature of the intake, i.e., low-level chronic exposure conditions significantly affect the interpretation of bioassay measurements. Chronic exposure to uranium occurs in the U03 Plant, FPF, and the 306-W Building, and therefore it is difficult to use urine sampling as the standard routine bioassay monitoring technique for acute intakes in these facilities. Instead, bioassay programs for these facilities are developed based on the assumption of chronic exposure and are described in Section 8.7. In other cases, it can be generally assumed that chronic exposures do not occur; i.e., that intakes are acute.

\subsubsection{Bioassay Measurements Following a Potential Acute Intake}

Bioassay monitoring should be initiated promptly upon indication that a potential acute intake has occurred. The primary consideration in determining the appropriate measurements is the mode of intake and the clearance rate of the material from the initial deposition site. For readily transportable materials, urine sampling to determine kidney burden is required. For slowly 
transportable material, in vivo measurements and collection of early fecal excretion are necessary. For unknown forms or mixtures with a range of transportabilities, both urine and fecal samples are recommended in addition to lung counts.

For potential intakes of readily transportable forms of uranium, a urine sample should be collected and analyzed within 12 hours of the intake. If preliminary information indicates that a significant intake was likely, the contractor should be advised to contact HEHF Occupational Medicine promptly for medical support. (See also Section 8.6.)

\subsection{ASSESSMENT OF INTERNAL DOSE}

Internal dose assessment can be performed for acute or chronic intakes using the methods described in Section 8.5.1. The kidney burden and potential chemical toxicity associated with uranium intakes are discussed in Section 8.5.2.

\subsubsection{Assessment of Dose Equivalent}

Assessment of internal dose equivalents from intakes of uranium is preferably based on evaluation of bioassay measurements. The choice of bioassay measurement depends on consideration of the transportability of the inhaled material and the nature of the exposure. Generally, urinalysis measurements are most indicative of systemically deposited uranium, and in vivo measurements provide a measure of lung burden. The potential for mixed chronic and acute intakes complicates the interpretation of available data and must be carefully considered during the evaluation process.

Experience has shown that actual uranium exposures usually involve varying mixtures of inhalation classes and particle sizes that are not adequately represented by a single classification. If there is no basis for establishing the inhalation class and particle size characteristics of the intake, then it is prudent to assume a class Y material with a particle AMAD of $1 \mu \mathrm{m}$ for evaluation of dose equivalent. Evaluations of potential for renal damage, based on urinalysis, are relatively insensitive to transportability and particle variations. If either the threshold for toxicity or an annual effective 
dose equivalent of 100 mrem is exceeded, simplifying assumptions should be reviewed for their appropriateness and additional bioassay and other measurements should be performed, as necessary, to improve the quality of the assessment.

Special care should be taken to account for the isotopic composition of the uranium. For example, the dose equivalent for an intake of recycled uranium, such as is present at the $\mathbf{N}$ Reactor FPF, will exceed the dose equivalent from an equal mass of natural uranium by about 33\% because of the higher specific alpha activity. Impurity radionuclides present in the recycled uranium can also increase the magnitude of the internal dose received, particularly for soluble forms of uranium. Section 8.7 provides facility-specific uranium dosimetry data for the U03 Plant, the N Reactor FPF, and the 306-W Building.

Tables and graphs provided in this section have been constructed using the ICRP 30 model for uranium biokinetics and thus can be used to convert bioassay measurement results to intake and first-year or committed effective dose equivalent. Although the tables and figures are sufficient for evaluating lower-level intakes and those that are relatively straightforward, additional computing capability may be necessary for more complex evaluations, particularly when bioassay data indicate that distribution and retention patterns deviate from the standard model. In this case, evaluations are performed using the computer code GENMOD (see Appendix A). GENMOD parameters are set up according to the ICRP 30 biokinetic model for uranium; however, the code provides the capability to change model parameters based on bioassay measurement results. Deviations from the standard ICRP model are documented in the assessment.

Dose assessments include annual and committed effective dose equivalents, as well as dose equivalents to specific organs of concern based on the criteria discussed in the Hanford Internal Dosimetry Program Manual. (a) (See

(a) Pacific Northwest Laboratory. 1989. Hanford Internal Dosimetry Program Manual. PNL-MA-552, Richland, Washington. 
also Appendix B.) Dose factors for organs receiving the greatest dose equivalent following intake are provided in Table 8.11.

The following subsections provide additional guidance for assessment of internal dose equivalents for acute and chronic exposures.

\section{Acute Exposure}

Acute exposures are best assessed through the performance of bioassay measurements beginning shortly after the intake. It is important that any additional exposure to uranium, even low-level chronic intakes, be avoided during the period of bioassay monitoring following an acute intake. Interpretation of excreta data is highly susceptible to errors introduced by subsequent intakes and thus, if the possibility of continued exposure cannot be ruled out, all excreta sample data collected following an acute intake must be considered to be potentially biased.

Acute intakes of readily transportable forms of uranium are best evaluated through collection and analysis of follow-up urine samples. Samples collected after the unabsorbed fraction is eliminated from the body provide the best estimate of systemically deposited material. Table 8.7 (Section 8.2.3) lists urine excretion fractions for selected times following an acute intake.

In vivo measurements of lung activity provide the most direct basis for the assessment of internal dose equivalent for moderately or poorly transportable forms of uranium. Multiple measurements of internal activity provide a measure of the pulmonary retention for the specific exposure case; however, the initial assessment of intake, based on a single in vivo measurement can be made using Figure 8.4 or 8.5 , for class Y or class W uranium, respectively, or the retention factors of Table 8.6 (Section 8.2.3).

Although intakes of poorly transportable uranium are preferably assessed using direct (in vivo) bioassay measurements, most acute intakes of such material will be below the sensitivity of in vivo measurement techniques. The collection and analysis of fecal samples within the first week provides an alternative indicator of activity deposited in the respiratory tract. It is difficult to obtain all fecal matter representing the rapidly clearing component from the lung to the GI tract, and normalizing available fecal sample 
data to account for partial collection may be required. Sample collections over 24-hour intervals should be normalized, as appropriate, to a total daily expected excretion of $135 \mathrm{~g}$ for males and $110 \mathrm{~g}$ for females if the mass is less than $60 \mathrm{~g}$, unless $i \mathrm{t}$ is known that the samples account for the total 24-hour excretion or there is a basis for otherwise determining total 24-hour excretion. Samples for three to five 24-hour intervals following the intake are advised to avoid the uncertainties associated with single samples.

Normalization to the total expected excretion during the period of rapid clearance is necessary, unless it is known that all early clearance has been intercepted. Table 8.21, which shows the daily expected excretion immediately following an inhalation of a 1- $\mu$ m-AMAD class $Y$ particulate, provides a basis for accounting for the fact that only a part of the early clearance is collected by the follow-up sampling program. Dividing the early clearance phase into 24-hour intervals and attributing normalized daily excretions to the intervals, as appropriate, enable an estimate of the total early clearance via the GI tract to be made. A 1- $\mu \mathrm{m}$-AMAD particle size should be assumed if no other information is available. Additional information on the collection and evaluation of fecal samples is provided in Appendix E, and Table 8.8 (Section 8.2.3) provides fecal excretion fractions for longer times post intake.

\section{Chronic Exposure}

Urinalysis is the preferred bioassay measurement technique for monitoring chronic exposures to readily transportable forms of uranium where the

TABLE 8.21. Fraction of Intake Excreted via Feces Following an Acute Inhalation of Class Y $1-\mu \mathrm{m}$-AMAD Uranium (Lessard et a 1. 1987)

$\begin{array}{lcc}\text { Days Post Intake } & \begin{array}{c}\text { Fraction of Intake Excreted } \\ \text { Durinq Interval }\end{array} & \begin{array}{c}\text { Accumul ated } \\ \text { Fecal Excrecic }\end{array} \\ 1(0-24 \mathrm{~h}) & 0.052 & 0.052 \\ 2(24-48 \mathrm{~h}) & 0.16 & 0.21 \\ 3(48-72 \mathrm{~h}) & 0.13 & 0.34 \\ 4(72-96 \mathrm{~h}) & 0.074 & 0.42 \\ 5(96-120 \mathrm{~h}) & 0.036 & 0.45 \\ 6(120-144 \mathrm{~h}) & 0.017 & 0.47\end{array}$


primary contribution to the effective dose equivalent is from deposition in the bone. For predominantly moderately or poorly transportable forms of uranium, the lung is the primary contributor to effective dose equivalent and in vivo chest measurements are the most direct indicator of internal dose. Because of the relatively poor sensitivity of in vivo techniques for lowenrichment uranium, the results of periodic urinalysis measurements may provide a means for estimating the magnitude of dose equivalent from chronic exposures below the sensitivity of the in vivo measurements.

Although chronic exposures are known to occur in several facilities at Hanford (U03 Plant, N Reactor FPF, and 306-W Machine Shop), exposure levels in the facilities have historically been minimal. Simplified schemes for assessing dose equivalents from low-level chronic exposures have been developed. The simplified dose assessment procedure is based on the establishment of default assumptions regarding the exposure scenario and the interpretation of bioassay data. These assumptions are expected to result in overestimates of internal dose; however, as long as the annual effective dose equivalent is estimated below $100 \mathrm{mrem} / \mathrm{yr}$, use of the simplified scheme is justified. If estimated doses exceed $100 \mathrm{mrem} / \mathrm{yr}$, then review of all exposures occurring during the year and the default assumptions used in evaluating these exposures should be performed, and collection of additional bioassay and other data regarding the exposures should be considered.

Chronic exposures to moderately or poorly transportable forms of uranium will result in accumulations of uranium activity in the lung. Use of in vivo chest activity measurements provides a direct means for assessing the magnitude of the chronic exposure and the resulting dose equivalents. Urinalysis and air monitoring data can be used to help characterize the nature of the exposures. The computer code GENMOD is used to estimate intakes yielding the observed bioassay measurement results and to cal culate resulting dose equivalents. Distribution and retention parameters in GENMOD may be modified to better reflect bioassay measurement results.

In cases where urinalysis data indicate chronic exposures, but in vivo measurements do not detect internal activity, the urinalysis data can be used to provide an estimate of intake; however, the uncertainty associated with 
such estimates is quite high and should be modified as necessary to be consistent with in vivo measurement results. Dose equivalents from chronic exposures to uranium, based on urinalysis, can be computed using the procedure described below by assuming the following:

- Intake is by intermittent inhalation throughout the year. (If a dominating acute intake occurs, it should be assessed separately.)

- The magnitude of the intake can be approximated by the geometric mean $(\mu \mathrm{g})$ of the daily excretion (or normalized daily excretion) rate $\left[M_{u}(t)\right]$ based on analysis of urine samples $(n)$ collected during the period of exposure.

$$
\mu \mathrm{g}=\operatorname{Antilog}\left[-\frac{\sum}{\log M_{u}(t)}{ }_{-}\right]
$$

- Chronic exposure has continued at the current rate for at least 5 years.

Calculation of the effective dose equivalent proceeds as follows:

1. Urine samples collected during the exposure period of interest are corrected for natural background levels (see Section 8.1.3) and normalized to daily excretion rates (see Section 8.4.1) and the geometric mean is calculated.

2. The daily intake rate is estimated by applying the excretion-tointake conversion factor from Table 8.22, according to the facility involved. This factor assumes that the exposure has been under way at the current level for the past 5 years. (This assumption is necessary because of the gradual buildup of uranium in the bone of chronically exposed individuals, and results in a slightly underestimated dose equivalent for actual chronic exposures of duration less than 5 years and a slightly overestimated dose for exposures longer than 5 years.)

3. The daily intake rate in mass units is converted to an annual intake in activity units using the data in Table 8.3, and the activities are apportioned into component inhalation classes, as appropriate considering the facility and material involved or use Table 8.14. 
TABLE 8.22. Ratio of Daily Excretion to Daily Inhalation at 5 Years After the Onset of Chronic Exposure

\begin{tabular}{|c|c|c|}
\hline Solubility Class & $\begin{array}{c}\text { Sample During } \\
\text { Exposure } \\
\end{array}$ & $\begin{array}{c}\text { Sample After Eārly } \\
\text { Clearance(â) }\end{array}$ \\
\hline Class D & 0.47 & 0.22 \\
\hline Class W & 0.14 & 0.065 \\
\hline Class $Y$ & 0.033 & 0.015 \\
\hline $\begin{array}{c}\text { U03 Plant } \\
(80 \%-\mathrm{D}, \quad 20 \%-\mathrm{W})\end{array}$ & 0.40 & 0.19 \\
\hline $\begin{array}{c}333 \text { Bldg } \\
(70 \%-Y, \quad 30 \%-D)\end{array}$ & 0.20 & 0.12 \\
\hline $\begin{array}{c}303-M \text { Bldg } \\
(90 \%-Y, \quad 10 \%-D)\end{array}$ & 0.089 & 0.064 \\
\hline $\begin{array}{c}306-W \text { Bldg } \\
(80 \%-Y, 20 \%-D)\end{array}$ & 0.12 & 0.060 \\
\hline
\end{tabular}

(a) After 2 days of no exposure.

4. The committed effective dose equivalent is calculated by application of the intake dose equivalent factors for natural uranium in Table 8.11 to each inhalation component. If recycled uranium is involved, the doses should be modified to account for the presence of impurity radionuclides using the factors provided in Tables 8.12 or 8.13. The contributions from the various components are then summed.

5. If the effective dose equivalent in any year is projected to exceed 100 mrem, then the assumptions and model should be reviewed for adequacy, and additional bioassay and other data should be collected as needed to better define the exposure.

Use of the above procedure will yield a committed effective dose equivalent of 100 mrem for an average net daily excretion of $14 \mu \mathrm{g}$ (assuming 365 days of intake and 2 days of no exposure) of U03 Plant uranium. The procedure will yield a committed effective dose equivalent of 100 mrem (assuming 365 days of intake and 2 days of no exposure) for a net daily excretion rate of $0.48 \mu \mathrm{g}$ of $\mathrm{N}$ Reactor FPF (333 Building) uranium. 


\subsubsection{Kidney Burden and Potential Chemical Toxicity Associated with Intakes}

Kidney burdens can be assessed from urinalysis data using the following information. Table 8.23 shows the expected urinary excretion rates following an acute inhalation resulting in the uptake of $7 \mathrm{mg}$ of uranium from rapidly clearing compartments of the respiratory tract, regardless of inhalation class. As previously discussed in Section 8.2.4, a 7-mg uptake of readily transportable uranium is below that considered harmful.

The average daily urinary excretion for continuous intake is related to the kidney burden as shown in Figure 8.7. This ratio varies with time, but is independent of inhalation class and particle size. For continuous exposures lasting longer than about 5 years, the ratio of the kidney burden to the average daily excretion is about 2. Thus, assuming a kidney burden of $340 \mu \mathrm{g}$ (i.e., $1.1 \mu \mathrm{g} / \mathrm{g}$; the assumed threshold level at which a chronic kidney burden may result in renal damage), the average daily excretion would be about $340 / 2=170 \mu \mathrm{g} /$ day. If exposure was halted for 2 days (such as during a

TABLE 8.23. Urinary Excretion of Uranium Following an Açute Inhalation Resulting in the Uptake of $7 \mathrm{mg}$ of Uranium(a)

Days Post Intake

2
5
7
14
30
90

180

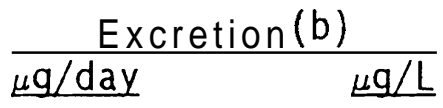

580

410

170

120

130

93

70

24

6.0

4.5

0.1

0.9

(a) Excluding environmental background levers in urine.

(b) Assuming a daily excretion volume of 1.4 L (ICRP 1974). 


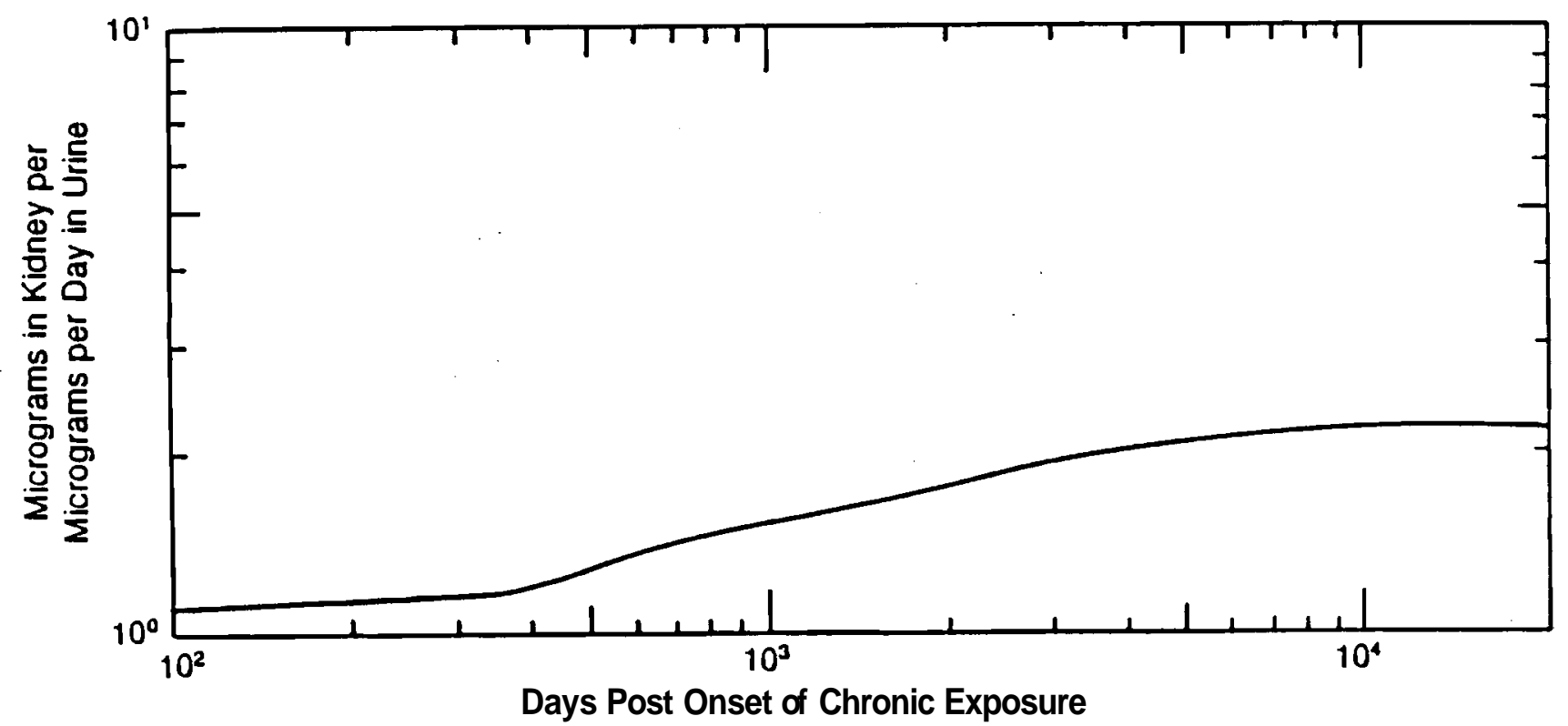

FIGURE 8.7. Ratio of Uranium in Kidneys to Daily Excretion in Urine for Chronic Exposure to Class D Uranium

weekend), the daily excretion would drop to about $85 \mu \mathrm{g} /$ day. For class $D$ uranium, the $340 \mu \mathrm{g}$ kidney burden would result from prolonged intakes of about $320 \mu \mathrm{g} /$ day.

If preliminary information indicates that an intake at the nephrotoxicity threshold was possible, investigation of the potential intake should be performed. If evidence suggests that a significant intake was likely, follow-up samples should be promptly collected and analyzed, and HEHF Occupational Medicine should be notified. Because acute damage of the kidneys is the primary consideration, kidney function tests provide the most direct and useful means of assessing the impact of the exposure. Sensitive tests for kidney damage include beta-2-microglobulin and catalase relative to creatinine (Fisher 1985). Albuminuria is also an indicator of kidney damage. Leggett (1989) and Fisher et a1. (1990) have identified a number of other potentially useful tests. The decision to perform such tests is made by HEHF Occupational Medicine. 


\subsection{MANAGEMENT OF INTERNAL CONTAMINATION CASES}

Acute intakes of uranium pose both radiological and nephrotoxicity concerns. Renal damage results in failure of the proximal tubules to reabsorb constituents filtered from the blood. Laboratory abnormalities include proteinuria, glucosuria, and increased urine output. Clinical symptoms of severe uranium poisoning may include nausea, vomiting, abdominal cramps, and diarrhea.

Urine samples should be collected within 3 to 4 hours following any potentially significant uranium uptake. As a general rule, biological indicators of kidney damage should be checked if urine concentrations exceed $2 \mathrm{mg} / \mathrm{L}$. Clinical indicators of kidney damage include albuminuria, glucose, catalase, and beta-2 microglobulin. Urine concentrations on the order of $20 \mathrm{mg} / \mathrm{L}$ indicate serious exposure with potential life-threatening consequences and are cause for immediate medical attention (Rich et al. 1988).

Antidotal therapy for uranium poisoning includes oral administration of sodium bicarbonate. The bicarbonate promotes formation of the urany bicarbonate complex, which is more rapidly excreted in urine (Fisher 1985). Ethylene diamine tetraacetic acid (EDTA) and DTPA have been used in experimental animals to increase the excretion of uranium; however, chelation therapy appears to have no beneficial effect more than 4 hours after exposure (NCRP 1980).

\subsection{BIOASSAY MONITORING AND INTERNAL DOSIMETRY FOR SPECIFIC FACILITIES}

Uncontained uranium is routinely handled in three Hanford facilities: the U03 Plant in the 200 West Area, the N Reactor FPF in the 300 Area (currently in cold standby condition), and the 306-W Building Machine Shop in the 300 Area. Although exposures to uranium in these facilities are low under normal operating conditions, the interpretation of routine bioassay measurements for workers at these facilities is complex due to the potentially chronic nature of intakes. For this reason, bioassay monitoring and internal dosimetry for these facilities have been specially evaluated. The internal dosimetry for workers at each of the three facilities is discussed in the fol lowing subsections. 


\subsubsection{Internal Dosimetry for Workers at the Uranium Oxide Plant}

This section provides the basis for bioassay monitoring of workers at the U03 Plant in the 200 West Area, but is equally applicable to any situation in which workers are potentially exposed to readily transportable forms of uranium for which chemical toxicity is the primary consideration (i.e., less than $10 \% 235 \mathrm{U}$ enrichment). The facility-specific uranium characteristics inhalation exposure conditions and bioassay monitoring program are discussed.

\section{Characteristics of Material}

The U03 Plant receives uranium as uranyl nitrate hexahydrate from the PUREX Plant and converts this to uranium trioxide for shipment offsite. Uranium trioxide, a yellow powder, is the predominant form of uranium available for intake in the $\mathrm{U} 03 \mathrm{Plant}$. The material is slightly enriched $10.8 \%$ $235 \mathrm{U}$ ) recycled uranium with a specific activity of about $2 \mathrm{dpm} / \mu \mathrm{g}$. The material also contains impurities, principally plutonium and ${ }^{237} \mathrm{~Np}$, as described in Table 8.4. A solubility test using simulated lung fluid, performed on a smear sample from the U03 Plant in 1984, showed the material to be approximately $80 \%$ class $D$ and $20 \%$ class $W$. This is consistent with a similarly performed evaluation of uranium trioxide solubility (Morrow, Gibb, and Beiter 1972) .

\section{Inhalation of Uranium}

Chemical toxicity of uranium in the U03 Plant is the primary health consideration for internal exposure. Because complete containment of the uranium is not provided, low-level chronic exposure conditions are assumed to exist; however, acute intakes can also occur in the facility. In the case of a chronic intake, a daily inhalation of $7.9 \mu \mathrm{g} /$ day would result in an annual effective dose equivalent of 100 mrem after 10 years. In the case of an acute inhalation intake, the first-year and 50-year effective dose equivalents are $2.1 \mathrm{mrem} / \mathrm{mg}(2.3 \mathrm{mrem} / \mathrm{nCi})$ and $3.9 \mathrm{mrem} / \mathrm{mg}(4.2 \mathrm{mrem} / \mathrm{nC} \mathrm{i})$, respectively. These dose factors assume recycled uranium as specified in Tables 8.3 and 8.4. 


\section{Bioassay Monitoring}

Urine sampling is the preferred method for the routine assessment of uptakes of readily transportable uranium. However, in identified exposure situations where renal damage is possible, tests for kidney function are the most direct and meaningful way to evaluate the significance of an intake. Medical assistance should therefore be requested in cases where a significant uptake may have occurred.

To minimize the contribution of the unabsorbed fraction of uranium that is excreted immediately following an intake, it is recommended that urine samples be collected following 2 days of no exposure. Samples should thus be simulated 12-hour collections beginning at the end of a weekend.

For a bioassay monitoring program that does not rely on facility air monitoring to assess and document exposure conditions, the urine sampling program should consider potential acute intakes as well as the underlying chronic exposure expected to occur routinely at the facility. It is recommended that follow-up investigation of potential exposures be initiated if bioassay results indicate that an intake at 33\% of the toxicity threshold levels established in Section 8.2.4 potentially occurred. Table 8.24 gives recommended fol low-up levels for various sampling frequencies.

Assessments based on bioassay measurement results are discussed in Section 8.5.1. Table 8.25 lists the expected urinary excretion rates following inhalation intakes of U03 Plant uranium. Based on the chemical toxicity discussion in Sections 8.2.4 and 8.5.2, chemical toxicity would not be an issue at levels three times those indicated in Table 8.24 for acute inhalation or over 50 times those shown for chronic inhalation.

Assessments of radiological dose equivalent (any associated nephrotoxicity) should be based on an assumed chronic exposure unless evidence suggests that the bioassay result should be attributed to a single acute or short duration exposure. A review of facility air monitoring data and contamination survey data, discussions with workers, as well as additional bioassay measurements from involved workers can help in the determination of the exposure scenario. 
TABLE 8.24. Recommended Follow-Up Leve1 1 f for Chronic
and Acute Intakes, $\mu \mathrm{g} /$ day $(\mathrm{a})$

Frequency

Follow-Up Level (b)

Weekly ${ }^{(d)}$ (33\% Threshold)

Biweekly

28

Monthly

23

Bimonthly

8

Quarterly

2

0.7

(a) Sample collected following a 2-day absence from any potential uranium exposure.

(b) Follow-up leve1: Internal Dosimetry will review available information to determine the potential intake scenario and will consider follow-up Samples. A work restriction or limitation will be considered until appropriate follow-up measurements are made and evaluated. If it appears that a significant intake was likely, then a recommendation for the contractor to notify HEHF Occupational Medicine will be made.

(c) Chronic exposure is limiting. For all other frequencies, an acute exposure is limiting.

8.7.2 Bioassay Monitoring and Internal Dosimetry for Workers at the 300 Area Fuel Production Facility

The N Reactor FPF in the 300 Area fabricated fuel elements for the Hanford $N$ Reactor. The operations performed in the FPF included extrusion, cutting, grinding, and welding of fuel elements. Airborne uranium generated during these operations resulted in intermittent or chronic exposures to workers in the immediate vicinity. The primary FPF facility is the 333 Building, where all steps in the fuel element production process were performed, and where FPF workers were normally located. The 303-M Building houses "burn 

TABLE 8.25. Predicted Uranium Excretion via Urine Following
an Inhalation of U03 Plant Recycled Uranium(a)

Micrograms of Uranium in Urine Per Day (b)

Acute Inhalation

Acute Inhalation

\begin{tabular}{|c|c|c|}
\hline $\begin{array}{l}\text { Days Post } \\
\text { Intake (c) } \\
\end{array}$ & $\begin{array}{l}\text { Intake }=4.8 \mathrm{mg} \\
\left(H_{E, ~}=10 \mathrm{mrem}\right) \\
\end{array}$ & $\begin{array}{c}\text { Intake }=2.6 \mathrm{mg} \\
\left(H_{E}^{C} 50=10 \mathrm{mrem}\right) \\
\end{array}$ \\
\hline 2 & 160 & 91 \\
\hline 5 & 48 & 26 \\
\hline 7 & 38 & 21 \\
\hline 14 & 21 & 11 \\
\hline 30 & 7.2 & 3.9 \\
\hline 60 & 2.1 & 1.2 \\
\hline 90 & 9.85 & 0.47 \\
\hline 180 & 0.12 & 0.965 \\
\hline 365 & 0.017 & 9.099 \\
\hline 730 & 0.607 & 0.003 \\
\hline
\end{tabular}

Chronic Inhalation

\begin{tabular}{|c|c|}
\hline \multicolumn{2}{|c|}{ Chronic Inhalation } \\
\hline \multicolumn{2}{|c|}{$\begin{array}{l}\text { Intake Rate }=7.9 \mu \mathrm{g} / \text { day } \\
\left(H_{E, 1 \emptyset}=10 \mathrm{mrem} / \mathrm{yr}\right)(\mathrm{d})\end{array}$} \\
\hline$\underline{\text { Direct }+ \text { Systemic }(e)}$ & $\underline{\text { Systemic only }}{ }^{(f)}$ \\
\hline 1.7 & 0.13 \\
\hline 2.1 & 0.38 \\
\hline 2.3 & 0.52 \\
\hline 2.5 & 0.85 \\
\hline 2.9 & 1.2 \\
\hline 3.1 & 1.4 \\
\hline 3.2 & 1.4 \\
\hline 3.2 & 1.4 \\
\hline 3.3 & 1.4 \\
\hline 3.3 & 1.4 \\
\hline
\end{tabular}

(a) Assumes uranium trioxide. $80 \%$ class $\mathrm{D}, 20 \%$ class $\mathrm{W}$; recycled uranium includes impurities at concentrations shown in Table 8.4.

(b) Excludes envi ronmental background levels in urine.

(c) Days post acute intake or post onset of chronic intake.

(d) Annual effective dose equivalent rate $=10 \mathrm{mrem} / \mathrm{yr}$ after 10 years of continuous intake.

(e) Includes a 11 excretion pathways.

(f) Excludes uranium excreted directly from blood; representative of levels that would be expected several days after cessation of chronic exposure.

boxes" where metal uranium scrap fines from the production facility were oxidized prior to shipment offsite. The 303-M Building was only used intermittently and is generally not occupied by workers. Bioassay monitoring programs are thus based on uranium that is characteristic of the 333 Building. However, data are also provided for uranium that is characteristic of the 303-M Building.

The facility-specific uranium characteristics, dose equivalent from intakes, and bioassay monitoring program are discussed in the following subsections. 


\section{Characteristics of Material}

Uranium in the FPF is recycled and is composed of the isotopic mixtures shown in Table 8.3. The specific alpha activity for recycled uranium (FPF-RU) is $2.0 \mathrm{dpm} / \mu \mathrm{g}(0.92 \mu \mathrm{Ci} / \mathrm{g})$, or about 1.33 times the specific alpha activity of natural uranium.

Aerosols generated during the machining and oxidizing of metallic uranium are composed of various oxides of uranium including $\mathrm{UO}_{2}$ and $\mathrm{U}_{3} \mathrm{O}_{8}$, as well as other forms. The degree to which various oxides are created depends on the heat generated by the pyrophoric combustion of uranium fines--with high temperatures resulting in the generation of more insoluble particulates. Insoluble oxides of uranium tend to be retained in the lung and are poorly absorbed by the circulatory system; however, the degree of retention depends on the particular oxide compound. Estimates of the retention characteristics of uranium particulates in the lung were made by studying the in vitro dissolution, in simulated lung fluid, of the uranium-bearing particulates from room air samples collected in the $303-\mathrm{M}$ and 333 Buildings. The study found that the uranium should be considered to be a mixture of readily transportable and slowly transportable material represented by the ICRP's TGLD inhal ation classifications (ICRP 1979) as given in Table 8.26.

The particle size distribution of airborne uranium particulates at locations in the 303-M and 333 Buildings was measured using a nine-stage cascade impactor air sampler. The samples were collected during normal operations. A sampler was located near the room air sampler between the two sets of "burn boxes" in the 303-M Building and near the De Sanno saw in the 333 Building. The results of the measurements indicated that in both cases the majority of the particulates was deposited on the first stage of the impactor representing

TABLE 8.26. In Vitro Solubility Classification of Uranium in the $\mathrm{N}$ Reactor Fuel Production Facility

$\begin{array}{lcc}\text { Building } & \text { Class D } & \text { Class Y } \\ 303-M & 10 \% & 90 \% \\ 333 & 29 \% & 71 \%\end{array}$


particles with an AMAD of greater than $8.35 \mu \mathrm{m}$. The distribution of particle sizes was not lognormal. Therefore, the regional deposition in the respiratory tract was estimated by applying deposition fractions for monodisperse aerosols to the mass of uranium collected on each stage of the cascade impactor air sampler, based on information provided in International Atomic Energy Agency (IAEA) Technical Report 142 (1973). Table 8.27 summarizes the resulting deposition fractions calculated for the airborne particulates in the 303-M and 333 Buildings. The distribution in the respiratory tract must be considered when evaluating excretion bioassay data, but the dose per unit intake is the same as for a 1- $\mu$ m-AMAD particulate.

\section{Dose Equivalent from Intakes}

Table 8.14 shows the first-year and 50-year committed effective dose equivalent from an acute inhalation of $1 \mathrm{mg}$ of $303-\mathrm{M}$ and 333 Building uranium. The doses were calculated based on retention functions given in ICRP 30 and assuming a pulmonary deposition of $25 \%$ of the intake (see Table 8.27 ). The lung accounts for essentially all of the effective dose equivalent received following inhalation exposures to these materials. Activity-to-dose conversion was performed using the SEE values in ICRP 30, weighted for the relative activities of the various isotopes in the mixture.

From Table 8.14, it can be calculated that an acute intake of about $1 \mathrm{mg}$ of 303-M Building uranium or about $1.3 \mathrm{mg}$ of 333 Building uranium could result in a 50-year committed effective dose equivalent of 100 mrem.

Table 8.28 shows, for different exposure periods, the daily intake rate of uranium that would cause a sufficient quantity of buildup in the lung to

TABLE 8.27. Expected Deposition Fractions for Airborne Uranium Particulates in the 303-M and 333 Buildings

\begin{tabular}{|c|c|c|}
\hline & \multicolumn{2}{|c|}{ Deposition Fraction } \\
\hline Reqion & 303-M & 333 \\
\hline Nasal-pharyngeal & 0.67 & 0.53 \\
\hline Tracheal-bronchial & 0.08 & 0.08 \\
\hline Pulmonary & 0.25 & 0.25 \\
\hline
\end{tabular}


TABLE 8.28. Daily Intake Rate of Uranium Yielding an Annua 1

Effective Dose Equivalent Rate of $100 \mathrm{mrem} / \mathrm{yr}$ (a)

by the End of the Intake Period $\underset{\text { Exposure Period, }}{\text { Ex }}$

1

2

5

10

20

$50^{(a)}$
Milliarams of Uranium Per Day

$303-\mathrm{M}(10 \% \mathrm{D}, 90 \% \mathrm{Y}) \quad 333(30 \% \mathrm{D}, 70 \% \mathrm{Y})$

0.012

0.016

0.0074

0.0093

0.0043

0.0055

0.0037

0.0047

0.0032

0.0041

0.0027

(a) Lung dose equivalent rate $=830 \mathrm{mrem} / \mathrm{yr}$.

(b) Intakes at this rate for one year will result in a 50-year committed effective dose equivalent of $100 \mathrm{mrem}$.

result in a $100-m r e m / y r$ effective dose equivalent. For example, a daily intake of $0.0035 \mathrm{mg}$ of 333 Building uranium would result in a gradual buildup of lung activity sufficient to produce a $100-\mathrm{mrem} / \mathrm{yr}$ effective dose equivalent rate after 50 years of exposure. Conversely, this intake rate, if maintained for 1 year, would result in a 50-year committed effective dose equivalent of 100 mrem.

Using the ICRP 30 model and assuming the particle-size distribution and inhalation classifications observed in samples collected in the 333 Building ( $30 \%$ class $D, 70 \%$ class $Y$ ), the assumed renal toxicity threshold for an acute uptake is calculated to be reached following an acute inhalation of about $30 \mathrm{mg}$. Similarly, a chronic intake of about $0.2 \mathrm{mg} /$ day of 333 Building uranium would eventually (after about 50 years) result in a retained quantity in the kidney at the assumed renal toxicity threshold.

\section{Bioassay Monitoring}

Bioassay monitoring for slowly transportable materials, for which the lung is the critical organ, is most directly and accurately performed through in vivo measurements; however, the sensitivity of in vivo measurements is somewhat limited as discussed below. 
In view of the limitations of in vivo measurements as a routine monitoring technique, urine sampling is also performed. Urine samples provide a measure of the systemically deposited uranium, and, using biokinetic models, this enables an indirect estimate of intake to be made. However, the interpretation of urine sample data is highly dependent on the nature of the intake; that is, whether acute, intermittent, or chronic.

In Vivo Measurements. Table 8.17 gives estimated in vivo measurement capabilities for the slightly enriched, class Y uranium, representative of the type of material in the FPF facilities. Based on these detection limits, the sensitivity of a 2000-second chest count is about 22\% of the annual effective dose equivalent standard of 5 rem at 1 year after an acute exposure, and about 18\% of the standard for a constant lung burden. Extending the counting time to 4000 seconds increases the sensitivity for the two cases to about $15 \%$ and $12 \%$, respectively.

An annual chest count is recommended for workers potentially exposed to poorly transportable forms of uranium. Any indication of uranium in the body via in vivo monitoring warrants follow-up investigation including additional in vivo measurements and urine samples. Positive in vivo measurements should be confirmed as soon as practical, and additional measurements should be performed as long as the uranium remains detectable.

Urinalysis. Figures 8.8 and 8.9 and Tables 8.29 and 8.30 show the urinary excretion following acute and chronic exposures to FPF recycled uranium. The predicted excretion values are based on an assumed acute intake that would result in a first-year effective dose equivalent of 100 mrem (a lung dose of $830 \mathrm{mrem}$ ) and an assumed chronic inhalation rate that would result in an effective dose equivalent rate of $100 \mathrm{mrem} / \mathrm{yr}$ after 10 years of continuous intake. The values do not include environmental uranium in the urine. The derived intake rates are $0.0037 \mathrm{mg} /$ day for $303-\mathrm{M}$ Building uranium and $0.0047 \mathrm{mg} /$ day for 333 Building uranium. For 50 years of chronic exposure, the intake rates to produce a $100-\mathrm{mrem} / \mathrm{yr}$ effective dose equivalent after the 50 years are $0.0027 \mathrm{mg} /$ day for the $303-\mathrm{M}$ Building and $0.0035 \mathrm{mg} /$ day for the 333 Building, and the expected excretion rates would thus be about $75 \%$ of those shown in Figures 8.8 and 8.9. 


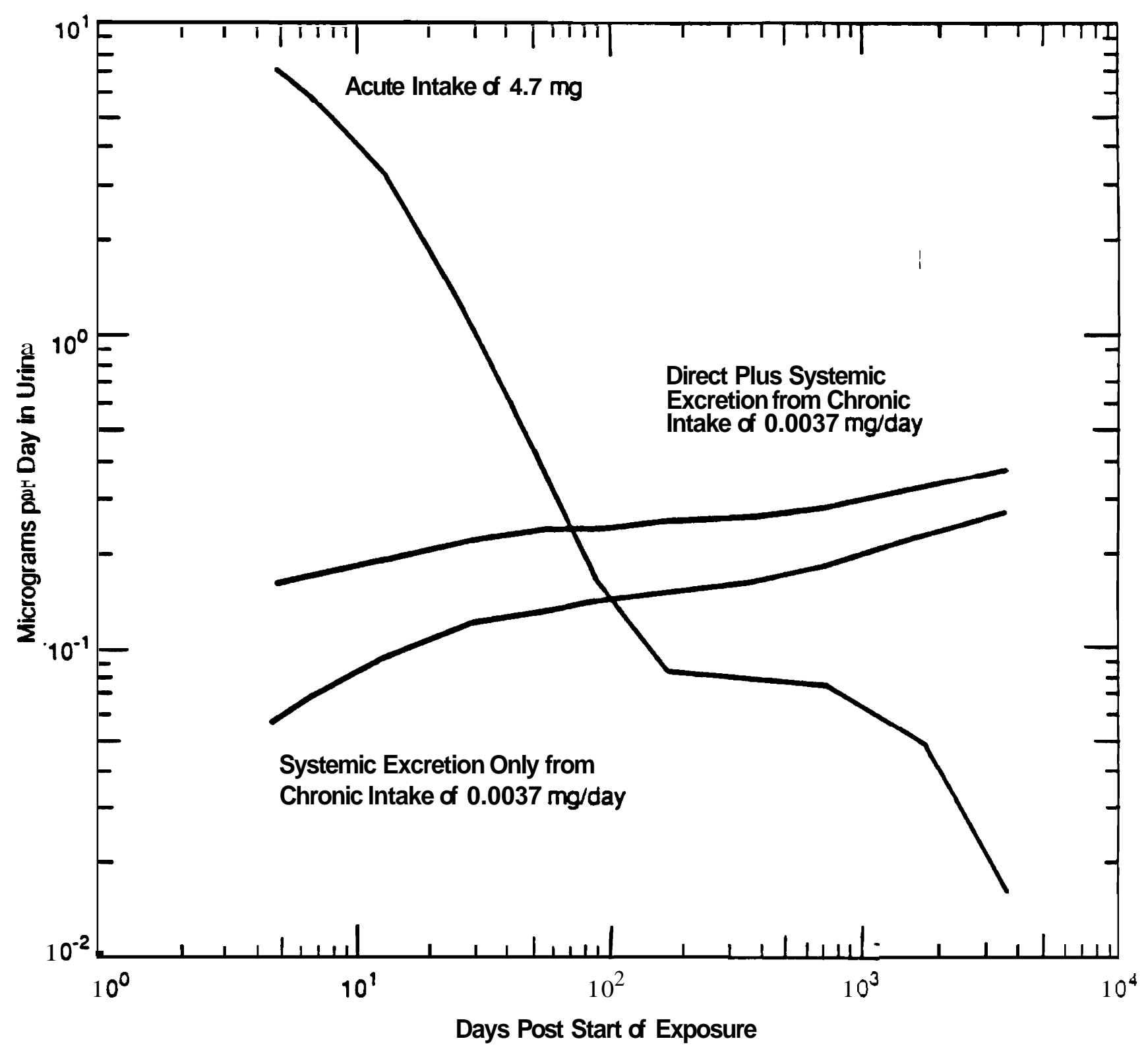

FIGURE 8.8. Predicted Urinary Excretion Following an Inhalation of 303-M Building Uranium Resulting in a First-Year Effective Dose Equivalent of 100 mrem (Curves exclude excretion of environmental uranium) 


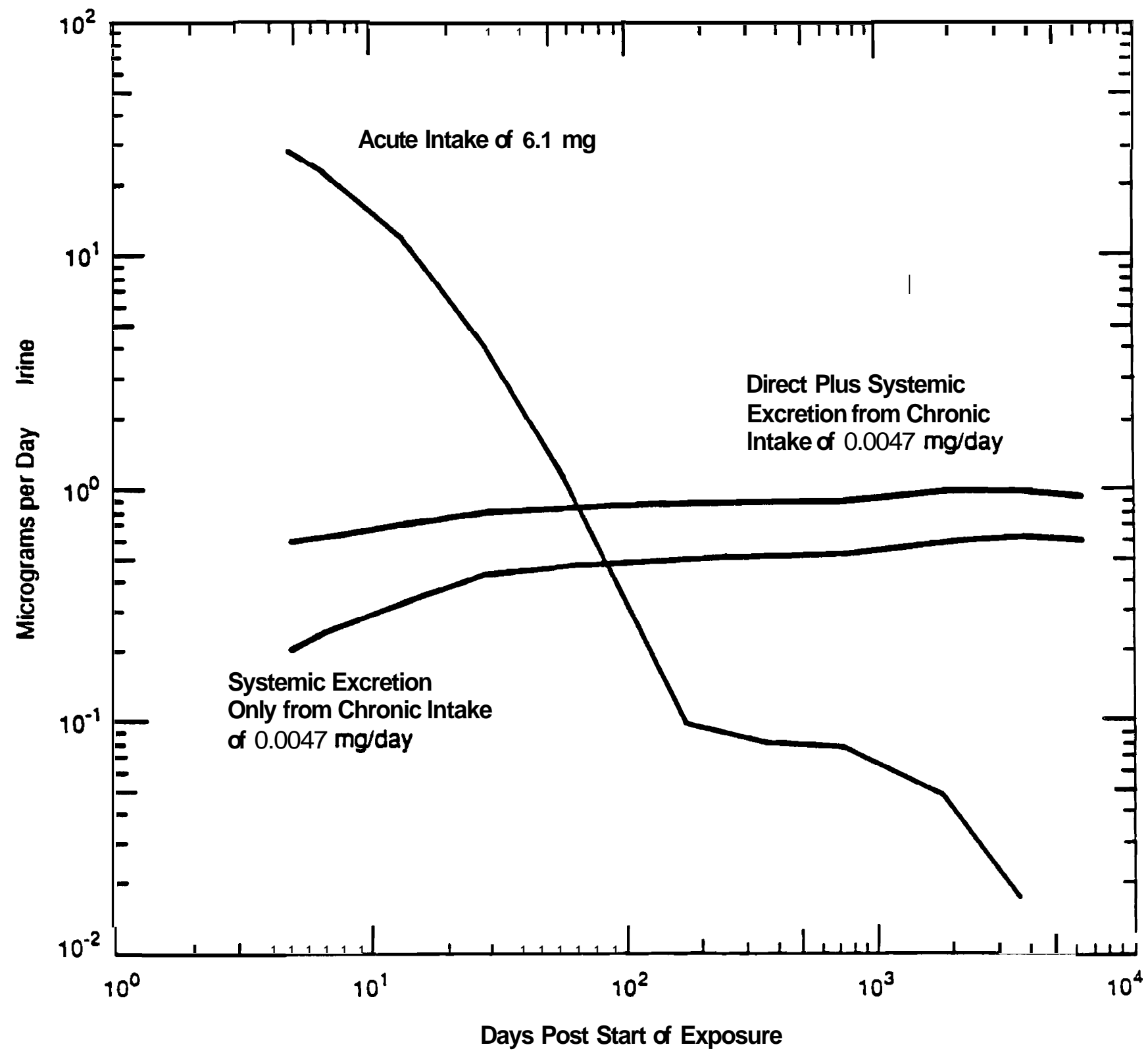

FIGURE 8.9. Predicted Urinary Excretion Following an Inhalation of 333 Building Uranium Resulting in a First-Year Effective Dose Equivalent of $100 \mathrm{mrem}$ (Curves exclude excretion of environmental uranium) 
TABLE 8.29. Predicted Uranium Excretion via Urine Foljowing an Inhalation of 303-M Building Uranium(a)

Microsrams of Uranium Per Dav Via Urine(b)

Chronic Inhalation

\begin{tabular}{|c|c|c|c|}
\hline \multirow{2}{*}{$\begin{array}{l}\text { Days Post } \\
\text { Intake (c) }\end{array}$} & \multirow{2}{*}{$\begin{array}{l}\text { Acute Inhalation } \\
\text { Intake }=4.7 \mathrm{ng} \\
{\left[\mathrm{H}_{\mathrm{E}, 1}=100 \mathrm{mrem}\right]}\end{array}$} & \multicolumn{2}{|c|}{$\begin{array}{l}\text { Intake Rate }=0.0037 \mathrm{mg} / \text { day } \\
{\left[H_{E, 10}=100 \mathrm{mrem} / \mathrm{yr}\right]^{(\mathrm{d})}}\end{array}$} \\
\hline & & Direct + Systemic $(e)$ & Systemic only (f) \\
\hline 5 & 7.1 & 0.16 & 0.058 \\
\hline 7 & 5.7 & 0.17 & 0.069 \\
\hline 14 & 3.1 & 0.19 & 0.094 \\
\hline 30 & 1.1 & 0.22 & 0.12 \\
\hline 60 & 0.34 & 0.24 & 0.13 \\
\hline 90 & 0.17 & 0.24 & 0.14 \\
\hline 180 & 0.082 & 0.25 & 0.15 \\
\hline 365 & 0.079 & 0.26 & 0.16 \\
\hline 730 & 0.074 & 0.28 & 0.18 \\
\hline 1825 & 0.047 & 0.33 & 0.23 \\
\hline 3650 & 0.016 & 0.37 & 0.27 \\
\hline
\end{tabular}

(a) Assumes $90 \%$ class Y, $10 \%$ class D; recycled uranium with impurity radionuclides as shown in Table 8.4.

(b) Excl udes environmental background levels in urine.

(c) Days post acute intake or post onset of chronic intake.

(d) Annual effective dose equivalent $\mathrm{rate}=100 \mathrm{mrem} / \mathrm{yr}$ after 10 years of continuous intake.

(e) Incl udes al1 excretion pathways.

(f) Excludes uranium excreted directly from blood; representative of levels that would be expected several days after cessation of chronic exposure.

Two levels have been developed for interpretation of urine samples from FPF workers. A screening level is defined as the excretion rate that exceeds that expected due only to environmental sources. This level is $0.2 \mu \mathrm{g} / \mathrm{day}$ as discussed in Section 8.1.3. Workers exceeding the screening level should be maintained on a quarterly urinalysis frequency and their dose should be assessed annually.

The second level is the net occupational excretion rate expected following chronic exposures in excess of the $100-\mathrm{mrem} / \mathrm{yr}$ effective dose equivalent. 
TABLE 8.30. Predicted Uranium Excretion via Urine Foflowing an Inhalation of 333-M Building Uranium(a)

Micrograms of Uranium Per Day Via Urine(b)

\begin{tabular}{|c|c|c|}
\hline \multirow{4}{*}{$\begin{array}{l}\text { Acute Inhalation } \\
\text { Intake }=6.1 \mathrm{mg} \\
{\left[\frac{\left[\mathrm{H}_{E, 1}=100 \mathrm{mrem}\right]}{28}\right.}\end{array}$} & \multicolumn{2}{|c|}{ Chronic Inhalation } \\
\hline & $\begin{array}{r}\text { Intake Rate }= \\
{\left[H_{5}=100\right.}\end{array}$ & $\begin{array}{l}47 \mathrm{mg} / \text { day } \\
\mathrm{n} / \mathrm{vr}](\mathrm{d})\end{array}$ \\
\hline & Direct + Svstemic $(e)$ & Svstemic Only $(f)$ \\
\hline & 0.58 & $\frac{0.20}{0}$ \\
\hline 22 & 0.62 & 0.24 \\
\hline 12 & 0.70 & 0.32 \\
\hline 4.0 & 0.79 & 0.42 \\
\hline 1.1 & 0.83 & 0.46 \\
\hline 0.44 & 0.85 & 0.48 \\
\hline 0.097 & 0.87 & 0.50 \\
\hline 0.082 & 0.88 & 0.51 \\
\hline 0.077 & 0.90 & 0.52 \\
\hline 0.049 & 0.97 & 0.59 \\
\hline 0.018 & 1.0 & 0.63 \\
\hline
\end{tabular}

Days Post Intake $=6.1 \mathrm{mg}$

$\frac{\text { Intake }(c)}{5}$

rH

7

7

14

30

60

90

180

365

730

1825

0.018

1.0

0.63

(a) Assumes $70 \%$ class Y, 30\% class D; recycled uranium with impurity radionuclides as shown in Table 8.4.

(b) Excludes environmental background levels in urine.

(c) Days post acute intake or post onset of chronic intake.

(d) Annual effective dose equivalent rate $=100 \mathrm{mrem} / \mathrm{yr}$ after 10 years of continuous intake.

(e) Includes all excretion pathways.

(f) Excludes uranium excreted directly from blood; representative of levels that would be expected several days after cessation of chronic exposure.

This level is calculated to be $0.63 \mu \mathrm{g} /$ day for 333 -Building uranium, assuming that the exposure has been occurring for 10 years. If this level is exceeded, then an investigation into the nature of the exposure is warranted. Additional follow-up bioassay measurements should be performed to confirm the nature and magnitude of the intake and the resulting dose equivalent should be assessed. In addition, it should be noted that an annual average excretion rate of $0.42 \mu \mathrm{g} /$ day (net after 2 days of no exposure) will result in a committed effective dose equivalent of $100 \mathrm{mrem}$. 


\subsubsection{Internal Dosimetrv for Workers at the 306-W Building}

The 306-W Building houses a machine shop where depleted uranium-titanium rods are handled. Machining operations conducted in the shop include cutting, milling, grinding, and lathing. Possible internal uranium exposure conditions exist in the shop due to the generation of airborne particulates during the machining operations.

\section{Characteristics of Material}

Depleted uranium in the 306-W Building Machine Shop is represented by the isotopic mixture shown in Table 8.3. Depleted uranium contains approximately one-half of the specific activity $(0.36 \mu \mathrm{Ci} / \mathrm{g})$ of natural uranium. The isotope ${ }^{238} \mathrm{U}$ accounts for about $92 \%$ of the activity in a given quantity of depleted uranium.

Aerosols generated during machining of the metallic uranium-titanium rods are composed of various oxides including $\mathrm{UO}_{2}, \mathrm{U}_{3} \mathrm{O}_{8}$, and other forms. The degree to which various oxides are created is related to the heat generated by the combustion of uranium fines--with high temperatures tending to result in the generation of more insoluble particulates. Inhaled insoluble oxides of uranium tend to be retained in the lung and poorly absorbed by the circulatory system; however, the degree of retention depends on the particular oxide compound. An estimate of the retention characteristics of uranium particulates in the lung was made by observing the in vitro dissolution of the uraniumbearing particulates from air samples collected in the shop in simulated lung fluid. The study found that the uranium in the shop should be considered to be a mixture of readily and slowly transportable material represented by the ICRP 30 inhalation classifications as $20 \%$ class $D$ and $80 \%$ class $Y$.

\section{Dose Equivalent from Intakes}

Table 8.31 shows the first-year and 50-year committed doses to the lung, bone surfaces, kidneys, and the effective dose equivalent following the acute inhalation of $1 \mathrm{mg}$ of 306-W depleted uranium. The doses were calculated using retention functions given in ICRP 30 for a 1- $\mu$ m-AMAD particle size. Activityto-dose conversion was performed using SEE values in ICRP 30, weighted for relative activities of the various uranium isotopes. 
TABLE 8.31. First-Year and 50-Year Committed Dose Following an Acute Inhalation of $1 \mathrm{mg}$ of 306-W Depleted Uranium

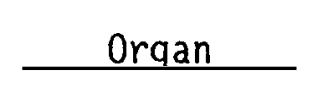

Lung

Bone Surfaces

Kidney

Effective
Dose Eauivalent, rnrem

First-Year Dose $\quad$ 50-Year Dose

57

270

0.017

1.0

0.052

0.43

6.9

Based on the data in Table 8.31, it can be calculated that an acute inhalation intake of about $3 \mathrm{mg}$ of $306-\mathrm{W}$ uranium would be expected to result in a 50-year committed effective dose equivalent of $100 \mathrm{mrem}$.

Table 8.32 shows the daily intake rate of $306-W$ depleted uranium that would result in a sufficient buildup in the lung to cause a $100-\mathrm{mrem} / \mathrm{yr}$ dose rate for different intake periods. For example, a daily intake of $0.0083 \mathrm{mg}$ of 306-W uranium would result in the gradual buildup in lung activity sufficient to produce a $100-\mathrm{mrem} / \mathrm{yr}$ dose rate by the end of 50 years. Conversely,

TABLE 8.32. Daily Intake Rate of Depletted Uranium Yielding an Effective Dose Equivalent by the End of the Exposure Period

\begin{tabular}{cc}
$\begin{array}{c}\text { Exposure Period, } \\
\text { r }\end{array}$ & $\frac{\text { Intake Rate }}{306-W \text { Mixt }}$ \\
\cline { 3 - 3 } 1 & 0.039 \\
2 & 0.023 \\
5 & 0.014 \\
10 & 0.011 \\
20 & 0.0098 \\
$50(b)$ & 0.0083
\end{tabular}

(a) Lung dose $=830$ mrem.

(b) Intakes at this rate for 1 year will result in a 50-year committed effective dose equivalent of $100 \mathrm{mrem}$. 
this intake rate, if maintained for 1 year, would result in a 50-year committed effective dose equivalent of 100 mrem.

\section{Bioassav Monitoring}

Intakes by 306-W workers are considered to be chronic unless otherwise indicated by workplace monitoring. Bioassay monitoring for slowly transportable materials for which the lung is the critical organ is most directly and accurately performed using in vivo measurements; however, the sensitivity of in vivo measurements is somewhat limited as discussed below.

In view of the limitations of in vivo measurements as a routine monitoring technique, urine sampling is also performed. Urine samples provide a measure of the systemically deposited uranium, and, using biokinetic models, this enables an indirect estimate of intake to be made. However, the interpretation of urine sample data is highly dependent on the nature of the intake; that is, whether it is acute, intermittent, or chronic.

In Vivo Measurements. Table 8.18 gives practical routine in vivo measurement capabilities for depleted uranium based upon the in vivo measurement detection levels in Table 8.17. At these levels, an annual chest count (2000seconds) is capable of detecting an internal exposure to class $Y$ depleted uranium of about 8\% of the annual effective dose equivalent standard of 5 rem for an acute exposure, and about 7\% of the standard for a constant burden. Increasing the length of the count to 4000 seconds will increase the sensitivity of the count to about 6\% of the standard.

An annual chest count is recommended for workers who are potentially exposed to poorly transportable forms of uranium. Any indication of uranium in the body via in vivo monitoring warrants follow-up investigation including additional in vivo measurements and urine samples. Positive in vivo measurements should be confirmed as soon as practical, and additional measurements should be performed at least quarterly as long as the uranium remains detectable.

Urine Sampling. Figure 8.10 and Table 8.33 show the urinary excretion following acute and chronic exposures to 306-W depleted uranium. The predicted excretion values are based on an assumed acute intake that would result 


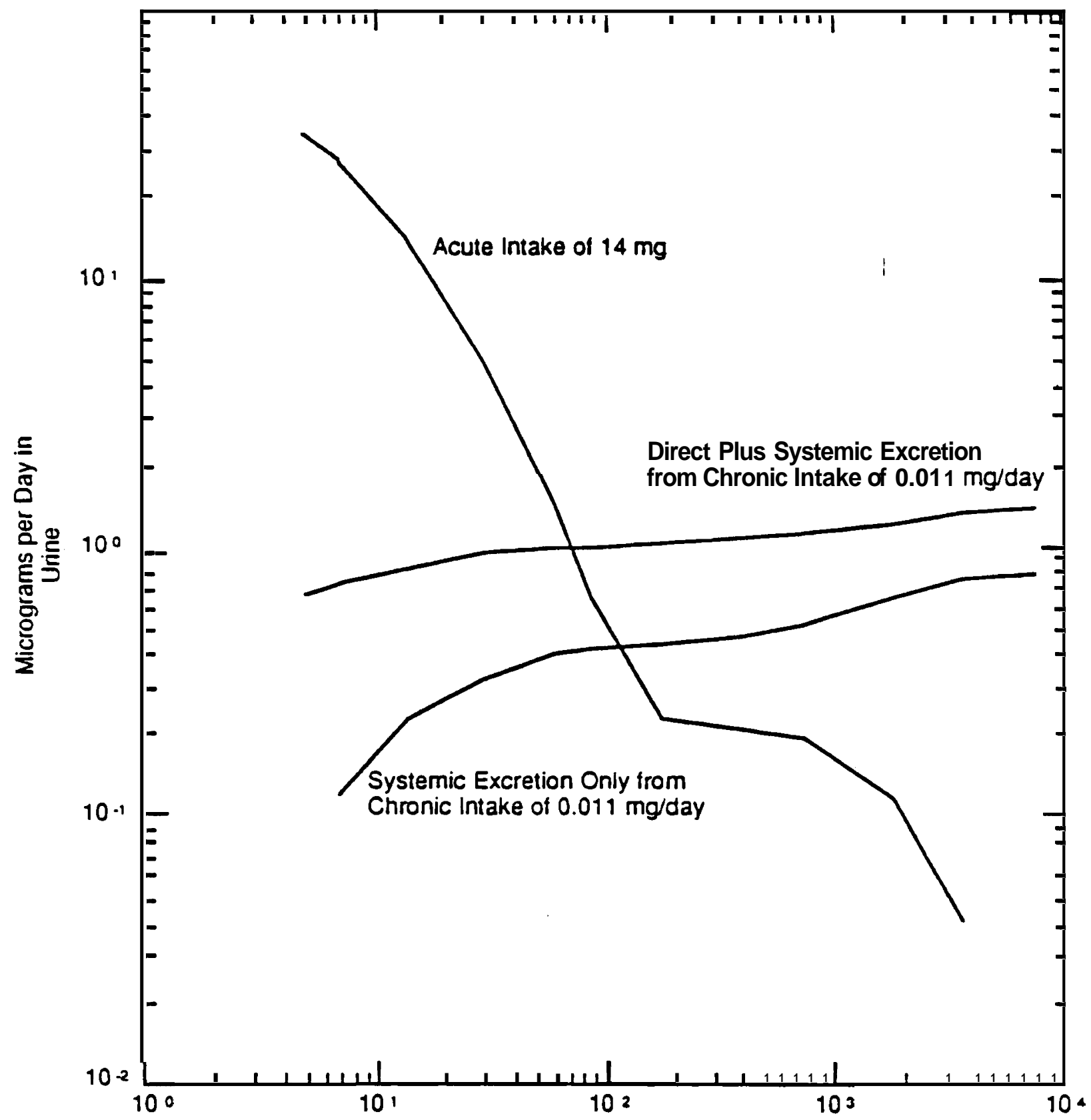

Days Post Start of Exposure

FIGURE 8.10. Predicted urinary Excretion Fol lowing an Inhalation of 306-W Building Uranium Resulting in a First-Year Effective Dose Equivalent of $100 \mathrm{mrem}$ (curves exclude excretion of environmental uranium) 
TABLE 8.33. Predicted Uranium Excretion Via Urine Foljowing an Inhalation of 306-W Building Uranium(a)

Microqrams of Uranium Per Day Via Urine(b)

\begin{tabular}{|c|c|c|c|}
\hline \multirow{4}{*}{$\begin{array}{l}\text { Days Post } \\
\text { Intake (c) }\end{array}$} & \multicolumn{3}{|c|}{ Microqrams of Uranium Per Day Via Urine(b) } \\
\hline & & & \\
\hline & $\begin{array}{l}\text { Acute Inhalation } \\
\text { Intake }=6.1 \mathrm{ng}\end{array}$ & $\begin{array}{r}\text { Intake Rate }= \\
{\left[H_{E} 100\right.}\end{array}$ & $\begin{array}{l}11 \mathrm{mg} / \mathrm{day} \\
\mathrm{m} / \mathrm{yr}]\end{array}$ \\
\hline & {$\left[\mathrm{H}_{\mathrm{E}, 1}=100 \mathrm{mrem}\right]$} & Direct + Svstemic $(e)$ & Systemic only $(\mathrm{f})$ \\
\hline 5 & 34 & 0.68 & $-\cdots$ \\
\hline 7 & 27 & 0.73 & 0.12 \\
\hline 14 & 15 & 0.83 & 0.23 \\
\hline 30 & 5.0 & 0.94 & 0.33 \\
\hline 60 & 1.5 & 1.0 & 0.40 \\
\hline 90 & 0.64 & 1.0 & 0.42 \\
\hline 180 & 0.23 & 1.0 & 0.44 \\
\hline 365 & 0.21 & 1.1 & 0.47 \\
\hline 730 & 0.19 & 1.2 & 0.52 \\
\hline 1825 & 0.11 & 1.3 & 0.66 \\
\hline 3650 & 0.04 & 1.4 & 0.76 \\
\hline
\end{tabular}

(a) Assumes $80 \%$ class Y, 20\% class D; depleted uranium.

(b) Excl udes envi ronmental background levels in urine.

(c) Days post acute intake or post onset of chronic intake.

(d) Annual effective dose equivalent $\mathrm{rate}=100 \mathrm{mrem} / \mathrm{yr}$ after 10 years of continuous intake.

(e) Incl udes a 11 excretion pathways.

(f) Excludes uranium excreted directly from blood; representative of levels that would be expected several days after cessation of chronic exposure

in a first-year effective dose equivalent of 100 mrem (a lung dose of 830 mrem) and an assumed chronic inhalation rate that would result in an effective dose equivalent rate of $100 \mathrm{mrem} / \mathrm{yr}$ after 10 years of continuous intake. The values do not include environmental uranium in the urine. The derived intakes are $14 \mathrm{ng}$ (acute) and $0.011 \mathrm{mg} /$ day (chronic).

Two levels have been developed for interpretation of urine samples from 306-W Machine Shop workers. A screening level is defined as the excretion rate that exceeds that expected due only to environmental sources. This level 
is $0.2 \mu \mathrm{g} /$ day. Workers exceeding the screening level should be maintained on a quarterly urinalysis frequency and their doses should be assessed annually.

The second level is the net occupational excretion rate expected following chronic exposures in excess of a $100-\mathrm{mrem} / \mathrm{yr}$ effective dose equivalent. This level is calculated to be $0.8 \mu \mathrm{g} /$ day for 306-W Building depleted uranium, assuming that the exposure has been occurring for 10 years. If this level is exceeded, then an investigation into the nature of the exposure is warranted. Additional follow-up bioassay measurements should be performed to confirm the nature and magnitude of the intake, and the resulting dose equivalent should be assessed and documented via an internal dose evaluation report. In addition, it should be noted that an annual average daily net excretion of $0.52 \mu \mathrm{g} /$ day (assuming 2 days of no intake) will result in a committed effective dose equivalent of $100 \mathrm{mrem}$. 


\section{SECTION 9.0}

\section{PLUTONIUM AND AMERICIUM}




\subsection{PLUTONIUM AND AMERICIUM}

This section provides information on the sources, characteristics, and biokinetics of plutonium and americium and summarizes the technical basis for their internal dosimetry at Hanford.

Historically, the general approach to plutonium internal dosimetry at Hanford has been to evaluate the systemic deposition based on urine data, and compare the result to a referenced MPBB. The most common reference for MPBBs has been ICRP 2 (1959). Prior to that publication, other reports containing MPBBs (for plutonium) consistent with those of ICRP 2 were referenced.

Prior to November 1986, evaluations of plutonium systemic deposition at Hanford were based on Langham's model for excretion of soluble plutonium (Langham et a1. 1950), Healy's model for excretion of initially insoluble plutonium (Healy 1957), or a combination of both. The procedures used for plutonium evaluation have been maintained in the Hanford Radiation Protection Historical Files of the Radiation Records Library. The most recent of these is the Hanford Dosimetry Evaluation Manual (PNL-MA-575).

Hanford plutonium evaluations have generally assessed systemic deposition and have not emphasized dose equivalent to specific organs. The assessed systemic deposition has been a "committed" systemic deposition, i.e., an estimate of the total amount of activity that would eventually reach systemic compartments. The calculated depositions have not addressed the time post intake at which the maximum systemic deposition might be expected, nor the amount of activity that might be retained in the body at various times post intake. Once the committed systemic deposition has been calculated, its value has been assumed to remain constant for the worker's life. The percentage of the MPBB has been used to indicate the degree of compliance (or noncompliance) with Atomic Energy Commission, Energy Research and Development Agency, and DOE standards for radiation protection.

(a) Pacific Northwest Laboratory. 1982. Hanford Dosimetry Evaluation Manual. PNL-MA-575, Richland, Washington. 
Historically, lung dose equivalents have been assessed in cases where in vivo measurements have observed activity in the lung. The approach used for assessment was documented on a case-by-case basis in the specific case evaluation. Generally, the approach was to use the best available information regarding isotope ratios, estimates of lung clearance rates based on ${ }^{241} \mathrm{Am}$ in vivo measurements, and fecal data (when available). Lacking such data, default assumptions have been used and documented in evaluations. The techniques for calculating dose were similar to those used in ICRP 2 (1959) and ICRP 10 (1969) and applied a quality factor of 10 for alpha particle emissions. The results of these lung dose estimates were compared with the long-standing 15-rem/yr limit of ICRP 2.

Changes in the technical approach to plutonium dosimetry at Hanford are being documented by this technical basis. These changes are required by DOE 5480.11 (DOE 1988), which addresses occupational radiation protection. The change entails a shift from the ICRP 2 critical organ dose limitation approach to the ICRP 26/30 (1977/1979) concepts of weighted summing of organ doses to give an effective dose equivalent. In addition, advances in measurement technology and modeling have improved the capabilities for plutonium dosimetry.

With this technical basis, a new term, "presystemic deposition," is introduced for the purpose of simulating biokinetic behavior in estimating internal doses. The presystemic deposition is defined as the component(s) of an initial deposition that will ultimately translocate to the blood, regardless of the time required to translocate. A transfer rate from the initial deposition into the systemic compartment is linked with each component of the presystemic deposition. Once material from the presystemic deposition has reached the systemic compartment, it is assumed to behave in accordance with the applicable biokinetic model. The presystemic deposition specifically excludes material that is permanently retained at the entry site or in Tymphatic tissues.

\subsection{SOURCES AND CHARACTERISTICS}

This section provides general information on the isotopes, mixtures, and forms of plutonium that are commonly found at Hanford. The physical and 
biological data were taken directly from, or calculated based on, information in ICRP 30, ICRP 38 (1983), and ICRP 48 (1986).

\subsubsection{Isotope Decay Data}

The plutonium and plutonium decay product isotopes of concern at Hanford and selected decay data are listed in Table 9.1. The radiological constants given in Table 9.1 are taken or calculated from data in ICRP 30 and 38 (1979, 1983).

\subsubsection{Reference Plutonium Mixtures}

At Hanford production and utilization facilities, pure isotopes of plutonium are seldom encountered. Instead, plutonium is usually encountered as a mixture of isotopes. For specific exposure situations where the isotopic composition of a mixture is known, that composition should be used for dosimetry purposes. In situations where mixtures are unknown, or for bioassay planning purposes, assumptions regarding the mixture should be made.

The isotopic composition of a plutonium mixture is related to several variables:

- the length of time fuel was irradiated (fuel exposure or burn-up time)

- the time since irradiation (cooling time)

- the time since processing of fuel or purification of plutonium.

TABLE 9.1. Plutonium and Americium Decay Data

\begin{tabular}{|c|c|c|c|c|c|}
\hline \multicolumn{2}{|c|}{ Half-Life, } & \multicolumn{2}{|c|}{ Decav Constant, } & \multirow[b]{2}{*}{ Decav Mode } & \multirow{2}{*}{$\begin{array}{c}\text { Specific } \\
\text { Activitv, } \mathrm{Ci} / \mathrm{g}\end{array}$} \\
\hline Isotope & $V r$ & $y r^{-1}$ & $\mathrm{dav}^{-1}$ & & \\
\hline${ }^{238} \mathrm{Pu}$ & 87.7 & $7.90 E-3$ & $2.16 \mathrm{E}-5$ & alpha & $1.71 \mathrm{E}+1$ \\
\hline${ }^{239} \mathrm{Pu}$ & 24,065 & $2.88 E-5$ & $7.89 E-8$ & alpha & $6.21 E-2$ \\
\hline${ }^{240} \mathrm{Pu}$ & 6,537 & $1.06 E-4$ & $2.90 \mathrm{E}-7$ & a lpha & $2.27 E-1$ \\
\hline${ }^{241} \mathrm{Pu}$ & 14.4 & $4.81 E-2$ & $1.32 E-4$ & beta & $1.03 E+2$ \\
\hline${ }^{242} \mathrm{Pu}$ & 376,300 & $1.84 E-6$ & $5.05 E-9$ & alpha & $3.92 E-3$ \\
\hline${ }^{241_{A m}}$ & 432.2 & $1.60 E-3$ & $4.39 E-6$ & alpha & $3.43 E+0$ \\
\hline
\end{tabular}


Typically, plutonium at Hanford falls into one of two generic mixtures. These mixtures are defined by the weight percent (wt \%) of ${ }^{240} \mathrm{Pu}$. Thus, $6 \%$ plutonium has a nominal ${ }^{240} \mathrm{Pu}$ content of $6 \mathrm{wt} \%$ and $12 \%$ plutonium has a nominal ${ }^{240} \mathrm{Pu}$ content of $12 \mathrm{wt} \%$. Other isotopic compositions may be encountered and should be addressed as needed.

Reference plutonium mixtures, prior to any ${ }^{241}$ Am ingrowth, are provided in Table 9.2. These reference mixtures are approximations based on the isotopic composition of a number of batches of freshly processed plutonium and are not intended to represent any specific batch. Actual exposures may or may not reflect these compositions. When the actual compositions of exposures can be obtained, such data should be used.

In the typical plutonium mixture, the plutonium-alpha activity is relatively constant over time due to the long decay half-life of the alpha emitters. The plutonium-beta activity $\left({ }^{241} \mathrm{Pu}\right)$ decays with a 14 -year halfI if e into ${ }^{241} \mathrm{Am}$. Thus, over a period of years, plutonium-beta activity in a mixture will decrease while at the same time the ${ }^{241}$ Am activity and the total alpha activity of the mixture will increase. Serial decay relationships can be used to estimate the activity of each isotope for any decay time.

For each reference mixture, a family of curves can be developed to describe the changing activity relationships between isotopes. These curves can then be used to identify, for dosimetry purposes, the plutonium mixture

TABLE 9.2. Reference Plutonium Isotope Mixtures Immediately Post Separation, wt\%

$\begin{array}{ccc}\text { Isotope } & \text { 6\% Plutonium Mixture } & \text { 12\% Plutonium Mixture } \\ { }^{238} \mathrm{Pu} & 0.05 & 0.10 \\ { }^{239} \mathrm{Pu} & 93.0 & 84.4 \\ { }^{240} \mathrm{Pu} & 6.1 & 12.4 \\ { }^{241} \mathrm{Pu} & 0.8 & 3.0 \\ { }^{242} \mathrm{Pu} & 0.05 & 0.1 \\ { }^{241} \mathrm{Am} & 0.0 & 0.0\end{array}$


and approximate age after processing or purification. These curves have been developed for three activity ratios (see Figures 9.1 through 9.3) using a technique developed by Rittman (1984).

When information about isotopic composition or activity ratios is lacking, assumptions must be made for dose assessment. Four reference plutonium mixtures are discussed in this technical basis. These four are referred to as fresh (or aged) $6 \%$ plutonium and fresh (or aged) $12 \%$ plutonium. As previously discussed, the percentage refers to the weight percent of ${ }^{240} \mathrm{Pu}$ in the mixture. Fresh mixtures are defined as having 2 weeks of ${ }^{241}$ Am ingrowth following chemical separation. Aged mixtures are defined as having 5 years of ${ }^{241} \mathrm{Am}$ ingrowth following chemical separation. These mixtures effectively cover most of the potential plutonium exposures at Hanford. The primary use for these reference mixtures is in the planning of bioassay monitoring frequencies and methods, and for stating the capability of the internal dosimetry program.

Table 9.3 provides the specific activities of each isotope in the reference mixtures and isotope ratios relative to ${ }^{239+240} \mathrm{Pu}$ and ${ }^{241} \mathrm{Am}$. Table 9.3 clearly shows that ${ }^{242} \mathrm{Pu}$ is an insignificant contributor to the specific activity of both reference mixtures.

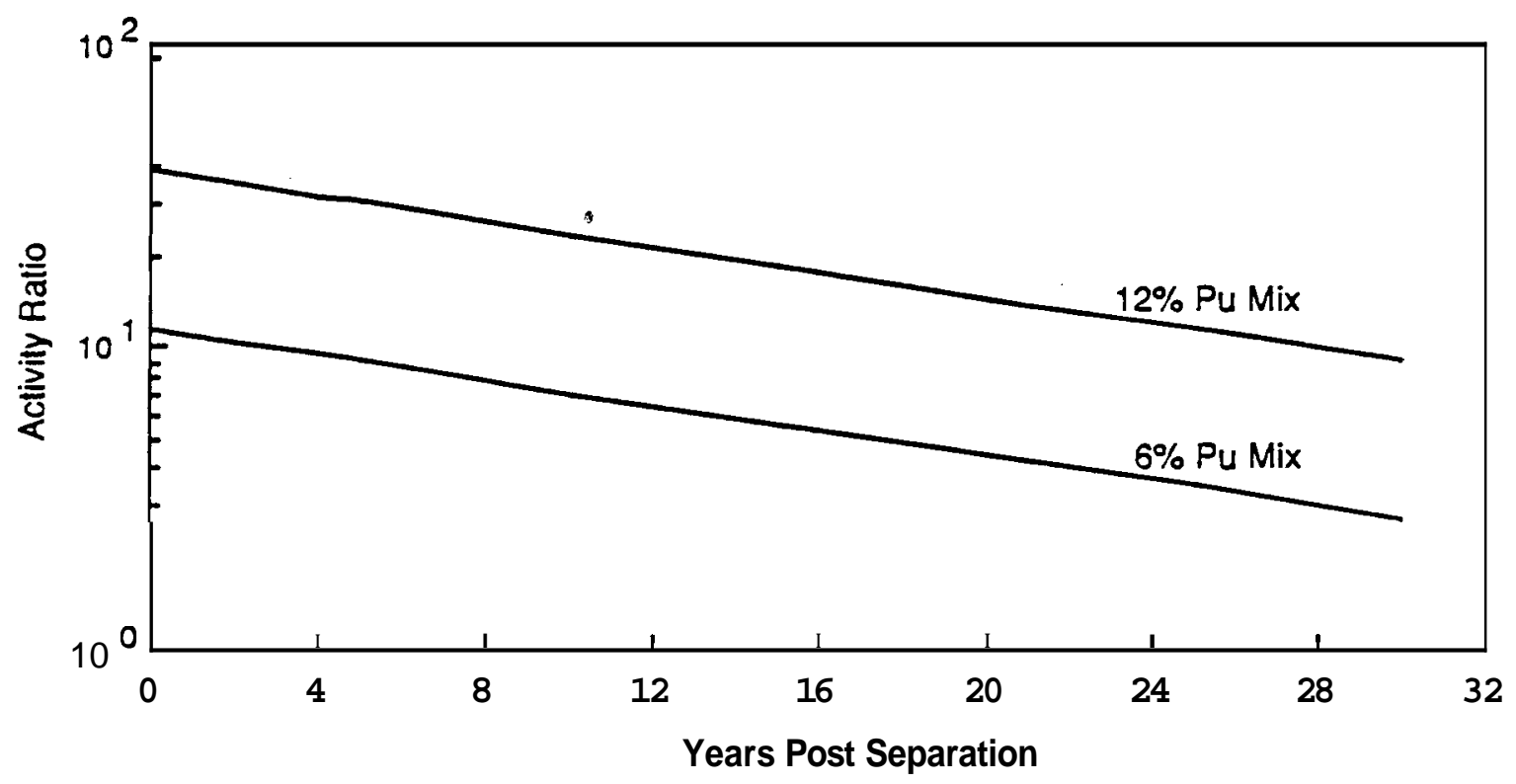

FIGURE 9.1. $241 \mathrm{Pu} /{ }^{239+240} \mathrm{Pu}$ Ratio as a Function of Time Post Separation 


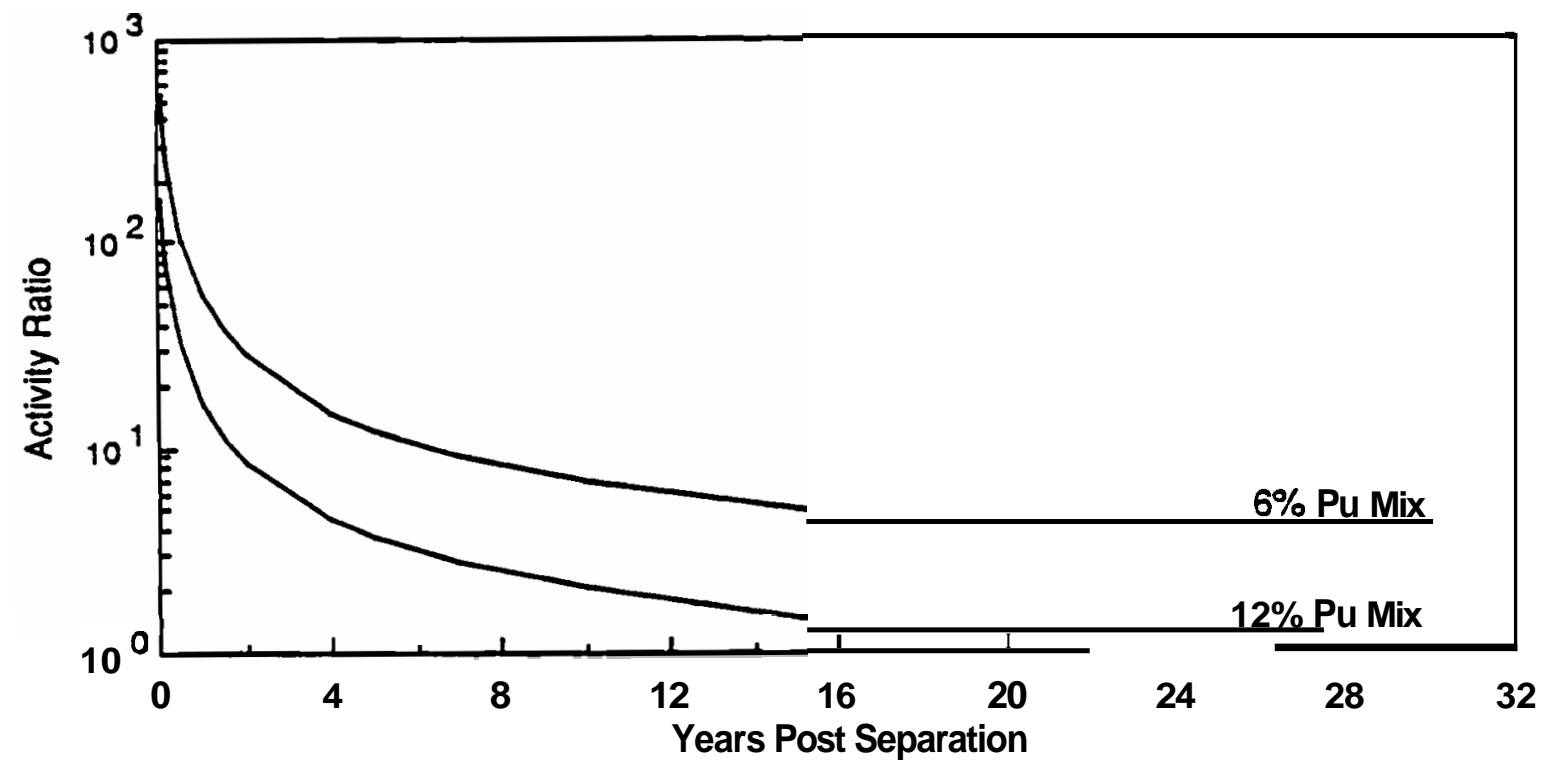

FIGURE 9.2. ${ }^{239+240} \mathrm{Pu} /{ }^{241} \mathrm{Am}$ Ratio as a Function of Time Post Separation

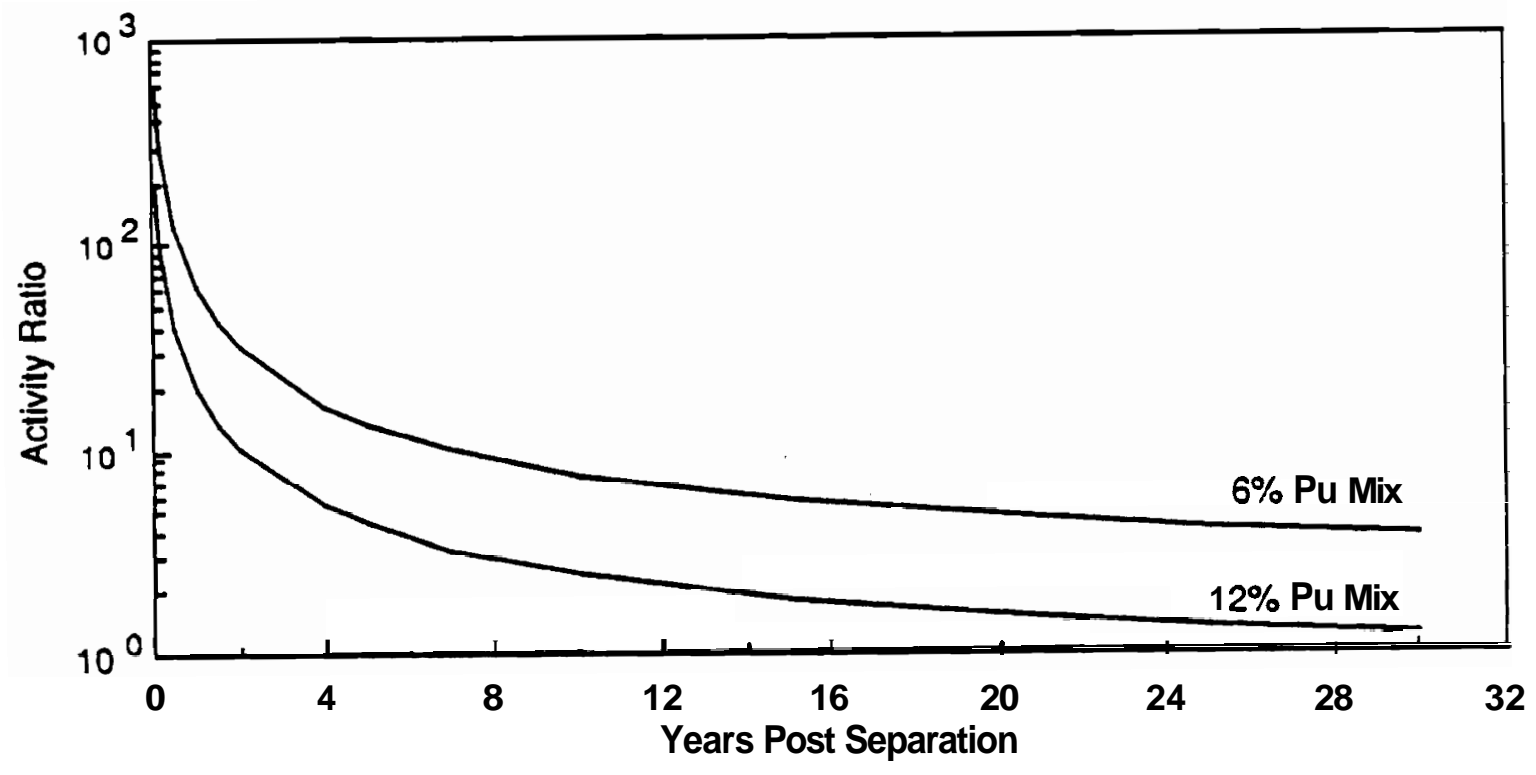

FIGURE 9.3. Plutonium-Alpha/ ${ }^{241}$ Am Ratio as a Function of Time Post Separation 
TABLE 9.3. Activity Composition for Reference Plutonium Mixtures

Reference Pl utoni um Mixture (a)

\begin{tabular}{|c|c|c|c|c|}
\hline \multirow[b]{2}{*}{ Isotopic Component } & \multicolumn{2}{|c|}{$6 \% \mathrm{Pu} \mathrm{Mix}$} & \multicolumn{2}{|c|}{$12 \% \mathrm{Pu}$ Mix } \\
\hline & Fresh & Aqed & Fresh & Aged \\
\hline \multicolumn{5}{|l|}{ Specific Activitv } \\
\hline${ }^{238} \mathrm{Pu}$ & $8.6 \mathrm{E}-3$ & $8.2 E-3$ & $1.7 \mathrm{E}-2$ & $1.6 \mathrm{E}-2$ \\
\hline $239+240 \mathrm{Pu}$ & $7.2 E-2$ & $7.2 \mathrm{E}-2$ & $8.0 E-2$ & $8.0 \mathrm{E}-2$ \\
\hline${ }^{241} \mathrm{Pu}$ & $8.2 E-1$ & $6.5 \mathrm{E}-1$ & $3.1 E+0$ & $2.4 \mathrm{E}+0$ \\
\hline${ }^{242} \mathrm{Pu}$ & $2.0 \mathrm{E}-6$ & $2.0 \mathrm{E}-6$ & $3.9 \mathrm{E}-6$ & $3.9 \mathrm{E}-6$ \\
\hline${ }^{241}{ }_{A m}$ & $5.3 E-5$ & $5.8 \mathrm{E}-3$ & $2.0 \mathrm{E}-4$ & $2.2 E-2$ \\
\hline Pu-alpha & $8.1 E-2$ & $8.0 \mathrm{E}-2$ & $9.7 \mathrm{E}-2$ & $9.6 \mathrm{E}-2$ \\
\hline Total alpha & $8.1 E-2$ & $8.6 \mathrm{E}-2$ & $9.7 \mathrm{E}-2$ & $1.2 \mathrm{E}-1$ \\
\hline$\frac{\text { Activity Ratios }}{239+240 \mathrm{Pu}:{ }^{241} \mathrm{Am}}$ & $1.3 E+3$ & $1.2 \mathrm{E}+1$ & $4.1 E+2$ & $3.7 \mathrm{E}+0$ \\
\hline Pu-alpha: ${ }^{241} \mathrm{Am}$ & $1.5 E+3$ & $1.4 \mathrm{E}+1$ & $4.9 E+2$ & $4.4 E+0$ \\
\hline $\mathrm{Pu}$ & $1.2 \mathrm{E}+1$ & $9.1 \mathrm{E}+0$ & $3.8 \mathrm{E}+1$ & $3.0 E+1$ \\
\hline
\end{tabular}

(a) $\%$ refers to nominal $240 \mathrm{Pu}$ weight percent in mixtures.
Fresh $=2$ weeks of $241 \mathrm{Am}$ ingrowth following separation.
Aged $=5$ years of $241 \mathrm{Am}$ ingrowth following separation.

\subsection{BIOKINETIC BEHAVIOR}

This section discusses the internal distribution and retention, transportability class, and urinary excretion of pl utonium.

\subsubsection{Transportability Class}

The transportability classes for plutonium are similar to those used in the ICRP 30 respiratory tract model and are sometimes referred to as solubility or inhalation classes. The class designation represents the relative speed at which material is solubilized and translocated into the transfer compartment.

The term "transportable injection" is used in this technical basis to refer to the material that is essentially immediately taken up by the transfer 
compartment upon intake. Classes W and Y, as used in this technical basis, are identical to the ICRP 30 classes of the same name.

Recent work by Stradling and Stather (1989) indicates that residual plutonium that has been subject to air oxidation for several years at normal room temperature and humidity may best be characterized as class Y material. Stradling and Stather studied the behavior of two dusts in rat lungs. One dust was a plutonium dioxide corrosion product of plutonium metal oxidized in air under ambient conditions $\left(20^{\circ}\right.$ to $25^{\circ} \mathrm{C}$ and relative humidity of 60 to $70 \%$ ) over a period of about 15 years. The second dust was a dry powder, process line residue consisting of an atmospherically degraded mixture of plutonium and uranium nitrates (originally $1.2 \mathrm{M} \mathrm{HNO}_{3}$ ) intimately mixed and highly diluted with inactive debris, resulting from the corrosion of an experimental rig over 15 years (i.e., rust). The plutonium oxide powder was found to exhibit very definite class $Y$ behavior characteristics. The translocation rate for plutonium in the nitrate-bearing residues was about three times faster than for a class $Y$ compound, but about 10 times slower than for a class W compound; i.e., the nitrate-bearing residue came closer to being class $Y$ than class $W$ in behavior. These findings imply that dry, residual plutonium contamination within facilities and gloveboxes should be treated as class $Y$ material regardless of its original chemical form. Designation of pl utonium as a class $\mathrm{W}$ material should be limited to current processes generating nitrates or residuals from recent runs of such processes. Plutonium worker bioassay programs should consider the potential exposure to aged plutonium oxides if there is any source of old residual contamination.

In addition to the above classes, a fourth class of material has been defined for use in this technical basis. Super class Y (super Y) has been established by the Hanford Internal Dosimetry Program to define highly nontransportable forms of plutonium based on some actual observed cases at Hanford (Bihl et a1. 1988). For inhalation exposures, super $Y$ material has been defined as being similar to class $Y$ material with respect to compartment deposition fractions in the respiratory tract model. However, retention halflives for the transport from the lung to the blood (ICRP 30 lung compartments a, $c, e$, and $i$ [see Appendix D]) have been adjusted to 10,000 days. The 
precise nature of super class $Y$ material is not known, although it appears to have been associated with certain Hanford processes involving fired plutonium oxides.

When combinations of transportability classes may exist in a matrix, the transportability of the mixture is assumed to be that of the predominant material. For example, in a plutonium oxide matrix containing americium oxide as an ingrown impurity, the transportability of the americium oxide is assumed to be the same as that of the major mass constituent of the matrix (Eidson 1980). Thus, the americium is assumed to exhibit the class $Y$ behavior of the host matrix (plutonium oxide), rather than the class $W$ behavior normally expected of americium oxide. The above-described behavior would not be the case if the mixture were merely a blend of the two oxide powders. In this latter case, each element would be expected to exhibit its own characteristic behavior. These assumptions are also consistent with the observations by Stradling and Stather (1989).

The fractional lung retention factors (lung + lymph nodes) for class $W$, $y$, and super $Y$ forms of plutonium are given in Table 9.4 for selected days post acute intake. These values were obtained using the GENMOD code.

\subsubsection{Systemic Distribution and Retention}

The ICRP 48 (1986) model is used for calculating the distribution and retention of plutonium in the body. For dissolved plutonium reaching the transfer compartment (i .e., the blood stream), the ICRP recommends the distribution and organ clearance (or retention) half-times shown in Table 9.5.

The activity deposited in bone is assumed to be deposited uniformly over bone surfaces of both cortical and trabecular bone, where it remains until it decays or is excreted. The "all other" deposition fraction is assumed to represent direct excretion and any short-term holdup in the tissues of the circulatory or urinary systems. For purposes of dosimetry, this fraction is considered to be an insignificant contributor to effective dose equivalent (relative to bone, red marrow, 1iver, and gonad dose contributors), and is ignored. 
TABLE 9.4. Selected Lung Retention Factors Exprês
Fraction of Acute Inhalation of 23 Pu $^{5}(a, b)$

\begin{tabular}{|c|c|c|c|}
\hline $\begin{array}{l}\text { Days Post } \\
\text { Intake }\end{array}$ & $\begin{array}{l}\text { Class W } \\
\text { Lung }\end{array}$ & $\begin{array}{l}\text { Class Y } \\
\text { Lung } \\
\end{array}$ & $\begin{array}{l}\text { Super } Y \\
\text { Lung }\end{array}$ \\
\hline 0 & $3.3 \mathrm{E}-1$ & $3.3 E-1$ & $3.3 \mathrm{E}-1$ \\
\hline 1 & $2.2 E-1$ & $2.1 \mathrm{E}-1$ & $2.2 \mathrm{E}-1$ \\
\hline 2 & $1.8 \mathrm{E}-1$ & $1.8 \mathrm{E}-1$ & $1.8 \mathrm{E}-1$ \\
\hline 5 & $1.5 \mathrm{E}-1$ & $1.5 \mathrm{E}-1$ & $1.5 \mathrm{E}-1$ \\
\hline 7 & $1.4 \mathrm{E}-1$ & $1.5 E-1$ & $1.5 \mathrm{E}-1$ \\
\hline 14 & 1. $3 \mathrm{E}-1$ & $.1 .5 \mathrm{E}-1$ & $1.5 \mathrm{E}-1$ \\
\hline 30 & $1.0 \mathrm{E}-1$ & $1.5 \mathrm{E}-1$ & $1.5 \mathrm{E}-1$ \\
\hline 60 & $7.0 E-2$ & $1.4 \mathrm{E}-1$ & $1.4 \mathrm{E}-1$ \\
\hline 90 & $4.8 E-2$ & $1.4 E-1$ & $1.4 \mathrm{E}-1$ \\
\hline 180 & $1.5 \mathrm{E}-2$ & $1.3 \mathrm{E}-1$ & $1.3 \mathrm{E}-1$ \\
\hline 365 & $1.4 \mathrm{E}-3$ & $1.0 \mathrm{E}-1$ & $1.1 \mathrm{E}-1$ \\
\hline 730 & $1.1 \mathrm{E}-5$ & $7.3 E-2$ & $8.6 E-2$ \\
\hline 1825 & $0.0 E+0$ & $2.9 \mathrm{E}-2$ & $5.5 E-2$ \\
\hline 3650 & $0.0 E+0$ & $9.6 \mathrm{E}-3$ & $4.2 E-2$ \\
\hline 7300 & $0.0 E+0$ & $4.2 E-3$ & $3.3 E-2$ \\
\hline 18,250 & $0.0 E+0$ & $3.7 E-3$ & $1.7 \mathrm{E}-2$ \\
\hline
\end{tabular}

(a) Assumes 1- $\mu$ m-AMAD particle size.

(b) Factors also apply to comparably long half-life plutonium isotopes.

TABLE 9.5. ICRP 48 Biokinetic Constants for PTutonium(a)

\begin{tabular}{|c|c|c|c|}
\hline$\frac{\text { Orqan }}{\text { Bone }}$ & $\begin{array}{c}\text { Translocated } \\
\text { Fraction }\end{array}$ & $\begin{array}{l}\text { Bioloaical } \\
\text { Half-Time }\end{array}$ & $\begin{array}{l}\text { Bioloaical } \\
\frac{\text { Rate }}{3.8 \mathrm{E}-5 / \text { day }}\end{array}$ \\
\hline Liver & 0.30 & $20 \mathrm{yr}$ & $9.5 E-5 /$ day \\
\hline $\begin{array}{l}\text { Gonads } \\
\text { Testes }\end{array}$ & $3.4 E-4$ & (permanent) & 0 \\
\hline Ovaries & $1.0 E-4$ & (permanent) & 0 \\
\hline All Other (b) & 0.20 & & \\
\hline
\end{tabular}

(a) From ICRP 1986.

(b) Includes tissue and early excretion. 
Although the translocated fractions for testes and ovaries shown in Table 9.5 differ, the gonadal dose equivalent for males and females is identical. This is attributed to the substantially differing masses of the two organs, with the result that the alpha activity concentration within the tis sues, and therefore the tissue doses, are the same.

\subsubsection{Urinarv Excretion}

In its Report 84 (NCRP 1985), the NCRP states that, "interpretation of excretion data for purposes of body burden estimation should be based on models derived with that application primarily in mind. The models of ICRP 30 and ICRP 48 (1986) were derived for the estimation of organ dose and were not necessarily intended to account for excretion." In recognition of this, the Hanford Internal Dosimetry Program has selected the Jones function (Jones 1985) to relate the urine excretion of plutonium to systemic uptake.

The Jones function is based on human injection studies originally reported by Langham et a1. (1950) and Langham (1956) and follow-up work by Rundo et al. (1976) and Moss and Gautier (1985). The studies involved direct intravenous injection of plutonium citrate. The application of the function to observed excretion data results in an estimate of the uptake of plutonium by systemic circulation.

The Jones function models urinary excretion of plutonium following systemic uptake as a four-component exponential function. Jones emphasized that his function was an empirical fit to human data and should not be interpreted as modeling retention in specifically identifiable compartments. Thus, its application at Hanford is limited to estimating uptake and predicting excretion based on uptake. It is specifically not being used for organ dose calculations.

The Jones function is mathematically defined as:

$$
\begin{aligned}
\mathrm{e}_{\mathrm{u}}{ }^{\mathrm{a}}(t) & =0.00475 \exp (-0.558 t) \mathrm{t} 0.000239 \exp (-0.0442 t) \\
& +0.0000855 \exp (-0.00380 t) \\
& +0.0000142 \exp (-0.0000284 t)
\end{aligned}
$$


where $e^{a}(t)$ is the fraction of uptake to blood excreted in urine on day $t$ post uptake, and $\mathbf{t}$ is the days post uptake (note: $\mathbf{t}=0$ is time of intake; $\mathbf{t}=1$ represents the first 24 hours following intake; $\mathbf{t}=2$ represents the second day post uptake; etc.) .

The Jones excretion function described above has replaced the Langham and Healy (Healy 1957) functions for evaluating plutonium depositions at Hanford. Further discussion of this change can be found in the Hanford Radiation Protection Historical Files of the Radiation Records Library. (a) The effective date for this change was November 1986.

The Jones excretion function has been applied to material that is not readily transportable to the systemic compartment through the use of one or more isolated presystemic compartments, initially containing all of the material that will ultimately become systemic uptake. Each presystemic compartment clears to the systemic compartment by an associated fractional transfer rate using simple first-order kinetics.

The PUCALC computer program has been developed by Internal Dosimetry to calculate presystemic depositions and urinary excretion based on a single presystemic-to-systemic uptake transfer rate. The program allows for fits of various combinations of transfer rate and presystemic deposition estimates to urine data and is particularly useful in cases involving substantial excretion data, where multiple presystemic components may be identifiable. The evaluation process is described in Section 9.5.

The GEMOD computer code can also be used to estimate the excretion. The Jones empirical excretion function is implemented as a pseudo uptake retention function (Skrable 1987) by GEMOD to describe excretion following an uptake. GEMOD is particularly useful for evaluating plutonium excretion following inhalation of class $W, Y$, or super $Y$ material. A description of the plutonium model parameters for GENDD is included in Appendix A.

(a) Carbaugh, E. H., and M. J. Sula. 1986. "Proposed Change to Plutonium Excretion Function Used for Hanford Internal Dosimetry." Letter report to the Hanford Radiation Protection Historical Files, December 11, 1986, Pacific Northwest Laboratory, Richland, Washington. 


\subsection{NIERNAL DOSMEIRY FACTORS}

This section contains factors that are useful in making internal dosimetry calculations. The factors included in this section are derived from the GENMOD computer code and incorporate standard assumptions. Their application is intended for those circumstances where such assumptions are appropriate or more specific information is lacking. Variation from these factors is appropriate if sufficient data are available.

\subsubsection{Intake Excretion Factors}

The intake excretion factor expresses the fraction of intake excreted by a particular pathway (urine or feces) at a given time post intake. For plutonium and americium excretion in urine, this factor is based on the Jones excretion function (discussed in Section 9.2). The intake urinary excretion functions for an acute transportable injection and for inhalation classes of ${ }^{239} \mathrm{Pu}$ are shown in Figure 9.4, and selected values are given in Table 9.6. Tabulated values for fecal excretion factors are shown in Table 9.7. Values for days other than those tabulated here can be obtained by linear interpolation between the tabulated data, or by obtaining the values directly from GENMOD.

\subsubsection{Dose Conversion Factors}

Activity deposited in a source organ is assumed to irradiate the target organ according to the ICRP 30 models. Dose conversion factors for potentially significant source and target organ combinations are tabulated by nuclide in Tables 9.8 through 9.11. These factors are derived by units conversion from the GENMOD computer code. They have been compared with results handcalculated from ICRP 30 data tables, and they were found to agree within calculational rounding errors of about $5 \%$. These factors can provide a convenient reference for dose equivalent to a target organ from decay occurring in a source organ. Dose conversion factors for other source and target organs can be obtained from GENMOD if desired.

\subsubsection{Intake Dose Eauivalent Factors}

Intake dose equivalent factors, in units of dose equivalent per unit activity of intake (rem per nanocurie of acute intake or rem per nanocurie per 


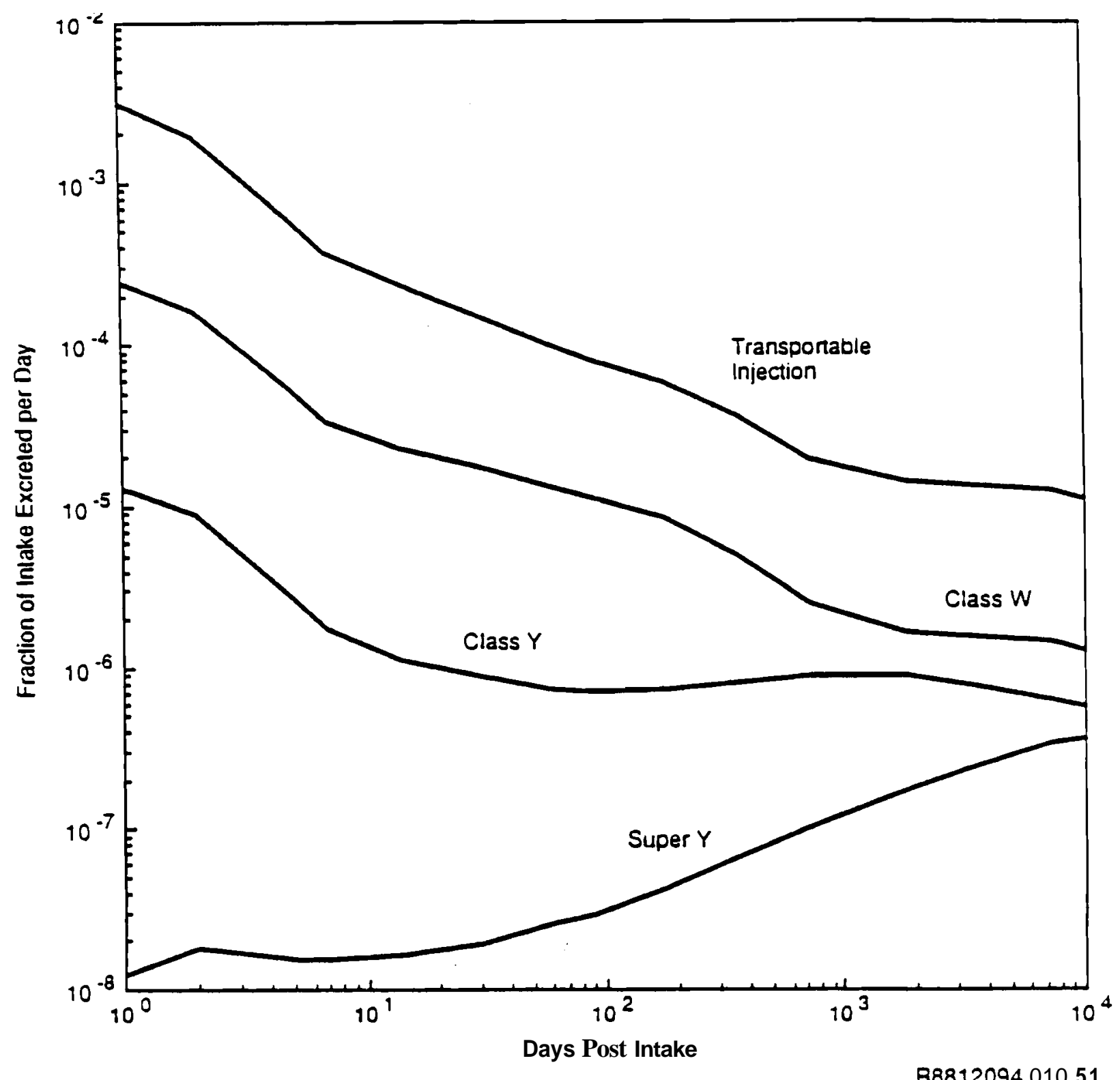

\section{FIGURE 9.4. $\quad{ }^{239} \mathrm{Pu}$ Acute Intake Urinary Excretion Functions}

day of chronic intake), are a convenient shortcut to estimating doses based on standard assumptions when the magnitude of an intake is known or assumed. Acute intake dose equivalent factors have been tabulated for the first-year and 50-yr committed dose equivalents resulting from readily transportable injection and class $W, Y$, and super $Y$ inhalation (based on 1- $\mu \mathrm{m}$-AMAD particle size). Factors for single isotopes are shown in Tables 9.12 through 9.15. In the case of ${ }^{241} \mathrm{Pu}$, the ${ }^{241} \mathrm{Am}$ ingrown from the time of intake is included in 
TABLE 9.6. Selected ${ }^{239}$ Pu Urinary Excretion Fractions Expressed as a Fraction of Acute Intake

\begin{tabular}{|c|c|c|c|c|}
\hline \multirow{2}{*}{$\begin{array}{l}\text { Days Post } \\
\text { Intake }\end{array}$} & \multirow{2}{*}{$\begin{array}{l}\text { Transportable } \\
\text { Injection } \\
\end{array}$} & \multicolumn{3}{|c|}{ Inhalation $(a)$} \\
\hline & & Class W & $\underline{\text { Class } Y}$ & Super Y \\
\hline $\begin{array}{r}1 \\
2 \\
5 \\
7 \\
14 \\
30 \\
60 \\
90 \\
180 \\
365 \\
730 \\
1,825 \\
3,650 \\
7,300 \\
18,250\end{array}$ & $\begin{array}{l}3.3 \mathrm{E}-3 \\
2.2 \mathrm{E}-3 \\
6.6 \mathrm{E}-4 \\
4.0 \mathrm{E}-4 \\
2.3 \mathrm{E}-4 \\
1.6 \mathrm{E}-4 \\
1.0 \mathrm{E}-4 \\
8.0 \mathrm{E}-5 \\
5.7 \mathrm{E}-5 \\
3.5 \mathrm{E}-5 \\
1.9 \mathrm{E}-5 \\
1.4 \mathrm{E}-5 \\
1.3 \mathrm{E}-5 \\
1.2 \mathrm{E}-5 \\
8.5 \mathrm{E}-6\end{array}$ & $\begin{array}{l}2.4 \mathrm{E}-4 \\
1.6 \mathrm{E}-4 \\
5.1 \mathrm{E}-5 \\
3.3 \mathrm{E}-5 \\
2.2 \mathrm{E}-5 \\
1.7 \mathrm{E}-5 \\
1.3 \mathrm{E}-5 \\
1.2 \mathrm{E}-5 \\
8.3 \mathrm{E}-6 \\
4.8 \mathrm{E}-6 \\
2.5 \mathrm{E}-6 \\
1.6 \mathrm{E}-6 \\
1.5 \mathrm{E}-6 \\
1.4 \mathrm{E}-6 \\
1.0 \mathrm{E}-6\end{array}$ & $\begin{array}{l}1.3 \mathrm{E}-5 \\
8.7 \mathrm{E}-6 \\
2.7 \mathrm{E}-6 \\
1.7 \mathrm{E}-6 \\
1 . \mathrm{IE}-6 \\
8.6 \mathrm{E}-7 \\
7.1 \mathrm{E}-7 \\
6.9 \mathrm{E}-7 \\
7.2 \mathrm{E}-7 \\
8.0 \mathrm{E}-7 \\
8.8 \mathrm{E}-7 \\
8.8 \mathrm{E}-7 \\
7.4 \mathrm{E}-7 \\
6.1 \mathrm{E}-7 \\
4.4 \mathrm{E}-7\end{array}$ & $\begin{array}{l}1.2 \mathrm{E}-8 \\
1.8 \mathrm{E}-8 \\
1.5 \mathrm{E}-8 \\
1.5 \mathrm{E}-8 \\
1.6 \mathrm{E}-8 \\
1.9 \mathrm{E}-8 \\
2.5 \mathrm{E}-8 \\
2.9 \mathrm{E}-8 \\
4.2 \mathrm{E}-8 \\
6.6 \mathrm{E}-8 \\
1.0 \mathrm{E}-7 \\
1.7 \mathrm{E}-7 \\
2.4 \mathrm{E}-7 \\
3.2 \mathrm{E}-7 \\
4.1 \mathrm{E}-7\end{array}$ \\
\hline
\end{tabular}

(a) Assumes 1- $\mu$ m-AMAD particle size.

TABLE 9.7.
Fraction of Acute Inhalation of $239 \mathrm{Pu}(\mathrm{a}, \mathrm{b}, \mathrm{c})$

\begin{tabular}{|c|c|c|c|}
\hline $\begin{array}{l}\text { Days Post } \\
\text { Intake } \\
\end{array}$ & $\begin{array}{l}\text { Class W } \\
\text { Lung } \\
\end{array}$ & $\begin{array}{l}\text { Class } Y \\
\text { Lung } \\
\end{array}$ & $\begin{array}{l}\text { Super Y } \\
\text { Lung }\end{array}$ \\
\hline $\begin{array}{r}0 \\
1 \\
2 \\
5 \\
7 \\
14 \\
30 \\
60 \\
90 \\
180 \\
365 \\
730 \\
1,825 \\
3,650 \\
7,300 \\
18,250\end{array}$ & $\begin{array}{l}0.0 \mathrm{E}+0 \\
1.1 \mathrm{E}-1 \\
1.3 \mathrm{E}-1 \\
2.4 \mathrm{E}-2 \\
6.4 \mathrm{E}-3 \\
1.2 \mathrm{E}-3 \\
9.6 \mathrm{E}-4 \\
6.3 \mathrm{E}-4 \\
4.2 \mathrm{E}-4 \\
1.3 \mathrm{E}-4 \\
1.4 \mathrm{E}-5 \\
2.5 \mathrm{E}-6 \\
1.6 \mathrm{E}-6 \\
1.5 \mathrm{E}-6 \\
1.4 \mathrm{E}-6 \\
1.0 \mathrm{E}-6\end{array}$ & $\begin{array}{l}0.0 \mathrm{E}+0 \\
1.3 \mathrm{E}-1 \\
1.6 \mathrm{E}-1 \\
2.5 \mathrm{E}-2 \\
5.5 \mathrm{E}-3 \\
1.7 \mathrm{E}-4 \\
1.3 \mathrm{E}-4 \\
1.3 \mathrm{E}-4 \\
1.2 \mathrm{E}-4 \\
1.3 \mathrm{E}-4 \\
8.5 \mathrm{E}-5 \\
5.1 \mathrm{E}-5 \\
1.2 \mathrm{E}-5 \\
1.4 \mathrm{E}-6 \\
6.2 \mathrm{E}-7 \\
4.4 \mathrm{E}-7\end{array}$ & $\begin{array}{l}0.0 \mathrm{E}+0 \\
1.3 \mathrm{E}-1 \\
1.8 \mathrm{E}-1 \\
2.5 \mathrm{E}-2 \\
5.5 \mathrm{E}-3 \\
1.7 \mathrm{E}-4 \\
1.3 \mathrm{E}-4 \\
1.3 \mathrm{E}-4 \\
1.2 \mathrm{E}-4 \\
1 . \mathrm{IE}-4 \\
8.4 \mathrm{E}-5 \\
5.1 \mathrm{E}-5 \\
1.1 \mathrm{E}-5 \\
1.1 \mathrm{E}-6 \\
3.2 \mathrm{E}-7 \\
4.1 \mathrm{E}-7\end{array}$ \\
\hline
\end{tabular}

(a) Assumes 1- $\mu$ m-AMAD particle size.

(b) Factors also apply to comparably long half-1ife isotopes of plutonium.

(c) Assumes $50 \%$ of excretion from systemic organs is via feces. 
TABLE 9.8. $238 \mathrm{Pu}$ Dose Conversion Factors

\begin{tabular}{llll} 
Target orqan & Source organ & \multicolumn{2}{c}{$\begin{array}{c}\text { Conversion Factors, } \\
\text { rem/nCi-day }\end{array}$} \\
Lung & Tissue & Weighted \\
Bone surface & Lung & $5.62 \mathrm{E}-3$ & $6.73 \mathrm{E}-4$ \\
Red marrow & Bone surface & $1.17 \mathrm{E}-2$ & $3.52 \mathrm{E}-4$ \\
Liver & Liver & $9.44 \mathrm{E}-4$ & $1.13 \mathrm{E}-4$ \\
Gonads & Gonads & $3.17 \mathrm{E}-3$ & $1.90 \mathrm{E}-4$ \\
Gut & Gut & $1.64 \mathrm{E}-1$ & $4.09 \mathrm{E}-2$ \\
SI & SI & $1.13 \mathrm{E}-4$ & $6.77 \mathrm{E}-6$ \\
ULI (b) & ULI & $7.07 \mathrm{E}-5$ & $4.26 \mathrm{E}-6$ \\
LLI (c) & LLI & $1.28 \mathrm{E}-4$ & $7.66 \mathrm{E}-6$ \\
& & $2.08 \mathrm{E}-4$ & $1.25 \mathrm{E}-5$
\end{tabular}

(a) $\mathrm{SI}=$ small intestine.

(b) ULI = upper large intestine.

(c) LLI = lower large intestine.

TABLE 9.9. $239 \mathrm{Pu}$ and/or $240 \mathrm{Pu}$ Dose Conversion Factors (a)

Tarqet Orqan

Lung

Bone surface

Red marrow

Liver

Gonads

Gut (b)

ULI (c)

LLI (d)

\section{Source Orsan}

Lung

Bone surface

Bone surface

Liver

Gonads

Gut

SI

ULI

LLI

Dose Conversion Factors, $\mathrm{rem} / \mathrm{nCi}$-day

Tissue

Weighted

5.37E-3

$1.03 \mathrm{E}-2$

8.81E-4

$2.98 \mathrm{E}-3$

1. $53 \mathrm{E}-1$

$1.06 \mathrm{E}-4$

$6.44 \mathrm{E}-4$

3. $10 \mathrm{E}-4$

1.06E-4

1. $79 \mathrm{E}-4$

$3.85 \mathrm{E}-2$

$6.62 \mathrm{E}-5$

6. $36 \mathrm{E}-6$

1. $18 \mathrm{E}-4$

3. $96 \mathrm{E}-6$

1. $96 \mathrm{E}-4$

7.10E-6

$1.18 \mathrm{E}-5$

\footnotetext{
(a) ${ }^{239} \mathrm{Pu}$ and $240 \mathrm{Pu}$ are dosimetrically equivalent, thus these factors can be used for the pure isotopes or the combined isotopes.

(b) $\mathrm{SI}=$ small intestine.

(c) ULI = upper large intestine.

(d) LLI = lower large intestine.
} 
TABLE 9.10. $\quad{ }^{241} \mathrm{Pu}$ Dose Conversion Factors

\begin{tabular}{|c|c|c|c|}
\hline \multirow[b]{2}{*}{ Tarqet Orqan } & \multirow[b]{2}{*}{ Source Orqan } & \multicolumn{2}{|c|}{$\begin{array}{c}\text { Dose Conversion Factors, } \\
\text { rem } / \mathrm{nC} \mathrm{i}-\mathrm{day}\end{array}$} \\
\hline & & Tissue & Weighted \\
\hline $\begin{array}{l}\text { Lung } \\
\text { Bone surface } \\
\text { Red marrow } \\
\text { Liver } \\
\text { Gonads } \\
\text { Gut } \\
\text { SI a) } \\
\text { ULI (b) } \\
\text { LLI (c) }\end{array}$ & $\begin{array}{l}\text { Lung } \\
\text { Bone surface } \\
\text { Bone surface } \\
\text { Liver } \\
\text { Gonads } \\
\text { Gut } \\
\text { SI } \\
\text { ULI } \\
\text { LLI }\end{array}$ & $\begin{array}{l}3.92 \mathrm{E}-7 \\
8.14 \mathrm{E}-7 \\
6.51 \mathrm{E}-8 \\
2.18 \mathrm{E}-7 \\
1.12 \mathrm{E}-5 \\
5.40 \mathrm{E}-7 \\
3.37 \mathrm{E}-7 \\
6.11 \mathrm{E}-7 \\
9.99 \mathrm{E}-7\end{array}$ & $\begin{array}{l}4.70 \mathrm{E}-8 \\
2.44 \mathrm{E}-8 \\
7.81 \mathrm{E}-9 \\
1.31 \mathrm{E}-8 \\
2.81 \mathrm{E}-6 \\
3.24 \mathrm{E}-8 \\
2.02 \mathrm{E}-8 \\
3.66 \mathrm{E}-8 \\
5.99 \mathrm{E}-8\end{array}$ \\
\hline
\end{tabular}

(a) $\mathrm{SI}=$ small intestine.
(b) $U L I=$ upper large intestine.
(c) $L L I=$ lower large intestine.

TABLE 9.11. $\quad{ }^{241}$ Am Dose Conversion Factors

\begin{tabular}{|c|c|c|c|}
\hline \multirow[b]{2}{*}{ Tarqet Orqan } & \multirow[b]{2}{*}{ Source Organ } & \multicolumn{2}{|c|}{$\begin{array}{c}\text { Dose Conversion Factors, } \\
\mathrm{rem} / \mathrm{nC} j \text {-day }\end{array}$} \\
\hline & & Tissue & Weighted \\
\hline Lung & Lung & $5.70 E-3$ & $6.85 E-4$ \\
\hline Bone surface & Bone surface & $1.17 \bar{E}-2$ & $3.51 E-4$ \\
\hline Red marrow & Bone surface & $9.36 \bar{E}-4$ & $1.12 E-4$ \\
\hline Liver & Liver & $3.17 E-3$ & $1.90 \mathrm{E}-4$ \\
\hline Gonads & Gonads & $1.63 \mathrm{E}-1$ & $4.07 E-2$ \\
\hline Gut a) & Gut & $1.17 \mathrm{E}-4$ & $6.99 \bar{E}-6$ \\
\hline$S I^{(a)}(b)$ & SI & $7.29 \mathrm{E}-5$ & $4.37 E-6$ \\
\hline ULI (D) & ULI & $1.30 E-4$ & $7.81 E-6$ \\
\hline $\operatorname{LLI}(c)$ & LLI & $2.16 \mathrm{E}-4$ & $1.30 E-5$ \\
\hline
\end{tabular}

(a) $S I=$ small intestine.
(b) ULI = upper large intestine.
(c) LLI = lower large intestine.

the ${ }^{241} \mathrm{Pu}$ dose equivalent factor, whereas ${ }^{241} \mathrm{Am}$ that existed at the time of intake is treated separate1y as pure ${ }^{241} \mathrm{Am}$, but having the transportability characteristics of the host matrix.

The factors in Tables 9.12 through 9.15 were used in conjunction with the reference isotope mixtures defined in Section 9.1 to derive intake dose equivalent factors for the reference mixtures, which are tabulated in 
TABLE 9.12. 238 Pu Acute Intake Dose Equivalent Factors (a) for First-Year and 50-Year Committed Doses

Tissue Transportable
Injection Inhalation $(c)$
$\underline{\text { Class } W} \quad \underline{\text { Class } Y} \underline{\text { Super } Y}$

Effective

First-year

$1.1 \mathrm{E}-1$

2.0E-2

$3.2 \mathrm{E}-2$

$3.2 \mathrm{E}-2$

50 -year

$3.2 \mathrm{E}+0$

4. OE-1

$2.9 \mathrm{E}-1$

$4.6 \mathrm{E}-1$

Lung

First-year

NA $(d)$

$6.7 \mathrm{E}-2$

2.6E-1

2.7E-1

50-year

NA $(d)$

$6.8 \mathrm{E}-2$

$1.2 \mathrm{E}+0$

$3.2 E+0$

Bone surface

First-year
50 -year

2. $1 \mathrm{E}+0$

2.3E-1

1.5E-2

$5.8 \mathrm{E}-4$

$6.5 \mathrm{E}+1$

$7.8 \mathrm{E}+0$

$3.0 \mathrm{E}+0$

$1.4 \mathrm{E}+0$

Red marrow

First-year

$1.7 \mathrm{E}-1$

1. $8 \mathrm{E}-2$

1.2E-3

4.7E-5

50-year

5. $2 \mathrm{E}+0$

$6.3 \mathrm{E}-1$

2. $4 \mathrm{E}-1$

1. $1 \mathrm{E}-1$

Liver

First-year

3. $4 \mathrm{E}-1$

3.7E-2

2. $4 \mathrm{E}-3$

9. $4 \mathrm{E}-5$

50-year

7. $2 \mathrm{E}+0$

8. $6 \mathrm{E}-1$

$3.4 \mathrm{E}-1$

$1.7 \mathrm{E}-1$

Gonads

First-year
50 -year

$$
2.0 \mathrm{E}-2
$$

2. $2 E-3$

1. $5 \mathrm{E}-4$

$5.7 \mathrm{E}-6$

8. $4 \mathrm{E}-1$

$1.0 \mathrm{E}-1$

$3.8 \mathrm{E}-2$

$1.7 \mathrm{E}-2$

(a) Units are rem/nci of acute intake.

(b) Assumes al1 plutonium is readily transportable.

(c) Assumes 1- $\mu$ m-AMAD particle size.

(d) Not applicable. 
TABLE 9.13. $239 \mathrm{Pu}$ and/or $240 \mathrm{Pu}$ Acute Intake Dose Equivalent Factors (a) for First-Year and 50-Year Committed Doses

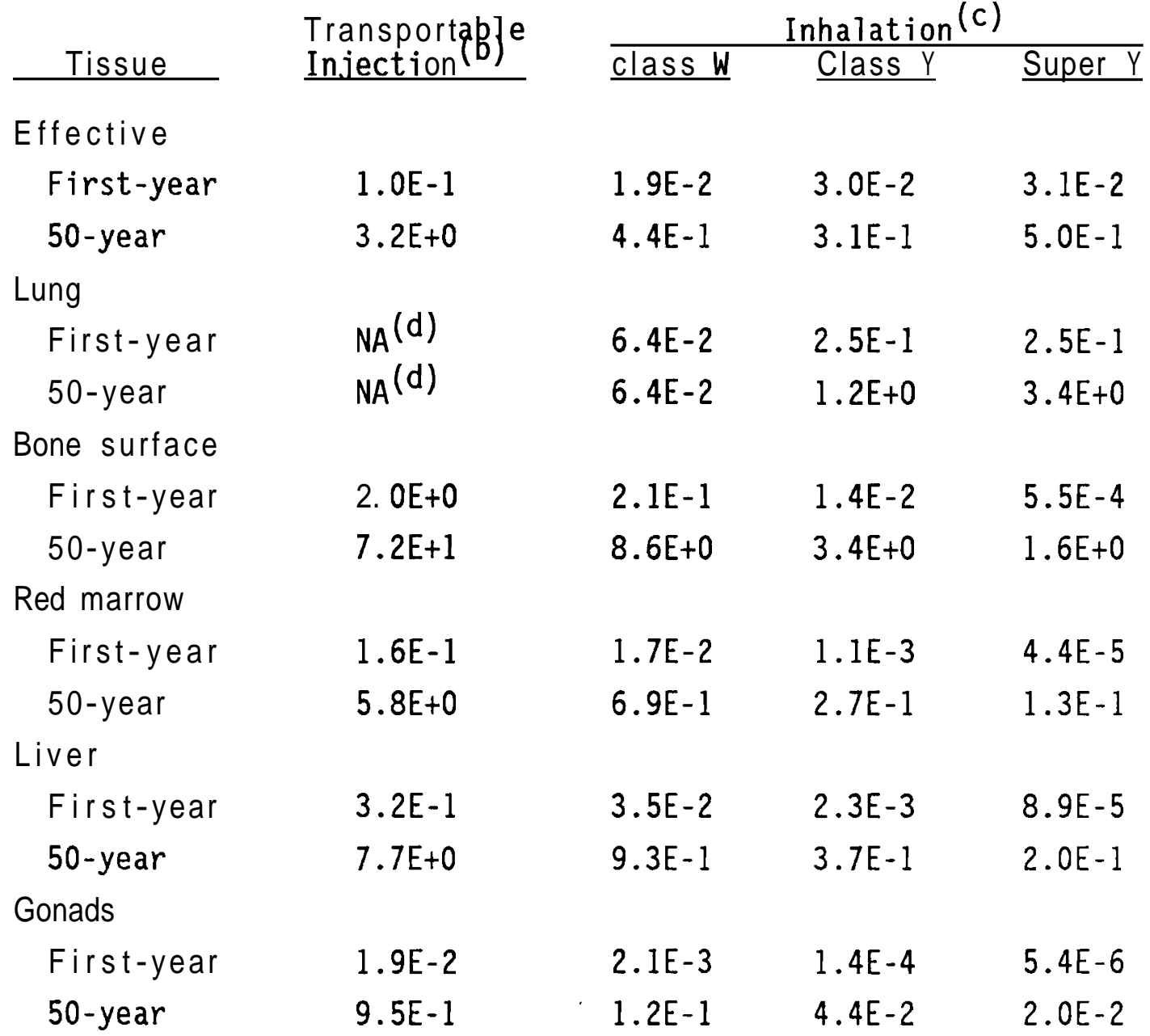
(a) Units are rem/nCi of acute intake.
(b) Assumes all plutonium is readily transportable.
(c) Assumes 1- $\mu \mathrm{m}-A M A D$ particle size.
(d) Not applicable. 
TABLE 9.14. ${ }^{241} \mathrm{Pu}$ Acute Intake Dose Equivalent Factors(a) for First-Year and 50-Year Committed Doses

$\frac{\text { Tissue }}{\text { Effective }}$

Transport ab]e

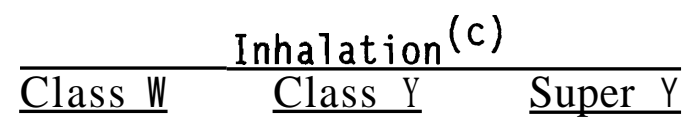

First-year

9.3E-5

$1.4 \mathrm{E}-5$

2.6E-5

2.6E-5

50-year

$7.0 \mathrm{E}-2$

$8.5 E-3$

$5.1 E-3$

$9.1 \mathrm{E}-3$

Lung

First-year

NA $(d)$

$2.6 \mathrm{E}-5$

2.1E-4

2.2E-4

50-year

NA $(d)$

$2.7 \mathrm{E}-5$

$1.2 \mathrm{E}-2$

$5.8 \mathrm{E}-2$

Bone surface

First-year

$1.8 \mathrm{E}-3$

2.1E-4

1. $5 \mathrm{E}-5$

$6.6 \mathrm{E}-7$

50-year

$1.4 \mathrm{E}+0$

1.7E-1

7.3E-2

4.1E-2

Red marrow

First-year

1.4E-4

1.7E-5

1. $2 \mathrm{E}-6$

5. $3 \mathrm{E}-8$

50-year

1.1E-1

1. $4 \mathrm{E}-2$

$5.9 \mathrm{E}-3$

$3.3 \mathrm{E}-3$

Liver

First-year

2. $9 \mathrm{E}-4$

3. $3 \mathrm{E}-5$

2. $4 \mathrm{E}-6$

1. $1 \mathrm{E}-7$

50-year

1. $3 \mathrm{E}-1$

1. $6 \mathrm{E}-2$

$7.4 \mathrm{E}-3$

$4.8 \mathrm{E}-3$

Gonads

First-year

$$
1.7 \mathrm{E}-5
$$

2. $0 \mathrm{E}-6$

1. $4 \mathrm{E}-7$

$6.4 \mathrm{E}-9$

50-year

2. $0 \mathrm{E}-2$

$2.5 \mathrm{E}-3$

1. $0 \mathrm{E}-3$

5. $1 \mathrm{E}-4$

(a) Units are rem/nCi of ${ }^{241} \mathrm{Pu}$ for acute intake; includes contribution

(b) Assumes all plutonium is readily transportable.

(c) Assumes 1- $\mu$ m-AMAD particle size.

(d) Not appl icable. 
TABLE 9.15. $241_{\text {Am Acute Intake Dose Equivalent Factors (a) }}$ for First-Year and 50-Year Committed Doses

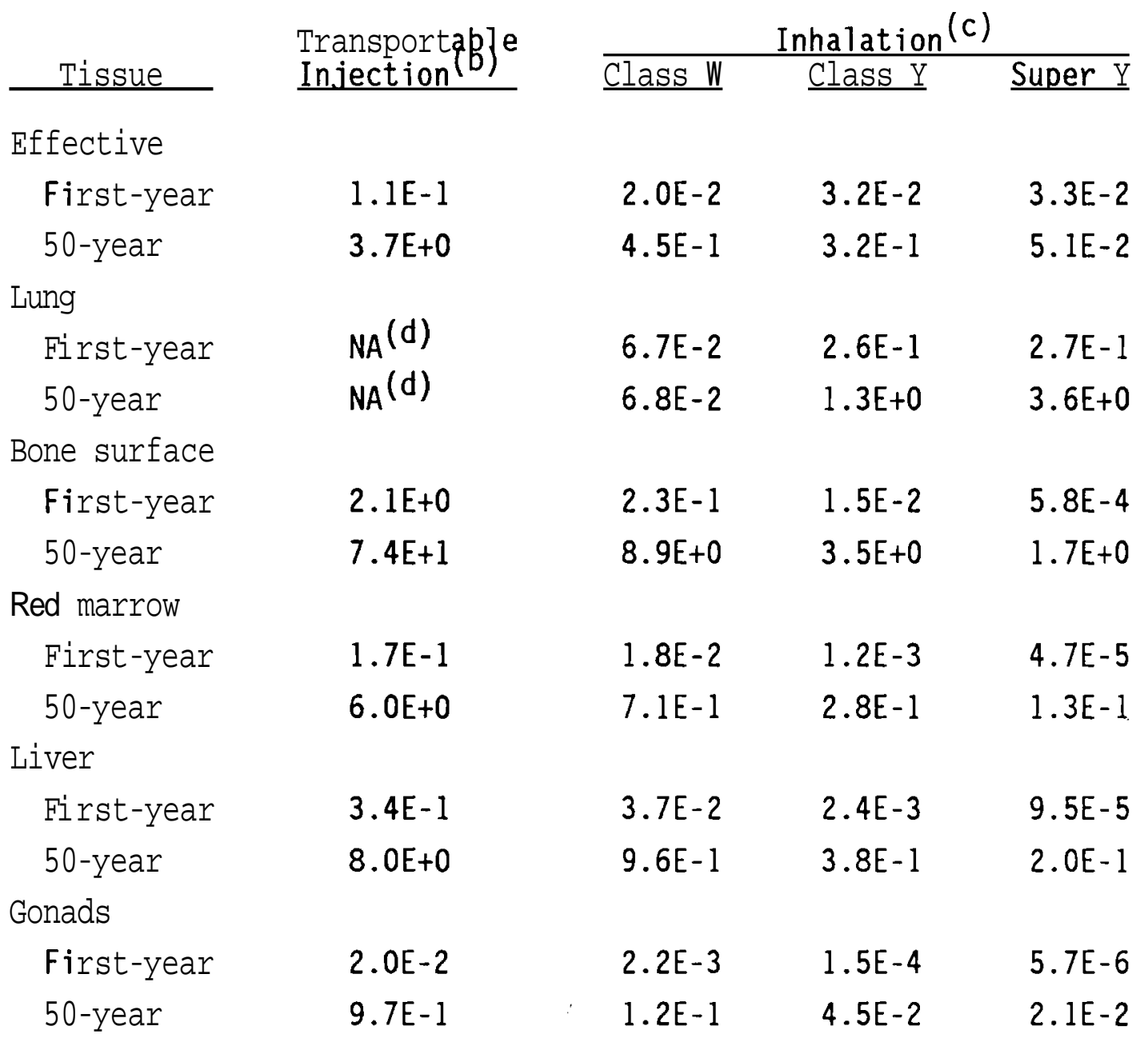

\footnotetext{
(a) Units are rem/nCi of ${ }^{241}$ Am of acute intake.

(b) Assumes all plutonium is readily transportable.

(c) Assumes 1- $\mu \mathrm{m}$-AMAD particle size.

(d) Not applicable.
} 
Tables 9.16 through 9.19. The reference mixture first-year dose equivalent factors are subsequently used in Section 9.4 to describe the bioassay monitoring capability for inhalation intakes.

Intake dose equivalent factors have not been provided for ingestion intakes, because historically ingestion has not been considered a significant mode of occupational exposure, due to extremely low GI tract uptake of plutonium. If an ingestion intake occurs, the dose to organs of the GI tract can be calculated using the GENMOD code.

\subsubsection{Cumulative Dose Equivalents}

The cumulative dose equivalent from an intake through various times post intake is frequently of interest with regard to tenaciously retained radionuclides. The most commonly referenced cumulative dose is the committed dose equivalent through a 50-year period following an intake. The cumulative effective dose equivalents (expressed as a percentage of the 50-year committed effective dose equivalent) through various times post intake are shown in Table 9.20 for ${ }^{239} \mathrm{Pu}$ class W, Y, and super Y inhalation intakes. Cumulative dose equivalents for other forms of plutonium or other time intervals can be readily obtained from the GENMOD computer code.

The ICRP 30 ALIs are $5.4 \mathrm{nCi}$ (class W) and $14 \mathrm{nCi}$ (class Y) for ${ }^{238} \mathrm{Pu}$, ${ }^{239} \mathrm{Pu},{ }^{240} \mathrm{Pu}$, and ${ }^{241} \mathrm{Am}$. For ${ }^{241} \mathrm{Pu}$, the ALIs are $270 \mathrm{nCi}$ (class W) and $540 \mathrm{nC}$ (class 1 ). These ALIs are based on a 50-year committed dose equivalent to the bone surfaces of 50 rem.

\subsection{BIOASSAY MONITORING}

This section discusses the general techniques and applicability of bioassay monitoring and describes the capabilities of excreta sample bioassay and in vivo measurements. Recommendations are also provided for routine bioassay monitoring for plutoni um.

\subsubsection{General Techniques and Applicability}

Bioassay monitoring for plutonium can be provided by both radiochemistry analysis of excreta and direct in vivo measurements. The application of these 
TABLE 9.16. Acute Intake Dose Equivalent Factors, (a) Fresh 6\% Plutonium Mixture ${ }^{(b)}$ First-Year and 50-Year Committed Doses

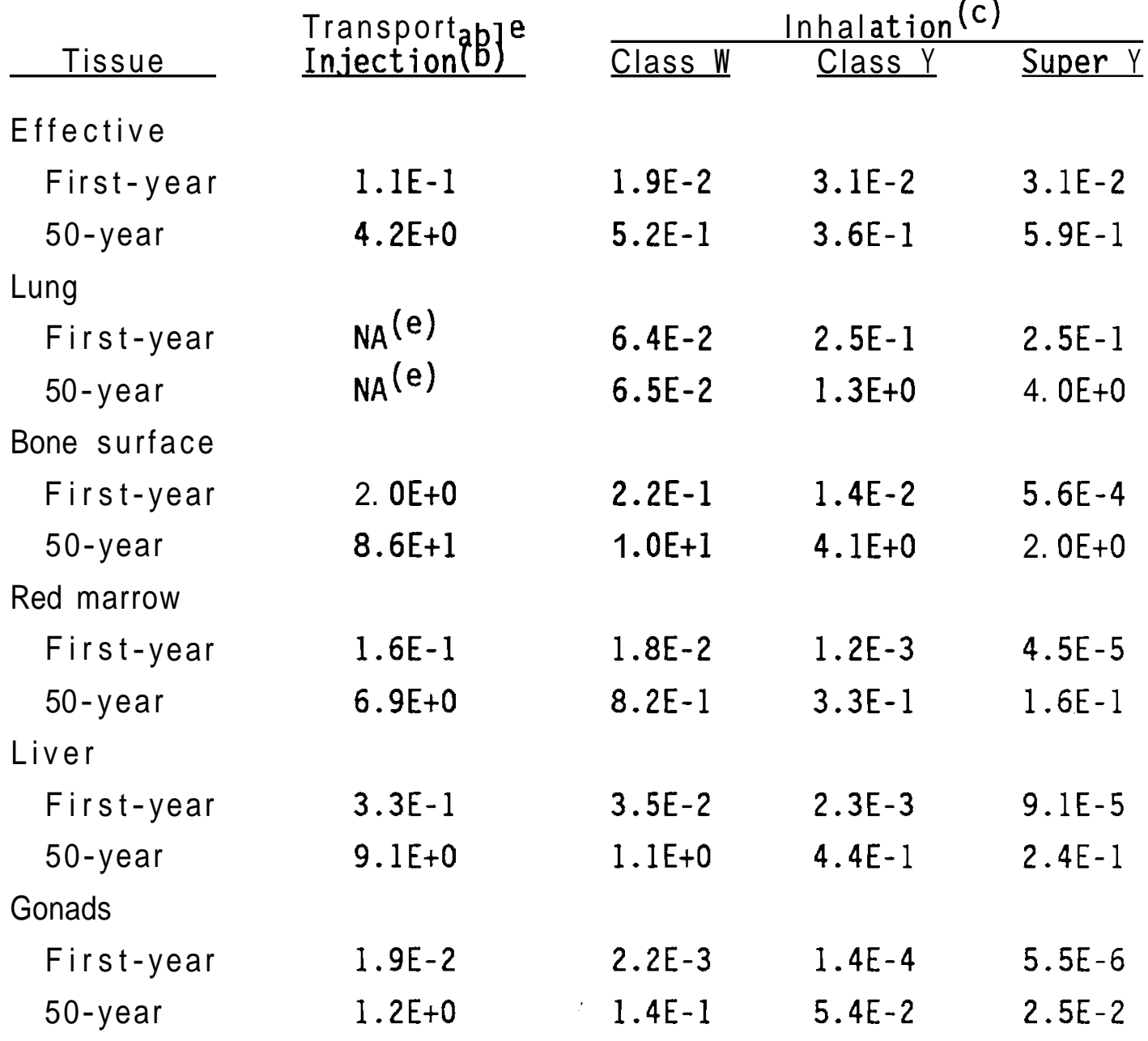

\footnotetext{
(a) Units are rem/nCi of total-a 1 hha of acute intake.

(b) $6 \%{ }^{240} \mathrm{Pu}$, aged 2 weeks after ${ }^{241}$ Am separation.

(c) Assumes 1- $\mu$ m-AMAD particle size.

(d) Assumes a17 plutonium is readily transportable.

(e) Not applicable.
} 
TABLE 9.17. Acute Intake Dose Equivalent Factors, (a) Aged 6\% Pl utoni um Mixture (b) First-Year and 50-Year Committed Doses

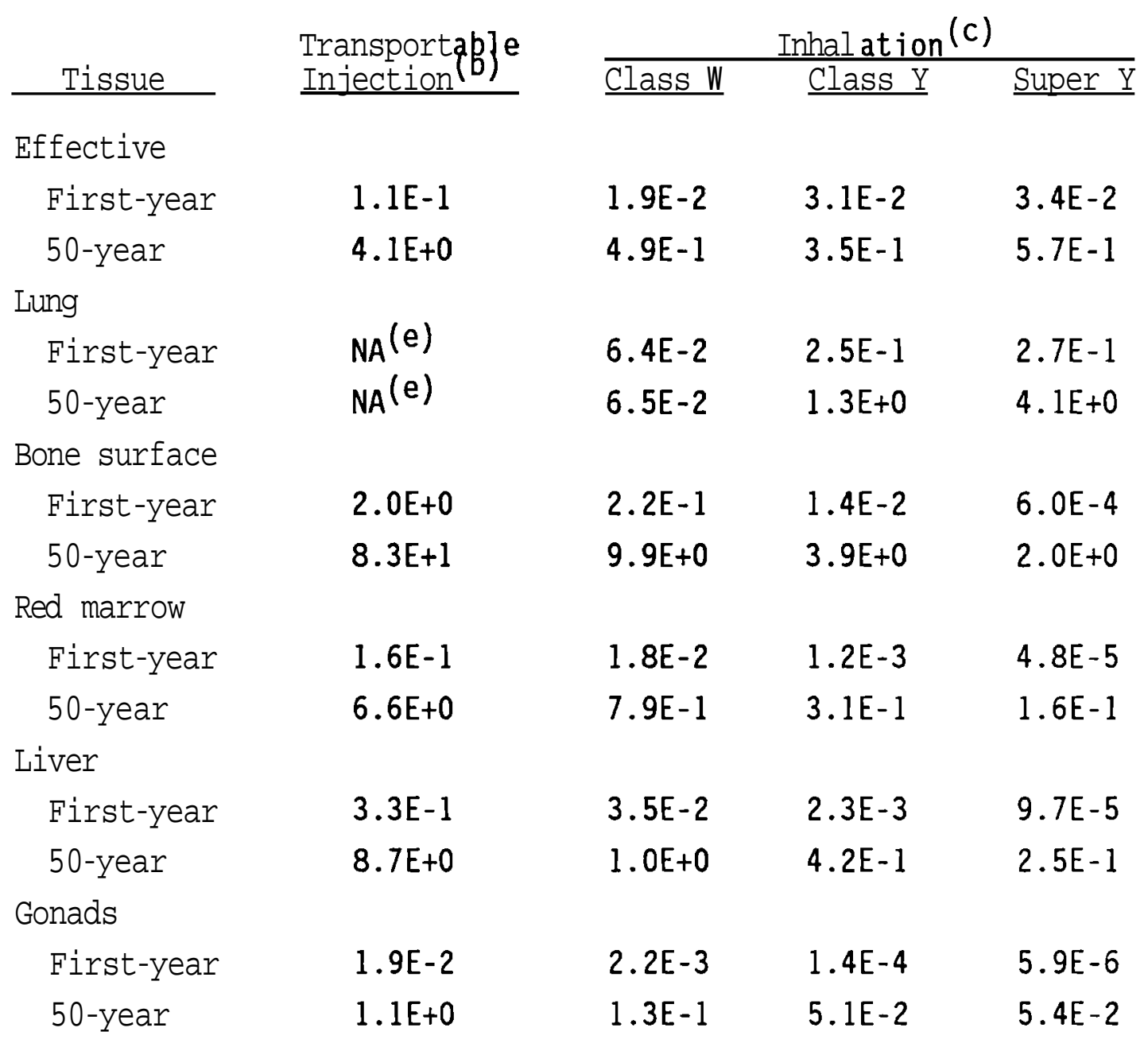

(a) Unitsqare rem/nCi of total-alpha for acute intake.

(b) $6 \% 24 \mathrm{Pu}$, aged 5 years after $241_{\mathrm{Am}}$ separation.

(c) Assumes 1- $\mu$ m-AMAD particle size.

(d) Assumes all plutonium is readily transportable.

(e) Not applicable. 
TABLE 9.18. Acute Intake Dose Equivalent Factors, (a) Fresh $12 \%$ Plutonium Mixture ${ }^{(b)}$ First-Year and 50-Year Committed Doses

\begin{tabular}{|c|c|c|c|c|}
\hline & Transportable & & nhalation & \\
\hline Tissue & $\underline{\text { Injection }}(\mathrm{b})^{\mathrm{C}}$ & $\underline{\text { Class W }}$ & $\underline{\text { Class } Y}$ & Super Y \\
\hline Effective & & & & \\
\hline First-year & $1.1 \mathrm{E}-1$ & $1.9 \mathrm{E}-2$ & $3.1 E-2$ & $3.2 \mathrm{E}-2$ \\
\hline 50-year & $5.7 E+0$ & $6.9 \mathrm{E}-1$ & $4.6 \mathrm{E}-1$ & $7.8 \mathrm{E}-1$ \\
\hline Lung & & & & \\
\hline First-year & $N A(e)$ & $6.5 \mathrm{E}-2$ & $2.6 \mathrm{E}-1$ & $2.6 \mathrm{E}-1$ \\
\hline 50-year & $N A(e)$ & $6.6 \mathrm{E}-2$ & $1.6 \mathrm{E}+0$ & $5.2 E+0$ \\
\hline Bone surface & & & & \\
\hline First-year & $2.1 E+0$ & $2.2 \mathrm{E}-1$ & $1.5 \mathrm{E}-2$ & $5.8 \mathrm{E}-4$ \\
\hline 50-year & $1.2 E+2$ & $1.4 \mathrm{E}+1$ & $5.6 \mathrm{E}+0$ & $2.9 E+0$ \\
\hline Red marrow & & & & \\
\hline First-year & $1.7 \mathrm{E}-1$ & $1.8 \mathrm{E}-2$ & $1.2 \mathrm{E}-3$ & $4.6 E-5$ \\
\hline 50-year & $9.3 E+0$ & $1.1 \mathrm{E}+0$ & $4.5 \mathrm{E}-1$ & $2.3 E-1$ \\
\hline Liver & & & & \\
\hline First-year & $3.3 \mathrm{E}-1$ & $3.6 \mathrm{E}-2$ & $2.4 \mathrm{E}-3$ & $9.4 \mathrm{E}-5$ \\
\hline 50-year & $1.2 E+1$ & $1.4 \mathrm{E}+0$ & 6. $\mathrm{OE}-1$ & $3.5 \mathrm{E}-1$ \\
\hline Gonads & & & & \\
\hline First-year & $2.0 \mathrm{E}-2$ & $2.2 \mathrm{E}-3$ & $1.5 \mathrm{E}-4$ & $5.7 E-6$ \\
\hline 50-year & $1.6 \mathrm{E}-0$ & $1.9 \mathrm{E}-1$ & $7.5 \mathrm{E}-2$ & $3.6 \mathrm{E}-2$ \\
\hline
\end{tabular}
(a) Units are rem/nCi of total-alpha for acute intake.
(b) $12 \% 24 \mathrm{Pu}$, aged 2 weeks after ${ }^{241}$ Am separation.
(c) Assumes 1- $\mu$ m-AMAD particle size.
(d) Assumes all plutonium is readily transportable.
(e) Not applicable. 
TABLE 9.19. Acute Intake Dose Equivalent Factors, (a) Aged 12\% Plutonium Mixture ${ }^{(b)}$ First-Year and 50-Year Committed Doses

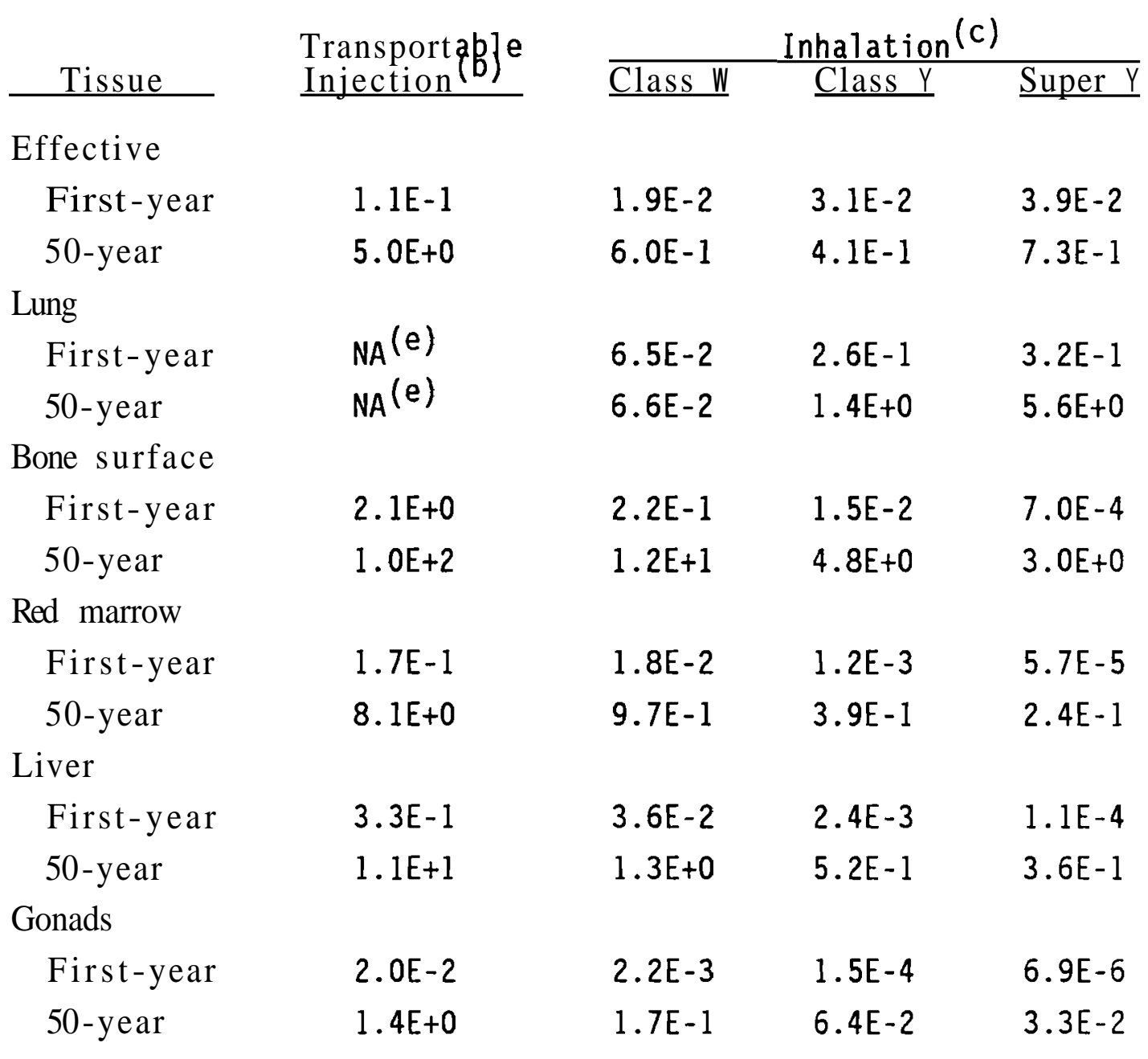

\footnotetext{
(a) Unitsagre rem/nCi of total-alpha for acute intake.

(b) $12 \%{ }^{24} \mathrm{Pu}$, aged 5 years after ${ }^{241}$ Am separation.

(c) Assumes 1- $\mu$ m-AMAD particle size.

(d) Assumes all plutonium is readily transportable.

(e) Not applicable.
} 
TABLE 9.20. Cumulative Effective Dose Equivalent for ${ }^{239} \mathrm{Pu}$ Intakes (expressed as percentage of 50-year committed dose)

\begin{tabular}{|c|c|c|c|c|}
\hline \multicolumn{2}{|c|}{$\begin{array}{l}\text { Cumul a ti ve Ti me } \\
\text { Post Intake }\end{array}$} & \multicolumn{3}{|c|}{ Inhalation Intake } \\
\hline days & years & $\underline{\text { Class W }}$ & Class $Y$ & $\underline{\text { Super Y }}$ \\
\hline 90 & 0.25 & $1.7 \%$ & $2.8 \%$ & $1.7 \%$ \\
\hline 180 & 0.5 & $2.7 \%$ & $5.2 \%$ & $3.3 \%$ \\
\hline 365 & 1 & $4.3 \%$ & $10 \%$ & $6.1 \%$ \\
\hline 730 & 2 & $7.1 \%$ & $17 \%$ & $11 \%$ \\
\hline 1825 & 5 & $15 \%$ & $30 \%$ & $20 \%$ \\
\hline 3650 & 10 & $28 \%$ & $43 \%$ & $32 \%$ \\
\hline 7300 & 20 & $50 \%$ & $60 \%$ & $53 \%$ \\
\hline 18,250 & 50 & $100 \%$ & $100 \%$ & $100 \%$ \\
\hline
\end{tabular}

techniques, and the interpretation of the resulting data, are highly dependent upon the type of plutonium to which a worker may be exposed.

Although the ICRP considers plutonium to be an inhalation class W or Y compound, substantially more and less transportable forms have apparently been observed in past Hanford cases. For this reason, bioassay guidance has been developed for readily transportable, class W, Y, and super Y compounds. The readily transportable form is assumed to behave as a direct injection of plutonium into the transfer compartment. The class $\mathbb{W}$ and $Y$ forms are assumed to behave according to the ICRP 30 respiratory tract model. The super $Y$ form is defined as being identical to class $Y$ with respect to compartment deposition fractions, however the transport rate from lung to blood (lung compartments a, c, e, and i) have been adjusted for a retention half-time of 10,000 days.

\subsubsection{Urine Sample Bioassay}

Urine sample analysis is the standard technique for confirming and evaluating the magnitude of uptakes. Uptake is required in order for material to be excreted by the urine pathway. It can also be used for estimating 
inhalation intakes and initial lung burdens of slowly transportable compounds; however, fecal samples and in vivo measurements are usually the preferred techniques.

To reach the urine, plutonium must first reach the transfer compartment (blood) in a soluble (dissolved) form, from which it can then be removed by the kidneys through normal metabol ic processes. Insoluble material in the transfer compartment is assumed not to be excreted by the urine pathway until it has been dissolved.

In reviewing urine sample results, anomalous results could be indicative of urine contamination from external sources (hands, sample container, clothing). Caution needs to be exercised when samples are obtained from externally contaminated workers.

The typical urine sampling practice is to collect a urine sample over a specified time interval and perform a chemical separation for plutonium. This technique is followed by electroplating and quantitative alpha spectrometry. The final results are reported as ${ }^{238} \mathrm{Pu}$ and ${ }^{239} \mathrm{Pu}$. The reported ${ }^{239} \mathrm{Pu}$ result is actually the sum of the measured ${ }^{239+240} \mathrm{Pu}$, because the alpha spectrometry system does not have the capability to differentiate between the alpha energies for ${ }^{239} \mathrm{Pu}$ and ${ }^{240} \mathrm{Pu}$ decay emissions. This does not pose a significant problem because the dosimetry for the two isotopes is essentially the same. When considering the total plutonium-alpha activity of a sample, it is important to combine the ${ }^{238} \mathrm{Pu}$ with the ${ }^{239} \mathrm{Pu}$ results.

Prior to October 1983, an autoradiography procedure was used instead of the electroplating/alpha spectrometry procedure. This autoradiography procedure actually measured the total plutonium-alpha activity, which was reported as ${ }^{239} \mathrm{Pu}$. This point should be remembered when comparing sample results and may help account for potential shifts in long-term data trends.

The reported detection levels for historical urine sample analysis procedures at various times are shown in Table 9.21. The method used to define the detection level has changed over time, so the values in Table 9.21 are not strictly comparable with each other. 
TABLE 9.21. Detection Limits for Routine Hanford Analyses of Plutonium in Urine

\begin{tabular}{lc}
\multicolumn{1}{c}{ Time Period } & $\begin{array}{c}\text { Detection } \\
\text { dpm/routine s }\end{array}$ \\
\hline Prior to June 1949 & 0.66 \\
June 1949 to Dec. 1952 & 0.33 \\
Dec. 1952 to $01 / 28 / 53$ & 0.18 \\
$01 / 28 / 53$ to $03 / 27 / 53$ & 0.15 \\
$03 / 27 / 53$ to $11 / 07 / 53$ & 0.05 \\
$11 / 07 / 53$ to $12 / 04 / 53$ & 0.07 \\
$12 / 53$ to $05 / 55$ & 0.057 \\
$05 / 55$ to $09 / 55$ & 0.027 \\
$09 / 55$ to $10 / 55$ & 0.04 \\
$10 / 55$ to $10 / 01 / 83$ & $0.05(a)$ \\
$10 / 01 / 83$ to $12 / 31 / 83$ & 0.035 \\
$12 / 31 / 83$ to present & 0.02
\end{tabular}

(a) During part of this period, results that were less than the detection limit were reported as 0.025 .

Special rapid analytical procedures are available for special circumstances. These procedures can be executed and results obtained in substantially shorter times than the routine procedure, but they are less sensitive. Their use is primarily for diagnostic bioassay of suspected internal contamination related to unplanned exposures (incidents). The decision to use such procedures involves considering the probability and potential magnitude of the exposure. The detection limits for plutonium in urine (based on the FY 1989 contractual requirements) are listed in Table 9.22.

\subsubsection{Fecal Sample Bioassay}

Fecal samples are useful for confirming and evaluating suspected inhalation and ingestion exposures. The sample results can be used in conjunction with the ICRP 30 respiratory tract model to estimate the magnitudes of intakes and initial lung depositions as a basis for lung dose assessment. They can 
TABLE 9.22. Contractual Detection Levels for Plutonium in Urine During FY 1989, dpm/sample

\begin{tabular}{|c|c|c|c|c|}
\hline \multirow[b]{2}{*}{ Isotope } & \multicolumn{4}{|c|}{ Categorv of Analysis (a) } \\
\hline & Routine & Priority & Expedite & Emerqency \\
\hline${ }^{238} \mathrm{Pu}$ & 0.02 & 0.02 & 0.08 & 0.5 \\
\hline $239+240 \mathrm{Pu}$ & 0.02 & 0.02 & 0.08 & 0.5 \\
\hline${ }^{241} \mathrm{Pu}$ & $N A^{(b)}$ & 2 & 4 & 20 \\
\hline${ }^{24} 1_{A m}$ & 0.02 & 0.02 & 0.08 & 1 \\
\hline
\end{tabular}

\footnotetext{
(a) Categories refer to different options for sensitivity and turnaround time.

(b) Not appl icable.
}

also be used as checks on urine-based estimates of presystemic deposition. In addition, fecal samples can provide radionuclide identification data and isotope ratios. Fecal samples are of primary value immediately following a suspected intake, when material is rapidly clearing the respiratory and GI tracts. They may also be of value at long times post intake as an aid to estimating residual lung burdens and isotope ratios, however substantial uncertainties exist for such applications.

Most fecal excretion following an intake occurs shortly after the intake. According to the ICRP 30 respiratory tract model, approximately one-half (48\%) of an intake of class Y plutonium (1- $\mu \mathrm{m}$-AMAD particle size) would be excreted in the first 5 days following intake. Additional long-term clearance from the lung by the fecal pathway would total approximately $10 \%$ of the intake, excreted at the fractional biological clearance rate of

\section{$0.0014 /$ day.}

Additional fecal excretion comes via the biliary pathway. This pathway represents fecal exc'retion from systemic deposition. While the magnitude of this pathway relative to the urine pathway has been investigated, it is not recommended that fecal excretion be used for evaluating systemic deposition. The primary reason for this is the interference that can be caused by very slight acute or chronic inhalation or ingestion exposures and the uncertainty of the magnitude of the biliary excretion relative to urinary excretion. 
There is no way to differentiate the source of fecal excretion (lung clearance, ingestion, or bile) when interpreting fecal sample results. For the purpose of modelling systemic excretion, it is assumed that systemic excretion is evenly distributed between the urine and biliary excretion pathways.

The complications of interpreting long-term fecal excretions do not rule out their potential value, particularly if certain conditions can be met regarding their collection; notably, lack of potential additional exposure immediately prior to collection of the sample and collection of more than one sample.

Multiple fecal samples are recommended if the data are critical for an evaluation. Normal daily fecal excretion rates vary greatly from those of ICRP 23 (1974) Reference Man and can be offset to some extent by collecting consecutive samples and averaging the results. Additional information on fecal sample interpretation is provided in Appendix E.

The laboratory pl utoni um analysis procedure for fecal samples involves wet ashing, dry ashing, chemical separation of plutonium, followed by electroplating and alpha spectrometry using a ${ }^{242} \mathrm{Pu}$ tracer to determine yield. The presence of ${ }^{241} \mathrm{Pu}$ is determined by liquid scintillation counting of the separated plutonium. The detection levels for the plutonium in feces analyses (based on the FY 1989 contractual capabilities) are shown in Table 9.23.

TABLE 9.23. Contractual Detection Levels for Plutonium in Feces During FY 1989, dpm/sample

\begin{tabular}{llcr} 
& \multicolumn{3}{c}{ Cateqory of Analysis (a) } \\
\cline { 2 - 4 } Isotope & Priority & Expedite & Emergencv \\
$238_{\mathrm{Pu}}$ & 0.2 & 3 & 9 \\
$239+240 \mathrm{Pu}$ & 0.2 & 3 & 9 \\
$241_{\mathrm{Pu}}$ & 7 & 70 & 200 \\
$241_{\mathrm{Am}}$ & 0.8 & 6 & 20
\end{tabular}

(a) Categories refer to different options for sensitivity and turnaround time. 


\subsubsection{In Vivo Measurement}

A variety of in vivo measurement techniques is available at the Hanford IVRRF (see Table 9.24). Most of these procedures involve measurement of the $60-\mathrm{keV}$ photons from the ${ }^{241} \mathrm{Am}$ present as an ingrown impurity in a plutonium mixture. Direct measurement of the $17-\mathrm{keV}$ plutonium $L \mathrm{x}$-rays is possible, but the sensitivity of the measurement is not adequate to detect most internal organ depositions. Direct measurement of plutonium in wounds is also feasible and commonly used.

TABLE 9.24. Sensitivities of Typica
Plutonium and Americium $(\text { a })^{\text {n Vivo Measurements for }}$ Plutonium and Americium(a)
Minimum Detectable Activitv, $\mathrm{nCi}$

Measurement
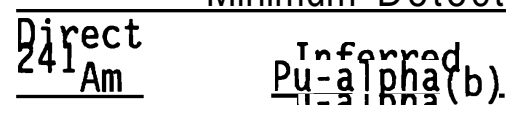

$2399_{\mathrm{Pu}}$ (c)

238 ${ }_{\mathrm{Pu}}^{\mathrm{pu}}$ (c)

Chest counts

$1000 \mathrm{~s}$

0.26

3.8

110

40

$2000 \mathrm{~s}$

0.18

2.7

75

30

Skeleton burden

Head count

$3000 \mathrm{~s}$

0.36

5.4

75

30

Liver count (2000 s)

0.15

2.3

150

60

Wound count (600 s)

EDF $^{(d)}$ system

0.01

0.15

0.4

0.17

WBC $^{(e)}$ system

0.0015

0.023

0.09

0.04

Upper extremity

lymph nodes

Scanning lung count

(being developed)

(being developed)

\footnotetext{
(a) Based on Table 7.1 of the Whole Body Counting Manual (Palmer et al. 1990).

(b) Based on 15:1 plutonium-alpha to ${ }^{241}$ Am activity ratio.

(c) Based on $17.0-\mathrm{keV}$ and $20.4-\mathrm{keV} \times$ rays and a $3-\mathrm{cm}$ chest wall thickness.

(d) $\mathrm{EDF}=$ Emergency Decontamination Facility.

(e) $\quad$ WBC $=$ Whole Body Counter.
} 
Because of the relative insensitivity of direct in vivo plutonium measurement techniques at low levels (other than for wounds), the presence of plutonium is inferred by detection of ${ }^{241} \mathrm{Am}$. Estimation of the amount of plutonium must be made using known or assumed isotope ratios. Such ratios may be obtained from workplace data (smear samples, air samples, etc.), inferred from excreta data (recognizing that fecal or urine samples may be biased by different clearance rates from the body), or from assumptions regarding material composition based on the facility and process involved.

The following subsections briefly describe the types of in vivo measurements available at the Hanford IVRRF. Nominal sensitivities for these measurements are summarized in Table 9.20. Further discussion of these measurement techniques can be found in the Whole Body Counting Manual (Palmer et al. 1990).

\section{Chest Counts}

Chest counting is a standard measurement technique used for monitoring plutonium workers. A count is performed by placing planar germanium detectors over the subject's chest.

Because of the potential impact of chest wall thickness on measurement sensitivity, measurement corrections are made on all workers based on a height-to-weight ratio. In addition, measurements on workers with known depositions will usually be corrected based on direct measurement of chest wall thickness using ultrasound techniques. Chest measurement results may not represent actual lung burdens unless they have been corrected for interference from activity deposited in other organs (notably the skeleton). When such a correction has been made the result is more correctly referred to as a lung burden estimate rather than a chest count result. Lacking such corrections, chest measurement results may conservatively be assumed to represent lung burdens.

The typical minimum detectable lung burden, assuming a 3-cm chest wall thickness, is $0.26 \mathrm{nCi}$ of ${ }^{241} \mathrm{Am}$ for a 1000 -second count, and $0.18 \mathrm{nCi}$ for a 2000-second count. 


\section{Head Counts (Skeleton Burdens)}

Head counts are performed using two planar germanium detectors and a 3000-second counting time. The results of the head count are extrapolated to an estimate of the total quantity retained in the skeleton using a human skeleton calibration phantom. Head counts will usually be performed when chest counts show detectable activity to determine if modification for skeleton activity is needed. Head counts can also be used as a check on urine-based systemic deposition estimates.

The typical MDA in the skeleton, as determined by head counting, is

\section{$0.36 \mathrm{nC} i$ of ${ }^{241} \mathrm{Am}$.}

\section{Liver Counts}

Liver counts provide a direct estimate of activity in the liver based on the Livermore calibration phantom (Griffith et al. 1978). These counts are primarily used for long-term follow-up and as a check on urine-based systemic deposition estimates. They also provide a check on the assumptions used in the computer codes for calculating annual and committed dose equivalents. The counting time is 2000 seconds.

The MDA for a typical 1 iver count is $0.15 \mathrm{nCi}$ of ${ }^{241} \mathrm{Am}$.

\section{Wound Counts}

Wound counts can directly measure plutonium and americium using a single planar germanium detector. Wound counts can be performed either at the Emergency Decontamination Facility (EDF) or at the IVRRF. The detection equipment is similar at both facilities, however MDAs are substantially better at the WBC due to the use of shielded counting rooms. Counts at either facility are typically 600-seconds long.

Directly measured MDAs are typically $0.01 \mathrm{nC}$ of ${ }^{241} \mathrm{Am}$ and $0.4 \mathrm{nCi}$ of ${ }^{239} \mathrm{Pu}$ at the EDF, and $0.0015 \mathrm{nCi}$ of ${ }^{241} \mathrm{Am}$ and $0.09 \mathrm{nCi}$ of ${ }^{239} \mathrm{Pu}$ at the WBC. The ${ }^{239} \mathrm{Pu}$ results can be significantly underestimated if the activity is deeply embedded in tissue. 


\section{Upper Extremity Lymph Node Counts}

The upper extremity lymph nodes are potential deposition sites for nontransportable or slowly transportable material deposited in extremity wounds. These nodes include the supratracular lymph nodes located near the elbow and the axil lary lymph nodes located near the armpit. The nodes are counted by placing planar germanium detectors in the lymph node region. Activity deposited in the axillary lymph nodes has the potential for interfering with chest count results. Precise calibrations for these counts are still under devel opment.

\section{$\underline{\text { Scanning Lung Counts }}$}

Scanning lung counts are used to determine the distribution of activity deposited in the lung. By a series of counts, the extent to which activity is deposited in the tracheal-bronchial region (including the lymph nodes) and the left and right pulmonary regions can be reasonably determined. The results of these counts are not likely to affect lung dose estimates, except to the extent that they shed light on the nature of the deposition and potential lung dynamics. The calibration for these counts is still under development. Results may be expressed as the percentage of total lung activity in a given counting region.

\subsubsection{Bioassay Monitorinq Capability}

The bioassay monitoring capability for plutonium can be discussed as the intake or dose associated with an MDA bioassay measurement at some time post intake. Analyses of the first-year and 50-year effective dose equivalents have been performed for fresh $6 \%$ and aged $12 \%$ reference plutonium mixtures using two bioassay methods, ${ }^{239} \mathrm{Pu}$ in urine and in vivo ${ }^{241} \mathrm{Am}$ lung counting.

To determine the capability of bioassay of plutonium by urine analysis, the intakes of ${ }^{239} \mathrm{Pu}$ associated with minimum detectable urine analysis results were calculated for transportable injection, and class W, Y, and super $Y$ inhalations. These intakes are given in Table 9.25. Based on the activity ratios described in Section 9.1, the plutonium-alpha intake was estimated for fresh $6 \%$ and aged $12 \%$ reference plutonium mixtures, and the first-year and 50-year committed effective dose equivalents were calculated using the factors 
TABLE 9.25. Acute ${ }^{239} \mathrm{Pu}$ Intake Associated with the Minimum Detectable Activity Urine Bioassay Measurement $(\mathrm{MDA}=0.02 \mathrm{dpm} / \mathrm{day})$

Days Post Intake

1

2

5

7

14

30

60

90

180

365

730

1825

3650

\begin{tabular}{|c|c|c|c|}
\hline \multicolumn{4}{|c|}{${ }^{239} \mathrm{Pu}$ Intake. $\mathrm{nCi}$} \\
\hline Transportable & & nhalatio & \\
\hline Injection & Class W & Class Y & Super $Y$ \\
\hline $3.0 \mathrm{E}-3$ & $3.8 \mathrm{E}-2$ & $6.9 \mathrm{E}-1$ & $7.5 E+2$ \\
\hline $4.7 \mathrm{E}-3$ & $5.6 \mathrm{E}-2$ & $1.0 E+0$ & $5.0 E+2$ \\
\hline $1.6 \mathrm{E}-2$ & $1.8 \mathrm{E}-1$ & $3.3 E+0$ & $6.0 \mathrm{E}+2$ \\
\hline $2.4 \mathrm{E}-2$ & $2.7 \mathrm{E}-1$ & $5.3 E+0$ & $6.0 \mathrm{E}+2$ \\
\hline $3.9 \mathrm{E}-2$ & $4.1 \mathrm{E}-1$ & $8.2 E+0$ & $5.6 \mathrm{E}+2$ \\
\hline $6.0 \mathrm{E}-2$ & $5.3 \mathrm{E}-1$ & $1.0 \mathrm{E}+\mathrm{I}$ & $4.7 E+2$ \\
\hline $9.1 \mathrm{E}-2$ & $6.9 \mathrm{E}-1$ & $1.3 E+1$ & $3.6 \mathrm{E}+2$ \\
\hline $1.1 \mathrm{E}-1$ & $8.2 E-1$ & $1.3 E+1$ & $3.1 E+2$ \\
\hline $1.6 \mathrm{E}-1$ & $1.1 \mathrm{E}+0$ & $1.3 \mathrm{E}+1$ & $2.1 \mathrm{E}+2$ \\
\hline $2.6 \mathrm{E}-1$ & $1.9 \mathrm{E}+0$ & $1.1 \mathrm{E}+1$ & $1.4 \mathrm{E}+2$ \\
\hline $4.7 \mathrm{E}-1$ & $3.8 \mathrm{E}+0$ & $1.0 \mathrm{E}+1$ & $9.0 \mathrm{E}+1$ \\
\hline $6.4 \mathrm{E}-1$ & $5.6 \mathrm{E}+0$ & $1.0 \mathrm{E}+1$ & $5.3 \mathrm{E}+1$ \\
\hline $6.9 \mathrm{E}-1$ & $6.0 \mathrm{E}+0$ & $1.2 E+1$ & $3.8 \mathrm{E}+1$ \\
\hline
\end{tabular}

of Tables 9.16 and 9.19. The results are summarized in Tables 9.26 through 9.29 and graphically presented in Figures 9.5 through 9.9 .

The capability of bioassay by in vivo chest counting was calculated assuming the presence of the MDA of ${ }^{241} \mathrm{Am}$ in the lung $(0.18 \mathrm{nCi})$ at a given time post intake. Based on activity relationships for fresh $6 \%$ and aged $12 \%$ reference plutonium mixtures, the corresponding intake of each mixture was calculated and the first-year and 50-year committed effective dose equivalents were calculated using the factors of Tables 9.16 and 9.19. The results are summarized in Tables 9.30 through 9.33 and graphically presented in Figures 9.9 through 9.12 .

\subsubsection{Recommended Bioassay Monitoring Program}

The recommended bioassay monitoring program for plutonium is to perform annual in vivo lung measurements and annual plutonium-in-urine assessments. These recommendations do not provide the high degree of sensitivity for 
TABLE 9.26. Potentially Undetected First-Year Effective Dose Equivalent (rem) for a Single Acute Intake of Fresh $6 \%$ Reference Plutghium Mixture Based on an MDA of $0.02 \mathrm{dpm} /$ day of ${ }^{239} \mathrm{Pu}$ Detected in Urine

Days Post Intake

\begin{tabular}{lcccc}
\multicolumn{3}{c}{ Mode of Intake } \\
\hline $\begin{array}{c}\text { Transportable } \\
\text { Injection }\end{array}$ & $\underline{\text { Class } W}$ & Inhalation \\
\hline
\end{tabular}

1
2
5
7
14
30
60
90
180
365
730
1825

$3.7 \mathrm{E}-4$
$5.8 \mathrm{E}-4$
$2.0 \mathrm{E}-3$
$3.0 \mathrm{E}-3$
$4.8 \mathrm{E}-3$
$7.4 \mathrm{E}-3$
$1.1 \mathrm{E}-2$
$1.4 \mathrm{E}-2$
$2.0 \mathrm{E}-2$
$3.2 \mathrm{E}-2$
$5.8 \mathrm{E}-2$
$7.9 \mathrm{E}-2$

8.1E-4

$2.4 \mathrm{E}-2$

2. $6 \mathrm{E}+1$

1. $2 \mathrm{E}-3$

3. $8 \mathrm{E}-3$

$5.8 \mathrm{E}-3$

8. $8 \mathrm{E}-3$

1.1E-2

1. $5 \mathrm{E}-2$

1. $8 \mathrm{E}-2$

2. $4 \mathrm{E}-2$

4. $1 \mathrm{E}-2$

8.1E-2

1. $2 \mathrm{E}-1$
3. $5 \mathrm{E}-2$

1. $2 \mathrm{E}-1$

1. $8 \mathrm{E}-1$

2. $9 \mathrm{E}-1$

3. $5 \mathrm{E}-1$

4. $5 \mathrm{E}-1$

4. $5 \mathrm{E}-1$

4. $5 \mathrm{E}-1$

3. $8 \mathrm{E}-1$

3. $5 \mathrm{E}-1$

3. $5 \mathrm{E}-1$
1. $7 \mathrm{E}+1$

2. $1 E+1$

2. $1 \mathrm{E}+1$

2. $0 \mathrm{E}+1$

1. $6 \mathrm{E}+1$

1. $3 \mathrm{E}+1$

1. $1 \mathrm{E}+1$

7. $3 \mathrm{E}+0$

4. $9 \mathrm{E}+0$

$3.1 \mathrm{E}+0$

1. $8 \mathrm{E}+0$

TABLE 9.27. Potentially Undetected 50-Year Committed Effective Dose Equivalent (rem) for a Single Acute Intake of Fresh 6\% Reference Plutoniym Mixture Based on an MDA of $0.02 \mathrm{dpm} /$ day of ${ }^{239} \mathrm{Pu}$ Detected in Urine

Days Post Intake

1
2
5
7
14
30
60
90
180
365
730
1825

\begin{tabular}{llll}
\hline \multicolumn{3}{c}{ Mode of Intake } \\
$\begin{array}{c}\text { Transportable } \\
\text { Injection }\end{array}$ & $\underline{\text { Class } W}$ & Class $Y$ & Super $Y$ \\
\hline
\end{tabular}
$1.4 \mathrm{E}-2$
2.2E-2
$7.6 \mathrm{E}-2$
$1.1 \mathrm{E}-1$
$1.8 \mathrm{E}-1$
$2.8 \mathrm{E}-1$
4.2E-1
5. $3 \mathrm{E}-1$
7.6E-1
1. $2 \mathrm{E}+0$
2. $2 \mathrm{E}+0$
3. $\mathrm{OE}+0$

2. $2 E-2$

3. $3 E-2$

1. $6 \mathrm{E}-1$

2. $4 \mathrm{E}-1$

3. $0 \mathrm{E}-1$

4. $1 \mathrm{E}-1$

4. $9 \mathrm{E}-1$

6. $6 \mathrm{E}-1$

1. $1 E+0$

2. $2 \mathrm{E}+0$

$3.3 \mathrm{E}+0$
2. $8 \mathrm{E}-1$

4. $1 \mathrm{E}-1$

1. $4 \mathrm{E}+0$

2. $1 E+0$

3. $4 \mathrm{E}+0$

4. $1 \mathrm{E}+0$

5. $2 \mathrm{E}+0$

$5.2 E+0$

5. $2 \mathrm{E}+0$

4. $4 E+0$

4. $1 E+0$

4. $I E+0$
4. $9 \mathrm{E}+2$

3. $2 \mathrm{E}+2$

4. $0 \mathrm{E}+2$

4. $0 \mathrm{E}+2$

3. $8 \mathrm{E}+2$

3. $0 \mathrm{E}+2$

2. $5 \mathrm{E}+2$

2. $1 \mathrm{E}+2$

1. $4 \mathrm{E}+2$

9. $3 \mathrm{E}+1$

5. $9 \mathrm{E}+1$

3. $4 \mathrm{E}+1$ 
TABLE 9.28. Potentially Undetected First-Year Effective Dose Equivalent (rem) for a Single Acute Intake of Aged 12\% Reference Plutogium Mixture Based on an MDA of $0.02 \mathrm{dpm} /$ day of ${ }^{239} \mathrm{Pu}$ Detected in Urine

\begin{tabular}{|c|c|c|c|c|}
\hline \multirow{3}{*}{$\begin{array}{l}\text { Days Post } \\
\text { Intake }\end{array}$} & \multicolumn{4}{|c|}{ Mode of Intake } \\
\hline & Transportable & & nhalation & \\
\hline & Injection & Class W & $\underline{\text { Class } Y}$ & Super Y \\
\hline $\begin{array}{r}1 \\
2 \\
5 \\
7 \\
14 \\
30 \\
60 \\
90 \\
180 \\
365 \\
730 \\
1825\end{array}$ & $\begin{array}{l}4.0 \mathrm{E}-4 \\
6.2 \mathrm{E}-4 \\
2.1 \mathrm{E}-3 \\
3.2 \mathrm{E}-3 \\
5.1 \mathrm{E}-3 \\
7.9 \mathrm{E}-3 \\
1.2 \mathrm{E}-2 \\
1.5 \mathrm{E}-2 \\
2.1 \mathrm{E}-2 \\
3.4 \mathrm{E}-2 \\
6.2 \mathrm{E}-2 \\
8.4 \mathrm{E}-2\end{array}$ & $\begin{array}{l}8.7 \mathrm{E}-4 \\
1.3 \mathrm{E}-3 \\
4.1 \mathrm{E}-3 \\
6.2 \mathrm{E}-3 \\
9.3 \mathrm{E}-3 \\
1.2 \mathrm{E}-2 \\
1.6 \mathrm{E}-2 \\
1.9 \mathrm{E}-2 \\
2.5 \mathrm{E}-2 \\
4.3 \mathrm{E}-2 \\
8.7 \mathrm{E}-2 \\
1.3 \mathrm{E}-1\end{array}$ & $\begin{array}{l}2.6 \mathrm{E}-2 \\
3.7 \mathrm{E}-2 \\
1.2 \mathrm{E}-1 \\
2.0 \mathrm{E}-1 \\
3.1 \mathrm{E}-1 \\
3.7 \mathrm{E}-1 \\
4.8 \mathrm{E}-1 \\
4.8 \mathrm{E}-1 \\
4.8 \mathrm{E}-1 \\
4.1 \mathrm{E}-1 \\
3.7 \mathrm{E}-1 \\
3.7 \mathrm{E}-1\end{array}$ & $\begin{array}{l}3.5 \mathrm{E}+1 \\
2.3 \mathrm{E}+1 \\
2.8 \mathrm{E}+1 \\
2.8 \mathrm{E}+1 \\
2.6 \mathrm{E}+1 \\
2.2 \mathrm{E}+1 \\
1.7 \mathrm{E}+1 \\
1.5 \mathrm{E}+1 \\
9.8 \mathrm{E}+0 \\
6.6 \mathrm{E}+0 \\
4.2 \mathrm{E}+0 \\
2.5 \mathrm{E}+0\end{array}$ \\
\hline
\end{tabular}

TABLE 9.29. Potentially Undetected 50-Year Committed Effective Dose Equivalent (rem) for a Single Acute Intake of Aged 12\% Reference Plutonium Mixture Based on an MDA of $0.02 \mathrm{dpm} /$ day of ${ }^{239} \mathrm{Pu}$ Detected in Urine

\begin{tabular}{r}
$\begin{array}{r}\text { Days Post } \\
\text { Intake }\end{array}$ \\
\hline 1 \\
2 \\
5 \\
7 \\
14 \\
30 \\
60 \\
90 \\
180 \\
365 \\
730 \\
1825
\end{tabular}

Mode of Intake

\begin{tabular}{|c|c|c|c|}
\hline \multirow{2}{*}{$\begin{array}{l}\text { Transportable } \\
\text { Injection } \\
\end{array}$} & \multicolumn{3}{|c|}{ Inhalation } \\
\hline & Class W & Class $Y$ & Super $Y$ \\
\hline $\begin{array}{l}1.8 \mathrm{E}-2 \\
2.8 \mathrm{E}-2 \\
9.5 \mathrm{E}-2 \\
1.5 \mathrm{E}-1 \\
2.3 \mathrm{E}-1 \\
3.6 \mathrm{E}-1 \\
5.5 \mathrm{E}-1 \\
6.8 \mathrm{E}-1 \\
9.5 \mathrm{E}-1 \\
1.5 \mathrm{E}+0 \\
2.8 \mathrm{E}+0 \\
3.8 \mathrm{E}+0\end{array}$ & $\begin{array}{l}2.7 \mathrm{E}-2 \\
4.1 \mathrm{E}-2 \\
1.3 \mathrm{E}-1 \\
2.0 \mathrm{E}-1 \\
2.9 \mathrm{E}-1 \\
3.8 \mathrm{E}-1 \\
5.1 \mathrm{E}-1 \\
6.0 \mathrm{E}-1 \\
7.9 \mathrm{E}-1 \\
1.4 \mathrm{E}+0 \\
2.7 \mathrm{E}+0 \\
4.1 \mathrm{E}+0\end{array}$ & $\begin{array}{l}3.4 \mathrm{E}-1 \\
4.9 \mathrm{E}-1 \\
1.6 \mathrm{E}+0 \\
2.6 \mathrm{E}+0 \\
4.1 \mathrm{E}+0 \\
4.9 \mathrm{E}+0 \\
6.3 \mathrm{E}+0 \\
6.3 \mathrm{E}+0 \\
6.3 \mathrm{E}+0 \\
5.4 \mathrm{E}+0 \\
4.9 \mathrm{E}+0 \\
4.9 \mathrm{E}+0\end{array}$ & $\begin{array}{l}6.6 \mathrm{E}+2 \\
4.3 \mathrm{E}+2 \\
5.2 \mathrm{E}+2 \\
5.2 \mathrm{E}+2 \\
4.9 \mathrm{E}+2 \\
4.1 \mathrm{E}+2 \\
3.2 \mathrm{E}+2 \\
2.8 \mathrm{E}+2 \\
1.8 \mathrm{E}+2 \\
1.2 \mathrm{E}+2 \\
7.9 \mathrm{E}+1 \\
4.7 \mathrm{E}+1\end{array}$ \\
\hline
\end{tabular}




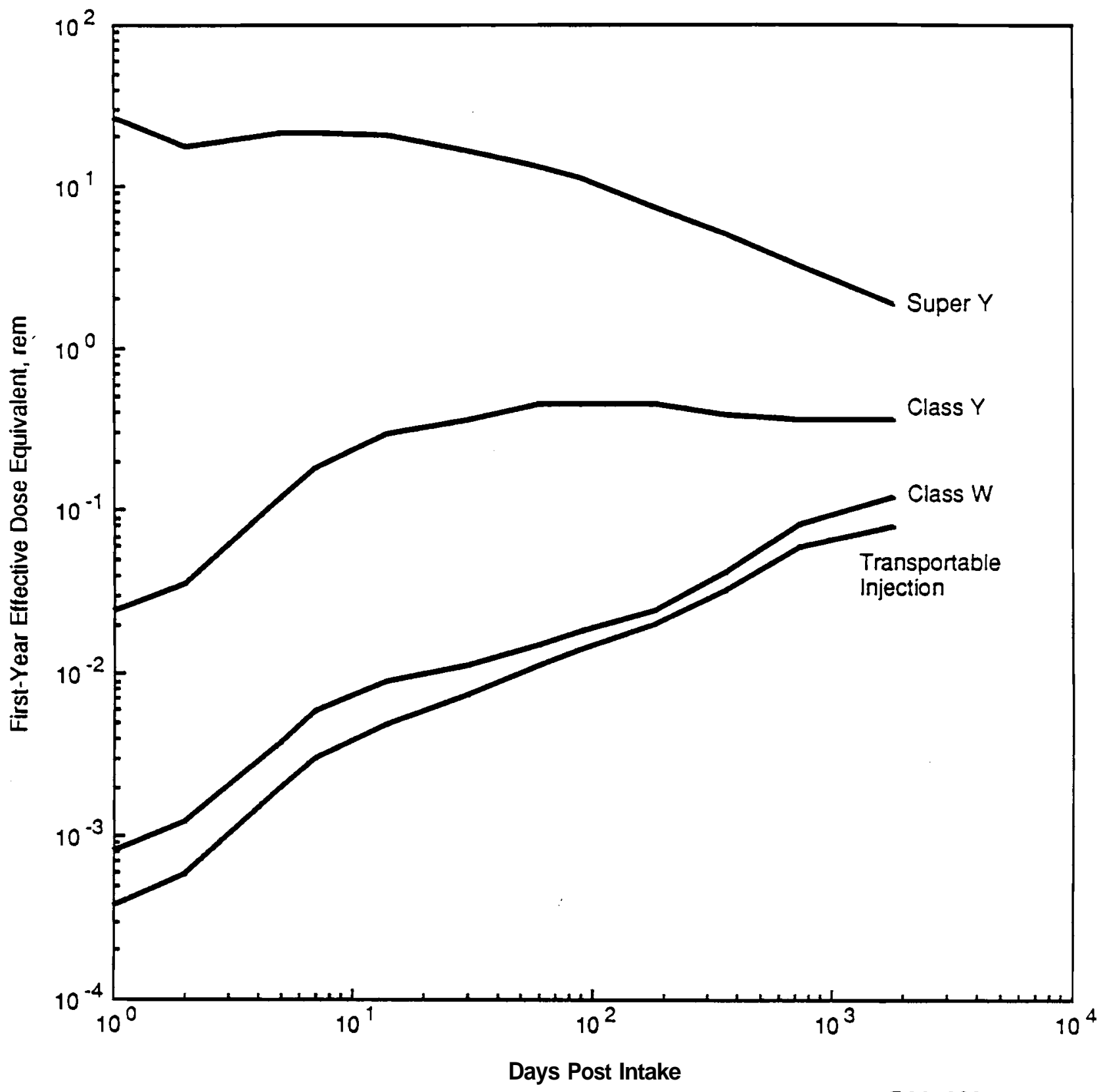

R881209400951

FIGURE 9.5. Potentially Undetected First-Year Effective Dose Equivalent (rem) for a Single Acute Intake of Fresh 6\% Reference 23ytonium Mixture Based on an MDA of $0.02 \mathrm{dpm} /$ day of 239 Pu Detected i n Urine 


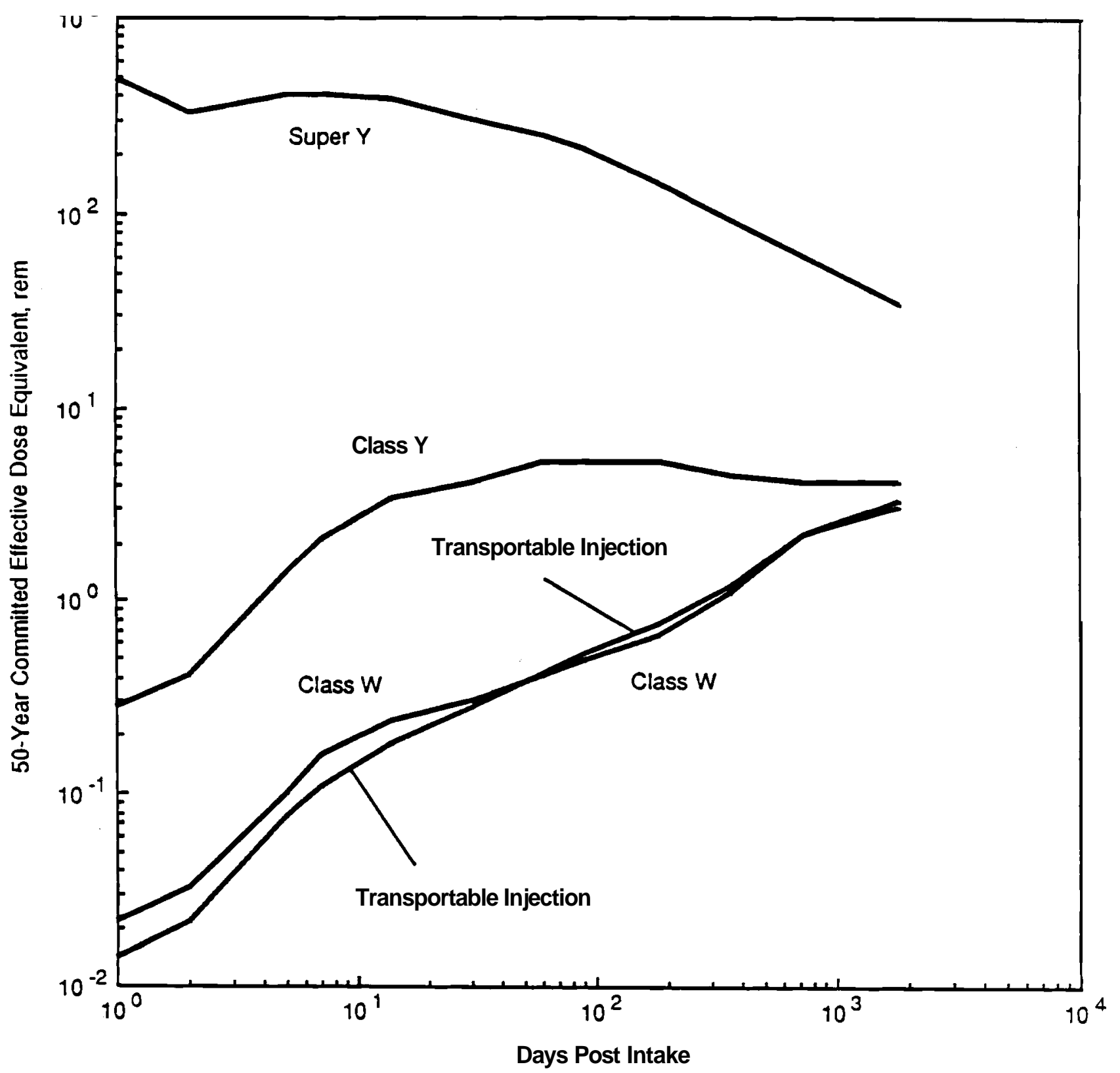

R881209401451

FIGURE 9.6. Potentially Undetected 50-Year Committed Effective Dose Equivalent (rem) for a Single Acute Intake of Fresh 6\% Reference Plutonjum Mixture Based on an MDA of $0.02 \mathrm{dpm} / \mathrm{day}$ of ${ }^{239} \mathrm{Pu}$ Detected in Urine 


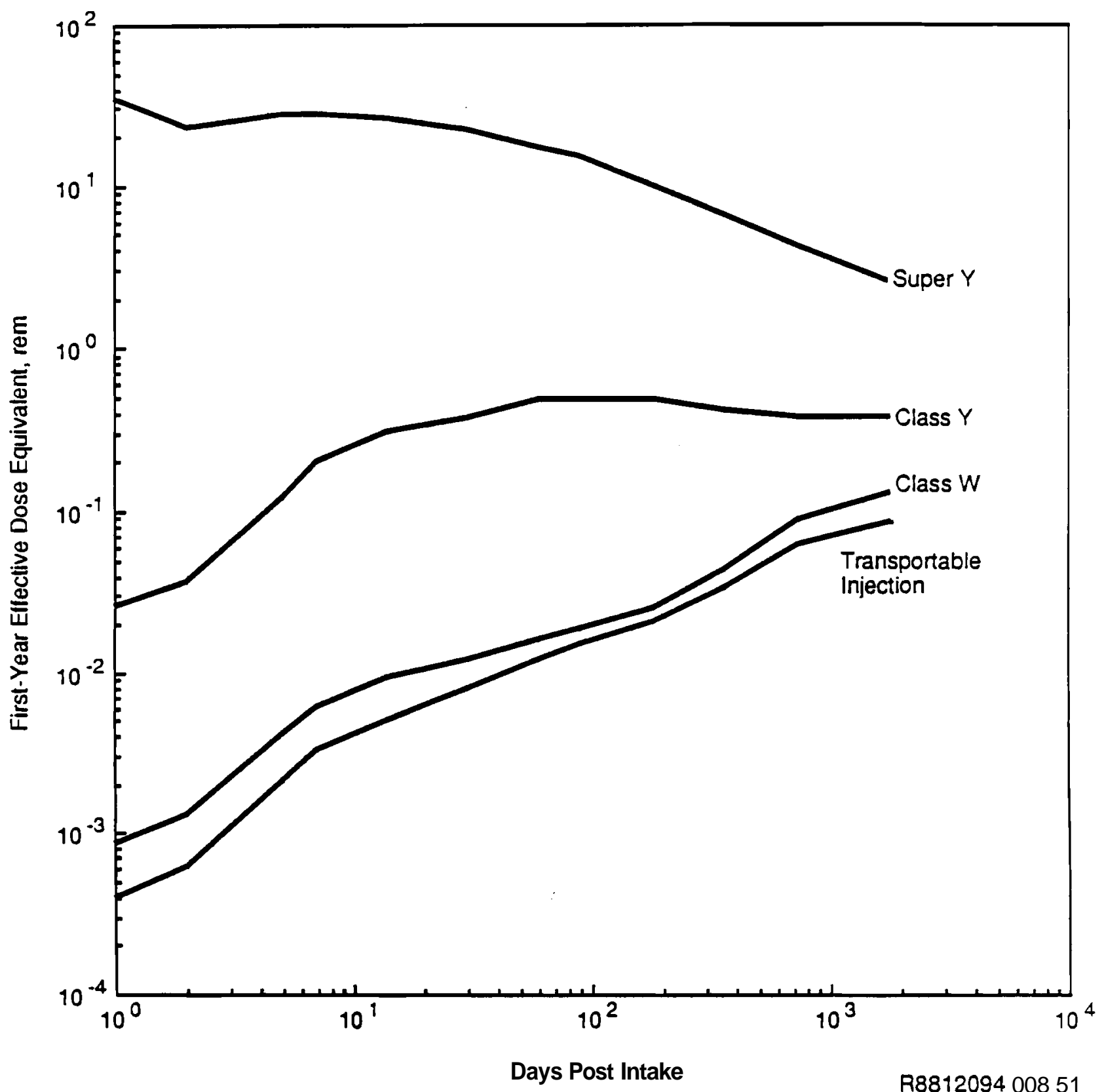

FIGURE 9.7. Potentially Undetected First-Year Effective Dose Equivalent (rem) for a Single Acute Intake of Aged 12\% Reference Plutonium Mixture Based on an MDA of $0.02 \mathrm{dpm} /$ day of ${ }^{239} \mathrm{Pu}$ Detected in Urine 


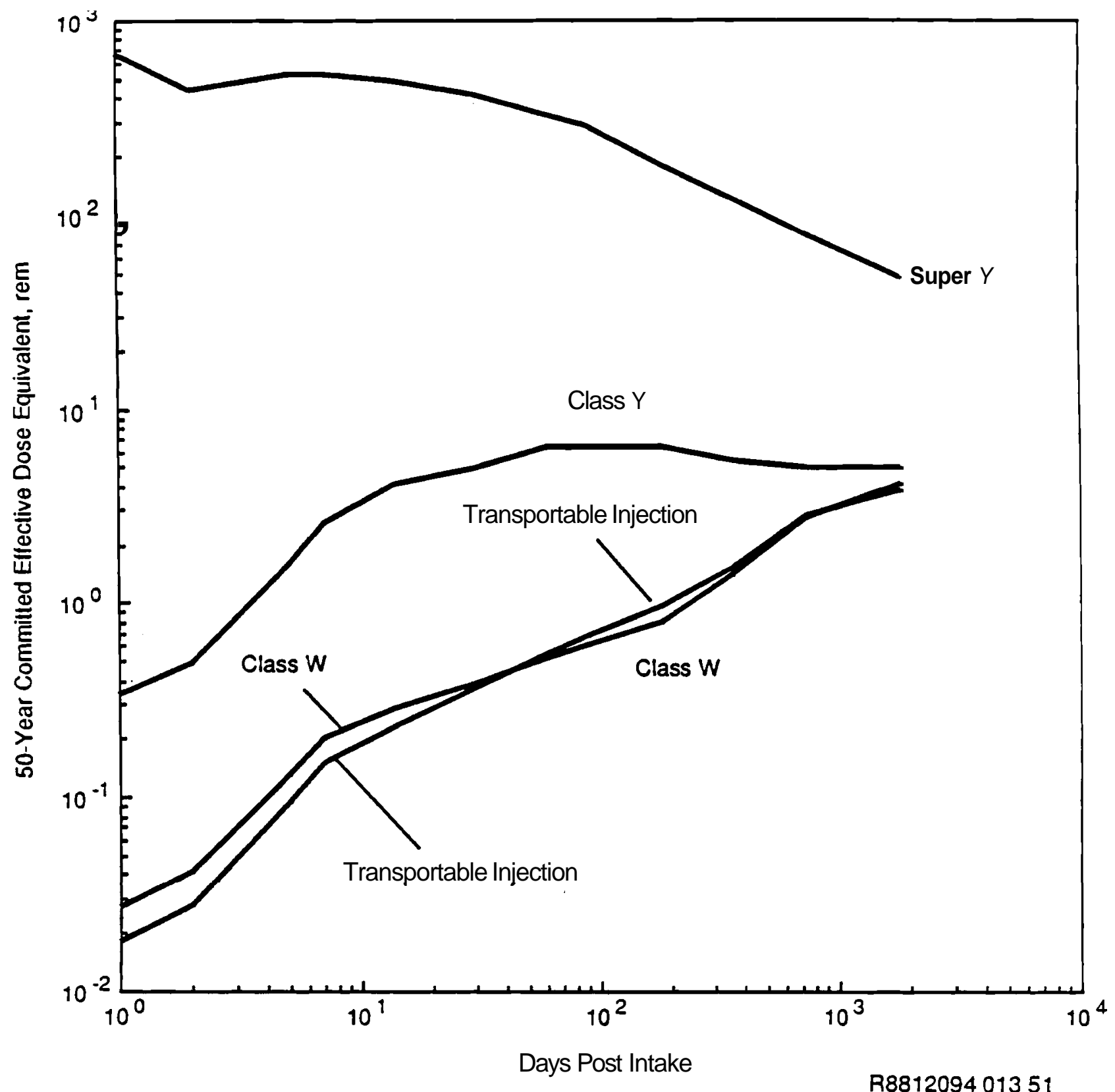

FIGURE 9.8. Potentially Undetected 50-Year Committed Effective Dose Equivalent (rem) for a Single Acute Intake of Aged 12\% Reference Plutonium Mixture Based on an MDA of $0.02 \mathrm{dpm} /$ day of ${ }^{33} \mathrm{Pu}$ Detected in Urine 
TABLE 9.30. Potentially Undetected First-Year Effective Dose Equivalent (rem) for a Single Acute Intake of Fresh 6\% Reference Plutonium Mixture Based on an MDA of $0.18 \mathrm{nCi}$ of ${ }^{24} \mathrm{Am}$ Detected by Lung Counting

Days Post Intake

TABLE 9.31. Potentially Undetected 50-Year Committed Effective Dose

Days Post Intake

0

1

2

5

30

60

90

180

365

730

1825
First-Year Effective Dose Equivalent (rem) from Inhalation Intake (1- $\mu$ m-AMAD particles) $\underline{\underline{\text { Class W }} \quad \underline{\text { Class Y }} \text { Super Y }}$

$1.6 E+1$
$2.3 E+1$
$2.6 E+1$
$2.7 E+1$
$2.5 E+1$
$2.1 E+1$
$1.6 E+1$
$1.4 E+1$
$1.5 E+1$
$2.6 E+1$
$1.5 E+2$
$9.8 E+3$

2. $6 \mathrm{E}+1$

$3.7 \mathrm{E}+1$

4. $1 E+1$

4. $1 \mathrm{E}+1$

$3.8 \mathrm{E}+1$

2. $9 E+1$

$1.9 \mathrm{E}+1$

1. $2 \mathrm{E}+1$

8. $7 \mathrm{E}+0$

$5.1 E+0$

$3.2 \mathrm{E}+0$

2. $26+0$
2. $6 \mathrm{E}+1$

3. $7 \mathrm{E}+1$

4. $1 E+1$

$4.1 E+1$

3. $8 \mathrm{E}+1$

2. $9 \mathrm{E}+1$

1. $9 \mathrm{E}+1$

1. $1 \mathrm{E}+1$

$8.5 E+0$

5. $O E+O$

3. $O E+O$

2. $0 E+0$ Equivalent (rem) for a Single Acute Intake of Fresh $6 \%$ Reference Plutonium Mixture Based on an MDA of $0.18 \mathrm{nC} i$ of ${ }^{24 I}$ Am Detected by Lung Counting

Fifty-Year Committed Effective Dose Equivalent (rem) from Inhalation Intake (1- $\mu \mathrm{m}$-AMAD particles) Class W $\quad \underline{\text { Class Y }}$ Super Y
$4.3 \mathrm{E}+2$
$3.0 \mathrm{E}+2$
$4.9 E+2$
$6.2 E+2$
$4.3 \mathrm{E}+2$
$7.0 \mathrm{E}+2$
$7.0 \mathrm{E}+2$
$4.8 \mathrm{E}+2$
$7.8 \mathrm{E}+2$
$7.3 \mathrm{E}+2$
$4.8 \mathrm{E}+2$
$7.8 \mathrm{E}+2$
$6.9 \mathrm{E}+2$
$4.4 \mathrm{E}+2$
$7.2 \mathrm{E}+2$
$5.7 \mathrm{E}+2$
$3.4 \mathrm{E}+2$
$5.5 \mathrm{E}+2$
$4.5 \mathrm{E}+2$
2. $2 E+2$
3. $6 \mathrm{E}+2$
$4.0 \mathrm{E}+2$
1. $4 \mathrm{E}+2$
2. $2 E+2$
4. $2 E+2$
1. $0 \mathrm{E}+2$
1. $6 \mathrm{E}+2$
$7.2 \mathrm{E}+2$
6. $0 E+1$
$9.5 \mathrm{E}+1$
$4.1 E+3$
3. $7 \mathrm{E}+1$
$5.7 \mathrm{E}+1$
2. $7 \mathrm{E}+5$
2. $8 \mathrm{E}+1$
$3.9 \mathrm{E}+1$
$2.6 \mathrm{E}+1$

1825 
TABLE 9.32. Potentially Undetected First-Year Effective Dose Equivalent (rem) for a Single Acute Intake of Aged $12 \%$ Reference Plutonium Mixture Based on an MDA of $0.18 \mathrm{nCi}$ of ${ }^{241} \mathrm{Am}$ Detected by Lung Counting

Days Post Intake

0
1
2
5
7
14
30
60
90
180
365
730
1825

TABLE 9.33.

Days Post Intake

0
1
2
5
7
14
30
60
90
180
365
730
1825

First-Year Effective Dose Equivalent (rem) from Inhalation Intake (1-um-AMAD particles) Class W $\quad \underline{\text { Class Y }}$ Super Y
$4.6 \mathrm{E}-2$
$7.0 \mathrm{E}-2$
$8.5 \mathrm{E}-2$
1. $0 \mathrm{E}-1$
$1.1 \mathrm{E}-1$
$1.2 \mathrm{E}-1$
$1.5 \mathrm{E}-1$
2.1E-1
3. $0 \mathrm{E}-1$
9.3E-1
$9.5 \mathrm{E}+0$
$1.0 \mathrm{E}+3$

7.5E-2

1. $2 \mathrm{E}-1$

1. $4 \mathrm{E}-1$

1. $6 \mathrm{E}-1$

1. $6 \mathrm{E}-1$

1.7E-1

1.7E-1

1.7E-1

$1.7 \mathrm{E}-1$

$1.8 \mathrm{E}-1$

2. $0 \mathrm{E}-1$

2.5E-1

9. $4 \mathrm{E}-2$

$1.4 \mathrm{E}-1$

1. $7 \mathrm{E}-1$

2. $0 \mathrm{E}-1$

2.1E-1

2.1E-1

2.1E-1

2.1E-1

2. $1 \mathrm{E}-1$

2. $2 \mathrm{E}-1$

2. $4 \mathrm{E}-1$

$2.7 \mathrm{E}-1$
$3.2 \mathrm{E}-1$

Potentially Undetected 50-Year Committed Effective Dose Equivalent (rem) for a Single Acute Intake of Aged $12 \%$ Reference Plutonium Mixture Based on an MDA of $0.18 \mathrm{nC} i$ of ${ }^{24}$ Am Detected by Lung Counting

Fifty-Year Committed Effective Dose Equivalent (rem) from Inhalation Intake (1-um-AMAD particles)

$\begin{array}{lll}\text { Class W } & \text { Class } Y & \text { Super } Y \\ 1.4 \mathrm{E}+0 & 9.9 \mathrm{E}-1 & 1.8 \mathrm{E}+0 \\ 2.2 \mathrm{E}+0 & 1.5 \mathrm{E}+0 & 2.7 \mathrm{E}+0 \\ 2.7 \mathrm{E}+0 & 1.8 \mathrm{E}+0 & 3.2 \mathrm{E}+0 \\ 3.3 \mathrm{E}+0 & 2.1 \mathrm{E}+0 & 3.8 \mathrm{E}+0 \\ 3.4 \mathrm{E}+0 & 2.2 \mathrm{E}+0 & 3.8 \mathrm{E}+0 \\ 3.8 \mathrm{E}+0 & 2.2 \mathrm{E}+0 & 3.9 \mathrm{E}+0 \\ 4.6 \mathrm{E}+0 & 2.2 \mathrm{E}+0 & 3.9 \mathrm{E}+0 \\ 6.6 \mathrm{E}+0 & 2.2 \mathrm{E}+0 & 3.9 \mathrm{E}+0 \\ 9.6 \mathrm{E}+0 & 2.3 \mathrm{E}+0 & 4.0 \mathrm{E}+0 \\ 2.9 \mathrm{E}+1 & 2.4 \mathrm{E}+0 & 4.2 \mathrm{E}+0 \\ 3.0 \mathrm{E}+2 & 2.7 \mathrm{E}+0 & 4.5 \mathrm{E}+0 \\ 3.3 \mathrm{E}+4 & 3.3 \mathrm{E}+0 & 5.1 \mathrm{E}+0 \\ -- & 6.3 \mathrm{E}+0 & 6.0 \mathrm{E}+0\end{array}$




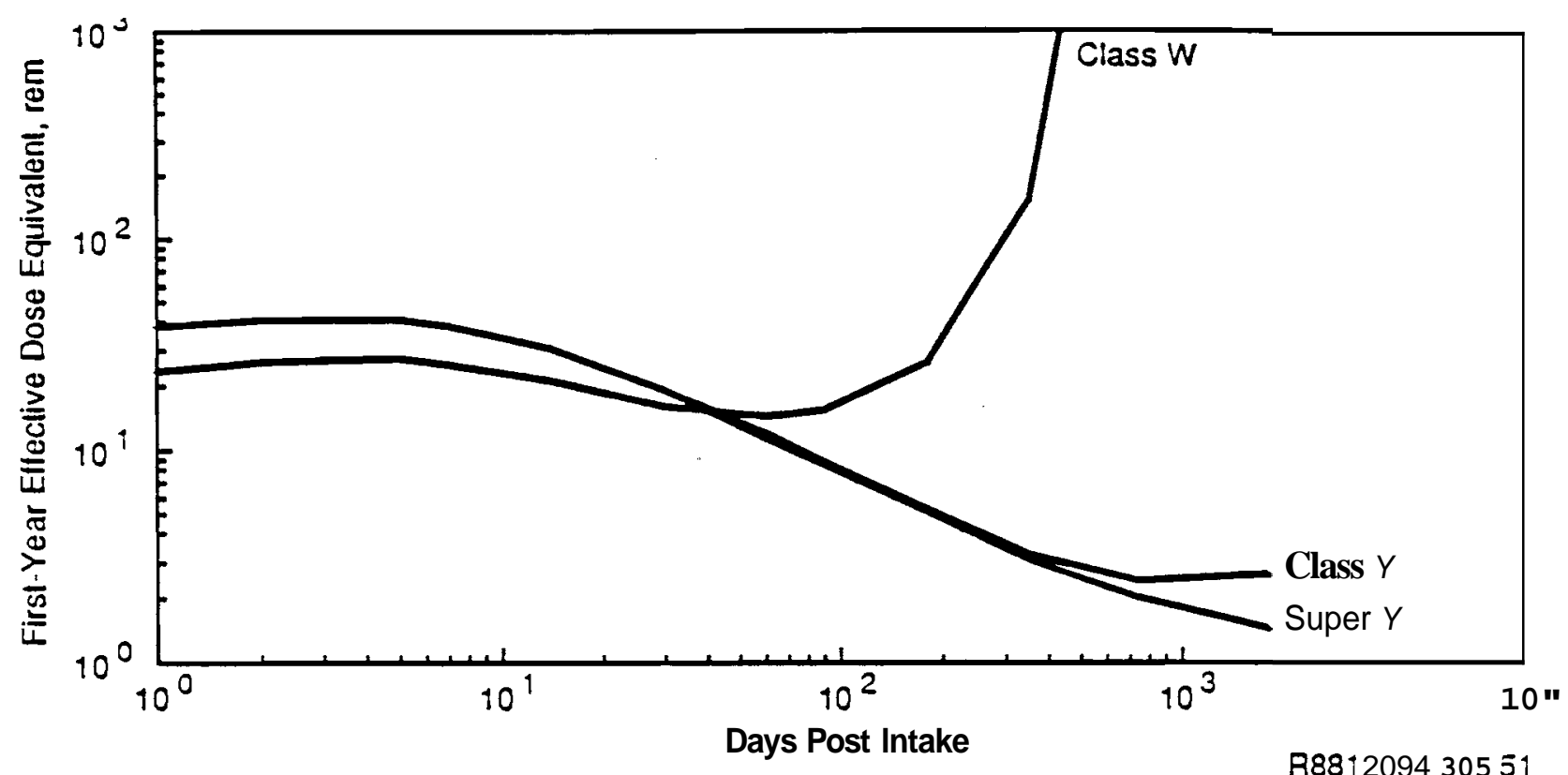

FIGURE 9.9. Potentially Undetected First-Year Effective Dose Equivalent (rem) for a Single Acute Intake of Fress 6\% Reference Plutonium Mixture Based on an MDA of $0.18 \mathrm{nC} ;$ of ${ }^{241}$ Am Detected by Lung Counting

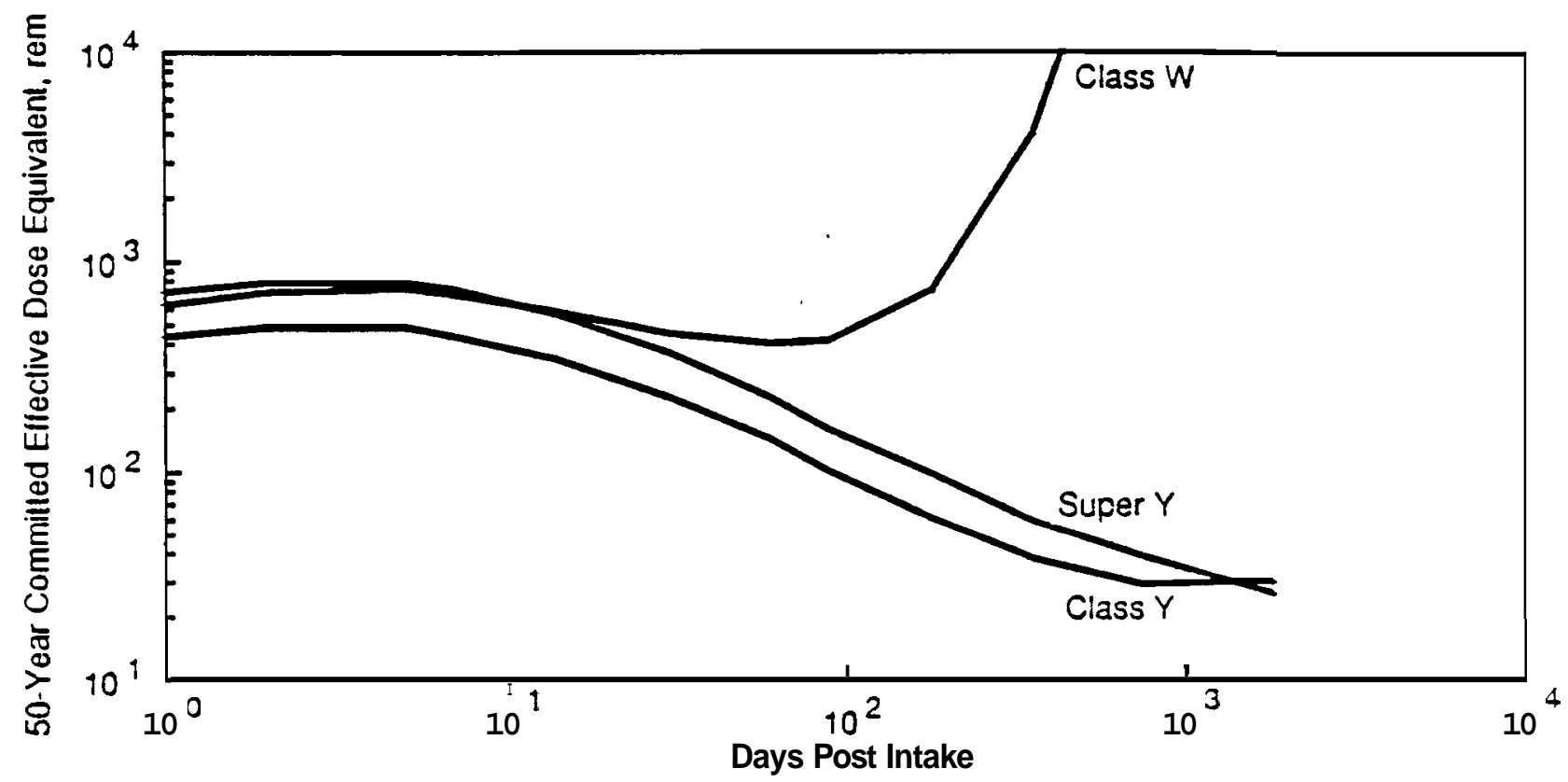

FIGURE 9.10. Potentially Undetected 50-Year Committed Effective Dose Equivalent (rem) for a Single Acute Intake of Fresh 6\% Befference Plutonium Mixture Based on an MDA of $0.18 \mathrm{nCi}$ 24 Am Detected by Lung Counting 


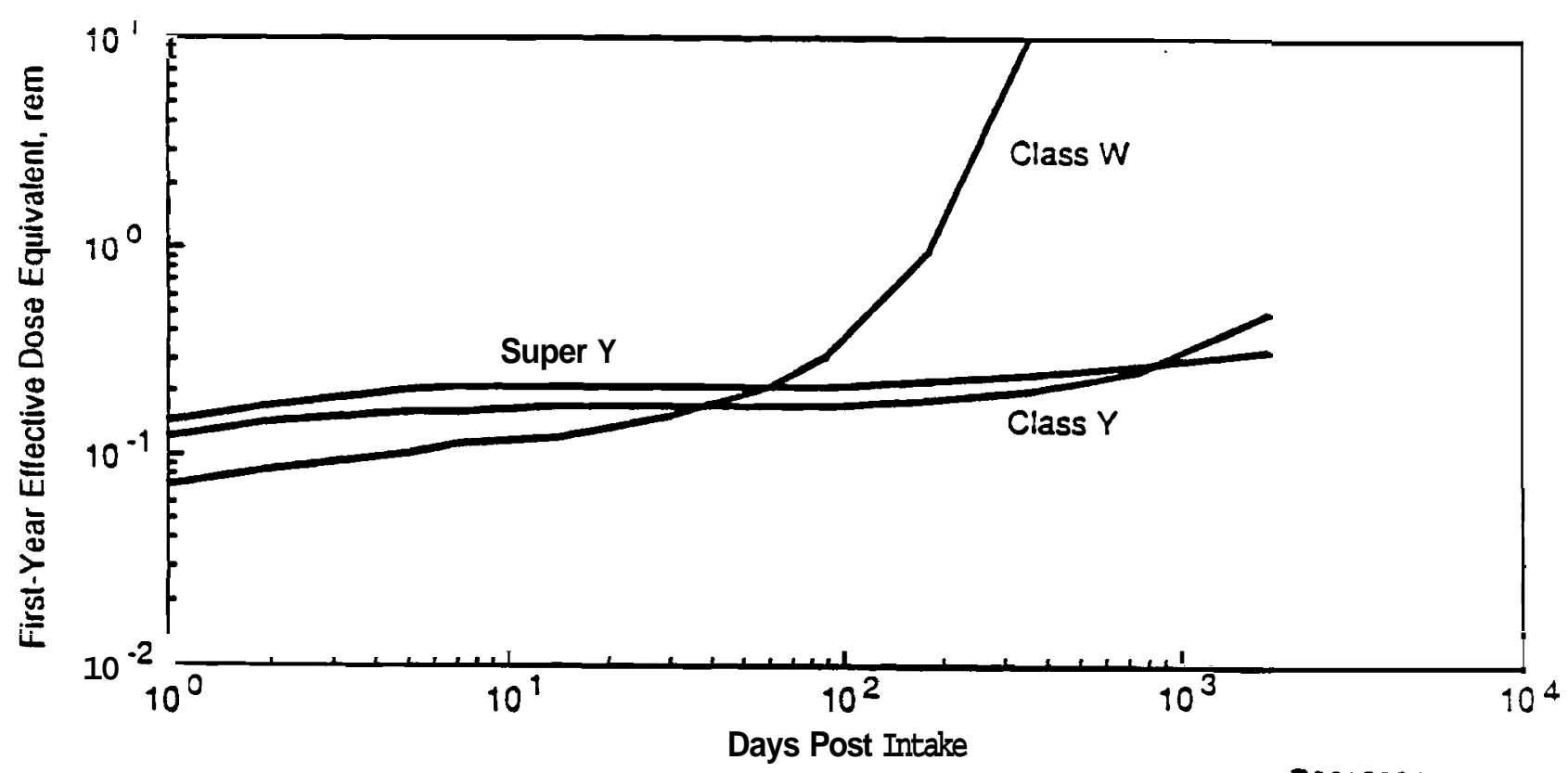

R8812094 ico 55

FIGURE 9.11. Potentially Undetected First-Year Effective Dose Equivalent (rem) for a Single Acute Intake of Aged 12\% Reference Plutonium Mixture Based on an MDA of $0.18 \mathrm{nC} i$ of ${ }^{24 \mathrm{Am}_{\mathrm{m}}}$ Detected by Lung Counting

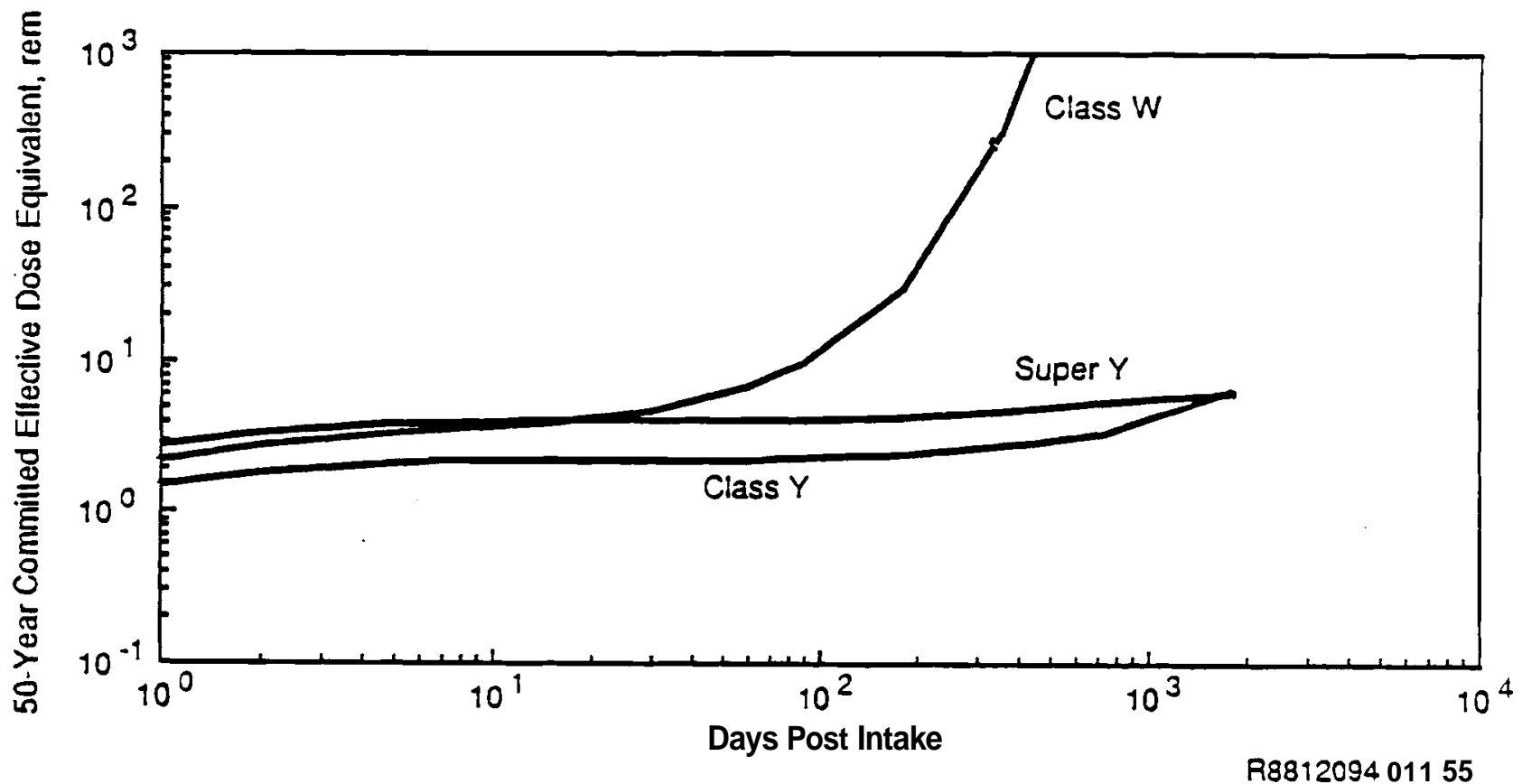

FIGURE 9.12. Potentiall y Undetected 50-Year Committed Effective Dose Equivalent (rem) for a Single Acute Intake of Aged 12\% Reference Plutonium Mixture Based on an MDA of $0.18 \mathrm{nC} ;$ of ${ }^{24}$ Am Detected by Lung Counting 
internal dose estimation available for fission products. The lack of sensitivity is due to the much higher dose per unit intake associated with tenaciously retained alpha-emitting radionuclides as compared with beta- and gamma-emitting fission products. As can be seen by the discussion in the previous subsection, more frequent routine bioassay measurements are unlikely to significantly improve this sensitivity. Some effort has been undertaken at Hanford to assess and develop improved methods of monitoring for super $Y$ forms of plutonium (Bihl et al. 1988). However, this work is in the development phase, and its conclusions are too preliminary for inclusion in this technical basis.

Because of the lack of sensitivity of routine bioassay, special bioassay monitoring as a supplement to the routine program should be promptly initiated by workplace indications of potential internal exposure to plutonium. When adequate measurements are made promptly after a suspected intake, good sensitivity to potential dose can be obtained.

\subsubsection{Special Bioassav Monitoring}

If a potential intake of plutonium is suspected, special bioassay monitoring should be quickly initiated. Typically this monitoring should include same-day in vivo measurements, overnight or first-day urine collection, and early fecal sample collection. The early fecal samples are particularly important for relatively insoluble forms of plutonium (class Y and super Y) because in vivo and urine sample measurements are relatively insensitive to these intakes. An early single voiding urine sample may also be warranted for determining the need for potential dose-reduction therapy. If DTPA chelation therapy was administered, then a total urine sample collection is recommended to reduce any uncertainties associated with sample normalization. Total urine sample collection should be continued until the excretion pattern is established.

\subsubsection{Bioassay Monitoring Capability for Workers with Known Plutonium Depositions}

The capability of a bioassay program is directly dependent upon the magnitude of an identifiable increase in a bioassay measurement. When a 
worker has a positive baseline bioassay level due to previous exposure, the ability to detect a subsequent increase in the bioassay level from an additional intake is more dependent on the variability of current bioassay levels and less dependent on analytical capability. In other words, to be detected, subsequent intakes must result in increases in bioassay measurements that exceed the background "noise" level. Guidance concerning the potential dose from potentially undetected intakes must be developed on a case-by-case basis. Appropriate adjustments to measurement frequencies can then be determined based on the potential undetected dose. As an approximate rule-of-thumb, a single bioassay measurement will probably have to be at least twice the base7 ine level to be readily recognized, due to the substantial variability in single bioassay measurements on individual people. For many situations, this may imply that a normally detectable intake may not be detectable on top of a pre-existing internal plutonium deposition. Like most rules-of-thumb, this is only a rough suggestion; cases of significance must be addressed individually.

\subsection{ASSESSMENT OF INTERNAL DOSE}

The following subsections discuss the general approach for assessing internal dose, estimating presystemic and lung depositions, assessing organ dose equivalents, estimating intake, and making simplified dose assessments.

\subsubsection{General Approach}

The dosimetry for plutonium involves a four-step process for in-depth assessments that roughly proceeds as follows:

- Estimate the clearance component rates.

- Estimate the presystemic deposition for each clearance component.

- Estimate the initial lung deposition for each clearance component.

- Assess the internal dose equivalents (organ and effective, annual and committed) based on deposition estimates and assumptions of Section 9.2.1.

Alternatively, a simplified dose assessment process can be used when only limited data are available. This process involves the following:

- Estimate the intake. 
- Assess the internal dose equivalents.

The techniques used for calculating these estimates are discussed in the following subsections. Assumptions about systemic organ biokinetics, organ mass, tissue or organ weighting factors, and transportability classes are those used in ICRP 26, 30, and 48 (1977; 1979; and 1986).

\subsubsection{Estimatina Presystemic Deposition}

The presystemic deposition is defined as the total radioactivity that will ultimately translocate into the transfer compartment from a metabolically isolated pool; in other words, the activity ultimately reaching the blood. Historically at Hanford, this has been the quantity that has been compared with the MPBB of $0.04 \mu \mathrm{Ci}\left({ }^{239} \mathrm{Pu}\right)$ listed in National Bureau of Standards Handbook 69 (NBS 1959), NCRP 22 (1959), and ICRP 2 (1959). It is related to, but significantly different from intake, lung deposition, longterm lung burden, and instantaneous body burden (or retained quantity).

Activity is deposited in presystemic compartments at the time of intake. From there, systemic uptake may be essentially instantaneous (as with a readily transportable wound intake), or it may occur gradually over an extended period of time (as in the case of an inhalation of class $Y$ material). Transfer from the presystemic compartment into systemic circulation is assumed to be governed by linear first-order kinetics, and can be described in terms of a transfer rate constant.

The computer program PUCALC has been written to evaluate alternate values of the transfer rate and presystemic deposition, based on the urinary excretion data. The program describes the urinary excretion of plutonium for user-selected values for the transfer rate and presystemic deposition. Additional information on PUCALC is provided in Appendix $F$.

It must be remembered that the presystemic deposition may be only part of the initial deposition in the body. In the case of the lung, the ICRP 30 lung model predicts that the presystemic deposition represents about onethird of the total deposition in the slowly clearing compartments of the lung. The total long-term lung deposition must be considered when assessing lung doses. Experience with wounds has shown that a significant fraction of slowly 
transportable activity can become bound up in tissue at the wound site and essentially walled-off or permanently isolated from the transfer compartment. Whether this might represent a true isolation, or merely an extremely slow transfer rate, is a matter of some speculation. The need to determine localized tissue deposits for potentially small wound areas from slowly transportable plutonium must be decided on a case-by-case basis.

\subsubsection{Estimating Initial Lung Deposition}

Initial lung depositions can be estimated based on direct in vivo measurements, fecal data, urine data, or a combination of such data. When there is direct knowledge, or a reasonable assumption, of the isotopic composition of a plutonium mixture, direct in vivo measurement of ${ }^{241} \mathrm{Am}$ in the lung can be used to evaluate 1 ung depositions. A series of detectable ${ }^{241}$ Am measurements can be used to establish the effective lung clearance rate, and the plutonium depositions can be estimated by activity ratios relative to ${ }^{241} \mathrm{Am}$. In analyzing long-term lung measurement data, consideration must be given to the potential impact of the ingrowth of ${ }^{241} \mathrm{Am}$ from ${ }^{241} \mathrm{Pu}$. This requires that the clearance rate of the ${ }^{241} \mathrm{Am}$ relative to that of ${ }^{241} \mathrm{Pu}$ be known. Laboratory animal research data have indicated that early clearance of plutonium mixtures from the lung may be enriched in ${ }^{241}$ Am relative to the intake composition. This has been attributed to a more rapidly clearing component of the ${ }^{241} \mathrm{Am}$ that is initially deposited in the lung.along with the plutonium. Once this initially soluble ${ }^{241} \mathrm{Am}$ has been cleared, the observed clearance rate for the

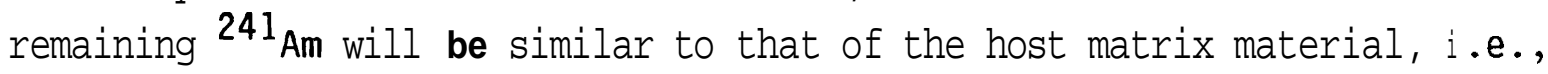
plutonium (Eidson 1980).

Fecal data can be used for estimating lung depositions in two ways. First, it can provide isotopic composition information for use with in vivo measurements. Secondly, it can be used in conjunction with the ICRP 30 respiratory tract model to estimate intake or initial depositions in various compartments of the respiratory tract. Caution must be exercised in interpreting fecal data because a slight ingestion intake can significantly bias lung deposition estimates. There is no way to differentiate inhalation from ingestion intakes by early fecal data. Follow-up fecal samples somewhat removed in time from the intake (2 to 4 weeks or more) may be helpful in 
determining if observed fecal activity is from lung clearance or ingestion clearance. Fecal excretion is also highly dependent on particle size, with larger sizes being more readily excreted in feces. Appendix E provides additional information on assessment of fecal sample data.

Urine sample data are generally not considered a good basis for estimating initial lung depositions; however, they can be helpful and occasionally may be the only data available. For known inhalation exposures, the presystemic deposition estimated using the technique described in the preceding section can provide an indication of initial lung deposition. By using the presystemic deposition estimate as the ultimate quantity to be translocated into the transfer compartment, the compartment fractions of the ICRP 30 respiratory tract model can be used to estimate initial deposition in the various compartments. For example, the initial deposition in the long-term pulmonary region compartments (ICRP 30 lung model compartments e, $g$, and h) (see Appendix D) can be estimated by attributing the slowly transportable presystemic deposition to pulmonary compartments $e$ and $h$, and then multiplying that value by the ratio of the total long-term compartment fractions to the fraction in the presystemic compartments as follows:

$$
P_{0}=U_{\infty}(e+h) *\left(F_{e}+F_{g}+F_{h}\right) /\left(F_{e}+F_{h}\right)
$$

where $P_{0}$ is the initial long-term pulmonary deposition, $U_{\infty}(e+h)$ is the slowly transportable presystemic deposition, and $F_{e}, F_{g}, F_{h}$ are ICRP 30 lung model compartment deposition fractions.

The long-term pulmonary deposition estimate, based on fecal, urine, or air sample data, should be compared with the estimates from in vivo measurements and activity relationships for consistency. In this example, the in vivo ${ }^{241} \mathrm{Am}$ MDA multiplied by the plutonium-americium ratio may be used as an upper bound for dose assessment with the "best" estimate within this bound based on the evaluation of urine sample data. 


\subsubsection{Assessing Orqan Dose Equivalents}

The organs of primary interest for plutonium dose evaluations are the bone surface, red marrow, liver, and gonads. The lung is also an organ of interest for inhalations.

Other organs or tissues may be of interest depending on the nature of an intake. For example, the dose to a specific lymph node or small volume of tissue may be of interest as the result of a wound intake of slowly transportable materials. Such cases can be dealt with as they arise and are beyond the general scope of this technical basis.

Plutonium reaching the transfer compartment is distributed to the liver, bone surfaces, and the gonads according to the ICRP 48 (1986) biokinetic model. Once deposited in these tissues, the ICRP 48 clearance rates are assumed to apply. Thus, for calculating organ doses, the ICRP 48 organretention functions and dosimetry factors are used.

Because plutonium cannot be effectively measured in the systemic organs, and because plutonium and americium may not behave similarly after reaching the systemic organs, caution must be exercised in using measurements of americium in systemic organs for plutonium dose calculations based on the isotope ratios existing at the time of intake. Isotope ratios can change with time due to the different solubility rates and retention characteristics of plutonium and americium. However, americium measurements can be used for americium dose calculations.

Once the magnitude of an intake, presystemic deposition, or initial lung deposition has been determined, organ dose equivalents and the effective dose equivalent can be assessed using hand-calculation techniques or computer codes. The Hanford Internal Dosimetry Program uses two computer codes to aid in dose calculations, GENMOD, and PLUDO. Each of these codes is briefly discussed in the following paragraphs. More detailed explanations and copies of the codes are maintained in the Hanford Radiation Protection Historical Files.

The GENMOD code (Johnson and Carver 1981), calculates organ retention and organ and effective dose equivalents for any time after intake based on 
default ICRP 30 parameters or user-modified parameters. For applications with the Hanford Internal Dosimetry Program, the biokinetic parameters of GENMOD have been modified to reflect the ICRP 48 (1986) model for distribution and retention of radionuclides within the body and the Jones urinary excretion function. Further discussion of GENMOD is provided in Appendix A.

The PLUDO computer code is a Hanford adaptation of the GENMOD code to calculate committed and calendar year organ and effective dose equivalents based on estimates of lung deposition and committed systemic uptake. These estimates of deposition and their associated transport rate constants are derived directly from analysis of urine excretion data, using PUCALC and evaluation of direct (in vivo) bioassay measurement results.

PLUDO implements GENMOD for ${ }^{238} \mathrm{Pu},{ }^{239 / 240} \mathrm{Pu},{ }^{241} \mathrm{Pu}$, and ${ }^{241} \mathrm{Am}$. Rather than specifying intake quantities, the user provides quantities deposited in the lung and presystemic compartments. The user also specifies the transport rate constants for retention of the plutonium in the lung and for uptake of plutonium from the presystemic compartment. The "presystemic compartment" is used to represent any site of radionuclide deposition from which uptake by systemic circulation occurs. For example, presystemic compartments may be associated with activity in the lung or a wound site. The presystemically deposited activity is the activity deposited that will eventually become systemically absorbed. PLUDO allows for specification of up to three lung and three presystemic compartments, each with a unique transport rate constant, for each radionuclide. PLUDO then invokes GENMOD to compute cumulated activities in source organs for each calendar year beginning with the year of intake, calculates resulting organ and effective dose equivalents for each calendar year, and sums these over all deposition compartments and radionucl ides.

\subsubsection{Estimating Intake}

An intake of plutonium can be estimated by fitting the urinary excretion data to the appropriate intake excretion function, using manual or computerized techniques. For a single data point, the intake can be estimated by dividing the measured excretion by the value of the intake excretion function on the day after intake represented by the sample in a manner similar to 
Equation (9.3). Values for the fractional intake excretion function can be obtained from Figure 9.4, Table 9.6, or directly from running the GENMOD computer code. For multiple data points, a least-squares fit of the data to the expected excretion function should be used, as described in Appendix $\mathbf{C}$.

In addition to their use for dose calculations, intakes calculated by the above techniques may also be compared with the ICRP ALIs or intake estimates based on air sample results. When bioassay data are not available, air sample results may be the basis for estimating intake. An intake may also be estimated from the fecal data explained in Appendix E.

\subsubsection{Simplified Dose Assessments}

Simplified dose assessments use the techniques and biokinetic models described previously and assume ICRP 23 (1974) Reference Man parameters, without correction for individual-specific characteristics. These assessments provide a basis for prospective bioassay program design, initial estimates when bioassay data are few, and retrospective evaluation of intakes that are too small to yield sufficient bioassay data to empirically describe the biokinetic processes. In addition, the bioassay projections associated with simplified assessments can be used as a trigger point for more in-depth measurements or dose assessments.

The procedure for performing a simplified dose assessment is as follows:

1. Normalize the result to the daily excretion rate, if necessary (see Appendix 0 .

2. Select the intake date (known or assumed).

3. Estimate the intake by fitting the data to the excretion model (see Appendix C).

4. Calculate the dose equivalents by multiplying the estimated intake by the appropriate intake dose equivalent factor from GENMOD.

The intakes of fresh $6 \%$ and aged $12 \%$ reference plutonium mixtures resulting in a first-year effective dose equivalent of 100 mrem have been calculated using the simplified dose assessment procedure. The results of these calculations are shown in Table 9.34. 
TABLE 9.34. Intakes for Reference Plutonium Mixtures Resulting in a First-Year Effective Dose Equivalent of 100 mrem

\begin{tabular}{|c|c|c|c|c|c|}
\hline \multirow{2}{*}{ 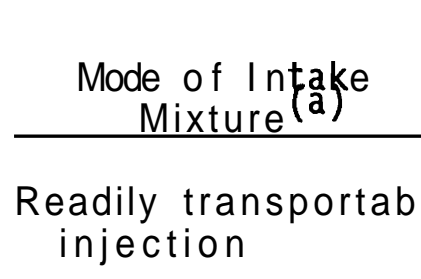 } & \multirow[t]{2}{*}{$\begin{array}{l}\text { Mass of } \\
\text { Intake, } \\
\text { nq } \\
\end{array}$} & \multirow[t]{2}{*}{$\begin{array}{c}238 \mathrm{Pu} \text {, } \\
\mathrm{nCi}^{\text {Is }}\end{array}$} & \multirow[t]{2}{*}{$\begin{array}{c}\text { opjig }\{240 \text { pus } \\
\text { nCi }\end{array}$} & \multirow[t]{2}{*}{$\begin{array}{c}{ }^{\circ}{ }_{24} \mathrm{P}_{\mathrm{Pu}}^{\mathrm{In}} \\
\mathrm{nCi} \\
\end{array}$} & \multirow[t]{2}{*}{$\begin{array}{c}{ }^{2}{ }^{241_{A m}}, \\
\mathrm{nCi}\end{array}$} \\
\hline & & & & & \\
\hline $6 \% \mathrm{Pu}$ - fresh & 12 & $1.0 \mathrm{E}-1$ & $8.5 \mathrm{E}-1$ & $9.7 \mathrm{E}+0$ & $6.0 \mathrm{E}-4$ \\
\hline $6 \% \mathrm{Pu}$ - aged & 11 & $9.1 \mathrm{E}-2$ & 8. $O E-1$ & $7.2 E+0$ & $6.5 \mathrm{E}-2$ \\
\hline $12 \% \mathrm{Pu}-$ fresh & 9.6 & $1.6 \mathrm{E}-1$ & $7.7 \mathrm{E}-1$ & $2.9 E+1$ & $1.8 \mathrm{E}-3$ \\
\hline $12 \% \mathrm{Pu}-$ aged & 7.9 & $1.3 \mathrm{E}-1$ & $6.3 \mathrm{E}-1$ & $1.9 E+1$ & $1.7 \mathrm{E}-1$ \\
\hline \multicolumn{6}{|l|}{ Class W inhalation } \\
\hline $6 \% \mathrm{Pu}-$ fresh & 66 & $5.6 \mathrm{E}-1$ & $4.7 E+0$ & $5.4 E+1$ & $3.3 E-3$ \\
\hline $6 \% \mathrm{Pu}$ - aged & 61 & 5. $O E-1$ & $4.4 E+0$ & $4.0 E+1$ & $3.6 \mathrm{E}-1$ \\
\hline $12 \% \mathrm{Pu}-$ fresh & 53 & $9.0 \mathrm{E}-1$ & $4.2 E+0$ & $1.6 E+2$ & $1.0 \mathrm{E}-2$ \\
\hline $12 \% \mathrm{Pu}-$ aged & 43 & $7.1 E-1$ & $3.5 \mathrm{E}+0$ & $1.1 E+2$ & $9.5 \mathrm{E}-1$ \\
\hline \multicolumn{6}{|l|}{ Class $Y$ inhalation } \\
\hline $6 \% \mathrm{Pu}$ - fresh & 41 & $3.5 \mathrm{E}-1$ & $2.9 E+0$ & $3.3 E+1$ & $2.1 E-3$ \\
\hline $6 \% \mathrm{Pu}-$ aged & 38 & $3.1 \mathrm{E}-1$ & $2.7 E+0$ & $2.5 E+1$ & $2.2 \mathrm{E}-1$ \\
\hline $12 \% \mathrm{Pu}$ - fresh & 33 & $5.6 \mathrm{E}-1$ & $2.6 E+0$ & $1.0 E+2$ & $6.2 E-3$ \\
\hline $12 \% \mathrm{Pu}$ - aged & 27 & $4.4 \mathrm{E}-1$ & $2.2 E+0$ & $6.5 E+1$ & $5.9 E-1$ \\
\hline \multicolumn{6}{|l|}{ Super $Y$ inhalation } \\
\hline $6 \% \mathrm{Pu}$ - fresh & 39 & $3.4 \mathrm{E}-1$ & $2.8 E+0$ & $3.3 E+1$ & $2.1 E-3$ \\
\hline $6 \% \mathrm{Pu}$ - aged & 37 & $3.0 \mathrm{E}-1$ & $2.6 \mathrm{E}+0$ & $2.4 E+1$ & $2.1 \mathrm{E}-1$ \\
\hline $12 \% \mathrm{Pu}$ - fresh & 32 & $5.5 \mathrm{E}-1$ & $2.6 \mathrm{E}+0$ & $1.0 E+2$ & $6.5 E-3$ \\
\hline $12 \% \mathrm{Pu}$ - aged & 27 & $4.3 \mathrm{E}-1$ & $2.1 E+0$ & $6.4 \mathrm{E}+1$ & $5.9 \mathrm{E}-1$ \\
\hline
\end{tabular}

(a) $\%=$ nominal $240 \mathrm{Pu}$ wejght percent in mixture. Fresh $=2$ weeks of 241 Am ingrowth following separation. Aged $=5$ years of ${ }^{241}$ Am ingrowth following separation. Inhalation intakes assume 1- $\mu$ m-AMAD particle size. 
The simplified dose assessment procedure was also used for determining the bioassay program capabilities described in section 9.4.

\subsection{MANAGEMENT OF INTERNAL CONTAMINATION CASES}

This section discusses the diagnostic procedures, therapeutic actions, and long-term monitoring of internal depositions.

\subsubsection{Diaanostic Procedures}

The diagnosis of an intake involves a combination of workplace monitoring to identify on-the-job potential intakes and bioassay measurements to confirm and quantify internal contamination.

Potential intakes are intended to be identified by workplace monitoring, such as personal contamination surveys, nasal smear analyses, air sample results, or workers' identifications of unusual conditions. These techniques provide qualitative screening to alert radiation protection staff to potential internal exposure, rather than absolute confirmation that exposure has or has not occurred. For example, activity detected on nasal smears is usually an indication of an inhalation intake; however, the absence of activity does not necessarily mean that an intake did not occur. The absence of nasal smear activity following an inhalation intake can be explained by a sufficient delay between the time of intake and the collection of nasal smears to allow for complete clearance of activity from the nares. The ICRP 30 respiratory tract model indicates that a delay of as little as 30 to 60 minutes may be adequate for this in some cases. Alternatively, some individuals are mouth-breathers, whose noses are partially or completely bypassed in the respiratory process, hence no activity may be deposited in the nares, despite the occurrence of an inhalation intake. Particle size can also significantly affect nasal deposition and clearance.

Once a worker has been identified as having incurred a potential internal exposure, the initial diagnostic measurements are arranged. These may include a chest count, wound count, single voiding (spot) urine sample analysis, first-day fecal sampling, and overnight urine sampling. 
The purpose of these initial procedures is to provide an order-ofmagnitude estimate of the potential internal exposure and dose. Initial diagnostic measurements are usually sufficient for final evaluations only when all results collectively rule out the possibility of an intake. In reality, initial measurements are not generally expected to do this, and follow-up measurements are necessary.

Follow-up diagnostic measurements may include additional urine and fecal samples, chest counts, liver counts, head counts, and lymph node counts. These analyses aid in determining the magnitude, location, and retention characteristics of the deposited material. In some cases, blood samples or tissue specimens may also be appropriate.

In addition, workplace or clothing contamination analyses, air sample analyses, particle size analyses, and/or solubility analyses may also be performed to more clearly define the physical and radiological characteristics of the material to which the worker was exposed.

It is the responsibility of the exposure evaluator, working closely with contractor radiation protection staff, to determine the appropriate diagnostic protocols. Scheduling of follow-up measurements will normally be done by the appropriate contractor radiation protection staff.

\subsubsection{Therapeutic Actions}

Therapeutic actions for potential internal contamination include the use of decorporation agents, catharsis, and surgical excision. For the purposes of this discussion, the normal skin decontamination procedures of Hanford contractors are not considered therapeutic actions, although it is acknowledged that these procedures can be quite effective in preventing the internal deposition of radioactivity.

The decision to undertake one or more of these measures is the responsibility of the participating HEHF Occupational Medicine physician with the concurrence of the patient. The exposure evaluator will provide advice and consultation to the physician and patient regarding the potential dose implications and efficacy of alternative actions. 
Decorporation therapy is also referred to as chelation therapy, and involves the chemical removal of radioactivity from the bloodstream through drug administration. The drug DTPA has U.S. Food and Drug Administration approval for use in removing plutonium and other heavy metals from the body. Other drugs are also available to HEHF Occupational Medicine.

Catharsis involves accelerating the passage of material through the G tract by means of laxative drugs or physical means such as an enema. Catharsis has potential value in reducing the adsorption of material into the bloodstream from the GI tract and in reducing the dose to the Gl tract organs from material passing through the GI tract. These measures are not generally considered for occupational exposures to plutonium, because the Gi tract adsorption of plutonium is so slight, and the dose to the Gl tract organs is usually an insignificant fraction of the total effective dose.

Surgical excision following wounds can be extremely effective in reducing the potential internal deposition, particularly when coupled with decorporation therapy. Minor excisions are usually performed at the EDF by HEHF Occupational Medicine staff, assisted by a PNL exposure evaluator and radiation protection personnel.

\subsubsection{Lonq-Term Monitoring of Internal Depositions}

Once an internal dosimetry evaluation has been completed, it may be recommended that the worker be placed on a specialized long-term bioassay monitoring schedule. The reasons for this are twofold: first, long-term followup monitoring results that are consistent with the projected results verify the conclusions of the evaluation. Second, if long-term results are projected to be detectable, and the worker returns to plutonium work, then the capability of a routine bioassay monitoring program to detect an additional intake may be affected. This latter point is addressed in greater detail in Section 9.4.8.

Specialized bioassay monitoring programs may be required for workers with known internal depositions of plutonium. These programs may include head counts, liver counts, periodic chest counts, and urine samples. In some cases fecal sampling may also be desired. It is the responsibility of the exposure 
evaluator to recommend appropriate long-term bioassay monitoring to the contractor dosimetry or radiation protection organization that has the responsibility for acting on these recommendations. 

SECTION 10.0

REFERENCES 

Alexander, R. E. 1974. Applications of Bioassay of Uranium. WASH 1251, U.S. Nuclear Regulatory Commission, Washington, D.C.

American National Standards Institute (ANSI). 1983. Internal Dosimetry Standards for Tritium. ANSI Standard N13.14-1983, New York, New York.

Bihl, D. E., T. P. Lynch, E. H. Carbaugh, and M. J. Sula. 1988. Methods to Improve Routine Bioassay Monitoring for Freshly Separated, Poorly Transported Plutonium. PNL-6695, Pacific Northwest Laboratory, Richland, Washington.

Brodsky, A. 1983. Information for Establishing Bioassay Measurements and Evaluations of Tritium Exposure. NUREG-0938, U.S. Nuclear Regulatory Commission, Washington, D.C.

Carbaugh, E. H., M. J. Sula, and K. M. McFadden. 1990. Use of Probability Analysis to Establish Routine Bioassay Screening Levels. PNL-SA-17716, Pacific Northwest Laboratory, Richland, Washington.

Dolphin, G. W., and I - S. Eve. 1963a. "The Metabolism of Strontium in Humans." Physics in Medicine and Biology 8(2):193-203.

Dolphin, G. W., and I. S. Eve. 1963b. "Some Aspects of Radiostrontium Dosimetry." Phvsics in Medicine and Biologv 8(2):205-214.

Eidson, A. F. 1980. Comparison of Physical Chemical Properties of Powders and Respirable Aerosols of Industrial Mixed Uranium and Plutonium Oxide Fuels. NUREG/CR-1736, U.S. Nuclear Regulatory Commission, Washington, D.C.

Environmental Health Directorate (EHD). 1983. Bioassay Guideline 2-Guidelines for Tritium Bioassav. 83-EHD-87, Department of National Health and Welfare, Ottawa, Canada.

Eve, I . S. 1964. "Some Suggested Maximum Permissible Single Intakes of Uranium." Health Physics 10:773-776.

Fisher, D. R. 1985. "Uranium." In Handbook on the Toxicity of Inorqanic Compounds, eds. H. G. Seiler and H. Sigel. Marcel Dekker, Inc., New York, New York.

General Electric Company. 1983. Chart of the Nuclides. 13th edition, San Jose, California.

Griffith, R. V., P. N. Dean, A. L. Anderson, and J. C. Fisher. 1978. "Fabrication of a Tissue-Equivalent Torso Phantom for Intercalibration of In-Vivo Transuranic-Nuclide Counting Facilities." In Advances in Radiation Monitoring, Proceedings of an International Atomic Energy Agency Conference. International Atomic Energy Agency, Vienna, Austria. 
Healy, J. W. 1957. "Estimation of Plutonium Lung Burden by Urine Analysis." American Industrial Hyqiene Association Quarterly 18(3):261-266.

Hedengren, D. C. 1985. ORIGEN2 Predictions of N-Reactor Fuel Fission Product Composition. SD-CP-I-077, Rockwell Hanford Operations, Richland, Washington.

Hursh, J. B., and N. L. Spoor. 1973. "Protection Criteria." In Uranium, Plutonium, and Transplutonium Elements, eds. H. C. Hodge, J. N. Stannard and J. 8. Hursh, pp. 197-239. Springer-Verlag, Berlin, West Germany.

International Atomic Energy Agency (IAFA). 1973. Inhalation Risks from Radioactive Contaminants. Technical Reports Series No. 142, Vienna, Austria.

International Atomic Energy Agency (IAEA). 1978. Manual on Early Medical Treatment of Possible Radiation Injury. Safety Series No. 47, Vienna, Austria.

International Commission on Radiological Protection (ICRP). 1959. Report of Committee II on Permissible Dose for Internal Radiation. ICRP Publication 2, Pergamon Press, New York, New York.

International Commission on Radiological Protection (ICRP). 1964. Recommendations of the Internal Commission on Radiological Protection. ICRP Publication 6, Pergamon Press, Oxford, England.

International Commission on Radiological Protection (ICRP) . 1969. Evaluation of Radiation Doses to Body Tissues from Internal Contamination Due to 0ccupational Exposure. ICRP Publication 10, Pergamon Press, New York, New York.

International Commission on Radiological Protection (ICRP). 1973. Alkaline Earth Metabolism in Adult Man. ICRP Publication 20, Pergamon Press, New York, New York.

International Commission on Radiological Protection (ICRP). 1974. Report of Task Group on Reference Man. ICRP Publication 23, Pergamon Press, New York, New York.

International Commission on Radiological Protection (ICRP). $\quad 1977 . \quad$ Recommendations of the International Commission on Radiological Protection. ICRP Publication 26, Pergamon Press, New York, New York.

International Commission on Radiological Protection (ICRP). 1979. Limits for Intakes of Radionuclides by Workers. ICRP Publication 30, Part 1 and Supplements, Pergamon Press, New York, New York.

International Commission on Radiological Protection (ICRP). 1983. Radionuclide Transformations: Enerqy and Intensity of Emissions. ICRP Publication 38, Pergamon Press, New York, New York. 
International Commission on Radiological Protection (ICRP). 1986. The Metabolism of Plutonium and Related Elements. ICRP Publication 48, Pergamon Press, New York, New York.

International Commission on Radiological Protection (ICRP). 1988 . Individual Monitoring for Intakes of Radionuclides by Workers: Design and Interpretation. ICRP Publication 54, Pergamon Press, New York, New York.

Jaquish, R. E., and R. W. Bryce, ed. 1989. Hanford Site Environmental Report for Calendar Year 1988. PNL-6825, Pacific Northwest Laboratory, Richland, Washington.

Johnson, J. R. 1982. "The Estimation of Effective Dose Equivalent from Tritiated Water Exposures Using Tritium Concentrations in Urine." Radiation Protection Dosimetrv 2(4):245-247.

Johnson, J. R., and M. B. Carver. 1981. "A General Model for Use in Internal Dosimetry." Health Physics 41:341-348.

Johnson, J. R., and R. C. Myers. 1981. "Alkaline Earth Metabolism: A Model Useful in Calculating Organ Burdens, Excretion Rates, and Committed Effective Dose Equivalent Conversion Factors." Radiation Protection Dosimetry $1(2): 87-95$.

Jones, S. R. 1985. "Derivation and Validation of a Urinary Excretion Function for Plutonium Applicable Over Tens of Years Post Intake." Radiation Protection Dosimetrv 11(1):19-27.

Kang, C. 1989. "Measurements of Whole Body Radiocesium at the Harwell Laboratory, 1976-1988." Health Physics 57:995-1001.

Lanaham., W. H. 1956. "Determination of Internally Deposited Radioactive Isotopes from Excretion Analysis. "American Industrial Hyqiene Association Quarterly 17(3):305-318.

Langham, W. H., S. H. Basset, P. S. Harris, and R. E. Carter. 1950. Distribution and Excretion of Plutonium Administered to Man. LA-1151, Los Alamos Scientific Laboratory, Los Alamos, New Mexico. (Reprinted in Health Physics 38:1031-1060.)

Leggett, R. W. 1989. "The Behavior and Chemical Toxicity of $U$ in the Kidney: A Reassessment." Health Physics 57(3):365-383.

Lessard, E. T., X. Yihua, K. W. Skrable, G. E. Chabot, C. S. French, T. R. La Bone, J. R. Johnson, D. R. Fisher, R. Belanger, and J. L. Lipsztein. 1987. Interpretation of Bioassay Measurements. NUREG/CR-4884, U.S. Nuclear Regulatory Commission, Washington, D.C.

Lloyd, R. D. 1990. "Chernobyl Fallout Radionuclides in Utah Residents." Health Physics 58:533-534. 
McGuire, S. A. 1990. "Chemical Toxicity of Uranium Hexafluoride Related to Radiation Doses. " NUREG-1391, draft report issued for comment, U. S. Nuclear Regulatory Commission, Washington D.C.

Moghissi, A. A., and Cothern, C. R. 1986. "Background Information for the Development of a Standard for Tritium in Drinking-water." Radiation Protection Dosimetry 16(1-2):175-179.

Morrow, P. E., F. R. Gibb, and H. D. Beiter. 1972. "Inhalation Studies of Uranium Trioxide." Health Physics 23:273-280.

Morrow, P. E., L. J. Leach, F. A. Smith, R. M. Gelein, J. B. Scott, H. D. Beiter, F. J. Amato, J. J. Picano, C. L. Yuile, and T. G. Consler. 1982. Metabolic Fate and Evaluation of Injury in Rats and Dogs Following Exposure to the Hydrolysis Products of Uranium Hexaflouride. NUREG/CR-2268, U.S. Nuclear Regulatory Commission, Washington D.C.

Moss, W. D., and M. A. Gautier. 1985. "Additional Short-Term Plutonium Urinary Excretion Data from the 1945-1947 Plutonium Injection Studies." Occupational Health and Environmental Research 1983: Health, Safety, and Environment Division, LA-10365-PR, Los Alamos National Laboratory, Los Alamos, New Mexico.

Myers, D. K., and J. R. Johnson. 1991. Toxicity and Dosimetrv of Tritium: A Review. ACRP-10, Advisory Committee on Radiological Protection, Ottawa, Canada.

National Bureau of Standards Handbook 69. 1959. Maximum Permissible Body Burdens and Maximum Permissible Concentrations of Radionuclides in A ir and Water for Occupational Exposure. U.S. Department of Commerce, Washington, D.C.

National Council on Radiation Protection and Measurements (NCRP). 1959. Maximum Permissible Body Burdens and Maximum Permissible Concentrations of Radionuclides in A ir and in Water for Occupational Exposure. NCRP Report No. 22, Bethesda, Maryland.

National Council on Radiation Protection and Measurements (NCRP). 1976. Tritium Measurement Techniaues. NCRP Report No. 47, Bethesda, Maryland.

National Council on Radiation Protection and Measurements (NCRP). 1977. Cesium-137 from the Environment to Man: Metabolism and Dose. NCRP Report No. 52, Washington, D.C.

National Council on Radiation Protection and Measurements (NCRP). 1979a. Tritium in the Environment. NCRP Report No. 62, Bethesda, Maryland.

National Council on Radiation Protection and Measurements (NCRP). 1979b. Tritium and Other Radionuclide Labeled Orqanic Compounds Incorporated in Genetic Material. NCRP Report No. 63, Bethesda, Maryland. 
National Council on Radiation Protection and Measurements (NCRP). 1980. Manaqement of Persons Accidentally Contaminated with Radionuclides. NCRP Report No. 65, Bethesda, Maryland.

National Council on Radiation Protection and Measurements (NCRP). 1985. General Concepts for the Dosimetry of Internally Deposited Radionuclides. NCRP Report No. 84, Bethesda, Maryland.

National Counci1 on Radiation Protection and Measurements (NCRP). $1987 . \quad \underline{\text { Use }}$ of Bioassay Procedures for Assessment of Internal Radionuclide Deposition. NCRP Report No. 87, Bethesda, Maryland.

Nelson, I - C. 1970. Build Up of Americium-241. BNWL-B-12, Battelle, Pacific Northwest Laboratories, Richland, Washington.

Palmer, H. E., C. P. Brim, G. A. Rieksts, and M. C. Rhoads. 1990. Hanford Whole Body Counting Manual. PNL-6198 Rev. 1, Pacific Northwest Laboratory, Richland, Washington.

Rich, B. L., S. L. Hinnefeld, C. R. Lagerquist, W. G. Mansfield, L. H. Munson, and E. R. Wagner. 1988. Health Physics Manual of Good Practices for Uranium Facilities. EGG-2530, EG\&G Idaho, Inc., Idaho Fa11s, Idaho.

Riggs, D. S. 1952. "Quantitative Aspects of lodine Metabolism in Man." Pharmacology Review 4:284-370.

Rittman, P. D. 1984. Seven Health Physics Calculator Programs for the HP-41CV. RHO-HS-ST-5 P, Rockwe11 Hanford Operations, Richland, Washington.

Rundo, J., P. M. Starzyk, J. Sedlet, R. P. Larsen, R. D. 0ldham, and J. J. Robinson. 1976. "The Excretion Rate and Retention of Plutonium 10,000 Days After Acquisition." In Diaqnosis and Treatment of Incorporated Radionuclides, International Atomic Energy Agency, Vienna, Austria.

Skrable, K. W., L. C. Sun, G. E. Chabot, C. S. French, and T. R. La Bone. 1987. "Pseudo Uptake Retention Functions for the Whole Body for Estimating Intakes from Excretion Bioassay Data." Radiation Protection Dosimetry $18(3): 133-139$.

Snyder, W. S., M. R. Ford, G. G. Warner, and S. B. Watson. 1974. A Tabulation of Dose Equivalent per Microcurie-Day of Source and Tarqet Orqans of an Adult for Various Radionuclides. ORNL-5000, Vol. 1 and 2, Oak Ridge National Laboratory, Oak Ridge, Tennessee.

Stradling, G. N., and Stather, J. W. 1989. "The Use of Animal Experiments for Assessing Annual Limits on Intake and Interpreting Chest-Monitoring Data for Workers Exposed to Industrial Actinide-Bearing Dusts." Health Physics 57: Supplement 1:221-228 
Strand, P., Bøe, E., Berteig, L., Berthelsen, T., Strand, T., Trygg, K., and Harbit, 0. 1989. "Whole Body Counting and Dietary Surveys in Norway During the First Year After the Chernobyl Accident." Radiation Protection Dosimetry $27(3): 163-171$.

Sula, M. J., Carbaugh, E. H., and Bihl, D. E. 1989. Techical Basis for Internal Dosimetry at Hanford. PNL-6866, Pacific Northwest Laboratory, Richland, Washington.

Sulu and Zhao, Fu-Yao. 1990. "Nephrotoxic Limit and Annual Limit on Intake for Natural U." Health Physics 58(5):619-623.

Tarroni, G., Melandri, "\{ 37 Battisłił P., Castellani, C. M., Formignani, M., and Rampa, E. 1990. " ${ }^{37} \mathrm{Cs}$ and ${ }^{34} \mathrm{Cs}$ Human Internal Contamination in Italy Following the 1986 Chernobyl Event." Radiation Protection Dosimetry $32(4): 259-271$.

Task Group on Lung Dynamics. 1966. "Deposition and Retention Models for Internal Dosimetry of the Human Respiratory Tract." Health Physics 12:173.

Thompson, R. J. 1986 . Operating Specifications for the Uranium Oxide Plant. OSD-U-185-00001, Rockwe11 Hanford Operations, Richland, Washington.

U.S. Environmental Protection Agency (EPA). 1976. National Interim Drinking Water Requlations. EPA-5709-76-003, Washington D.C.

U. S. Environmental Protection Agency (EPA). 1985. Environmental Radiation Data - Report 42. ÐA 520/5-85-031, Eastern Environmental Radiation Facilīty, Montgomery, Alabama.

U.S. Department of Energy (DOE). 1988. Radiation Protection for Occupational Workers. DOE 5480.11, Washington, D.C.

United States Testing Company, Inc. 1988. "Statement of Work for the First Operational Year, Appendix A of Subcontract B-Q5145-A-I," Analytical Personnel Dosimetry Support Services. Richland, Washington.

Watson, S. B., and M. R. Ford. 1980. A User's Manual to the ICRP Code--A Series of Computer Programs to Perform Dosimetric Calculations for the ICRP Committee 2 Report. ORNL/TM-6980, Oak Ridge National Laboratory, Oak Ridge, Tennessee.

Weetman, R. A., and H. W. DeHaven. 1982a. Characterization of Airborne Radionuclides in UNC Facilities. UNI-2164, UNC Nuclear Industries, Richland, Washington.

Weetman, R. A., and H. W. DeHaven. 1982b. Characterization of Surface Contamination in UNC Facilities. UNI-2137, UNC Nuclear Industries, Richland, Washington. 
"WHO - FAO Coden Alimentarius Commission Agrees Activity Levels in Foods." Health Physics 57:1048.

Wrenn, M. E. 1985. Metabolism of Ingested Uranium and Radium." Health Physics 48:601. 



\section{APPENDIX A}

\section{GENMOD INTERNAL DOSIMETRY COMPUTER CODE}





\section{APPENDIX A}

\section{GENMOD NIERNAL DOSMEIRY COMPUTER CODE}

The computer code GENMOD is employed for evaluation of bioassay measurement data and computation of internal dose equivalent. The code implements standard biokinetic models of the ICRP to describe the fate of radionuclides taken into the body. Dose factors are applied to cumulative activities in source organs to compute dose equivalent to target organs and effective dose equivalent. The code is described in detail by Johnson and Carver (1981) and Dunford and Johnson (1988). The following subsections provide a summary description of the biokinetic models and dose computation methods employed by GENMOD as implemented by the Hanford Internal Dosimetry Program.

\section{GENMOD BIOKINETIC MODELS}

The GENMOD internal dosimetry code employs the ICRP's Task Group on Lung Dynamics Model (TGLD 1966) for the respiratory tract and the Eve-Dolphin model for transport of material through the gastrointestinal (GI) tract (Eve 1966). A general systemic compartment model describes the uptake and transport of most elements. Exceptions are iodine and alkaline earths that are described by specific models, In addition, a modification of the general model permits evaluation of systemic excretion of plutonium using the empirically derived excretion function of Jones (1985). The models are diagrammed in Figures A.I through A.5 (from Dunford and Johnson 1988) and are described in the following subsections.

\section{$\underline{\text { Respiratory Tract Model }}$}

The respiratory tract model (Figure A.1) of the TGLD is employed as described by Dunford and Johnson (1988). A special inhalation class is described in the plutonium section for highly nontransportable compounds. Default model parameters for this "super $Y$ " class as well as for classes D, W, and $Y$ are provided in Table A.1. 


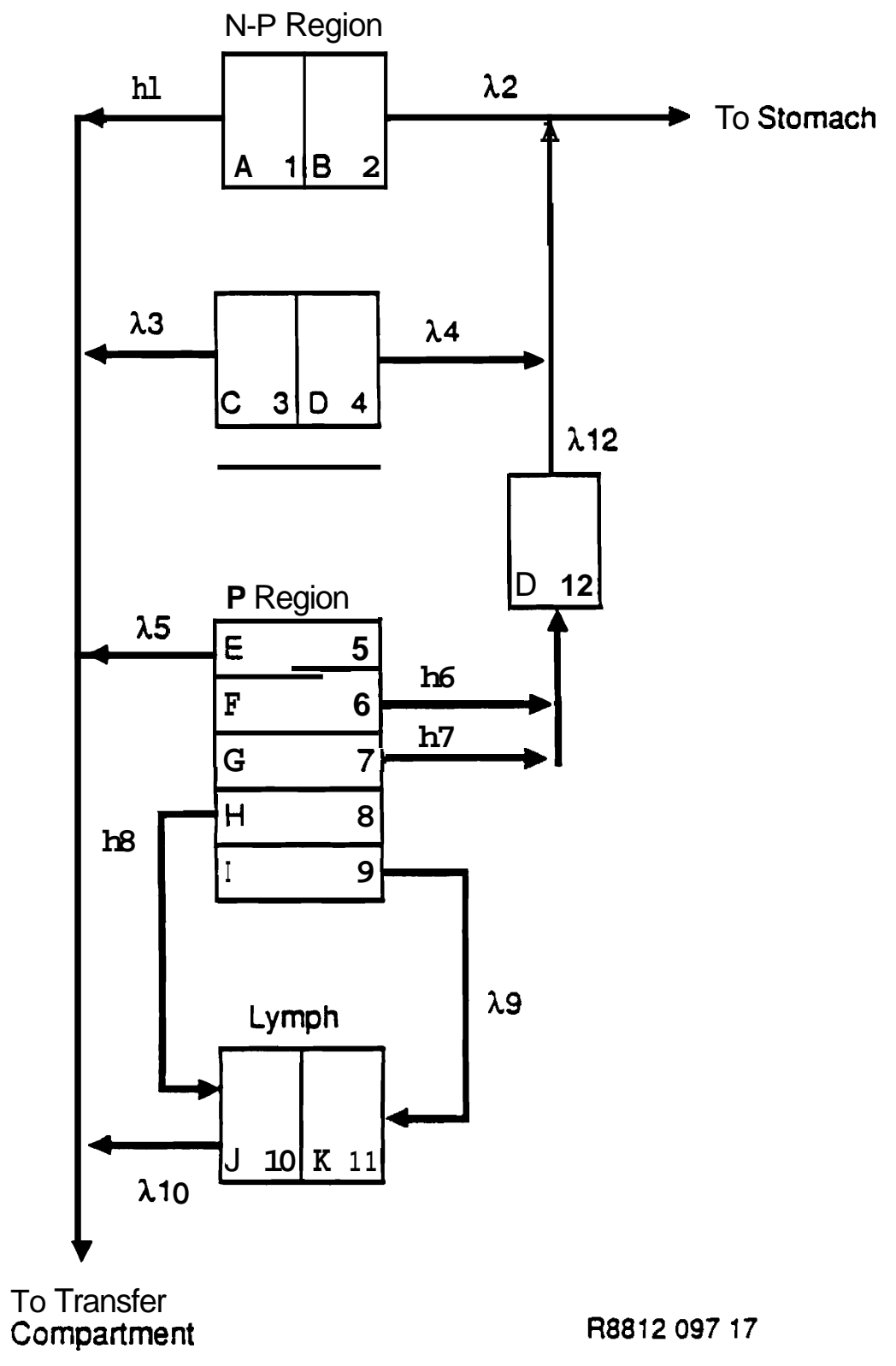

FIGURE A.1. GENMOD Lung Model (Compartments A through $\mathrm{H}$ to ICRP 30 Notation.) 


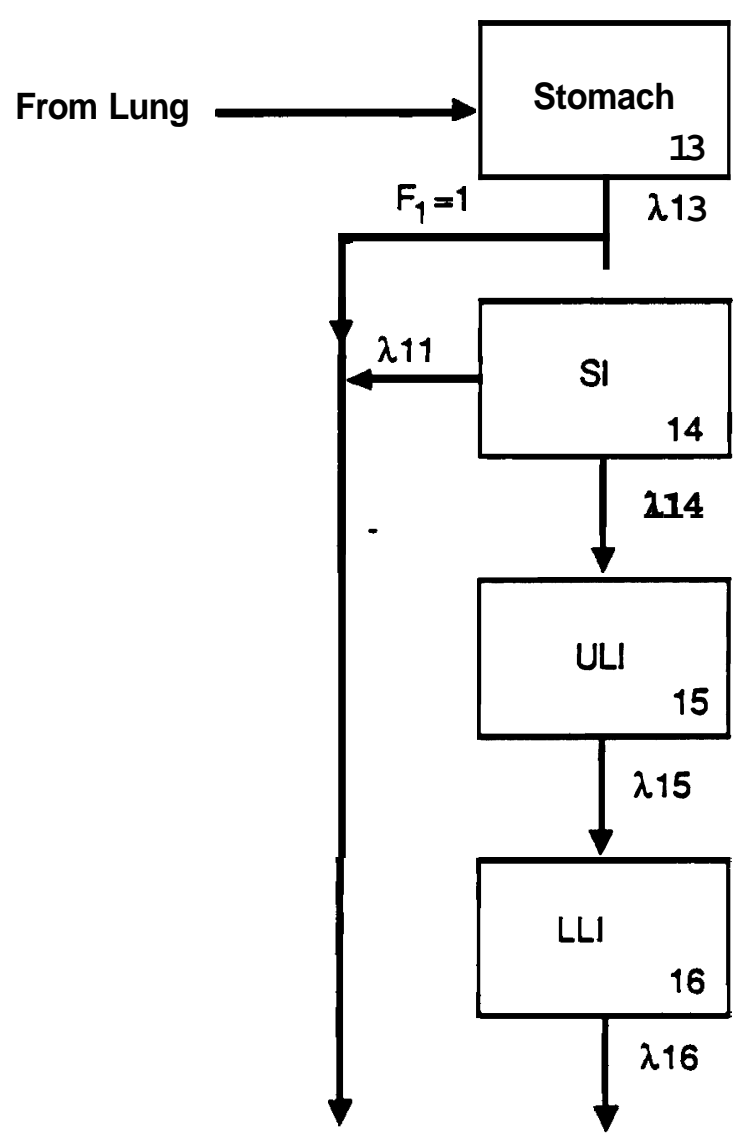

To Transfer Fecal Excretion

Compartment (Unabsorbed)

$\mathrm{R} 881209418$

FIGURE A.2. GENMOD GI Tract Model

A. 3 


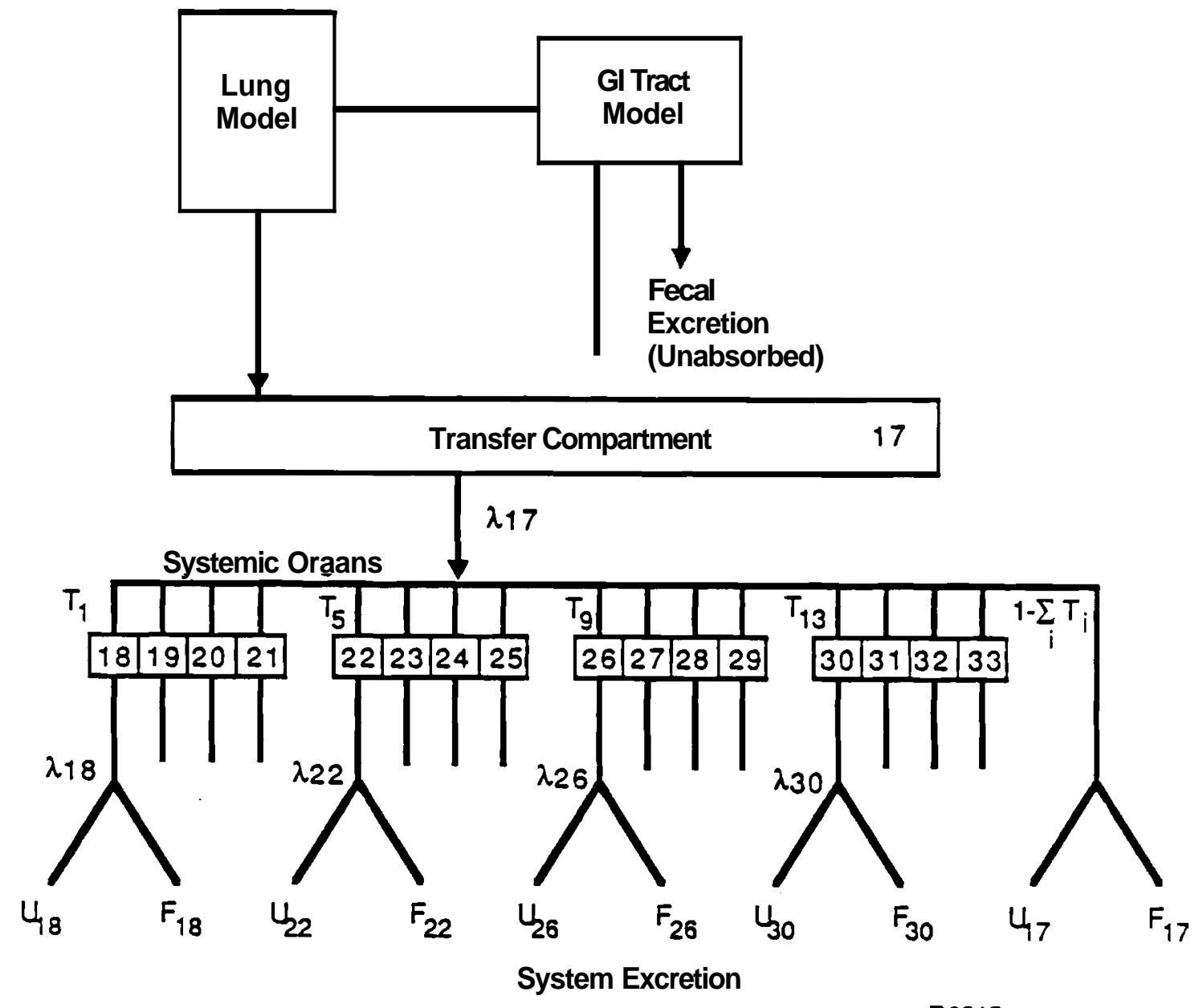

R881209419

FIGURE A.3. GEMOD General Model 


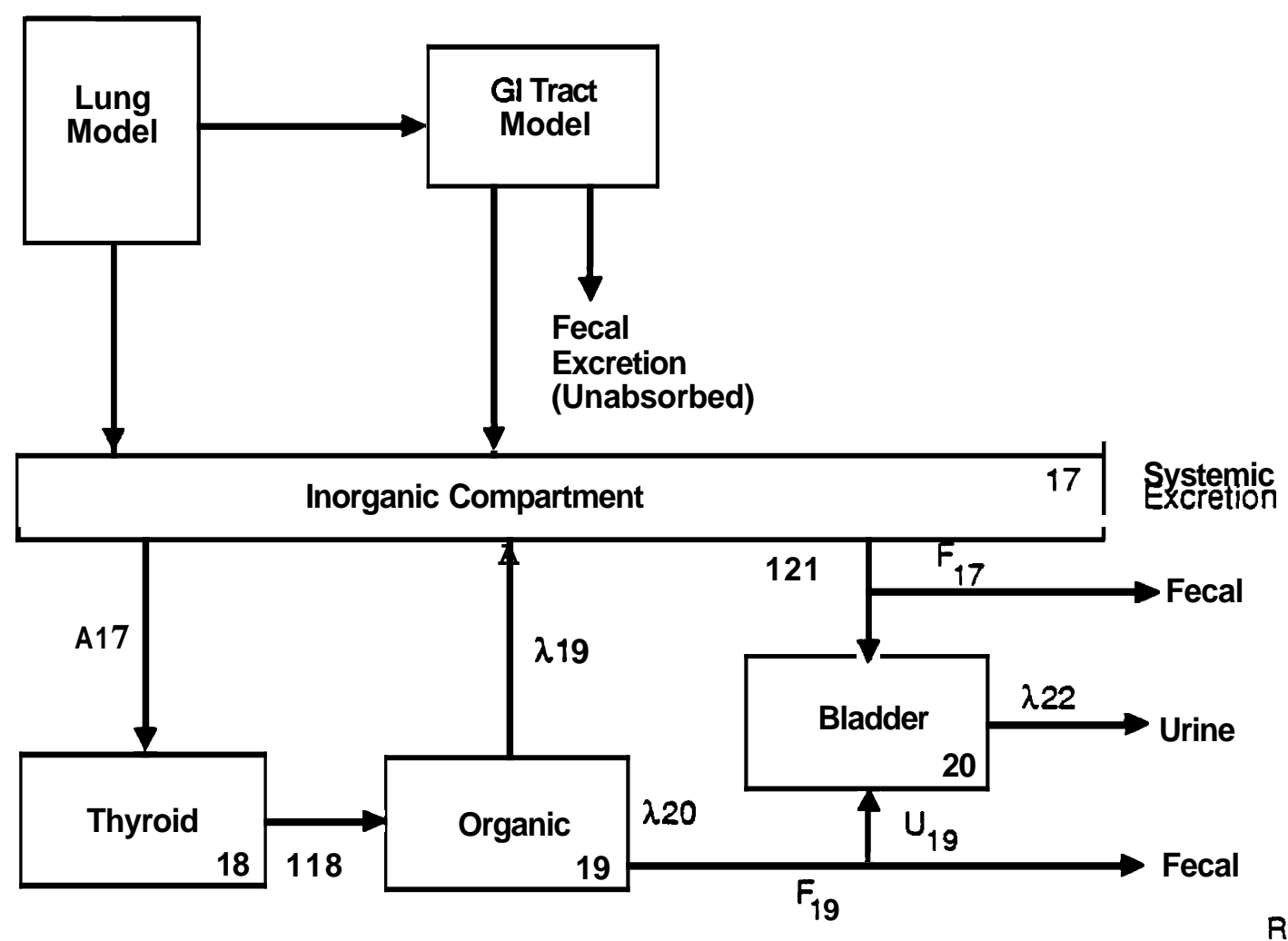

FIGURE A.4. GENMOD lodine Model 


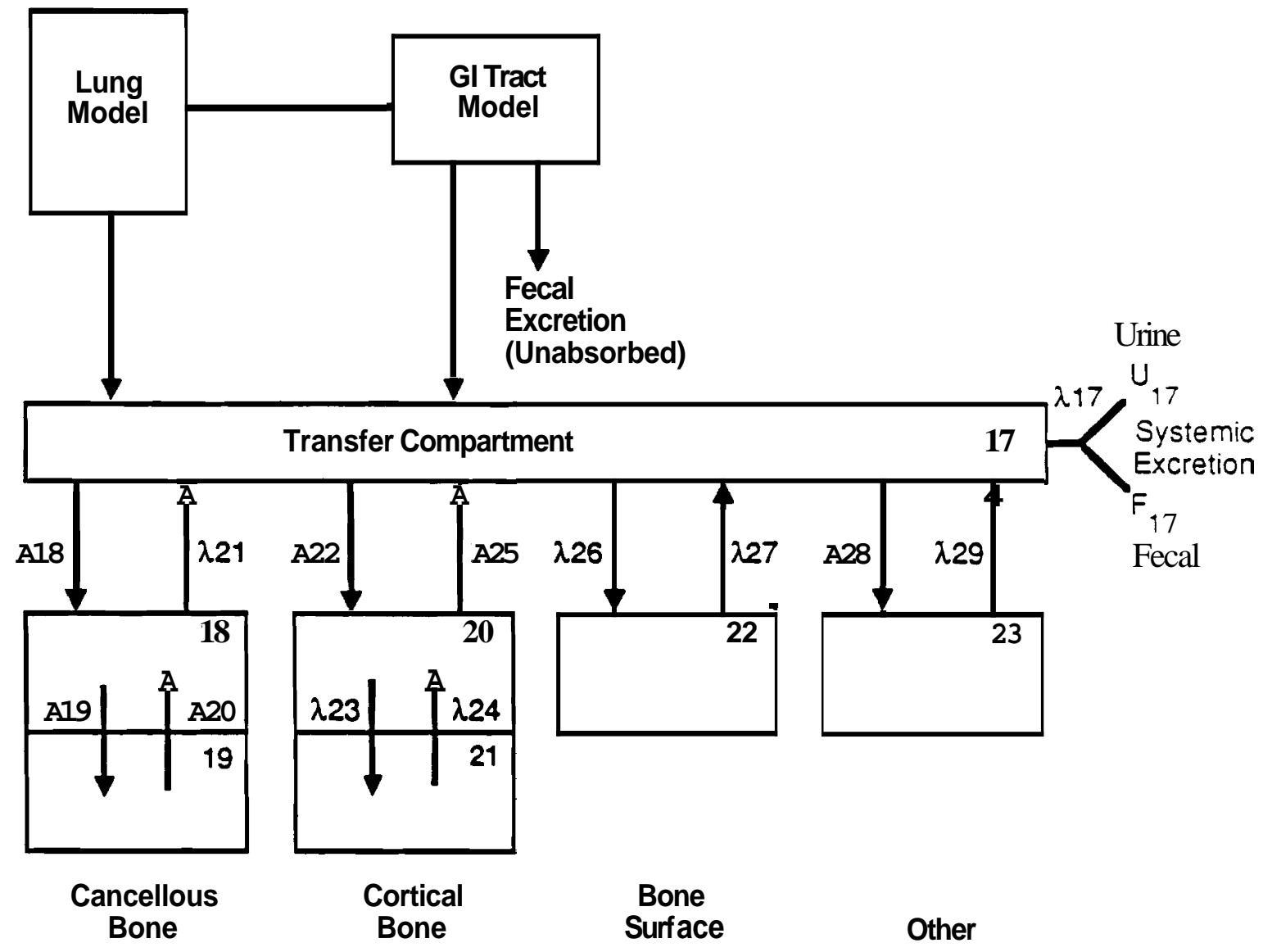

$R 881209420$

FIGURE A.5. GENMD Alkaline Earth Model 
TABLE A.1. GENMOD Parameters - Respiratory Tract Model

\section{Model Parameter (a)}

Regional Deposition

\section{ZNP \\ ZTB \\ ZP}

Input Name

Amount (1)
Amount(2)
Amount(3)
Amount (4)
Amount(5)
Amount(6)
Amount(7)
Amount (8)
Amount (9)
Amount (10)
Amount (11)
Amount(12)

Removal Rate $\left(\right.$ day $\left.^{-1}\right)$
Lung rate(1)

Lung rate(2)

Lung rate(3)

Lung rate (4)

Lung rate(6)

Lung rate(7)

Lung rate (8)

Lung rate(10)

Lung rate(12)
0.5

0.5

$0.95 \cdot 0.5$

$0.05 \quad 0.5$

0.8

0.0

0.0

0.2

0.0

-.

-.

0.0

0.15

0.4

0.4

0.05

0.0

$-$

0.0

$69.3 \quad 69.3$

69.3

69.3

3.43

-. $\quad 0.693$

- $\quad 1.39 \mathrm{E}-2$

$1.39 \quad 1.39 \mathrm{E}-2$

1.39

$\lambda_{4}$
1.73

69.3

3.47

-.

1.39E-2

$\lambda_{4}$ (c)

(c)

(c) Y Super Y 


\section{Gastrointestinal Tract Model}

The GI tract model (Figure A.2) documented by Eve (1966) is employed as described by Dunford and Johnson (1988). Table A.2 lists the parameters used by GENMOD to describe the fate of material entering the GI tract.

TABLE A.2. GENMOD Parameters - GI Tract Model

Model
Parameter (a)

Removal Rate

Stomach

$U L I(c)$
$\operatorname{LLI}(c)$
Name

Lung rate(13)

Lung rate (14)

Lung rate(11)

Lung rate(15)

Lung rate(16)
Value, $\operatorname{dav}^{-1}$

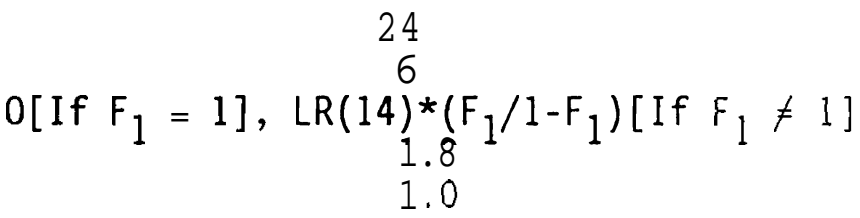

and the $F_{1}$ value is:

Inhalation Class

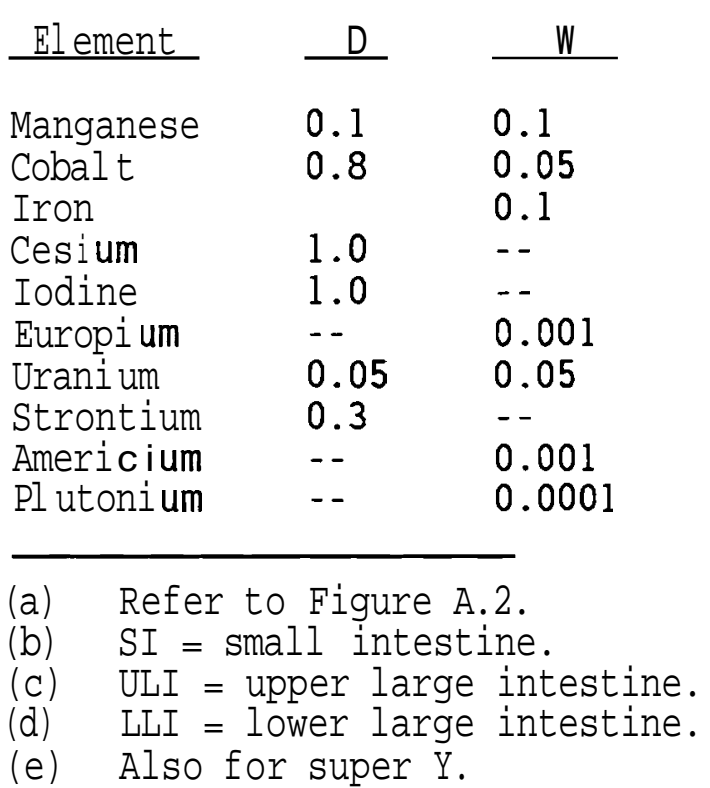

y (e) $\frac{\text { Ingestion }}{\text { Soluble Insoluble }}$

$\begin{array}{lll}-- & 0.1 & -- \\ 0.05 & 0.3 & 0.05 \\ 0.1 & -- & 0.1-- \\ & 1.0 & \\ -- & 1.0 & -- \\ 0.001 & 0.001 & -- \\ 0.002 & 0.05 & 0.002 \\ 0.01 & 0.3 & 0.01 \\ -- & 0.001 & 0.0005 \\ 0.00001 & 0.001 & 0.0001\end{array}$




\section{Systemic Compartment Model}

The general model (Figure A.3), iodine model (Figure A.4), and alkal ine earth model (Figure A.5) employed by GENMOD are described by Dunford and Johnson (1988). However, several changes in the parameters used by the models have been made as follows:

- The radioiodine model parameters were modified to provide an effective biological half-life for the thyroid of 120 days as recommended by the ICRP (1979).

- The general model parameters for plutonium were modified to reflect the uptake distribution and retention values recommended in ICRP 48 (1987).

- The ICRP 48 uptake-excretion pathways were eliminated and the pseudo-uptake retention function for plutonium described by Skrable (1987) was added to incorporate the plutonium uptake excretion function of Jones (1985) .

Tables A.3 through A.5 provide systemic compartment values for the general model, the iodine model, and the alkaline earth model, respectively.

\section{GENMOD DOSE EQUIVALENT COMPUTATIONS}

GENMOD is a dosimetry code that is based on ICRP 30; however, there are some differences in the way that dose equivalent computations are performed, as discussed in the following subsectiohs.

\section{Orqan Dose Equivalent}

GENMOD calculates organ dose equivalents due to activity deposited in source organs. Source organs may include the lung, pulmonary lymphatics, stomach contents, small intestine (SI), upper large intestine (ULI), lower large intestine (LLI), and specific sites of systemic deposition listed in ICRP 30 for the element. For material distributed uniformly throughout the body (i.e., if a site of deposition in ICRP 30 is given as "all other organs and tissues"), the source organ is considered to be the total body. Target organs include all source organs (except that the pulmonary lymph is considered to be part of the lung for dose calculation purposes) plus bone marrow if bone surfaces are a source tissue, and both bone marrow and bone 


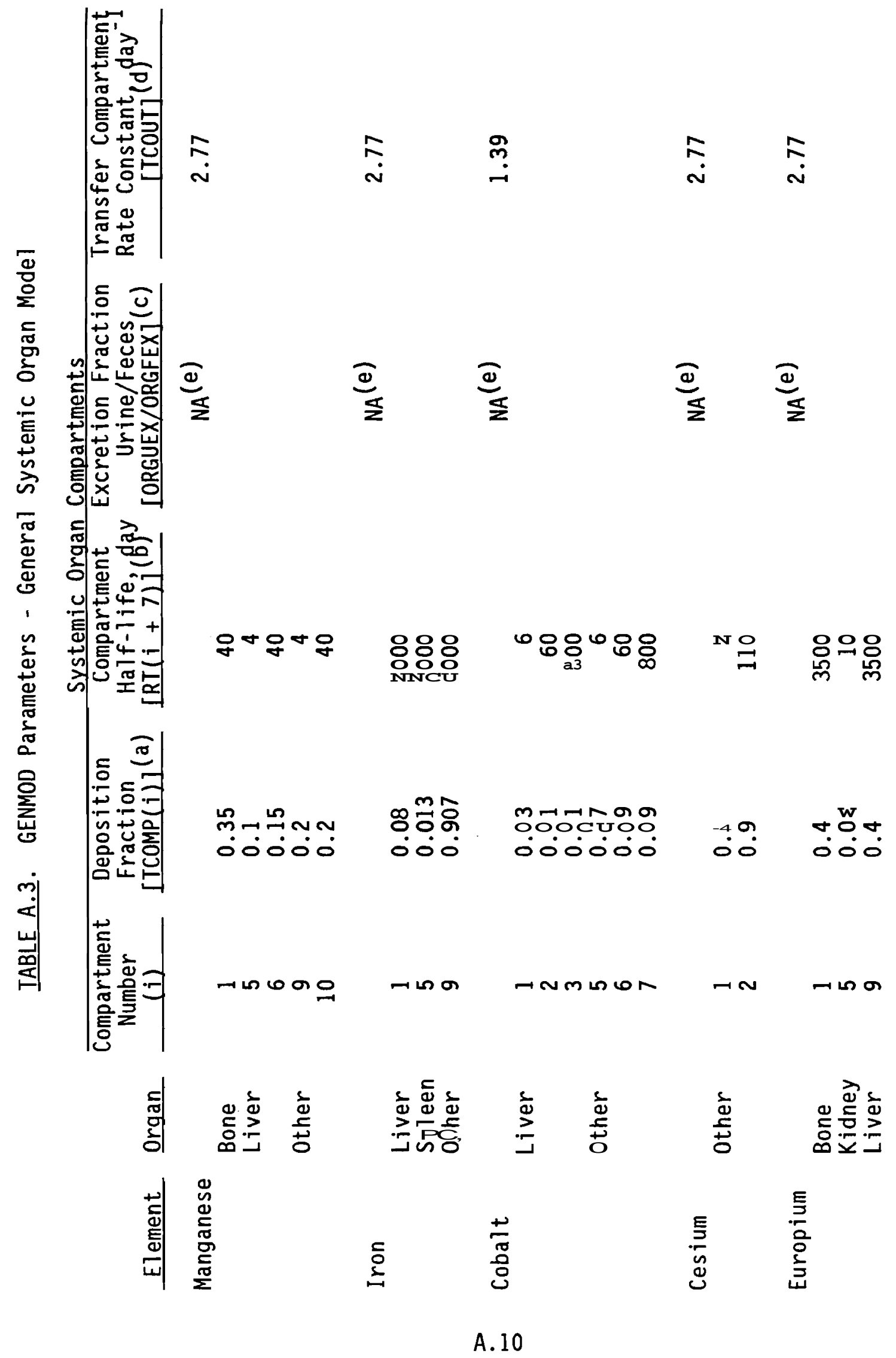


TABLE A.3. (contd)

Svstemic Orqan Compartments

\begin{tabular}{|c|c|c|c|c|c|c|}
\hline & & & & & & \\
\hline ement & rgan & $\begin{array}{c}\text { Compartment } \\
\text { Number } \\
\text { (i) }\end{array}$ & $\begin{array}{l}\text { Deposition } \\
\text { Fraction }(a) \\
{[\operatorname{TCOMP}(\mathbf{i})]}\end{array}$ & $\begin{array}{l}\text { Compartment } \\
\text { Half-1ife, day } \\
{[\text { RT }(\mathbf{i}+7)]}\end{array}$ & $\begin{array}{c}\text { Excretion Fraction } \\
\text { Urine/Feces } \\
\text { [ORGUEX/ORGFE] } \\
\text { [C) }\end{array}$ & $\begin{array}{l}\text { Transfer Compartment } \\
\text { Rate Constant } \\
\text { [TCOUT] (d) }\end{array}$ \\
\hline
\end{tabular}

Uranium

\begin{tabular}{lrlr} 
Bone & 1 & 0.2 & 20 \\
& 2 & 0.023 & 5000 \\
Kidney & 5 & 0.12 & 6 \\
\multirow{3}{*}{ Other } & 6 & 0.00052 & 1500 \\
& 9 & 0.12 & 6 \\
& 10 & 0.00052 & 1500
\end{tabular}

\subsection{7}

$$
1.0 / 0.0
$$

6

1500

1500

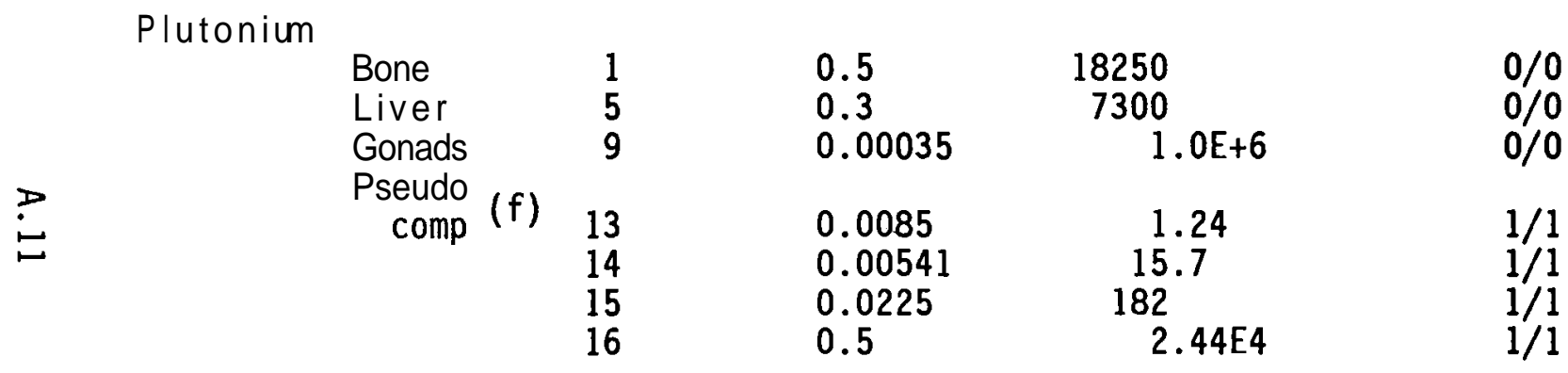

(a) Shown as $\mathrm{Ti}$ in Figure A.3.

(b) Shown as I $(\mathrm{i}+7)$ in Figure A.3.

(c) Shown as $U(i+7)$ and $F(i+7)$ in Figure A.3.

(d) Shown as 117 in Figure A.3.

(e) NA - not applicable.

(f) Pseudo compartment devised as a way to include Jones' empirically derived excretion function i $n$ model. To do so required setting the excretion from specified organ compartments to 0.0 , and from pseudo compartments to 1.0 . 
TABLE A.4. GEMOD Parameters - lodine Model

\begin{tabular}{|c|c|c|c|}
\hline \multirow{2}{*}{$\frac{\text { Model }}{\lambda_{17}}$} & \multirow{2}{*}{$\frac{\begin{array}{c}\text { Input } \\
\text { Name }\end{array}}{\operatorname{TCOMP(1)}}$} & \multicolumn{2}{|c|}{$\begin{array}{c}\text { Parameter } \\
\text { Value }\end{array}$} \\
\hline & & 0.87 & $\mathrm{day}^{-1}$ \\
\hline$\lambda_{18}$ & $\operatorname{TCOMP}(9)$ & 0.00866 & $\mathrm{day}^{-1}$ \\
\hline$\lambda_{19}$ & ORGUEX (26) & 0.052 & day $^{-1}$ \\
\hline$\lambda_{20}$ & $\operatorname{TCOMP}(5)$ & 0.0058 & $\mathrm{day}^{-1}$ \\
\hline$\lambda_{21}$ & TCOUT & 1.9 & day $\boldsymbol{*}$ \\
\hline$\lambda_{22}$ & ORGUEX (22) & 7.5 & $\mathrm{day}^{-1}$ \\
\hline$U_{17}$ & UEX & 1.0 & \\
\hline$U_{19}$ & $\mathrm{RT}(22)$ & 0.9 & \\
\hline $\mathrm{F}_{17}$ & $\mathrm{FEX}$ & 0.0 & \\
\hline$F_{19}$ & $\mathrm{RT}(26)$ & 0.1 & \\
\hline
\end{tabular}

(a) Refer to Figure A.4.

if bone volume is a source. If "other tissues" is listed as a source organ, then it is also considered to be a target organ.

Doses to target organs are calculated in the same way as in ICRP 30 with the following exception. The dose equivalent to "other tissues" does not include crossfire from activity deposited in other organs nor does it contribute to the dose received by other organs. That is, the dose equivalent to "other tissues" is solely due to self-irradiation. Source-to-target dose factors are listed by Snyder et al. (1974) and Dunning, Pleasant, and Killough (1977). Dose factors for activity deposited in "other tissues" are listed under "T-Body" in these publications. 
TABLE A. 5. GEMDD Parameters - Alkaline Earth Model

\begin{tabular}{|c|c|c|}
\hline Model & $\begin{array}{l}\text { Input } \\
\text { Name }\end{array}$ & $\begin{array}{l}\text { Parameter } \\
\text { Value }\end{array}$ \\
\hline $1_{17}$ & TCOUT & 3.44 \\
\hline $1_{18}$ & TCOMP (1) & 0.378 \\
\hline $1_{19}$ & $\operatorname{TCOMP}(2)$ & 0.00725 \\
\hline $1_{20}$ & $\mathrm{RT}(18)$ & 0.00479 \\
\hline $1_{21}$ & $\mathrm{RT}(19)$ & 0.00105 \\
\hline $1_{22}$ & $\operatorname{TCOMP}(5)$ & 0.516 \\
\hline $1_{23}$ & $\operatorname{TCOMP}(6)$ & 0.00136 \\
\hline $1_{24}$ & $R T(22)$ & 0.00214 \\
\hline $1_{25}$ & $\mathrm{RT}(23)$ & 0.000149 \\
\hline $1_{26}$ & $\operatorname{TCOMP}(9)$ & 2.66 \\
\hline $1_{27}$ & $\operatorname{RT}(26)$ & 0.403 \\
\hline $1_{28}$ & TСОМР (13) & 17.6 \\
\hline $1_{29}$ & $\operatorname{RT}(30)$ & 1.29 \\
\hline$U_{17}$ & UEX & 0.8 \\
\hline$F_{17}$ & FEX & 0.2 \\
\hline
\end{tabular}

(a) Refer to Figure A.5.

(b) Units are inverse days except UEX and FEX are unitless. 


\section{Effective Dose Equivalent (a)}

The total stochastic risk incurred from the irradiation of body tissues following intakes of radionuclides is considered to be proportional to the effective dose equivalent. The effective dose equivalent is defined in DOE 5480.11 (1988) as:

$$
H_{E}=\sum_{1} w_{T} H_{T}(r e m)
$$

where $H_{T}$ is the dose equivalent for an organ or tissue $T$ from all internal sources and $w_{T}$ is a weighting factor representing the ratio of the risk arising from irradiation of tissue $\mathrm{T}$ to the total risk when the whole body is irradiated uniformly.

The weighting factors $\left(\boldsymbol{w}_{\mathrm{T}}\right)$ are defined in DOE 5480.11 (1988) as:

$\begin{array}{lc}\text { Organ or Tissue } & \text { Weighting Factor } \\ \text { Gonads } & 0.25 \\ \text { Breasts } & 0.15 \\ \text { Red bone marrow } & 0.12 \\ \text { Lungs } & 0.12 \\ \text { Thyroid } & 0.03 \\ \text { Bone surfaces } & 0.03 \\ \text { Remainder } & 0.30\end{array}$

In the above table, "remainder" means the five other organs with the highest dose and the weighting factor for each such organ is 0.06 . Organs considered in the "remainder" category include the following:

(a) The effective dose equivalent, as defined in DOE 5480.11 (1988), includes contributions from internally deposited radionuclides and from external exposure to radioactive material and/or radiationgenerating devices. This guide addresses the assessment of dose from internally deposited radionuclides and thus the term "effective dose equivalent" when used here refers to the internal component only. 


$\begin{array}{lll}\text { Muscle } & \text { Stomach wall } & \text { Kidneys } \\ \text { Liver } & \text { Small intestine wall } & \text { Pancreas } \\ \text { Spleen } & \text { Upper large intestine wall } & \text { Uterus } \\ \text { Thymus } & \text { Lower large intestine wall } & \text { Adrenal s } \\ \text { Bladder wall } & & \end{array}$

According to DOE 5480.11 (1988), the skin, lens of the eyes, and extremities are specifically excluded from the list of organs to be considered in the calculation of effective dose equivalent from internally deposited radionuclides.

The GENMOD approach to the computation of effective dose equivalent differs from the ICRP 30 method by summing the effective dose equivalent contributions from activity in source organs rather than by summing the weighted target organ dose equivalents.

Another difference is the way that activity deposited uniformly throughout the body is handled, as described in the following summary of the GENMOD procedure.

1. Source organs are identified. The source organs always include the lung, pulmonary lymphatics, stomach contents, SI contents, UU contents, and the U contents. The organs identified as systemic deposition sites in the metabolic model are also included. If the model predicts that a portion of the uptake will be deposited throughout the body, then the source organ for this deposition is identified as the total body.

2. A factor that converts the activity in a source organ to effective dose equivalent is computed for each of the identified source organs. These factors, called S-prime factors (Johnson, Stewart, and Carver 1979), are calcul ated as follows:

$$
S_{S^{\prime}}=\sum_{T} w_{T} S_{S T}
$$

where $S_{S}{ }^{\prime}$ is the sum of the weighted dose equivalents to target organs $T$ from activity deposited in source organs $S$. The $S_{S T}$. factors are SEE(T-S) values converted into units of dose equivalent per unit cumulated activity (Sv/Bq-day). The weighting factors are as given previously. Thus, each $S_{S}^{\prime}$ factor is based on the sum of the contributions to each of the six "risk organs" and the five highest remaining organs. This procedure is applied to the calculation of $S_{S}$ ' values for all source organs except for the 
source "total body." In this case, the calculation is performed by considering self-irradiation only, and by applying a weighting factor of 1.0 .

3. The effective dose equivalent, $H$, is computed by summing the effective dose equivalent contributions from each source organ as follows:

$$
H_{E}=\sum_{T} S_{S}^{\prime} Z Q_{S}(t) d t
$$

where $R Q_{S}(t) d t$ is the cumulated activity in source organ $S$ over the time period of interest.

The ICRP and GEMOD approaches to the calculation of effective dose equivalent show excellent agreement when activity is essentially all deposited in a few primary sites such as for plutonium, uranium, and strontium. Agreement is also very good for radionuclides that distribute uniformly throughout the body; however, in these cases the effective dose equivalents computed by GEMOD generally exceed those computed using the ICRP procedure. As example comparisons, the committed effective dose equivalent calculated by GEMOD and ICRP 30 are in perfect agreement for inhalation of class $D{ }^{106} \mathrm{Ru}$; however, the GENMOD-computed dose exceeds the ICRP 30 dose by $3 \%$ for inhaled, class D ${ }^{137} \mathrm{Cs}$ and by $16 \%$ for class $W^{60} \mathrm{Co}$. The differences are attributed to the application of the $10 \%$ rule in ICRP 30 to eliminate some target organs from the effective dose equivalent computation, and to GENMOO's use of a weighting factor of 1.0 for activity deposited in "other organs and tissues of the body. "

\section{REFERENCES}

Dunford, D. W., and J. R. Johnson. 1988. GENOD - A Program for Internal Dosimetry Calculations. AECL-9434, Chalk River Nuclear Laboratories, Chalk River, Ontario, Canada.

Dunning, D. E. Jr., J. C. Pleasant, and G. G. Killough. 1977. SFACTOR: A Computer Code for Calculating Dose Equivalent to a Tarqet Orqan per Microcurie-Day Residence of a Radionuclide in a Source Orqan. ORNL/NUREG/TM-85, Oak Ridge National Laboratory, Oak Ridge, Tennessee. 
Eve, I- S. 1966. "A Review of the Physiology of the Gastro-Intestinal Tract in Relation to Radiation Doses from Radioactive Materials." Health Physics $12: 131$.

International Commission on Radiological Protection (ICRP). 1979. Limits for Intakes of Radionuclides bv Workers. ICRP Publication 30, Part 1 and Supplement, Pergamon Press, New York, New York.

International Commission on Radiological Protection (ICRP). 1986. The Metabolism of Plutonium. and Related Elements. ICRP Publication 48, Pergamon Press, New York, New York.

Johnson, J. R., and M. B. Carver. 1981. "A General Model for Use in Internal Dosimetry." Health Phvsics 41:341-348.

Johnson, J. R., E. G. Stewart, M. B. Carver. 1979. Committed Effective Dose Eauivalent Conversion Factors for Intakes of Selected Radionuclides bv Infants and Adults. AECL-654, Chalk River Nuclear Laboratories, Chalk River, Ontario, Canada.

Jones, S. R. 1985. "Derivation and Validation of a Urinary Excretion Function for Plutonium Applicable Over Tens of Years Post Intake. " Radiation Protection Dosimetrv 11(1):19-27.

Skrable, K. W., L. C. Sun, G. E. Chabot, C. S. French, and T. R. La Bone. 1987. "Pseudo Uptake Retention Functions for the Whole Body for Estimating Intakes from Excretion Bioassay Data. " Radiation Protection Dosimetry $18(3): 133-139$

Snyder, W. S., M. R. Ford, G. G. Warner, and S. B. Watson. 1974. A Tabulation of Dose Eauivalent per Microcurie-Dav of Source and Tarqet Orqans of an Adult for Various Radionuclides. ORNL-5000, Vol. 1 and 2, Oak Ridge National Laboratory, Oak Ridge, Tennessee.

Task Group on Lung Dynamics. 1966. "Deposition and Retention Models for Internal Dosimetry of the Human Respiratory Tract." Health Phvsics 12:173.

U.S. Department of Energy (DOE). 1988. Radiation Protection for Occupational Workers. DOE 5480.11, Washington, D.C. 



\section{APPENDIX B}

\section{ORGANS OR TISSUES OF CONCERN}





\section{APPENDIX B}

\section{ORGANS OR TISSUES OF CONCERN}

The U.S. Department of Energy has established limiting values for occupational exposure to radiation in DOE 5480.11 (1988). These values include a limit on dose to individual organs or tissues to prevent deleterious nonstochastic effects, and a limit on the effective dose equivalent based on the risk of stochastic effects. Section $9 . \mathrm{m}$ of the Order requires the recording of annual and committed dose equivalents to organs and tissues of concern as well as the annual and committed effective dose equivalent. However, the Order does not explicitly state which organs and tissues are to be considered in the calculation of effective dose equivalent, nor does it state what constitutes an organ or tissue of concern.

For the purposes of performing internal dose assessments to determine compliance with limiting values for occupational dose, and for complying with recording and reporting requirements in the Order, organs and tissues considered in the evaluation of effective dose equivalent and as "organs/tissues of concern" are those listed as potential target organs in Publication 30 of the International Commission on Radiological Protection (ICRP 1979). As noted below, doses received by localized tissues are not included in either the assessment of effective dose equivalent or in the assessment of dose equivalent to organs and tissues of concern.

Practices for recording doses to "organs and tissues of concern" are defined in the Hanford Internal Dosimetry Program Manual (PNL-MA-552). (a) Candidate organs are those identified above. Chapters of this technical basis document provide organ dose factors for specific radionuclides, based on intake and on cumulated activity at deposition sites for organs considered to most likely meet the recording criteria in PNL-MA-552. In cases involving

(a) Pacific Northwest Laboratory. 1989. Hanford Internal Dosimetry Program Manual. PNL-MA-552, Richland, Washington. 
relatively small effective dose equivalents, there may be no single organ that meets the recording criteria, whereas for a very significant exposure, several organs may qualify.

Effective dose equivalent is calculated by summing, over specified tissues, the products of the dose equivalent in a tissue and the weighting factor for the tissue. Appendix A describes the criteria used for determining the organs contributing to effective dose equivalent. Chapters on specific radionuclides provide dose factors that can be used to evaluate effective dose equivalent from intake or from cumulated activity (in $\mathrm{nCi}$-day) in source organs. Where assessment of internally deposited activity is readily accomplished by in vivo measurements, effective dose equivalent factors are shown for cumulated activity in the lung, as well as for cumulated activity in the remainder of the body. The total effective dose equivalent is calculated by summing the contributions from these two sources.

Intakes of radionuclides via wounds may result in the irradiation of local tissues at the wound site, as well as regional lymph nodes that drain the wound region. Because of their small mass, the absorbed dose to the regional lymph nodes may greatly exceed that to other tissues. Evidence from studies of experimental animals suggests that the lymph nodes are not primary sites for development of radiation-induced malignant disease (Nenot and Stather 1979). For this reason, there has been no attempt by either the ICRP (1979) or the BEIR Committee (National Research Council 1988) to derive stochastic risk estimates for lymphatic tissue. Similarly, the irradiation of local tissues at the wound site is not considered to carry significant risk of carcinogenesis.

Concentrated activity in such localized sources can be expected to result in relatively high doses and cell death within a limited area, but unless this area comprises more than a minor fraction of the organ/tissue, there will likely be no observable nonstochastic effect at any dose. Assessment of organ or tissue dose equivalent from highly localized sources, made by averaging the energy deposited in the organ over the organ mass, is not a relevant measure for comparison to the limiting values for assessed dose based on nonstochastic effects. Furthermore, in most situations, it is not possible 
to determine the actual mass of affected tissue for computing the absorbed dose. Because the absorbed dose is highly nonuniform over the tissue and only a limited number of cells within the organ/tissue are affected, the use of dose equivalent for assessing this localized exposure is not valid.

For these situations, the Hanford Internal Dosimetry Program will estimate the quantity of radionuclide(s) locally deposited and the projected retention half-time. These estimates become part of the individual's radiation protection record, but are not used for determining compliance with either the stochastic or nonstochastic limits. This approach is analogous to the approach required in DOE 5480.11 for irradiation of limited areas of the skin.

\section{REFERENCES}

International Commission on Radiological Protection (ICRP). 1979. Limits for Intakes of Radionuclides by Workers. ICRP Publication 30, Part 1, Pergamon Press, New York.

National Research Council. 1988. Health Risks of Radon and Other Internally Deposited Alpha-Emitters. BEIR IV, National Academy Press, Washington, D.C.

Nenot, J. E., and J. W. Stather. 1979. The Toxicity of Plutonium, Americium, and Curium. Commission of the European Communities, Pergamon Press, Oxford, Engl and.

U.S. Department of Energy (DOE). 1988. Radiation Protection for Occupational Workers. DOE 5480.11, Washington, D.C. 


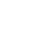




\section{APPENDIX C}

\section{STATISTICAL METHODS FOR INTERPRETING}

BIOASSAY DATA 

APPENDIX C

\section{STATISTICAL METHODS FOR INTERPRETING BIOASSAY DATA}

Inevitably statistical methods must be applied to bioassay data to provide meaning to the data and to use the data in models. The more important statistical methods used by the Hanford Internal Dosimetry Program are described below.

\section{DECISION LEVEL AND MINIMUM DETECTABLE AMOUNI}

Three fundamental questions in dealing with bioassay data are 1) when does a sample result indicate the presence of something (the analyte)? i.e., when is the analyte detected? 2) what is the overall capability of the bioassay method for continual assurance of detection of the analyte?, and 3) when does a sample result indicate the presence of analyte above the natural background? The third question is important mostly for uranium in excreta and is discussed in the section on uranium. Concerning the first two questions, the Hanford Internal Dosimetry Program follows the concepts of decision level (also called critical level) and minimum detectable amount (also called detection level or lower level of detection) as described by Currie (1968, 1984), Brodsky (1986), the American National Standards Institute $^{(a)}$, and many others.

The decision level, $L_{c}$, is the parameter that is used to answer question 1) above. The $L_{c}$ is dependent on the probability of obtaining false positive results (or probability of a type I error) that one is willing to accept. For indirect bioassay samples, a $5 \%$ probability of false positives is used to calculate the $L_{c}$. The $L_{c}$ is calculated from the results of analyses of blank

(a) American National Standards Institute (ANSI). 1987. Performance Criteria for Radiobioassav. Draft ANSI Standard N13.30, New York, New York. 
samples. (b) Because the actual $L_{c}$ value for a given radionuclide analysis will vary slightly over time, a single value is then chosen to define "positive" samples. This value, called positive level, is set to be slightly greater than the temporal fluctuations of the short-term $L_{c}$ values and is a number that is convenient to use by all concerned parties. Any sample result that is equal to or greater than the positive level is considered positive, i.e., the analyte has been detected. It is inherent in this method that when dealing with large numbers of samples many samples containing no activity will be declared positive, those being somewhat less than $5 \%$ of the total unless a subtle bias exists in the population of samples.

The minimum detectable amount (or activity), MDA is the parameter that answers question 2) above. The MDA is a function of the probabilities of both false positive and false negative (type II error) results. For indirect bioassay results, the probability of each kind of error is set at 5\%. The MDA is determined annually from analysis of blank samples. Annual MDAs are compared with values set by contract with the bioassay laboratory. (The MDAs must be less than contractual detection levels or corrective action is immediately undertaken.) It is the contractual detection levels that are referenced throughout this document because only the contractual detection levels are enforceable and are generally applicable over long periods of time. At any time though, actual MDAs are usually somewhat lower than the contractual detection levels quoted in this document.

For in vivo measurements, because each person provides a different background spectrum resulting from different amounts of natural radionuclides, detectability is determined using information from both blank subjects (with normal activities of ${ }^{40} \mathrm{~K}$ ) and from the person being counted. Background counts in the region of interest in the photon energy spectrum are determined by measuring the counts in nearby channels. From a group of blank subjects, the ratio between the counts in the region of interest and the counts in nearby channels is determined. This ratio is then applied to the counts in the nearby channels of the spectrum from the person being counted to determine

(b) Blank samples are those that are equivalent to an actual sample but are known not to contain the analyte (uranium excepted). 
the background in the region of interest. The standard deviation of the counts in the nearby channels is also calculated. If the total counts in the region of interest are greater than the background counts plus $K$ times the standard deviation, then a photopeak in the region of interest is considered "detected." $\mathrm{K}$ is 3 for spectra obtained using germanium detectors and 4.6 for spectra obtained using $\mathrm{NaI}$ detectors. Except at very low energies, the ratio of nearby-channel counts to background-region-of-interest counts is considered to be 1 for spectra obtained using germanium detectors. Consideration is given to the presence or absence of accompanying photopeaks and possible interference from other radionuclides before a radionuclide is considered "detected." Application of complete Currie-type statistics to in vivo counting is under development.

\section{NORMALIZATION OF INDIRECT BIOASSAY DATA}

Indirect bioassay data may be normalized differently according to the type and processing category of the sample. Table C.I describes the types of samples and Table C.2 describes the processing categories.

TABLE C.1. Types of Indirect Bioassay Samples

$\underline{\text { Media }}$ Description

Urine Simulated 24-hour collection. Total excretion between just before sleeping and just after rising on 2 consecutive days. Not collected at work (NCRP 1987).

Urine Total 24-hour collection, including col lection at work if necessary.

Urine Simulated 12-hour collection. Total excretion between just before sleeping and just after rising; one time, not at work.

Urine Spot sample. A single voiding.

Feces Single voiding. 


\section{TABLE C.2. Processing Categories}

Name

Routine

Priority

Expedite

Emergency
Description

Longest turnaround time, most sensitive analysis techniques. Used for most routine samples and samples for which turnaround time is not critical.

Shorter turnaround time but same sensitivity as routine processing. Generally used for sampling terminating workers and for following up on potential intakes.

Three-day turnaround time, intermediate sensitivity. Used for follow-up on a potential intake, usually shortly after the intake.

Turnaround in a few hours, least sensitivity. Used for rapid indication of the seriousness of an intake.

Generally, the urine data are normalized to total 24-hour excretion. Provided the sample is collected properly, a total or simulated 24-hour urine sample result is used as is; no further normalization is done. A proper 12-hour sample result is normal ized by doubling the result.

If it is suspected that a sample has not been provided according to instructions, several approaches are taken. A routine-category sample that is supposed to contain 24-hour excretion is not analyzed if the volume is less than $500 \mathrm{~mL}$ because the volume is too small to represent a true 24-hour collection. The worker is asked to provide another sample. The minimum volume for other routine-category samples and for all priority-category samples is $20 \mathrm{~mL}$. When a sample is above the cutoff for analysis but is believed not to represent 24-hour (or 12-hour) excretion, the result may be 1) normalized to 24-hour based on information from the provider, 2) ignored, 3) normalized by volume to 24-hour excretion, or 4) normalized by creatinine to 24-hour excretion. To normalize by volume, $1400 \mathrm{~mL}$ for males and $1000 \mathrm{~mL}$ for females (from Reference Man [ICRP 19741) should be used for 24-hour excretion unless the person-specific daily excretion rate is known. Normalization by creatinine should be used only if the person-specific daily creatinine excretion is establ ished. 
The one exception to the above discussion concerns analysis for tritium in urine. Spot urine samples are collected, and the data are reported and used directly in units of activity per volume (see Section 2.0).

Concerning fecal samples, total fecal excretion over a specified period of time (e.g., 3 or 5 days) is obtained. If it appears that the person has not followed instructions, attempts are made to determine what portion of the time is represented by the samples collected. As a last resort, a single voiding is assumed to represent 24-hour excretion. (See also Appendix E.)

\section{COMPARISON OF RETENTION OR EXCRETION FUNCTIONS TO DATA}

Generally, following an acute intake, more than one datum of a similar nature (e.g., urine results) is obtained, and the appropriate retention or excretion function is fit to the data. Two options for fitting the function to the data are used (1 isted in order of preference]: 1) weighted leastsquares fit, 2) unweighted least-squares fit), and other methods are being investigated.

The weighted least-squares fit should be used when two results of the measurement process are known--the result itself (whether zero, negative, or whatever), $\mathbf{x}_{\mathbf{j}}$, and its variance, of--and when the variances are all determined in the same manner. The weighting factor is the inverse of the sum of the variances. The intake is given by

$$
I=\left[\sum_{i=1}^{n} \frac{x_{i} r_{i}}{\sigma_{i}^{2}}\right] /\left[\sum_{i=1}^{n} \frac{r_{i}^{2}}{\sigma_{i}^{2}}\right]
$$

where $r_{j}$ is the value of the fractional retention or excretion function at the same time after intake as the sample result $\mathbf{x}_{\boldsymbol{j}}$ (Bevington 1969). Use of the weighted least-squares fit avoids having the calculation of intake or uptake dominated by a few large data points that may have poor precision, such as a hastily analyzed urine sample collected shortly after an intake.

If the variances are unknown, are known to be equal, or were determined differently (such as counting uncertainty versus total propagated

\section{C.5}


uncertainty), then the unweighted least-squares fit should be used. The unweighted least-squares fit is represented by Equation (C. 1) when a11 variances are set equal to one.

Data that are listed only as "less than" some value are difficult to use in a mathematical fitting technique. The Hanford Internal Dosimetry Program arbitrarily sets the value for the measurement as one-half of the less-than value for use in least-squares fitting techniques. This does not work well if too many of the data are less-than values. If there are many less-than values and a few wel1-known data, then the evaluator may need to use only the we17known data in the least-squares fitting technique, making sure that the best fit does not seem unreasonable with regard to the many less-than data.

In all cases, outliers, or data that are not relevant to the equation being fit, should not be included in a fitting technique. Examples would include urine data influenced by diethylene triamine penta acetate (DTPA) therapy or a datum with a very high less-than result. The assessment should document which data are being ignored and why.

\section{IREATMENT OF RECOUNIED DATA BEFORE USING IT WITH ONCE-COUNIED DATA}

Results from samples that have been recounted should not be used directly with results from once-counted samples in analysis programs such as PCPLOT. The best estimate of the mean value of the recounted sample and the best estimate of the uncertainty of the mean value need to be determined first so that each sample has only one value. The mean value $(\bar{x})$ should be determined by the formula for a weighted average:

$$
\left.\overline{\mathbf{x}}=\sum_{\mathbf{i}=}^{\mathrm{n}} \frac{\mathrm{x}_{\mathbf{i}}}{\mathbf{S}_{\mathbf{i}}{ }^{2}} \div \sum_{\mathbf{i}=}^{n} \frac{1}{\mathbf{s}_{\mathbf{i}}^{2}} \quad \text { (n is usually } 2 \text { or } 3\right)
$$

where $x_{j}$ are the results from the recounts and $S_{j}$ are the total propagated uncertainties.

The best estimate of the uncertainty of the mean value should be determined by the formula for a weighted uncertainty: 


$$
\bar{s}=\left[1 \div\left[\sum_{i=1}^{n}\left[\frac{1}{s_{i}^{2}}\right]\right)\right]^{1 / 2}
$$

This approach provides consistency in the way recounted sample data are used in dose assessments, and prevents recounted data from acquiring unwarranted weight relative to once-counted data for curve-fitting purposes.

\section{REFERENCES}

Bevington, P. R. 1969. Data Reduction and Error Analysis for the Physical Sciences, pp. 69-73. McGraw-Hill Book Company, New York, New York.

Brodsky, A. 1986. Accuracy and Detection Limits for Bioassay Measurements in Radiation Protection. NUREG-1156, U.S. Nuclear Regulatory Commission, Washington D.C.

Currie, I. A. 1968. "Limits for Qualitative Detection and Quantitative Determination." Anal ytical Chemistry 40(3):586-593.

Currie, L. A. 1984. Lower Limit of Detection: Definition and Elaboration of a Proposed Position for Radioloqical Effluent and Environmental Measurements. NUREG/CR-4007, U.S. Nuclear Regulatory Commission, Washington D.C.

National Council on Radiation Protection and Measurements (NCRP). 1987. Use of Bioassay Procedures for Assessment of Internal Radionuclide Deposition. NCRP Report No. 87, Bethesda, Maryland. 



\section{APPENDIX D}

\section{ICRP LUNG MODEL}





\section{APPENDIX D}

\section{ICRP LUNG MODE}

Figure D.1 presents the International Commission on Radiological Protection (ICRP) lung model as published in ICRP 30 (1979). The deposition fractions, $D_{N-P}, D_{T-B}$, and $D_{p}$, as given in Figure $D .1$ apply to an aerosol with an activity median aerodynamic diameter (AMAD) of $1 \mu \mathrm{m}$. Figure D.2, also from ICRP 30, shows how the deposition fractions vary as a function of AMAD. Deposition fractions for particle sizes other than $1 \mu \mathrm{m}$ may be estimated from Figure D.2 or may be obtained from Table D. 1. 


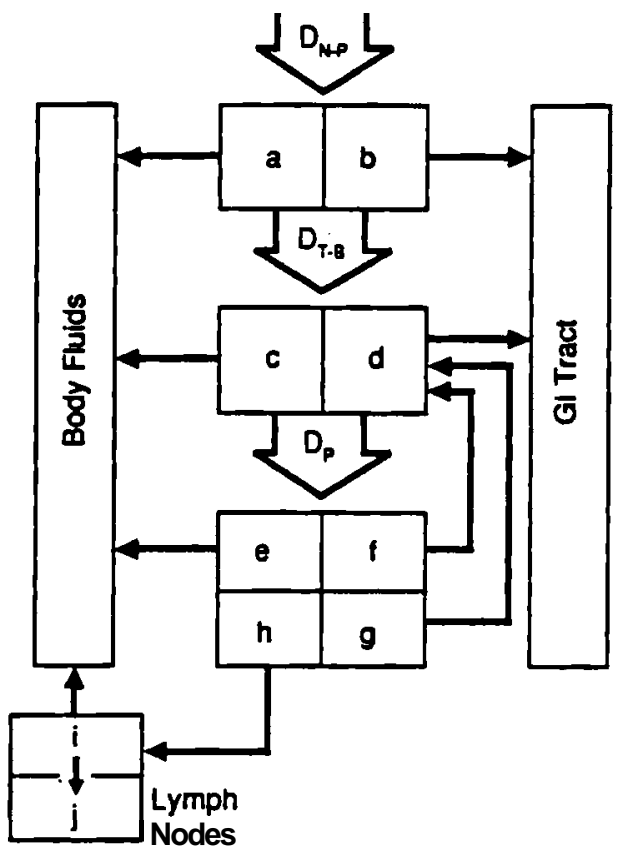

\begin{tabular}{|c|c|c|c|c|c|c|c|}
\hline \multirow{3}{*}{ Region } & \multirow{3}{*}{ 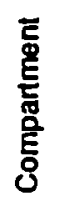 } & \multicolumn{6}{|c|}{ Class } \\
\hline & & \multicolumn{2}{|c|}{$D$} & \multicolumn{2}{|c|}{$w$} & \multicolumn{2}{|c|}{$Y$} \\
\hline & & $\begin{array}{c}\mathrm{T} \\
\text { Days }\end{array}$ & $F$ & $\begin{array}{c}\mathrm{T} \\
\text { Days }\end{array}$ & $F$ & $\begin{array}{c}\mathrm{T} \\
\text { Days }\end{array}$ & $F$ \\
\hline $\begin{array}{c}N-P \\
\left(D_{N-\rho}=0.30\right)\end{array}$ & $\begin{array}{l}\mathbf{a} \\
\mathbf{b}\end{array}$ & $\begin{array}{l}0.01 \\
0.01\end{array}$ & $\begin{array}{l}0.5 \\
0.5\end{array}$ & $\begin{array}{l}0.01 \\
0.40\end{array}$ & $\begin{array}{l}0.1 \\
0.9\end{array}$ & $\begin{array}{l}0.01 \\
0.40\end{array}$ & $\begin{array}{l}0.01 \\
0.99\end{array}$ \\
\hline $\begin{array}{c}T-B \\
\left(D_{T-8}=0.08\right)\end{array}$ & $\begin{array}{l}c \\
\text { d }\end{array}$ & $\begin{array}{l}0.01 \\
0.2 \\
\end{array}$ & $\begin{array}{l}0.95 \\
0.05\end{array}$ & $\begin{array}{l}0.01 \\
0.2\end{array}$ & $\begin{array}{l}0.5 \\
0.5 \\
\end{array}$ & $\begin{array}{l}0.01 \\
0.2 \\
\end{array}$ & $\begin{array}{l}0.01 \\
0.99 \\
\end{array}$ \\
\hline \multirow{2}{*}{$\begin{array}{c}P \\
\left(D_{p}=0.25\right)\end{array}$} & e & $\begin{array}{l}0.5 \\
\text { n.a. }\end{array}$ & $\begin{array}{l}0.8 \\
\text { n.a. }\end{array}$ & $\begin{array}{l}50 \\
1.0\end{array}$ & $\begin{array}{l}0.15 \\
0.4\end{array}$ & $\begin{array}{l}500 \\
1.0\end{array}$ & $\begin{array}{l}0.05 \\
0.4\end{array}$ \\
\hline & $\begin{array}{l}g \\
h\end{array}$ & $\begin{array}{l}\text { n.a. } \\
0.5\end{array}$ & $\begin{array}{l}\text { n.a. } \\
0.2\end{array}$ & $\begin{array}{l}50 \\
50\end{array}$ & $\begin{array}{l}0.4 \\
0.05\end{array}$ & $\begin{array}{l}500 \\
500\end{array}$ & $\begin{array}{l}0.4 \\
0.15\end{array}$ \\
\hline$L$ & $\mathbf{i}$ & $\begin{array}{c}0.5 \\
-\end{array}$ & $\begin{array}{l}1.0 \\
0.0\end{array}$ & 50 & $\begin{array}{l}1.0 \\
0.0\end{array}$ & 1000 & $\begin{array}{l}0.9 \\
0: 1\end{array}$ \\
\hline
\end{tabular}

R88120942351

FIGURE 0.1. Mathematical Model Used to Describe Clearance from the Respiratory System. (The values for the removal half-times, $T_{a-j}$ and compartmental fractions, $F_{a-j}$, are given in the tabular portion of the figure for each of the three classes of retained materials. The values given for $D_{N}-P, D_{T}-B$, and $D p$ [left column] are the regional depositions for an aerosol with an AMAD of $1 \mu \mathrm{m}$. The schematic drawing identifies the various clearance pathways from compartments $a-j$ in the four respiratory regions, nasal passages $[N-P]$, tracheal-bronchial tree $[T-B]$, pulmonary $[P]$, and lymph nodes [L] .) 


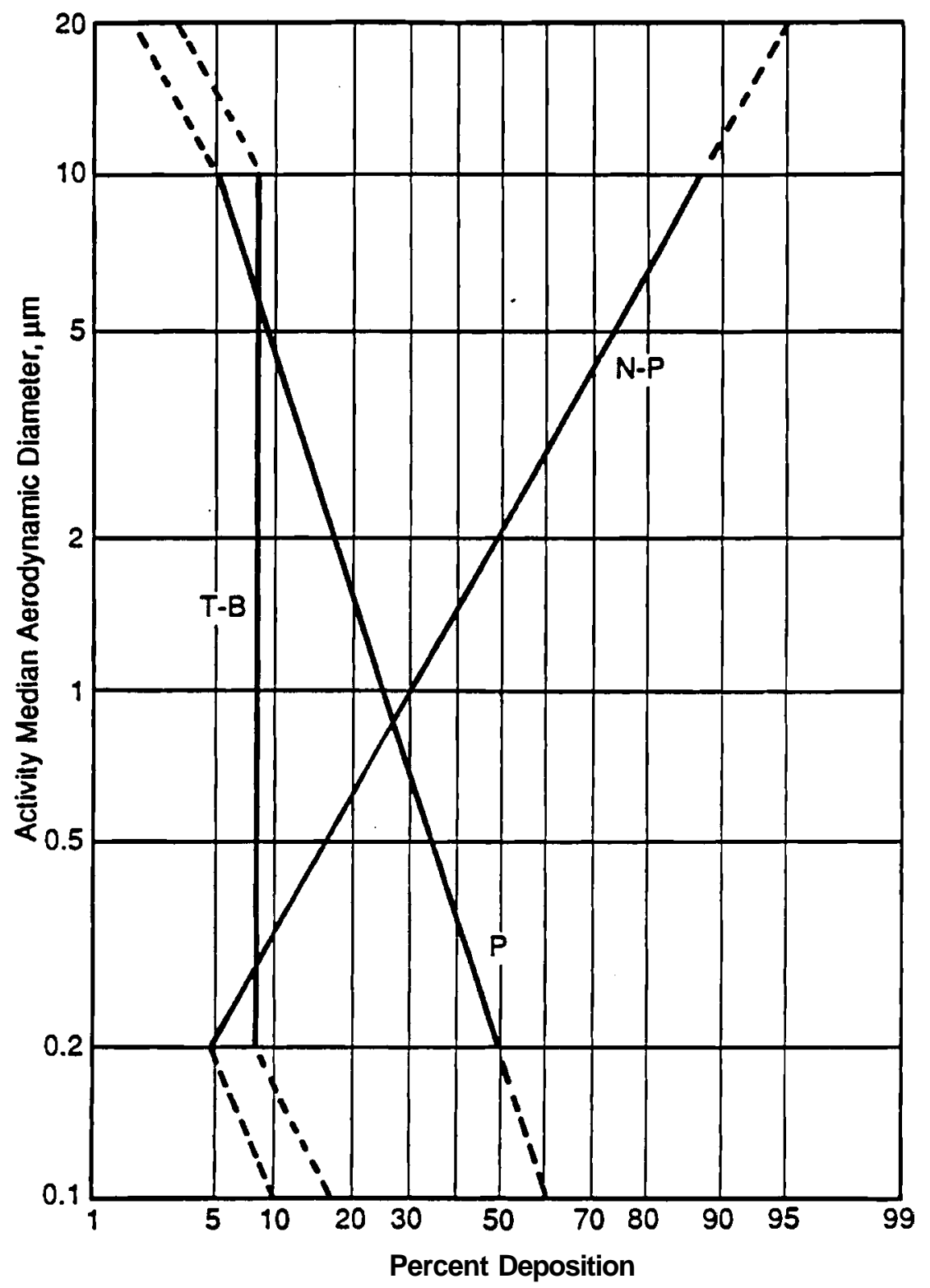

FIGURE D.2. Deposition of Dust in the Respiratory System. (The percentage of activity or mass of an aerosol that is deposited in the N-P, $T-B$, and $P$ regions is given in relation to the AMAD. The model is intended for use with aerosol distributions with AMADs between 0.2 and $10 \mu \mathrm{m}$ and with geometric standard deviations of less then 4.5. Provisional estimates of deposition further extending the size range are given by the dashed lines. For an unusual distribution with an AMAD of greater than $20 \mu \mathrm{m}$, complete deposition in the $\mathrm{N}-\mathrm{P}$ region can be assumed. The model does not apply to aerosols with AMADs of less than $0.1 \mathrm{pm}$. 


\section{of Aerosol AMAD(a)}

AMAD, $\mu \mathrm{m}$

Deposition Fractions

$\begin{array}{lll}0.2 & 0.050 & 0.50 \\ 0.3 & 0.088 & 0.43 \\ 0.4 & 0.13 & 0.38 \\ 0.5 & 0.16 & 0.34 \\ 0.6 & 0.19 & 0.32 \\ 0.7 & 0.23 & 0.30 \\ 0.9 & 0.26 & 0.28 \\ 1.0 & 0.30 & 0.25 \\ 2.0 & 0.50 & 0.17 \\ 3.0 & 0.61 & 0.13 \\ 4.0 & 0.69 & 0.10 \\ 5.0 & 0.74 & 0.088 \\ 6.0 & 0.78 & 0.076 \\ 7.0 & 0.81 & 0.067 \\ 8.0 & 0.84 & 0.060 \\ 9.0 & 0.86 & 0.055 \\ 10.0 & 0.87 & 0.050\end{array}$

(a) From NUREG/CR-1962, p. 25 (Eckerman, Watson, and Ford 1981). The deposition fraction for the T-B region is 0.08 , independent of AMAD.

(b) $\mathrm{N}-\mathrm{P}=$ nasal-passage region.

(c) $\mathrm{P}=$ pulmonary region.

\section{REFERENCES}

Eckerman, K. F., S. B. Watson, and M. R. Ford. 1981. Internal Dosimetry Data and Methods of the ICRP Part 2. Volume 1: Committed Dose Eauivalent and Secondary Limits. NUREG/CR-1962, U.S. Nuclear Regulatory Commission, Washington, D.C.

International Commission on Radiological Protection (ICRP). 1979. Limits for Intakes of Radionuclides by Workers. ICRP Publication 30, Part 1 and Supplements, Pergamon Press, New York. 
APPENDIXE

FECAL SAMPLING 



\section{APPENDIX E}

\section{FECAL SAMPLING}

Fecal sampling can be a valuable aid for estimating the magnitude of an inhalation intake. Through application of the lung and digestive tract models (ICRP 1979), estimates can be made of the expected daily fecal excretion following an inhalation intake. For class W and class Y radionuclides, the expected fecal excretion can be divided into two components: that which represents rapid clearance from the respiratory tract and that which represents longer-term clearance from the pulmonary region of the lung. Measurement of the quantity of a class W or $Y$ radionuclide excreted via feces in the rapid clearance phase (first few days following an intake) can provide an early estimate of intake that is often more sensitive than other bioassay measurements. This estimate may be especially helpful for class y radionuclides with little absorption from the GI tract and for which in vivo counting is difficult, e.g., class Y forms of plutonium, uranium, ${ }^{147} \mathrm{Pm}$. Additionally, fecal sampling during the rapid clearance phase may be helpful with more readily transported forms when the use of medication invalidates the use of normal systemic retention or excretion models, e.g., during chelation therapy.

\section{BIOKINETICS}

Figure E.l shows the expected daily fecal excretion as a fraction of

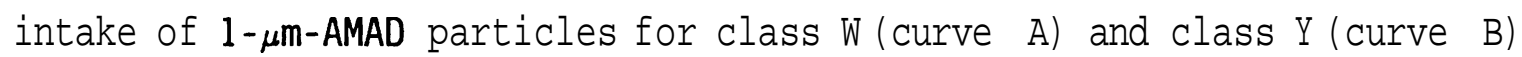
material for which radioactive decay, uptake from the gastrointestinal (GI) tract, and systemic excretion to the GI tract are negligible (from NUREG/CR-4884 [Lessard et a1. 1987] using ${ }^{239} \mathrm{Pu}$ as the model). Nearly half of the intake is excreted via feces in the first 5 days, which makes fecal sampling a very sensitive indicator of intake at that time. Excretion during the next 5 to 10 days decreases rapidly, and the daily excretion beyond about 15 days is relatively constant, representing the slowly clearing component from the pulmonary. Note that excretion during the rapid clearance phase is 


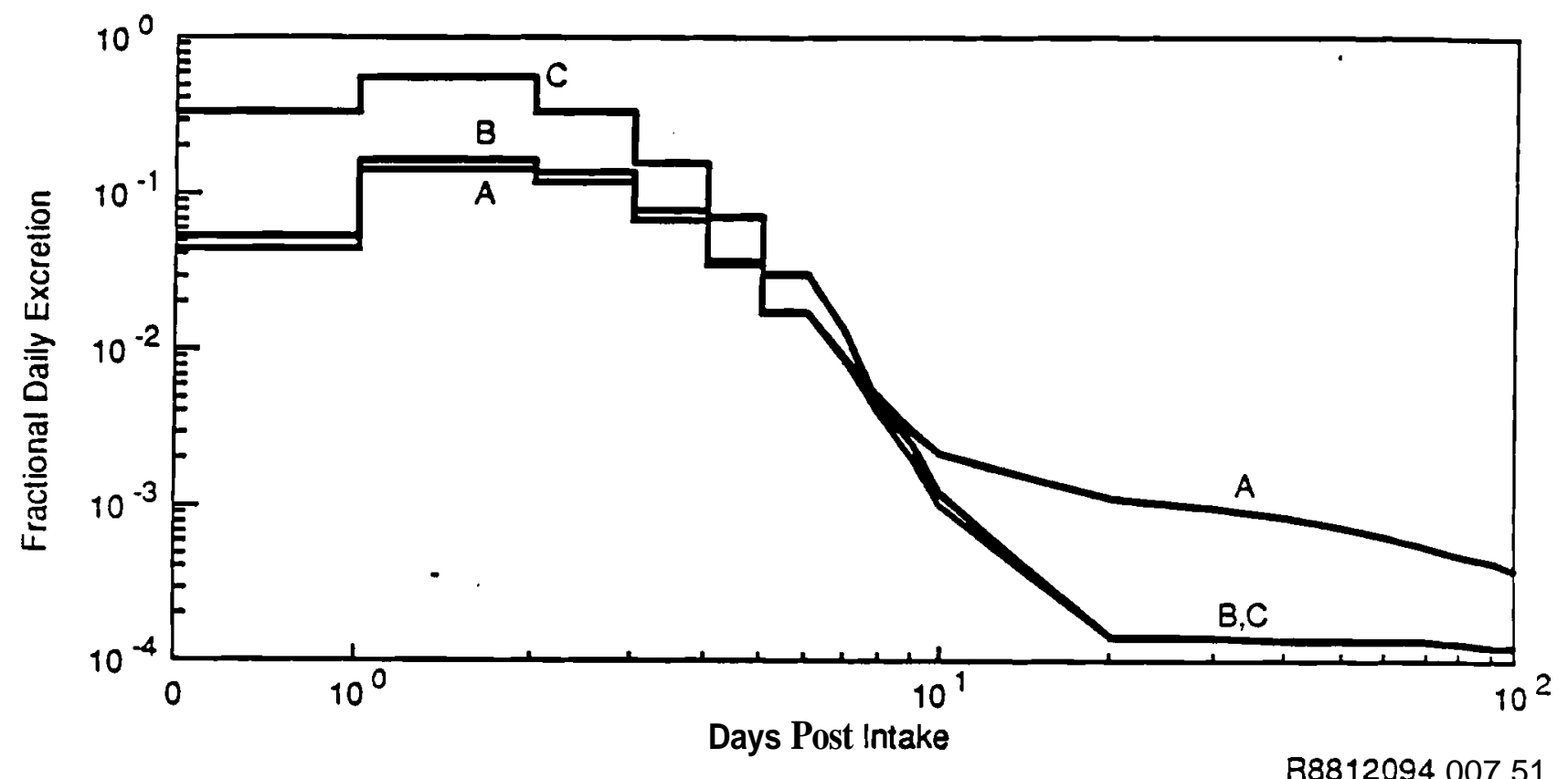

FGURE E.1. Daily Fecal Excretion of Plutonium as a Fraction of Inhalation Intake for Three Intake Scenarios (all 1- $\mu$ m-AMAD particle size) A -- inhalation of 1 unit of class $W$ plutonium

$B$-- inhalation of 1 unit of class $Y$ plutonium

C -- inhalation of 1 unit and ingestion of 1 unit of class $Y$ pl utoni um

relatively independent of inhalation class, and that excretion after about 10 days is unaffected by ingestion that. may have occurred along with the inhal ation.

Table E.1 lists fecal excretion fractions and accumulated fractional excretion during the rapid clearance phase for the material described in the above paragraph (Lessard et a1. 1987). Use of the accumulated fecal excretion data in Table E.1 is generally recommended over use of the daily fractional excretion data because of the difficulty in collecting (or at least in knowing that you have collected) a day's excretion. (See Pitfalls section for more discussion of this problem.) 
TABLE E.1. Fraction of Intake Exycreted via Feces Following
an Acute Inhalation(a)

\begin{tabular}{|c|c|c|c|c|c|}
\hline \multirow{2}{*}{\multicolumn{2}{|c|}{ Days Post Intake }} & \multicolumn{2}{|c|}{$\begin{array}{c}\text { Fraction of Intake } \\
\text { Excreted During Interval }\end{array}$} & \multicolumn{2}{|c|}{$\begin{array}{l}\text { Fractional } \\
\text { Accumulated Excretion }\end{array}$} \\
\hline & & W & $Y$ & $\mathrm{~W}$ & \\
\hline $1(0$ & - 24 hours) & 0.042 & 0.052 & 0.042 & 0.052 \\
\hline $2(24$ & - 48 hours) & 0.14 & 0.16 & 0.18 & 0.21 \\
\hline $3(48$ & - 72 hours) & 0.11 & 0.13 & 0.29 & 0.34 \\
\hline $4(72$ & - 96 hours) & 0.066 & 0.074 & 0.36 & 0.42 \\
\hline $5(96$ & - 120 hours) & 0.034 & 0.036 & 0.39 & 0.45 \\
\hline
\end{tabular}

(a) Assumes 1- $\mu$ m-AMAD particles and negligible uptake from the GI tract and negl igible systemic excretion to the GI tract.

\section{RECOMMENDATIONS FOR USE OF FECAL SAMPLING}

Because of problems discussed in the Pitfalls section, fecal sampling is best used in combination with other bioassay measurements. When the quality of data from the other bioassay measurements is good, e.g., the data are not near the detection level or are not biased by the effects of medication, then preference should be given to estimates of intake from the other bioassay measurements.

However, for moderately or poorly , absorbedradionuclides, fecal sampling during the first few days after an inhalation intake is a very sensitive indicator. Fecal sampling should be included as part of a regime of bioassay measurements for follow-up to a suspected intake if detectability of the intake using other bioassay measurements is greater than a first-year effective dose equivalent of 100 mrem.

The extent of use of fecal sampling depends on the expected severity of the intake. For intakes that are estimated (based on workplace monitoring) to result in a first-year effective dose equivalent of less than 100 mrem, or for situations where confirmation that an intake did not occur is desired, a fecal sample collected from 24 to 72 hours after the potential intake is recommended. If the sample shows detectable activity, additional bioassay measurements should be obtained, including additional fecal samples collected from 20 
to 100 days post intake. In some situations these additional fecal samples may still be more sensitive to intake than other bioassay measurements, but special care is necessary to avoid further small intakes prior to collection of these additional samples. If the first sample is not collected or if the results are invalidated during analysis, another sample should be collected as soon as possible; however, samples collected from 5 to 20 days post intake should be used only as a confirmation (or otherwise) of intake, not as an estimator of intake, because of the steepness of the fecal excretion curve during this period.

If workplace monitoring results indicate a more serious intake, all fecal excretion from about 6 to 72 hours post intake should be collected. The total result from all samples collected during this period is divided by the fractional accumulated excretion for the first 3 days post intake to provide an estimate of intake. Table E.I can be used for isotopes of plutonium and uranium (also other radionuclides where $G \mid$ absorption and radioactive decay can be neglected); NUREG/CR-4884 (Lessard et al. 1987) can be used for other radionuclides (1- $\mu \mathrm{m}-A M A D$ particles only).

If the estimate of dose from the intake exceeds a first-year effective dose equivalent of $100 \mathrm{mrem}$, and especially if other bioassay data cannot provide an adequate estimate of intake, then additional fecal samples at beyond 20 days post intake should be obtained and consideration should be given to determining the intake particle size distribution. The fractional daily fecal excretion at times after intake beyond 5 days can be obtained from the GEMOD code or from NUREG/CR-4884 (Lessard et al. 1987).

The fecal samples obtained after 20 days post intake can help determine the inhalation class and clearance rate from the pulmonary region to the $G I$ tract. But it needs to be recognized that, despite appearances in the ICRP lung model, the clearance rate from the pulmonary region to the GI tract (compartment $g$ [see Appendix D] is not necessarily identical to the clearance rates from the pulmonary region to the blood or lymph system (compartments $e$ and $h$ ). Urine data provide the best estimates of the latter clearance rates. Lacking good urine data, default values should be used. For example, if fecal data indicate a long-term clearance half-time of 400 days and urine data are 
lacking or are not definitive, the material should be assumed to be class $Y$ and clearance half-times of 500 days should be used for compartments e and h.

\section{NORMALZATION OF FECAL DATA}

Reference Mn (ICRP 1974) excretion for adults ranges from 60 to $500 \mathrm{~g} /$ day, with a recommended average of $135 \mathrm{~g} /$ day for an adult male and $110 \mathrm{~g} /$ day for an adult female. Note that these values represent excretion "per day" not excretion "per bowel movement." When a single bowel movement is collected, it is generally interpreted as representing excretion for one day. If the sample is greater than $60 \mathrm{~g}$, no normalization is used. If the sample is less than $60 \mathrm{~g}$, the sample results should be normalized to $135 \mathrm{~g}$ for males and $110 \mathrm{~g}$ for females.

If total accumulated excretion over a time period was requested and there is no apparent reason to suspect that total excretion was not provided, then all sample results should be used as is, without regard for the mass of individual samples. If excretions were missed during the time period, then normalization of the total mass to the total mass expected based on the reference values given above should be used.

\section{PITFALLS}

There are problems with interpretation of fecal data for which the evaluator needs to stay alert. One is the possibility of interference by ingested material. In Figure E.1, curve $C$ shows the expected daily fecal excretion from a unit intake of class $Y$ material by inhalation and a unit intake by ingestion. Note that curve $C$ follows the same general shape of the other curves, and hence a combined inhalation/ingestion intake of nearly equal proportions would not be readily discernible using early fecal data. Also note that the influence of the ingestion remains significant until about 8 days post intake. The accumulated fecal excretion in the first 3 days from this intake would be 3.5 times the accumulated fecal excretion from inhalation alone, and hence the estimate of intake determined in this manner would be 3.5 times too great. The point is that because ingested material contributes in toto to fecal excretion, it has a magnifying effect on the determination of 
inhalation intake. For sufficiently large intakes, this problem can be overcome by sampling during the slow clearance phase.

Interpretation of fecal data is also sensitive to the size of the particles inhaled. For example, Figure E.2 shows fractional daily excretion for class $W$ and class $Y$ plutonium for 3- and 8- $\mu \mathrm{m}$-AMAD particles. In these cases collection of the first 3 days' feces and assumption of 1-pin-AMAD particles would result in overestimation of the intake by 1.7 and 2.2 for intakes actually involving class W 3 - and 8- $\mathrm{m}$-AMAD particles, respectively, and by 1.6 and 2.0 for class Y 3- and 8- $\mu \mathrm{m}$-AMAD particles, respectively. Additional error would then be made in the calculation of doses to the lung and systemic organs because the fraction of intake deposited in the pulmonary region of the lung and/or transferred to the blood would be overestimated also.

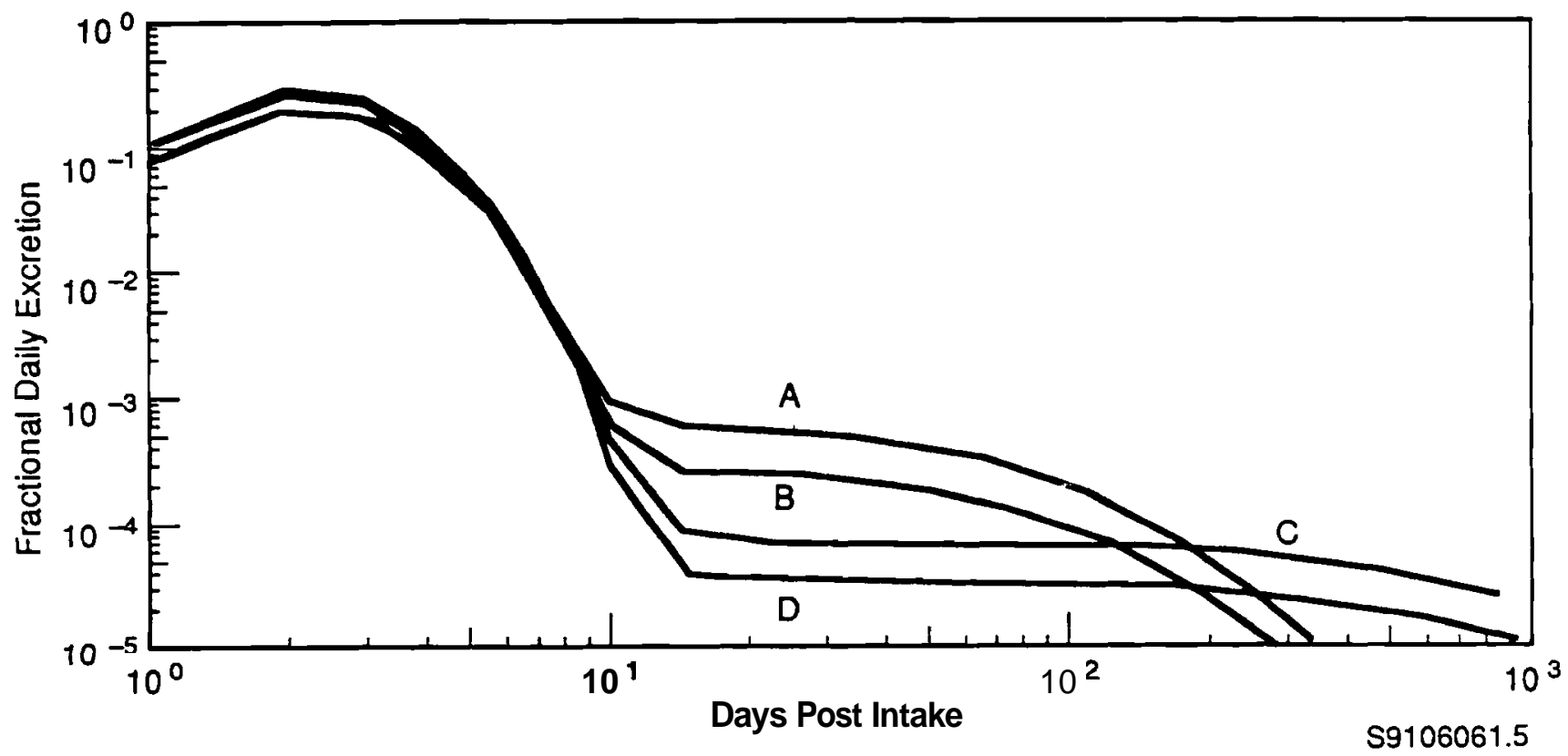

FIGURE E.2. Daily Fecal Excretion of Plutonium as a Fraction of Inhalation Intake for Four Intake Scenarios.

A -- class W, 3- $\mu \mathrm{m}-A M A D$ particles

B -- class W, 8- $\mu$ m-AMAD particles

C - - class $Y, 3-\mu \mathrm{m}-A M A D$ particles

D -- class $Y, 8$ - $\mu \mathrm{m}$-AMAD particles 
The GENMOD computer code can be used by adjusting deposition fractions to obtain fecal excretion fractions for particle-size distributions other than $1-\mu \mathrm{m}$ AMAD.

Another difficulty arises from single-voiding samples. These are generally easier to obtain than total excretion over a specific period. But both inter- and intra-individual variation in the regularity of bowel movements can introduce large uncertainties if a single voiding is used to represent daily excretion. Normalization by mass can help reduce error when a single sample represents a fraction of a day's excretion, but it does not help when a single sample represents excretion for several days.

Contamination of a fecal sample by urine should be avoided, but generally should not introduce significant error if it should occur.

For uranium, natural daily ingestion (about $2 \mu \mathrm{g}$ but variable [ICRP 19791) needs to be taken into account.

\section{REFERENCES}

International Commission on Radiological Protection (ICRP) . 1974. Report of the Task Group on Reference Man. ICRP Publication 23, Pergamon Press, New York, New York.

International Commission on Radiological Protection (ICRP). 1979. Limits for Intakes of Radionuclides bv Workers. ICRP Publication 30, Part 1, Pergamon Press, New York, New York.

Lessard, E. T., X. Yihua, K. W. Skrable, G. E. Chabot, C. S. French, T. R. La Bone, J. R. Johnson, D. R. Fisher, R. Belanger, and J. L. Lipsztein. 1987. Interpretation of Bioassav Measurements. NUREG/CR-4884, U.S. Nuclear Regulatory Commission, Washington, D.C. 



\section{APPENDIX F}

\section{OTHER COMPUTER CODES}





\section{APPENDIX $F$}

\section{OTHER COMPUIER CODES}

\section{PUCALC COMPUIER CODE}

The computer program PUCALC is used to produce plutonium urinary excretion curves as a function of time post intake for alternative values of systemic transfer rate and presystemic deposition. The computer-generated curve is superimposed on a plot of actual plutonium-in-urine data to provide a visual comparison of fit. Various values for systemic transfer rate and presystemic deposition can be entered until an acceptable fit is obtained.

\section{Generation of Excretion Curve}

The excretion curve generated by PUCALC is based on the excretion function developed by Jones (1985) (Equation [9.1]). The Jones function predicts the urinary excretion of plutonium following an acute uptake. For PUCALC, the Jones function has been extended to the general case in which there is a gradual transfer of plutonium into the bloodstream from a presystemic compartment. The acute uptake case becomes a special case where the transfer of plutonium into the systemic circulation occurs rapidly.

The equation describing the general case is as follows:

$$
E_{u}(R) / U(\infty)=\lambda \int_{0}^{R} J(R-x) \exp (-\lambda x) d x
$$

where $E_{u}(R)=$ the urinary excretion, in disintegrations per minute, on day $R$ following initial deposition of the plutonium in the presystemic compartment

$U(\infty)=$ the total quantity of plutonium, in disintegrations per minute, initially deposited into the presystemic compartment

1 = the rate of transfer, in day ${ }^{-1}$, from the presystemic compartment into the blood 
$R=$ the number of days after intake to the day for which the excretion is to be calculated

$x=$ the number of days between intake and incremental uptake

$J(R-x)=$ the value of the Jones excretion function at time $R-x$.

The $J(R-x)$ is determined by substituting $R-x$ for $t$ in Equation (9.1).

The excretion.curve plotted by PUCALC is produced by solving Equation (F.I) for 75 different values of $R$ spaced equally to cover the period from 1 to about 15,000 days. Solution of Equation (F.1), by integration over the period 0 to $R$, gives the following function:

$$
E_{u}(R)=\lambda U(\infty) \sum_{i=1}^{4} k \quad i
$$

$$
\begin{array}{lrl}
\text { where } & k_{i}=a_{i}\left[\exp (-\lambda R)-\exp \left(-b_{j} R\right)\right] /\left(b_{i}-A\right) \\
\text { and } & \mathbf{i} & \frac{a_{\mathbf{i}}}{b_{i}} \\
& 1 & .00475 .558 \\
& & .00024 .0442 \\
& & .0000855 .0038 \\
& 4 & .0000142 .0000284
\end{array}
$$

The curve generated by Equation (F.2) can be subtracted from the observed excretion data to show if there is residual urinary activity. The curve-subtraction process is performed by solving Equation (F.2) for each value of $R$ for which a bioassay result exists and subtracting this value from each data point. A tendency of the adjusted data to show the presence of net observed activity indicates either a component(s) of the intake not accounted for (i.e., part of the activity in the presystemic compartment is clearing with a different transfer rate) or an additional intake. 


\section{THE GENERAL COMPARTMENT MODEER (GENCOMP) COMPUIER CODE)}

The GENCOMP computer code ${ }^{(a)}$ was developed by Hanford Internal Dosimetry staff to solve a system of first-order differential equations for catenary compartments using a stiff numerical algorithm. It allows determination of activities or amounts in a series of catenary compartments for any time post intake or onset of intake. The code allows a wide variety of options for input to the first compartment. For instance, it can accommodate a repeating pattern of $x$ days of input followed by $y$ days of no input, which more closely simulates the "chronic-acute" intake condition experienced by routinely exposed workers. Activities or amounts in each compartment can be calculated for any time during the period of intake or after intakes have stopped. As an example of its use, GENCONP can model fecal excretion by 3 days of no intake prior to excretion. Thus, it can be used to estimate inhalation intake rates for dose evaluation from fecal samples.

\section{REFERENCE}

Jones, S. R. 1985. "Derivation and Validation of a Urinary Excretion Function for Plutonium Applicable Over Tens of Years Post Intake." Radiation Protection Dosimetrv 11(1):19-27.

(a) May, R. A. 1990. "User documentation for the General Compartment Modeler, Version 1.0." Copy available in the Hanford Radiation Protection Historical Files, Pacific Northwest Laboratory, Richland, Washington. 

PNL-6866 Rev. 1

UC-607

\section{DISTRIBUTION}

No. of

Cooies

OFFSITE

2 DOE/Office of Scientific and Technical Information

\section{ONSITE}

DOE Richland Operations

D. L. Clark (c)

Hanford Environmental Health Foundation

R. L. Kathren

M. J. Swint (c)

Kaiser Enqineers Hanford

D. J. Foust (c)

3 Westinghouse Hanford Company

T. L. Aldridge (c)

D. S. Cunningham

T. J. Kelly (c)

(c) denotes controlled document issue.
No. of

Copies

Pacific Northwest Laboratory

41 V. L. Berndt (c)

D. E. Bihl (c)

E. H. Carbaugh (c) + (19)

S. K. Ennor

D. P. Higby

J. R. Houston

J. R. Johnston

T. P. Lynch (c)

M. Lyon (c)

J. A. MacLellan (c)

K. M. McFadden (c)

C. L. Oxley (c)

J. M. Selby

M. L. Sula (c)

Hanford Radiation Records Historical File

Health Physics Department Library

Publishing Coordination

Technical Report Files (5) 
